San Jose State University

SJSU ScholarWorks

Master's Theses

Master's Theses and Graduate Research

Fall 2020

\title{
Spatial and Temporal Effects of Dry Air on Tropical Cyclone Intensity and Tracks over the Eastern Atlantic Ocean Basin
}

Amy Ip

San Jose State University

Follow this and additional works at: https://scholarworks.sjsu.edu/etd_theses

\section{Recommended Citation}

Ip, Amy, "Spatial and Temporal Effects of Dry Air on Tropical Cyclone Intensity and Tracks over the Eastern Atlantic Ocean Basin" (2020). Master's Theses. 5149.

DOI: https://doi.org/10.31979/etd.xw5m-ntsk

https://scholarworks.sjsu.edu/etd_theses/5149

This Thesis is brought to you for free and open access by the Master's Theses and Graduate Research at SJSU ScholarWorks. It has been accepted for inclusion in Master's Theses by an authorized administrator of SJSU ScholarWorks. For more information, please contact scholarworks@sjsu.edu. 
A Thesis

Presented to

The Faculty of the Department of Meteorology and Climate Science

San José State University

\author{
In Partial Fulfillment \\ of the Requirements for the Degree \\ Master of Science
}

by

Amy Ip

December 2020 
(C) 2020

Amy Ip

ALL RIGHTS RESERVED 
The Designated Thesis Committee Approves the Thesis Titled

SPATIAL AND TEMPORAL EFFECTS OF DRY AIR ON TROPICAL CYCLONE INTENSITY AND TRACKS OVER THE EASTERN ATLANTIC OCEAN BASIN

\author{
by \\ Amy Ip \\ APPROVED FOR THE DEPARTMENT OF METEOROLOGY \\ AND CLIMATE SCIENCE
}

SAN JOSÉ STATE UNIVERSITY

DECEMBER 2020

Sen Chiao, Ph.D. Department of Meteorology and Climate Science

Qian Tan, Ph.D. Bay Area Environmental Research Institute

Patrick J. Hamill, Ph.D. Department of Physics and Astronomy 


\begin{abstract}
SPATIAL AND TEMPORAL EFFECTS OF DRY AIR ON TROPICAL CYCLONE INTENSITY AND TRACKS OVER THE EASTERN ATLANTIC OCEAN BASIN
\end{abstract}

by Amy Ip

This study aims to understand how often dry air occurs or co-exists with a tropical cyclone (TC) and to what degree dry air will affect the way the TC proceeds. Four tropical cyclones of 2015 were chosen: Hurricane Fred, Hurricane Danny, Tropical Storm (TS) Grace and Tropical Depression (TD) 9 as their formation and tracks were located within the eastern Atlantic Ocean region. Relative humidity (RH) from MERRA-2 and NCEP-FNL datasets were compared within 3 days of the highest storm status and looking forward 3 days on the storm path. Results at $700 \mathrm{hPa}$ suggested that dry air $(\leq 30 \% \mathrm{RH})$ tended to precede TCs regardless of final intensity status. Hurricane Danny showed dry air transpiring earlier by at least 2 days before hurricane status was declared. Dry air occurred closer to the time point observed but further down the future storm path for TD9 and TS Grace. For Hurricane Fred, dry air was more frequently observed closer to the actual time point and physical location on the storm path compared to Hurricane Danny. Results from this study may help to provide early warning guidance on TC formation and tracks. 


\section{ACKNOWLEDGMENTS}

I would like to thank Dr. Tan and Dr. Hamill for their continual effort, support and time; my family and friends, my current and past colleagues, numerous professors and teachers for their encouragement, advice and constructive criticism; and Dr. Chiao for his guidance, support and unwavering faith in his students.

We would like to acknowledge the authors and support staff for the multiple datasets used in this investigation. Many initial and final analyses used were produced with the Giovanni online data system, developed and maintained by the NASA GES DISC. Images of SAL and visible satellite imagery provided courtesy of University of Wisconsin-Madison SSEC/CIMSS (from CIMSS website). The PSL at NOAA in collaboration with ESRL provided background figures of the central Atlantic basin.

This thesis was partially funded by the Center for Applied Atmospheric Research and Education (CAARE) with NASA MUREP grant \# NNX15AQ02A and by the Walker Scholarship.

Special thanks to Dr. Jason Dunion and Tim Olander for answering questions and providing clarification about the SAL-dry air imagery product from CIMSS. 


\section{TABLE OF CONTENTS}

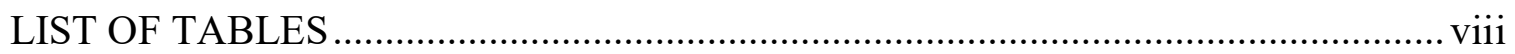

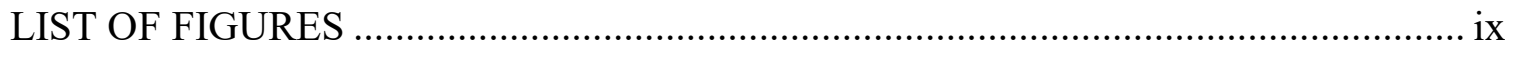

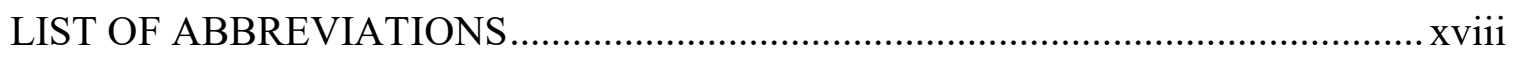

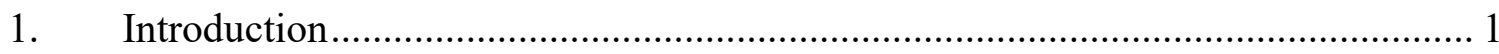

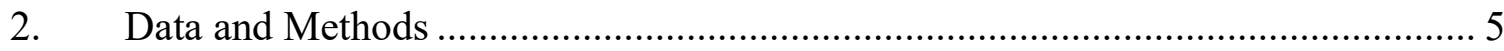

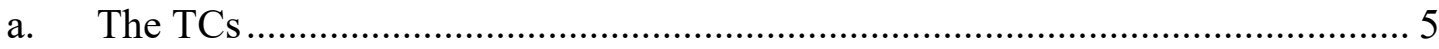

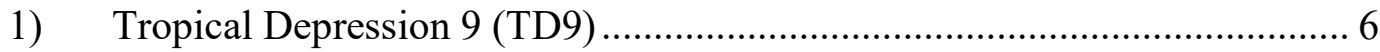

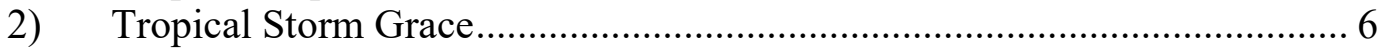

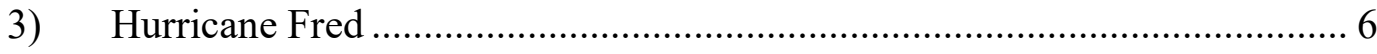

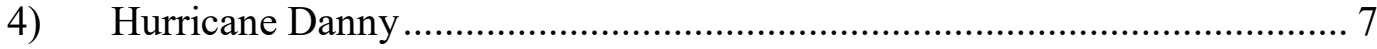

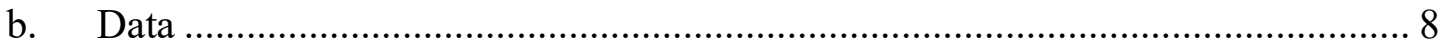

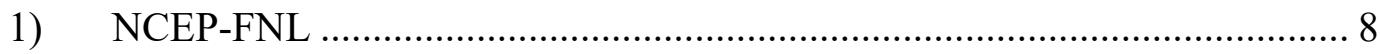

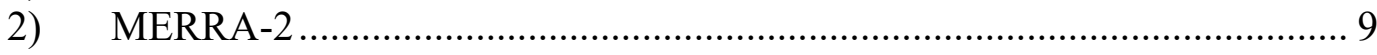

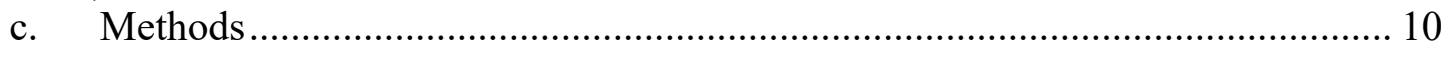

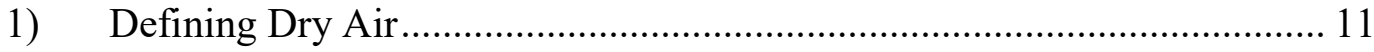

2) Time Period for Analysis ........................................................................ 12

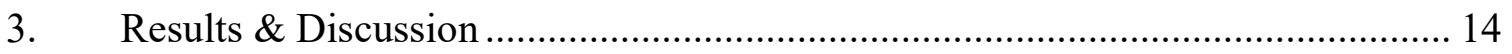

a. General Characteristics of the Environment ……………………………........ 14

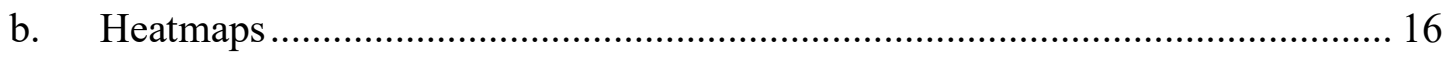

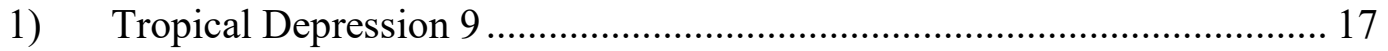

2) Tropical Storm Grace.......................................................................... 20

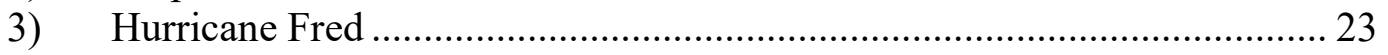

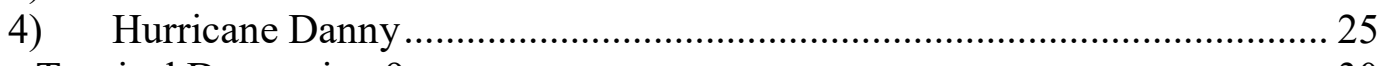

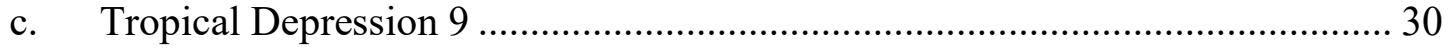

1) $t=-3$ days starting at 12 UTC 13 Sep 2015............................................ 30

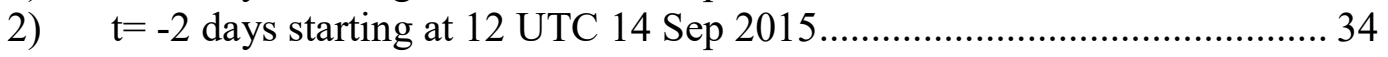

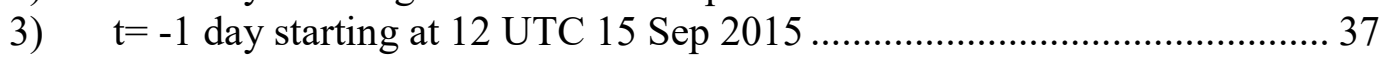

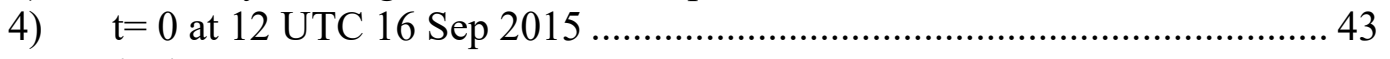

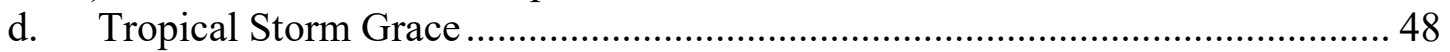

1) $\mathrm{t}=-3$ starting at 18 UTC 02 Sep 2015 .................................................. 48

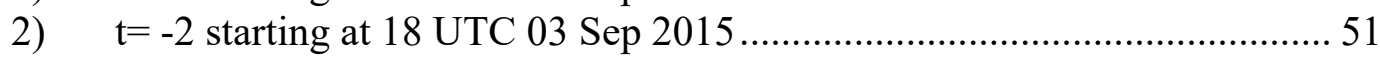

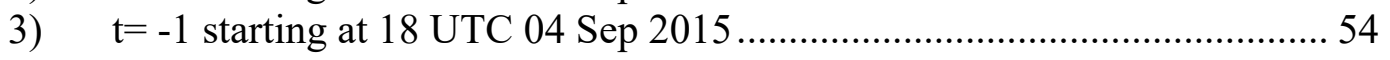

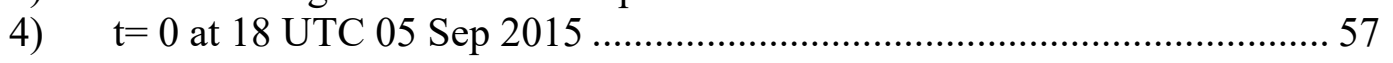




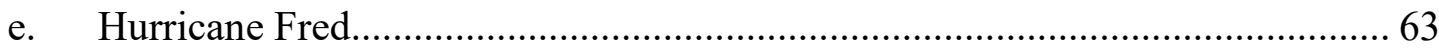

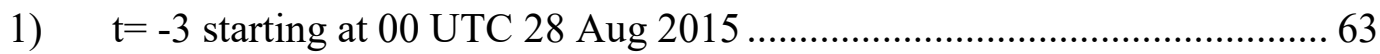

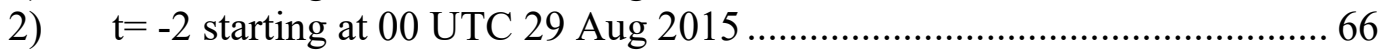

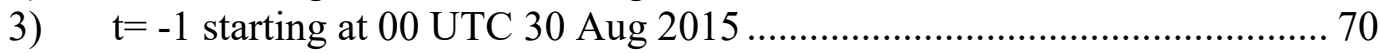

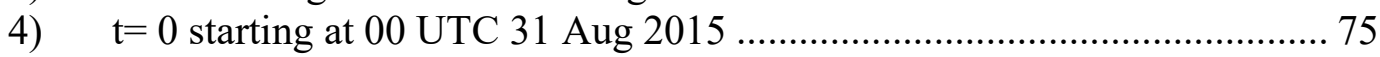

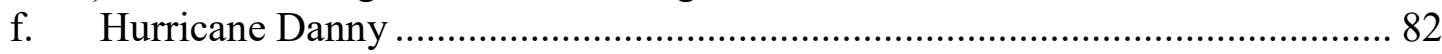

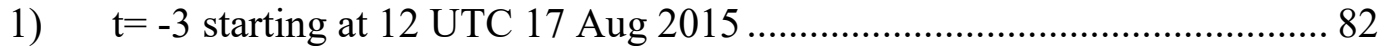

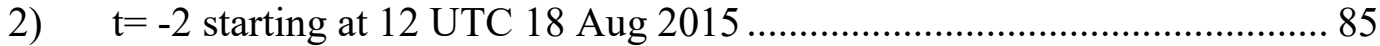

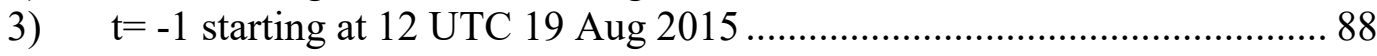

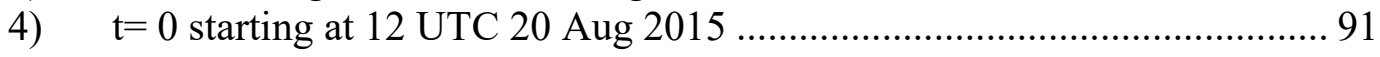

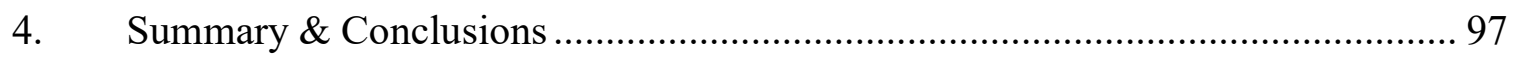

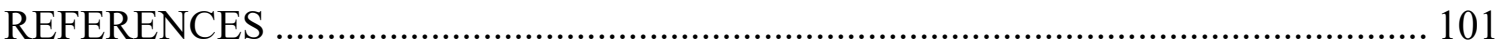




\section{LIST OF TABLES}

Table 1. Dates when TD, TS and H stages were declared by case. ...................... 6

Table 2. Time and frequency when dry air $(\mathrm{RH} \leq 30 \%)$ occurred within 3 days of $\mathrm{TC}$ approach and highest storm stage at $700 \mathrm{hPa}$.

Table 3. Average, minimum and maximum $\mathrm{RH} \leq 30 \%$ within 3 days of TC approach and highest storm stage. 


\section{LIST OF FIGURES}

FIG. 1. Storm paths of TD9 (2015), TS Grace (2015), Hurricane Fred (2015), and Hurricane Danny (2015)

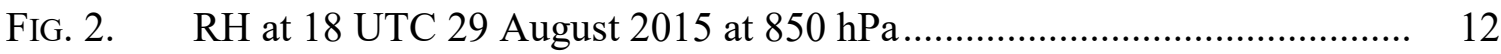

FIG. 3. Zonal wind at $850 \mathrm{hPa}$ from 20th Century Reanalysis V3........................ 14

FIG. 4. Meridional Wind at $850 \mathrm{hPa}$ from 20th Century Reanalysis V3 ............... 15

FIG. 5. SST of the central Atlantic Ocean Basin................................................... 16

FIG. 6. Heatmap of RH values for TD9 (2015) at $700 \mathrm{hPa}$ from NCEP-FNL........ 17

FIG. 7. Heatmap of RH values for TD9 (2015) at $700 \mathrm{hPa}$ from MERRA-2 ........ 18

FIG. 8. Heatmap of RH values for TD9 (2015) at $850 \mathrm{hPa}$ from NCEP-FNL........ 19

FIG. 9. Heatmap of RH values for TD9 (2015) at $850 \mathrm{hPa}$ from MERRA-2 ........ 19

FIG. 10. Heatmap of RH values for TS Grace (2015) at $700 \mathrm{hPa}$ from NCEP-FNL 20

FIG. 11. Heatmap of RH values for TS Grace (2015) at $700 \mathrm{hPa}$ from MERRA-2 21

FIG. 12. Heatmap of RH values for TS Grace (2015) at $850 \mathrm{hPa}$ from NCEP-FNL 22

FIG. 13. Heatmap of RH values for TS Grace (2015) at $850 \mathrm{hPa}$ from MERRA-2 22

FIG. 14. Heatmap of RH values for Hurricane Fred (2015) at $700 \mathrm{hPa}$ from NCEP-FNL

FIG. 15. Heatmap of RH values for Hurricane Fred (2015) at $700 \mathrm{hPa}$ from MERRA-2

FIG. 16. Heatmap of RH values for Hurricane Fred (2015) at $850 \mathrm{hPa}$ from NCEP-FNL

FIG. 17. Heatmap of RH values for Hurricane Fred (2015) at $850 \mathrm{hPa}$ from MERRA-2

FIG. 18. Heatmap of RH for Hurricane Danny (2015) at $700 \mathrm{hPa}$ from NCEPFNL 
FIG. 19. Heatmap of RH values for Hurricane Danny (2015) at $700 \mathrm{hPa}$ from MERRA-2

FIG. 20. Heatmap of RH for Hurricane Danny (2015) at $850 \mathrm{hPa}$ from NCEP-

FNL

FIG. 21. Heatmap of RH values for Hurricane Danny (2015) at $850 \mathrm{hPa}$ from MERRA-2....

FIG. 22. CIMSS SAL-Dry Air Imagery for 12 UTC 13 Sep 2015

FIG. 23. RH at $700 \mathrm{hPa}$ for TD9 at 12 UTC 13 Sep 2015 from MERRA-2

FIG. 24. RH at $700 \mathrm{hPa}$ for TD9 at 12 UTC 13 Sep 2015 from NCEP-FNL............

FIG. 25. Cross section of storm path from the first available best location $\left(11.5^{\circ} \mathrm{N}\right.$, $\left.-38.3^{\circ} \mathrm{E}\right)$ to near the location of TD status $\left(14.5^{\circ} \mathrm{N},-45.7^{\circ} \mathrm{E}\right)$ for TD9 at 12 UTC 13 Sep 2015 from NCEP-FNL

FIG. 26. Cross section of storm path from the first available best location $\left(11.5^{\circ} \mathrm{N}\right.$, $\left.-38.3^{\circ} \mathrm{E}\right)$ to near the location of TD status $\left(14.5^{\circ} \mathrm{N},-45.7^{\circ} \mathrm{E}\right)$ for TD9 at 12 UTC 13 Sep 2015 from MERRA-2

FIG. 27. Cross section of storm path from the first available best location $\left(11.5^{\circ} \mathrm{N}\right.$, $\left.-38.3^{\circ} \mathrm{E}\right)$ to near the location of TD status $\left(14.5^{\circ} \mathrm{N},-45.7^{\circ} \mathrm{E}\right)$ for TD9 at 21 UTC 13 Sep 2015 from MERRA-2

FIG. 28. Cross section path (large black dots, thick black line) for analysis portion of TD9's storm track

FIG. 29. CIMSS SAL-Dry Air Imagery for 00 UTC 15 Sep 2015

FIG. 30. RH at $700 \mathrm{hPa}$ for TD9 at 00 UTC $15 \mathrm{Sep} 2015$ from MERRA-2 ............. 35

FIG. 31. $\quad \mathrm{RH}$ at $700 \mathrm{hPa}$ for TD9 at $00 \mathrm{UTC} 15 \mathrm{Sep} 2015$ from NCEP-FNL............ 35

FIG. 32. Cross section of storm path from the first available best location $\left(11.5^{\circ} \mathrm{N}\right.$, $\left.-38.3^{\circ} \mathrm{E}\right)$ to near the location of TD status $\left(14.5^{\circ} \mathrm{N},-45.7^{\circ} \mathrm{E}\right)$ for TD9 at 12 UTC 14 Sep 2015 from NCEP-FNL

FIG. 33. Cross section of storm path from the first available best location $\left(11.5^{\circ} \mathrm{N}\right.$, $\left.-38.3^{\circ} \mathrm{E}\right)$ to near the location of TD status $\left(14.5^{\circ} \mathrm{N},-45.7^{\circ} \mathrm{E}\right)$ for TD9 at 12 UTC 14 Sep 2015 from MERRA-2 


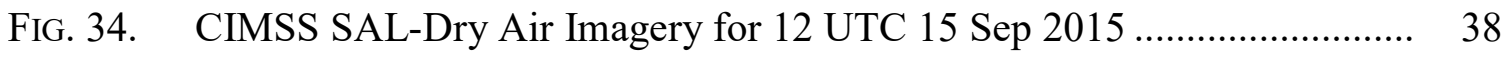

FIG. 35. CIMSS SAL-Dry Air Imagery for 15 UTC 15 Sep $2015 \ldots \ldots \ldots \ldots \ldots \ldots \ldots \ldots \ldots \ldots \ldots \ldots$

FIG. 36. CIMSS SAL-Dry Air Imagery for 18 UTC 15 Sep 2015 ....................... 38

FIG. 37. $\mathrm{RH}$ at $700 \mathrm{hPa}$ for TD9 at 12 UTC 15 Sep 2015 from MERRA-2 ............ 39

FIG. 38. RH at $700 \mathrm{hPa}$ for TD9 at 18 UTC 15 Sep 2015 from MERRA-2 ............ 39

Fig. 39. RH at $700 \mathrm{hPa}$ for TD9 at 12 UTC 15 Sep 2015 from NCEP-FNL........... 39

FIG. 40. $\quad \mathrm{RH}$ at $700 \mathrm{hPa}$ for TD9 at 18 UTC 15 Sep 2015 from NCEP-FNL........... 40

FIG. 41. Cross section of storm path from the first available best location $\left(11.5^{\circ} \mathrm{N}\right.$, $\left.-38.3^{\circ} \mathrm{E}\right)$ to near the location of TD status $\left(14.5^{\circ} \mathrm{N},-45.7^{\circ} \mathrm{E}\right)$ for TD9 at 18 UTC 15 Sep 2015 from NCEP-FNL ............................................... 42

FIG. 42. Cross section of storm path from the first available best location $\left(11.5^{\circ} \mathrm{N}\right.$, $\left.-38.3^{\circ} \mathrm{E}\right)$ to near the location of TD status $\left(14.5^{\circ} \mathrm{N},-45.7^{\circ} \mathrm{E}\right)$ for TD9 at 12 UTC 15 Sep 2015 from MERRA-2 …........................................... 43

FIG. 43. CIMSS SAL-Dry Air Imagery for 12 UTC 16 Sep 2015 ....................... 44

FIG. 44. RH at $700 \mathrm{hPa}$ for TD9 at 12 UTC 16 Sep 2015 from MERRA-2 ........... 44

FIG. 45. $\quad \mathrm{RH}$ at $700 \mathrm{hPa}$ for TD9 at 12 UTC 16 Sep 2015 from NCEP-FNL........... 44

FIG. 46. Cross section of storm path from the first available best location $\left(11.5^{\circ} \mathrm{N}\right.$, $\left.-38.3^{\circ} \mathrm{E}\right)$ to near the location of TD status $\left(14.5^{\circ} \mathrm{N},-45.7^{\circ} \mathrm{E}\right)$ for TD9 at 12 UTC 16 Sep 2015 from NCEP-FNL

FIG. 47. Cross section of storm path from the first available best location $\left(11.5^{\circ} \mathrm{N}\right.$, $\left.-38.3^{\circ} \mathrm{E}\right)$ to near the location of TD status $\left(14.5^{\circ} \mathrm{N},-45.7^{\circ} \mathrm{E}\right)$ for TD9 at 12 UTC 16 Sep 2015 from MERRA-2

FIG. 48. (above) $\mathrm{RH}$ cross section beginning at $14.5^{\circ} \mathrm{N},-40.3^{\circ} \mathrm{E}$ to $14.5^{\circ} \mathrm{N}$, $-46.7^{\circ} \mathrm{E}$ at $12 \mathrm{UTC} 16 \mathrm{Sep} 2015$ for TD9 at TD stage from NCEP-FNL ...

FIG. 49. (above) $\mathrm{RH}$ cross section beginning at $14.5^{\circ} \mathrm{N},-40.3^{\circ} \mathrm{E}$ to $14.5^{\circ} \mathrm{N}$, $-46.7^{\circ} \mathrm{E}$ at $12 \mathrm{UTC} 16 \mathrm{Sep} 2015$ for TD9 at TD stage from MERRA-2.....

FIG. 50. CIMSS SAL-Dry Air Imagery for 18 UTC 02 Sep 2015 48 
FIG. 51. $\mathrm{RH}$ at $700 \mathrm{hPa}$ for TS Grace at 06 UTC 03 Sep 2015 from MERRA-2 .....

FIG. 52. $\mathrm{RH}$ at $700 \mathrm{hPa}$ for TS Grace at 06 UTC 03 Sep 2015 from NCEP-FNL....

FIG. 53. Cross section of storm path from the first available best location $\left(12.0^{\circ} \mathrm{N}\right.$, $\left.-21.1^{\circ} \mathrm{E}\right)$ to near the location of TS status $\left(12.3^{\circ} \mathrm{N},-27.7^{\circ} \mathrm{E}\right)$ for TS Grace at 06 UTC 03 Sep 2015 from NCEP-FNL

FIG. 54. Cross section of storm path from the first available best location $\left(12.0^{\circ} \mathrm{N}\right.$, $\left.-21.1^{\circ} \mathrm{E}\right)$ to near the location of TS status $\left(12.3^{\circ} \mathrm{N},-27.7^{\circ} \mathrm{E}\right)$ for TS Grace at 06 UTC 03 Sep 2015 from MERRA-2

FIG. 55. Cross section path (large black dots, thick black line) for analysis portion of TS Grace's storm track

FIG. 56. $\mathrm{RH}$ at $700 \mathrm{hPa}$ for TS Grace at 18 UTC 03 Sep 2015 from MERRA-2 .....

FIG. 57. $\quad \mathrm{RH}$ at $700 \mathrm{hPa}$ for TS Grace at 18 UTC 03 Sep 2015 from NCEP-FNL.... 52

FIG. 58. Cross section of storm path from the first available best location $\left(12.0^{\circ} \mathrm{N}\right.$, $\left.-21.1^{\circ} \mathrm{E}\right)$ to near the location of TS status $\left(12.3^{\circ} \mathrm{N},-27.7^{\circ} \mathrm{E}\right)$ for TS Grace at 18 UTC 03 Sep 2015 from NCEP-FNL

FIG. 59. Cross section of storm path from the first available best location $\left(12.0^{\circ} \mathrm{N}\right.$, $\left.-21.1^{\circ} \mathrm{E}\right)$ to near the location of TS status $\left(12.3^{\circ} \mathrm{N},-27.7^{\circ} \mathrm{E}\right)$ for TS Grace at 18 UTC 03 Sep 2015 from MERRA-2

FIG. 60. CIMSS SAL-Dry Air Imagery for 15 UTC 03 Sep 2015 ........................ 54

FIG. 61. CIMSS SAL-Dry Air Imagery for 12 UTC 04 Sep 2015 ....................... 55

FIG. 62. CIMSS SAL-Dry Air Imagery for 21 UTC 04 Sep 2015 ....................... 55

FIG. 63. RH at $700 \mathrm{hPa}$ for TS Grace at 12 UTC 05 Sep 2015 from NCEP-FNL.... 55

FIG. 64. RH at $700 \mathrm{hPa}$ for TS Grace at 03 UTC 05 Sep 2015 from MERRA-2 .... 56

FIG. 65. Cross section of storm path from the first available best location $\left(12.0^{\circ} \mathrm{N}\right.$, $\left.-21.1^{\circ} \mathrm{E}\right)$ to near the location of TS status $\left(12.3^{\circ} \mathrm{N},-27.7^{\circ} \mathrm{E}\right)$ for TS Grace at 06 UTC 05 Sep 2015 from NCEP-FNL

FIG. 66. Cross section of storm path from the first available best location $\left(12.0^{\circ} \mathrm{N}\right.$, $\left.-21.1^{\circ} \mathrm{E}\right)$ to near the location of TS status $\left(12.3^{\circ} \mathrm{N},-27.7^{\circ} \mathrm{E}\right)$ for TS Grace at 09 UTC 05 Sep 2015 from MERRA-2 
FIG. 67. RH at $700 \mathrm{hPa}$ for TS Grace at 18 UTC 05 Sep 2015 from NCEP-FNL.... 58

FIG. 68. RH at $700 \mathrm{hPa}$ for TS Grace at 18 UTC 05 Sep 2015 from MERRA-2 ..... 58

FIG. 69. Cross section of storm path from the first available best location $\left(12.0^{\circ} \mathrm{N}\right.$, $\left.-21.1^{\circ} \mathrm{E}\right)$ to near the location of TS status $\left(12.3^{\circ} \mathrm{N},-27.7^{\circ} \mathrm{E}\right)$ for TS Grace at 18 UTC 05 Sep 2015 from NCEP-FNL

FIG. 70. CIMSS SAL-Dry Air Imagery for 18 UTC 05 Sep 2015

FIG. 71. Cross section of storm path from the first available best location $\left(12.0^{\circ} \mathrm{N}\right.$, $\left.-21.1^{\circ} \mathrm{E}\right)$ to near the location of TS status $\left(12.3^{\circ} \mathrm{N},-27.7^{\circ} \mathrm{E}\right)$ for TS Grace at 18 UTC 05 Sep 2015 from MERRA-2

FIG. 72. (above) $\mathrm{RH}$ cross section beginning at $12.3^{\circ} \mathrm{N},-23.1^{\circ} \mathrm{E}$ to $12.3^{\circ} \mathrm{N}$, $-28.7^{\circ} \mathrm{E}$ at $18 \mathrm{UTC} 05 \mathrm{Sep} 2015$ for TS Grace at TS stage from NCEP-

FNL

FIG. 73. (above) $\mathrm{RH}$ cross section beginning at $11.3^{\circ} \mathrm{N},-33.1^{\circ} \mathrm{E}$ to $11.3^{\circ} \mathrm{N}$, $-26.7^{\circ} \mathrm{E}$ at $18 \mathrm{UTC} 05 \mathrm{Sep} 2015$ for TS Grace at TS stage from MERRA2

FIG. 74. CIMSS SAL-Dry Air Imagery for 00 UTC 28 Aug 2015

FIG. 75. $\quad \mathrm{RH}$ at $700 \mathrm{hPa}$ for Hurricane Fred at 00 UTC 28 Aug 2015 from MERRA-2

FIG. 76. $\mathrm{RH}$ at $700 \mathrm{hPa}$ for Hurricane Fred at 00 UTC 28 Aug 2015 from NCEPFNL

FIG. 77. Cross section of storm path from the first available best location $\left(11.6^{\circ} \mathrm{N}\right.$, $\left.-15.5^{\circ} \mathrm{E}\right)$ to near the location of hurricane status $\left(14.6^{\circ} \mathrm{N},-23.7^{\circ} \mathrm{E}\right)$ for Hurricane Fred at 00 UTC 28 Aug 2015 from NCEP-FNL

FIG. 78. Cross section of storm path from the first available best location $\left(11.6^{\circ} \mathrm{N}\right.$, $\left.-15.5^{\circ} \mathrm{E}\right)$ to near the location of hurricane status $\left(14.6^{\circ} \mathrm{N},-23.7^{\circ} \mathrm{E}\right)$ for Hurricane Fred at 00 UTC 28 Aug 2015 from MERRA-2

FIG. 79. Cross section path (large black dots, thick black line) for analysis portion of Hurricane Fred's storm track

FIG. 80. RH at $700 \mathrm{hPa}$ for Hurricane Fred at 12 UTC 29 Aug 2015 from NCEPFNL 
FIG. 81. $\mathrm{RH}$ at $700 \mathrm{hPa}$ for Hurricane Fred at 12 UTC 29 Aug 2015 from

MERRA-2

FIG. 82. CIMSS SAL-Dry Air Imagery for 00 UTC 29 Aug 2015 ....................... 68

FIG. 83. CIMSS SAL-Dry Air Imagery for 18 UTC 29 Aug 2015 ........................ 68

FIG. 84. Cross section of storm path from the first available best location $\left(11.6^{\circ} \mathrm{N}\right.$, $\left.-15.5^{\circ} \mathrm{E}\right)$ to near the location of hurricane status $\left(14.6^{\circ} \mathrm{N},-23.7^{\circ} \mathrm{E}\right)$ for Hurricane Fred at 06 UTC 29 Aug 2015 from NCEP-FNL

FIG. 85. Cross section of storm path from the first available best location $\left(11.6^{\circ} \mathrm{N}\right.$, $\left.-15.5^{\circ} \mathrm{E}\right)$ to near the location of hurricane status $\left(14.6^{\circ} \mathrm{N},-23.7^{\circ} \mathrm{E}\right)$ for Hurricane Fred at 00 UTC 29 Aug 2015 from MERRA-2

FIG. 86. CIMSS SAL-Dry Air Imagery for 06 UTC 30 Aug 2015 70

FIG. 87. CIMSS SAL-Dry Air Imagery for 12 UTC 30 Aug 2015 71

FIG. 88. RH at $700 \mathrm{hPa}$ for Hurricane Fred at 12 UTC 30 Aug 2015 from MERRA-2

FIG. 89. $\mathrm{RH}$ at $700 \mathrm{hPa}$ for Hurricane Fred at 21 UTC $30 \mathrm{Aug} 2015$ from MERRA-2

FIG. 90. $\mathrm{RH}$ at $700 \mathrm{hPa}$ for Hurricane Fred at 00 UTC 30 Aug 2015 from NCEPFNL

FIG. 91. RH at $700 \mathrm{hPa}$ for Hurricane Fred at 12 UTC 30 Aug 2015 from NCEPFNL

FIG. 92. Cross section of storm path from the first available best location $\left(11.6^{\circ} \mathrm{N}\right.$, $\left.-15.5^{\circ} \mathrm{E}\right)$ to near the location of hurricane status $\left(14.6^{\circ} \mathrm{N},-23.7^{\circ} \mathrm{E}\right)$ for Hurricane Fred at 03 UTC 30 Aug 2015 from MERRA-2

FIG. 93. Cross section of storm path from the first available best location $\left(11.6^{\circ} \mathrm{N}\right.$, $\left.-15.5^{\circ} \mathrm{E}\right)$ to near the location of hurricane status $\left(14.6^{\circ} \mathrm{N},-23.7^{\circ} \mathrm{E}\right)$ for Hurricane Fred at 06 UTC 30 Aug 2015 from NCEP-FNL

FIG. 94. CIMSS SAL-Dry Air Imagery for 00 UTC 31 Aug 2015 77

FIG. 95. RH at $700 \mathrm{hPa}$ for Hurricane Fred at 00 UTC 31 Aug 2015 from NCEPFNL 
FIG. 96. $\quad \mathrm{RH}$ at $700 \mathrm{hPa}$ for Hurricane Fred at 00 UTC $31 \mathrm{Aug} 2015$ from MERRA-2

FIG. 97. Cross section of storm path from the first available best location $\left(11.6^{\circ} \mathrm{N}\right.$, $\left.-15.5^{\circ} \mathrm{E}\right)$ to near the location of hurricane status $\left(14.6^{\circ} \mathrm{N},-23.7^{\circ} \mathrm{E}\right)$ for Hurricane Fred at 00 UTC 31 Aug 2015 from NCEP-FNL

FIG. 98. Cross section of storm path from the first available best location $\left(11.6^{\circ} \mathrm{N}\right.$, $\left.-15.5^{\circ} \mathrm{E}\right)$ to near the location of hurricane status $\left(14.6^{\circ} \mathrm{N},-23.7^{\circ} \mathrm{E}\right)$ for Hurricane Fred at 00 UTC 31 Aug 2015 from MERRA-2

FIG. 99. (above) $\mathrm{RH}$ cross section beginning at $15.1^{\circ} \mathrm{N},-18.5^{\circ} \mathrm{E}$ to $15.1^{\circ} \mathrm{N}$, $-25.7^{\circ} \mathrm{E}$ at 00 UTC 31 Aug 2015 for Hurricane Fred at hurricane stage from NCEP-FNL

FIG. 100. (above) RH cross section beginning at $16.1^{\circ} \mathrm{N},-19.5^{\circ} \mathrm{E}$ to $16.1^{\circ} \mathrm{N}$, $-28.2^{\circ} \mathrm{E}$ at 12 UTC 31 Aug 2015 for Hurricane Fred at hurricane stage from MERRA-2

FIG. 101. (above) $\mathrm{RH}$ cross section beginning at $13.0^{\circ} \mathrm{N},-20.0^{\circ} \mathrm{E}$ to $19.0^{\circ} \mathrm{N}$, $-27.5^{\circ} \mathrm{E}$ at 12 UTC 31 Aug 2015 for Hurricane Fred at hurricane stage from MERRA-2

FIG. 102. RH at $700 \mathrm{hPa}$ for Hurricane Danny at 12 UTC 17 Aug 2015 from MERRA-2

FIG. 103. RH at $700 \mathrm{hPa}$ for Hurricane Danny at 12 UTC 17 Aug 2015 from NCEP-FNL

FIG. 104. Cross section path (large black dots, thick black line) for analysis portion of Hurricane Danny’s storm track

FIG. 105. Cross section of storm path from the first available best location $\left(9.6^{\circ} \mathrm{N}\right.$, $\left.-27.3^{\circ} \mathrm{E}\right)$ to near the location of hurricane status $\left(12.3^{\circ} \mathrm{N},-46.4^{\circ} \mathrm{E}\right)$ for Hurricane Danny at 12 UTC 17 Aug 2015 from NCEP-FNL

FIG. 106. Cross section of storm path from the first available best location $\left(9.6^{\circ} \mathrm{N}\right.$, $\left.-27.3^{\circ} \mathrm{E}\right)$ to near the location of hurricane status $\left(12.3^{\circ} \mathrm{N},-46.4^{\circ} \mathrm{E}\right)$ for Hurricane Danny at 12 UTC 17 Aug 2015 from MERRA-2

FIG. 107. CIMSS SAL-Dry Air Imagery for 12 UTC 17 Aug 2015 85

FIG. 108. CIMSS SAL-Dry Air Imagery for 12 UTC 18 Aug 2015 86 
FIG. 109. RH at $700 \mathrm{hPa}$ for Hurricane Danny at 12 UTC 18 Aug 2015 from MERRA-2

FIG. 110. RH at $700 \mathrm{hPa}$ for Hurricane Danny at 12 UTC 18 Aug 2015 from NCEP-FNL

FIG. 111. Cross section of storm path from the first available best location $\left(9.6^{\circ} \mathrm{N}\right.$, $\left.-27.3^{\circ} \mathrm{E}\right)$ to near the location of hurricane status $\left(12.3^{\circ} \mathrm{N},-46.4^{\circ} \mathrm{E}\right)$ for Hurricane Danny at 00 UTC 19 Aug 2015 from NCEP-FNL

FIG. 112. Cross section of storm path from the first available best location $\left(9.6^{\circ} \mathrm{N}\right.$, $\left.-27.3^{\circ} \mathrm{E}\right)$ to near the location of hurricane status $\left(12.3^{\circ} \mathrm{N},-46.4^{\circ} \mathrm{E}\right)$ for Hurricane Danny at 00 UTC 19 Aug 2015 from MERRA-2.

FIG. 113. RH at $700 \mathrm{hPa}$ for Hurricane Danny at 12 UTC 19 Aug 2015 from NCEP-FNL

FIG. 114. RH at $700 \mathrm{hPa}$ for Hurricane Danny at 12 UTC 19 Aug 2015 from MERRA-2

FIG. 115. CIMSS SAL-Dry Air Imagery for 12 UTC 19 Aug 2015

FIG. 116. CIMSS SAL-Dry Air Imagery for 21 UTC 19 Aug 2015 89

FIG. 117. CIMSS SAL-Dry Air Imagery for 00 UTC 20 Aug 2015 90

FIG. 118. Cross section of storm path from the first available best location $\left(9.6^{\circ} \mathrm{N}\right.$, $\left.-27.3^{\circ} \mathrm{E}\right)$ to near the location of hurricane status $\left(12.3^{\circ} \mathrm{N},-46.4^{\circ} \mathrm{E}\right)$ for Hurricane Danny at 18 UTC 19 Aug 2015 from NCEP-FNL

FIG. 119. Cross section of storm path from the first available best location $\left(9.6^{\circ} \mathrm{N}\right.$, $\left.-27.3^{\circ} \mathrm{E}\right)$ to near the location of hurricane status $\left(12.3^{\circ} \mathrm{N},-46.4^{\circ} \mathrm{E}\right)$ for Hurricane Danny at 18 UTC 19 Aug 2015 from MERRA-2

FIG. 120. CIMSS SAL-Dry Air Imagery for 12 UTC 20 Aug 2015 92

FIG. 121. RH at $700 \mathrm{hPa}$ for Hurricane Danny at 12 UTC 20 Aug 2015 from NCEP-FNL

FIG. 122. RH at $700 \mathrm{hPa}$ for Hurricane Danny at 12 UTC 20 Aug 2015 from MERRA-2 
FIG. 123. Cross section of storm path from the first available best location $\left(9.6^{\circ} \mathrm{N}\right.$, $\left.-27.3^{\circ} \mathrm{E}\right)$ to near the location of hurricane status $\left(12.3^{\circ} \mathrm{N},-46.4^{\circ} \mathrm{E}\right)$ for Hurricane Danny at 12 UTC 20 Aug 2015 from NCEP-FNL

FIG. 124. Cross section of storm path from the first available best location $\left(9.6^{\circ} \mathrm{N}\right.$, $\left.-27.3^{\circ} \mathrm{E}\right)$ to near the location of hurricane status $\left(12.3^{\circ} \mathrm{N},-46.4^{\circ} \mathrm{E}\right)$ for Hurricane Danny at 12 UTC 20 Aug 2015 for MERRA-2 ...

FIG. 125. (above) $\mathrm{RH}$ cross section beginning at $12.3^{\circ} \mathrm{N},-40.3^{\circ} \mathrm{E}$ to $12.3^{\circ} \mathrm{N}$, $-48.4^{\circ} \mathrm{E}$ at 12 UTC 20 Aug 2015 for Hurricane Danny at hurricane stage from NCEP-FNL

FIG. 126. (above) $\mathrm{RH}$ cross section beginning at $12.3^{\circ} \mathrm{N},-37.3^{\circ} \mathrm{E}$ to $12.3^{\circ} \mathrm{N}$, $-47.4^{\circ} \mathrm{E}$ at $12 \mathrm{UTC} 20 \mathrm{Aug} 2015$ for Hurricane Danny at hurricane stage from MERRA-2 


\section{LIST OF ABBREVIATIONS}

AEW - African Easterly Wave

AEJ - African Easterly Jet

CIMSS - Cooperative Institute for Meteorological Satellite Studies

$\mathrm{E}$ - east direction

ECMWF - European Centre for Medium-Range Weather Forecasts

ESRL - Earth System Research Laboratory

$\mathrm{H}$ - hurricane

lat - latitude

lon - longitude

MERRA-2 - Modern-Era Retrospective Analysis for Research and

Applications, Version 2

mph - miles per hour

$\mathrm{N}$ - north direction

NASA Goddard Earth Sciences (GES) Data and Information Services Center (DISC)

NCEP-FNL - National Centers for Environmental Prediction Final Operational

Global Analysis

NHC -National Hurricane Center

NOAA - National Oceanic and Atmospheric Administration

$\mathrm{hPa}$ - hectopascal(s)

PSL - Physical Sciences Laboratory

$\mathrm{RI}$ - rapid intensification

SAL - Saharan Air Layer

SSEC - Space Science and Engineering Center

SST - Sea surface temperature

$\mathrm{TC}$ - tropical cyclone

TD - tropical depression

TS - tropical storm

UW-Madison - University of Wisconsin-Madison

VWS - vertical wind shear

$\mathrm{W}$ - west direction 


\section{Introduction}

The Atlantic Ocean basin produces tropical cyclones (TCs), storms originating in the tropics, which can affect countries on the western African coast to those in Europe and North America. Understanding how TCs move and develop allows for longer lead times, more accurate prediction and pertinent warnings to alleviate caution fatigue and allocation of resources to needed areas for disaster preparation. The focus of this study is the effects of dry air on intensity and storm tracks in the Atlantic basin.

Four TC cases in 2015 are chosen for this study: Tropical Depression 9, Tropical Storm Grace, Hurricane Fred and Hurricane Danny because their life cycles occurred within a similar time frame and area. TC stages for this study were based on definitions from the National Oceanic and Atmospheric Administration (NOAA)'s National Hurricane Center (NHC). A TC was considered a tropical depression (TD) when average surface winds are 33 knots (38 mph or $62 \mathrm{~km} / \mathrm{hr}$ ) or less (NHC 2020). For a TC to become a tropical storm (TS), wind speeds must fall within the range from 34-63 kts (39$73 \mathrm{mph}$ or $63-118 \mathrm{~km} / \mathrm{hr}$ ) (NHC 2020). Hurricane $(\mathrm{H})$ stage is achieved when winds measure 64 knots (74 mph or $119 \mathrm{~km} / \mathrm{hr}$ ) or more (NHC 2020). Occasionally, conditions over the ocean are sufficient to organize the system and generate higher wind speeds, subsequently reaching TD, TS or hurricane stages.

However, many Atlantic based TCs can trace their origins to waves developed from continental heating over Africa and propagated over the Atlantic Ocean (i.e., Thorncroft and Hodges 2001, Zipser et al. 2009, Ventrice et al. 2012). The African Easterly Wave (AEW) has been extensively studied linking to TC genesis (i.e., Zipser et al. 2009) and 
investigations often were related to its influence on the Saharan Air Layer (SAL) events, a large dry dynamic air mass with a transcontinental ability to transport Saharan dust (Karyampudi et al. 1999, Prospero and Carlson 1980, Ventrice et al. 2012, etc.). The SAL has also garnered much attention in terms of whether the phenomenon can strengthen or reduce TC intensity (Dunion and Velden 2004, Braun 2010, Sun et al. 2009, etc.).

In addition to SAL events, low humidity air in the troposphere could have an impact on TC development and its strength. Per Gray (1977), when the area is characterized by lower than $40 \%$ RH between $500-700 \mathrm{hPa}$, TCs were unable to develop. Fink and Vincent (2003) found that RH can change when a TC traverses from one point to another. It has been found that intrusions of dry air possibly originating from Mexico or Central America may have played a role in increasing surface wind speeds for TC Kevin (1985), though it was classified as a weak TC (Fink and Vincent 2003). Backward trajectories suggested dry air from land entrained earlier on its track at the first location but the surface wind speeds gained 10 knots after traversing to the final location. Braun et al. (2013) found dry air surrounding Hurricane Helene (2006) during its intensification stage, suggesting that the dry air only delayed development. Similarly, drier air between $750-450 \mathrm{hPa}$ and $450-150 \mathrm{hPa}$ could slow TC development for 20 hours or more in the rapid intensification (RI) case of Durian (2001) (Wang et al. 2018). In addition, they also found that dry air remained in the surrounding area and was not entrained in the innermost region of the TC (Wang et al. 2018). In the mid and upper atmospheric levels, dry air also hindered the TC development compared to a higher RH environment (Wang et al. 2018). While the initial motivation for this study was to investigate the SAL and its 
effects on TC genesis, the focus has shifted to understanding how dry air may affect storm intensity of different types of TCs. The first hypothesis proposed is more dry air (30\% RH or less) surrounded TD9 and TS Grace compared to Hurricanes Danny and Fred.

The second objective of this investigation is to examine how dry air may affect storm tracks. George and Gray (1976) sought to further understand this process by quantifying winds at various pressure levels and found storms move faster than the surrounding environment. At $500 \mathrm{mb}$, storms deviated to the left of the surrounding winds, regardless of the storm's characteristics such as intensity (George and Gray 1976). Carr and Elsberry (1995) investigated why some TCs in the Pacific Basin suddenly head northward, which could not be accounted by known effects. They found interaction between monsoon gyre and the TC can change the TC's path. However, two factors dominate the conversation about how TCs move: vorticity advection by steering flow and beta drift as stated in the review by Wang et al. (1998) (Wu and Wang 2004). While these two important influences may explain how storm tracks are generated from a climatological perspective, different nuances such as dry air could be impacting at the individual storm level (i.e., Carr and Elsberry 1995). The second hypothesis states that the storm track ahead of the TC is higher than $30 \%$ RH 3 days before the TC approaches.

Understanding how tropical cyclones (TCs) move and how they become more intense has important implications to tropical weather forecasting and mitigating losses of life and property. Reducing hurricane track errors may allow for more accurate forecasting and storm preparation. In modeling studies, changing a parameter or adding new data 
often reduced track errors. Li and Liu (2009) assimilated sounding data from Advanced InfraRed Sounder (AIRS) coupled with an algorithm developed by University of Wisconsin's Cooperative Institute for Meteorological Satellite Studies (CIMSS) into Weather Research and Forecasting (WRF) models. By using these high resolution data, the researchers found a 50\% reduction in hurricane track errors in modeling runs ( $\mathrm{Li}$ and Liu 2009). Torn and Davis (2012) also used WRF models to study error in storm tracks, focusing on how shallow convection played a role. They found that the Tiedtke scheme, which more accurately modelled shallow convection over oceans, reduced errors in hurricane tracks prediction by $25 \%$ compared to using Kain-Fritsch scheme (Torn and Davis 2012). This also applied to storm position where runs with the Tiedtke scheme also exhibited less position bias (Torn and Davis 2012). Cloud-radiative feedback (CRF) appeared to affect the direction of storm tracks. Idealized hurricane cases with activated CRF would follow a more northwest track while scenarios without CRF would follow a more direct northward path (Fovell et al. 2010).

While no individual model runs were performed to generate data, results from this investigation could be relevant to reducing model errors. A similar approach to other studies (i.e., Karyampudi et al. 1999, Fink and Vincent 2003) was followed, using realtime observational and reanalysis data. The best storm track locations from NHC, satellite imagery from CIMSS, and two types of reanalysis data, Modern-Era Retrospective Analysis for Research and Applications, Version 2 (MERRA-2) and National Centers for Environmental Prediction Final Operational Global Analysis (NCEP-FNL), were utilized for comparison among the four cases. 


\section{Data and Methods}

a. The TCs

Four TCs from 2015, TD9, TS Grace, Hurricane Fred, and Hurricane Danny, were chosen based on similarity in location and time period. The storm paths of these TCs were situated in the eastern North and Central Atlantic Ocean basin (Fig. 1). These TCs occurred within approximately a month's time, starting with Danny in mid-August and ending with TD9 developing in mid-September (Table 1). These TCs also showcased different peak storm intensities, TC development and dry air strength in the surrounding environment. Per the respective NHC reports, each case also began from a tropical wave propagating over the African coast (Beven II 2016, Blake 2015, Brown 2015, Stewart 2016).

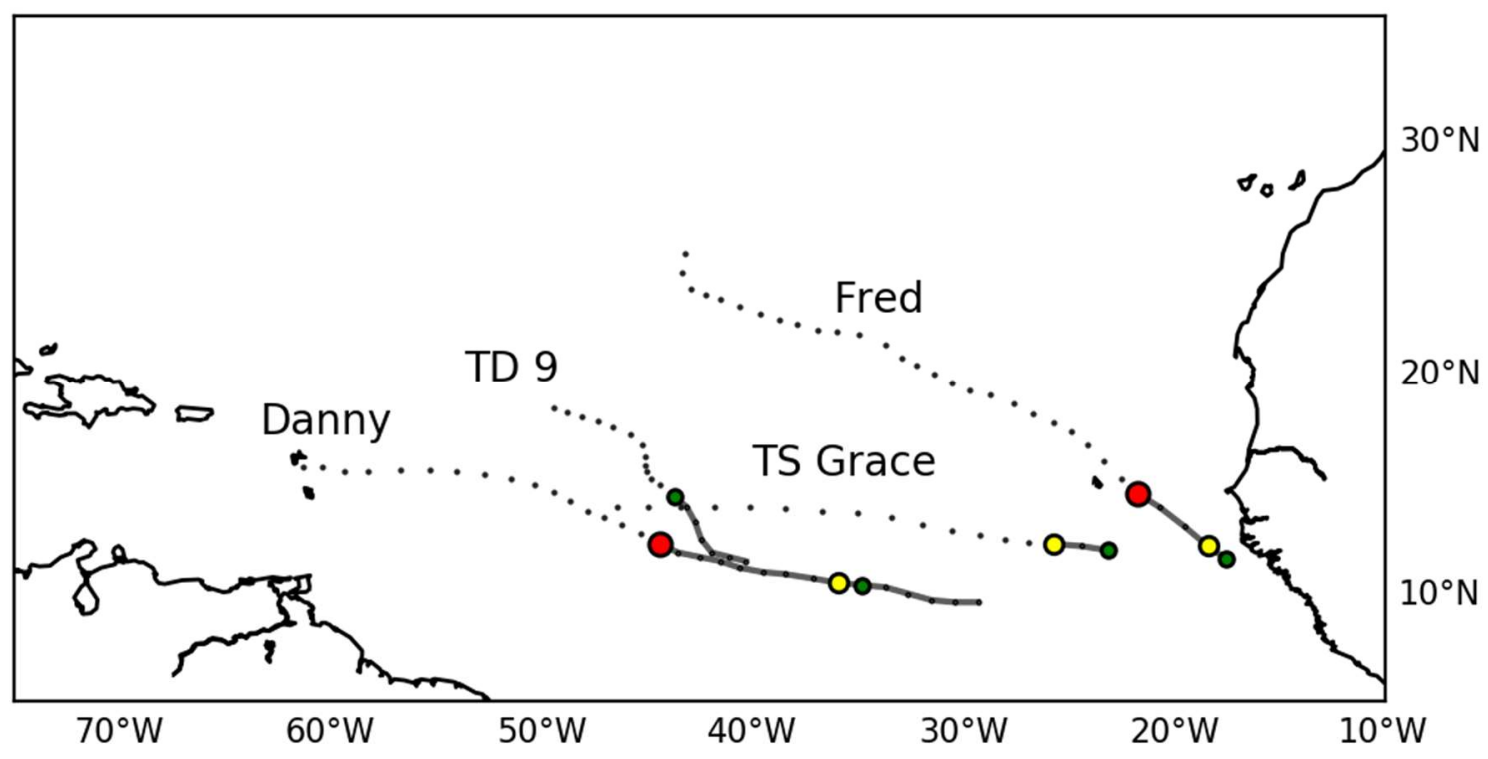

FIG. 1. Storm paths of TD9 (2015), TS Grace (2015), Hurricane Fred (2015), and Hurricane Danny (2015); green marker denotes when the TC was declared TD, yellow marker for TS, and red for hurricane. Solid (dotted) grey line connects the best storm locations before (after) the highest storm stage was declared. 
TABLE 1. Dates when TD, TS and H stages were declared by case.

\begin{tabular}{llcc} 
& \multicolumn{3}{c}{ TC Stages } \\
\cline { 2 - 4 } & \multicolumn{1}{c}{ TD } & TS & H \\
H Danny & 0600 UTC 18 Aug & 1200 UTC 18 Aug & 1200 UTC 20 Aug \\
\cline { 2 - 3 } H Fred & 0000 UTC 30 Aug & 0600 UTC 30 Aug & 0000 UTC 31 Aug \\
\cline { 2 - 3 } TS Grace & 0600 UTC 05 Sep & 1800 UTC 05 Sep & \\
TD9 & 1200 UTC 16 Sep & \multicolumn{2}{c}{ UTC }
\end{tabular}

\section{1) Tropical Depression 9 (TD9)}

On September 10, 2015, Tropical Depression 9 (TD9) (September 15 - 19, 2015) began forming into a TC. After traversing south of Cabo Verde, it gained strength and organization on September 13, 2015 (Brown 2015). After becoming less organized, the TC regained power on September 15, 2015 before being declared a TD on 12 UTC 16 Sep (Brown 2015, Table 1).

\section{2) Tropical Storm Grace}

Similar to TD9, Tropical Storm Grace (TS Grace) (September 5 - 9, 2015) was able to develop because the environment included warm sea surface temperatures (SSTs) and low vertical wind shear (VWS) from an atmospheric wave on September 3, 2015 (Blake 2015). Convection assisted in creating more defined structure of the TC on September 5, 2015, eventually resulting in reaching TD stage at 06 UTC 05 Sep south of Cabo Verde (Blake 2015, Table 1). Twelve hours later at 18 UTC 05 Sep, the TD was upgraded to TS Grace (Blake 2015).

\section{3) Hurricane Fred}

Hurricane Fred (2015) was chosen as the storm system followed an atypical path becoming the first hurricane since 1892 to pass through Cape Verde (Beven II 2015, 
Jenkins et al. 2017). The storm system reached hurricane status on 31 Aug 2015 00Z, veering northwest from the area where African Easterly Waves tend to form (Beven II 2016). In addition, this was the only case of the four to undergo RI, in which wind speeds for a TC increase 35 knots in 24 hours (Chih and Wu 2020, Kaplan and DeMaria 2003, Beven II 2016).

\section{4) Hurricane Danny}

The precursor of Hurricane Danny started on August 14, 2015 over the African continent (Stewart 2016). The system became more organized southeast of Cabo Verde on August 15, 2015 and was tracked as a low on 00 UTC 17 Aug 2015. The NHC reported that the system experienced low VWS and eventually the SAL encompassing it during a period of several days (Stewart 2016). During this time, the TC developed from a TD at 06 UTC 18 Aug into a hurricane at 1200 UTC 20 Aug (Stewart 2016, Table 1). Eventually, the hurricane was upgraded to a major hurricane on 1200 UTC 15 Aug (Stewart 2016). For the purposes of this study, the final time point for analysis was 1200 UTC 20 Aug as the focus is on TC developing stages into a TD, TS or hurricane.

While Hurricane Danny did not meet the RI requirements presented by Kaplan and DeMaria (2003), the TC did gain 30 knots in 48 hours (Stewart 2016) and was used as a case to investigate RI (Plotkin et al. 2019). Because the majority of Danny's life cycle remained over the ocean, no reported loss of life or property damage resulted (Stewart 2016). The lack of human impact may also contribute to the few studies on this hurricane at the time of this investigation. 


\section{b. Data}

The Tropical Cyclone group of the Cooperative Institute for Meteorological Satellite Studies (CIMSS), a collaborative research institute with NOAA, NASA and the University of Wisconsin-Madison, generated the SAL-dry air product used for this investigation. The SAL-dry air satellite imagery is a combination of visible and dry air images, showing dry air between $\sim 600-925 \mathrm{hPa}$ per correspondence with Dr. Dunion and Tim Olander of CIMSS; more information could be found in the article authored by Dunion (2010).

In addition, both reanalysis datasets used, NCEP-FNL and MERRA-2, incorporated satellite observations and modeling results. Hodges et al. (2017) compared how well TCs were represented in reanalysis datasets, including MERRA-2. While the identification of TCs was $98 \%$ for the six datasets analyzed, there were some discrepancies with TC characteristics including underestimations of winds, when compared with actual observations (Hodges et al. 2017).

\section{1) NCEP-FNL}

National Centers for Environmental Prediction Final Operational Global Analysis (NCEP-FNL) data were spatially defined as $1^{\circ}$ by $1^{\circ}$ grids for every 6 hours (NCEP 2000). NCEP-FNL datasets incorporated more available observations than the GFS forecast, often completed about an hour after the forecast (NCEP 2000). These reanalysis data were also used to initialize future GFS runs (NCEP 2000). The data contributors to NCEP-FNL included the National Centers for Environmental Prediction, National Weather Service, National Oceanic and Atmospheric Administration (NOAA), and the 
United States Department of Commerce. RH was utilized from dataset ds 083.2 for the four TC cases; henceforth, referred to as NCEP-FNL for simplicity.

While the $1^{\circ} \mathrm{x} 1^{\circ}$ grid means $111 \mathrm{~km}$ and could be coarse to observe TCs in finer detail, the resolution was sufficient to allow for investigation of the surrounding environment, including air moisture. Fink and Vincent (2003) noted that they and other investigators showed that the European Centre for Medium-Range Weather Forecasts (ECMWF) reanalysis data with the same resolution of $1^{\circ} \times 1^{\circ}$, was able to find $61-89 \%$ of TCs, using mean sea-level pressure and vorticity. Although the study was focused on the Pacific Ocean basin, Fink and Vincent (2003) demonstrated that data at such a resolution could aid in analyzing TCs.

\section{2) MERRA-2}

The creation of MERRA-2 was partly driven by a need for an update to MERRA and identified as a stepping stone to an integrated Earth system analysis (Gelaro et al. 2017). Some observations from the previous version, MERRA, were depended on instrumentation possibly expiring, such as the Earth Observing System (EOS) Aqua (Gelaro et al. 2017). In order to maintain relevancy, MERRA-2 included updates from the GEOS-1 model and other data by the Global Modeling and Assimilation Office (GMAO). MERRA-2 also included aerosol assimilation described in detail by Randles et al. (2017), as stated in the article authored by Gelaro et al. (2017). Compared to NCEPFNL, the resolution of MERRA-2 data was more fine with a grid size of $0.5^{\circ} \times 0.625^{\circ}$ (Gelaro et al. 2017). 
MERRA-2 file inst3_3d_asm_Nv (M2I3NVASM) was utilized for this study, henceforth referred to as MERRA-2 (GMAO 2015, Bosilovich et al. 2016, NASA 2017). This specific file contained instantaneous data for every 3 hours with 72 eta levels (Bosilovich et al. 2016, NASA 2017).

MERRA-2 presented RH as a pseudorelative humidity, the variable used in this investigation (Gelaro et al. 2017). Per Holm (2003), the RH values recorded in MERRA2 were transformed to be symmetrical defined with the following formula:

$$
\delta R H=\frac{\delta R H}{\sigma\left(R H^{b}+\frac{1}{2} \delta R H\right)}
$$

where $\mathrm{b}$ represents background, $\mathrm{RH}$ is relative humidity, $\sigma$ is standard deviation

The pseudorelative humidity was a product of background error derived from forecast errors (Holm 2003). The best method to create a Gaussian distribution from the given $\mathrm{RH}$ was using symmetric transformation (Holm 2003). More details can be found in the specific article (Holm 2003). Henceforth, the pseudorelative humidity used in MERRA-2 will be referred to as $\mathrm{RH}$ for simplicity.

Per Bosilovich et al. (2015), RH in MERRA-2 was more similar to ERA-interim compared to MERRA. However, MERRA-2's RH was still higher in the upper levels tropospheric when compared to ERA-interim (Bosilovich et al. 2015).

\section{c. Methods}

Storm path locations were labeled as the date when the TC would reach based on the best locations from the respective NHC reports (Beven II 2016, Blake 2015, Brown 2015, Stewart 2016). While the nomenclature may be unexpected as both physical locations and 
time points are labelled as a date and hour, it would likely simplify how the RH value was related to the actual time point and TC location, pending availability.

As the exact location of the storm from NHC may not fall precisely on the grid of the particular dataset, RH values were frequently averaged before presented in this study (Beven II 2016, Blake 2015, Brown 2015, Stewart 2016). In the case of NCEP-FNL characterized by a $1^{\circ}$ by $1^{\circ}$ resolution, any latitude (lat) or longitude (lon) with a decimal value less than 0.5 would be automatically rounded down to the nearest whole degree. In contrast, a degree of lat/lon ending with a decimal value above 0.5 was rounded up to the nearest degree. For example, a location of $14.4^{\circ} \mathrm{N}, 15.0^{\circ} \mathrm{W}$ would be converted to $14.0^{\circ} \mathrm{N}, 15.0^{\circ} \mathrm{W}$, where the $\mathrm{RH}$ value could be extracted. If the lat or lon ended exactly as ".5", then the RH values from the two positions bracketing the point was averaged. As an example, the average $\mathrm{RH}$ value for $14.0^{\circ} \mathrm{N}$ and $15.0^{\circ} \mathrm{N}$ would be calculated for a lat of $14.5^{\circ} \mathrm{N}$. The same idea for MERRA-2 was also applied except the closest lat/lon to the desired location were determined. The method developed subtracted the desired lat/lon from the corresponding grid, making an array containing degree differences. The position of this minimum difference determined which $\mathrm{RH}$ value to extract for analysis.

\section{1) Defining Dry Air}

At times, the terms dry air and the SAL appeared interchangeable in current research. However, low RH does not verify the presence of the SAL. An RH gradient is characteristic of the widely accepted SAL model from Karyampudi et al. (1999), where the RH may range from $<20 \%$ to $70 \%$ (From Figure 14a, 16a). Hankes et al. (2015) used $40 \%$ and below to distinguish air as dry in the African Easterly Jet (AEJ). In contrast, 
$40 \%$ seemed too high after reviewing the preliminary contour plots created from MERRA-2 and NCEP-FNL (Fig. 2). In addition, the SAL could span from $850 \mathrm{hPa}$ to $500 \mathrm{hPa}$ (Karyampudi et al. 1999) while this investigation mainly focused on $700 \mathrm{hPa}$. For this study, dry air was defined as 30\% RH (NCEP-FNL) or 0.30 (MERRA-2). Thus, instead of the SAL specifically, this study focused on dry air presence, often at the 700 $\mathrm{hPa}$.
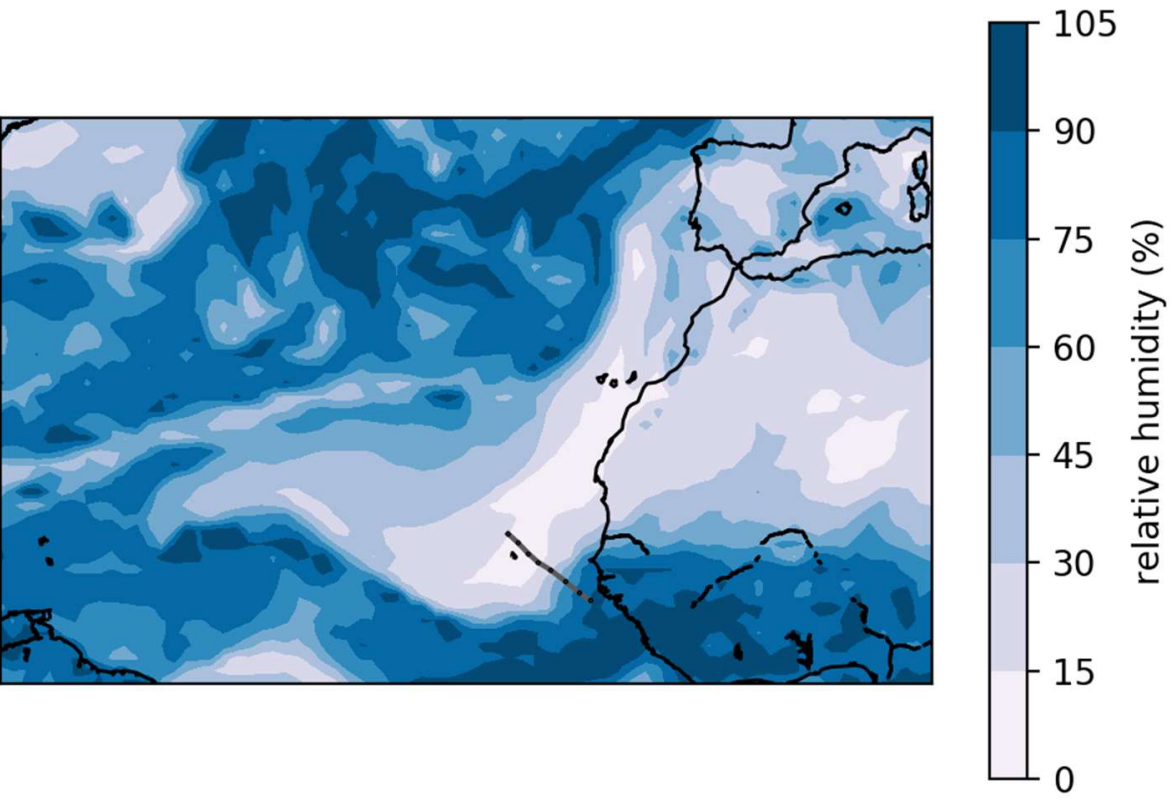

FIG. 2. RH at 18 UTC 29 August 2015 at $850 \mathrm{hPa}$; evidence of low RH air overlapping track prior to the Fred (2015).

\section{2) Time Period for Analysis}

The dry air in the environment up to 3 days ahead of a TC may be close enough in proximity to affect its properties. Any time beyond this limit may not directly influence the behavior of a TC. Additional motivation for a 3-day limit was lead time in forecast. In the South China Sea, this could mean only a few days (Wang et al. 2018, Park et al. 2015). The NHC reports also indicated a mixed review of how well forecasts predicted 
for each TC (Beven II 2016, Blake 2015, Brown 2015, Stewart 2016). In contrast, evidence exists that TC genesis could be influenced by features occurring longer than a 3day period. A wave pouch attributed to the development of Hurricane Isabel (2003) occurred 5 days prior (Hankes et al. 2015). A longer period of analysis in future studies may be suitable. 


\section{Results \& Discussion}

\section{a. General Characteristics of the Environment}

Evidence of wind wave activity was apparent in FIg. 3 and FIg. 4 (NOAA Physical Science Laboratory (PSL) 2020). It would suggest that dry and moist air may follow similar patterns. Such trends were also noticeable in the heatmaps (see next subsection: Heatmaps). Fig. 5 also indicated that sea surface temperatures were higher south of Cape Verde and closer to the western African continent (NOAA PSL 2020).

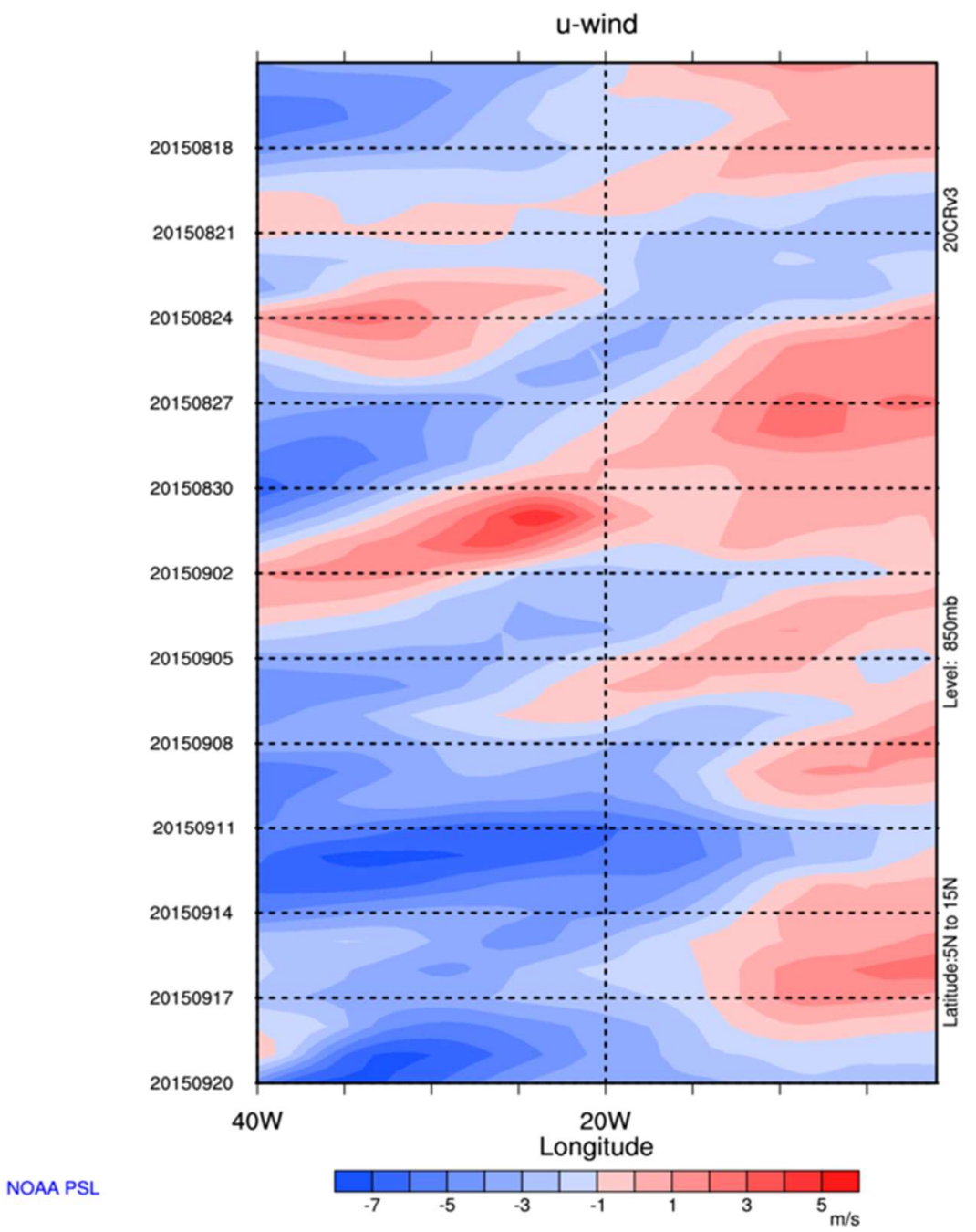

FIG. 3. Zonal wind at $850 \mathrm{hPa}$ from 20th Century Reanalysis V3. Image provided by the NOAA/ESRL PSL, Boulder Colorado from their Web site at http://psl.noaa.gov/. 


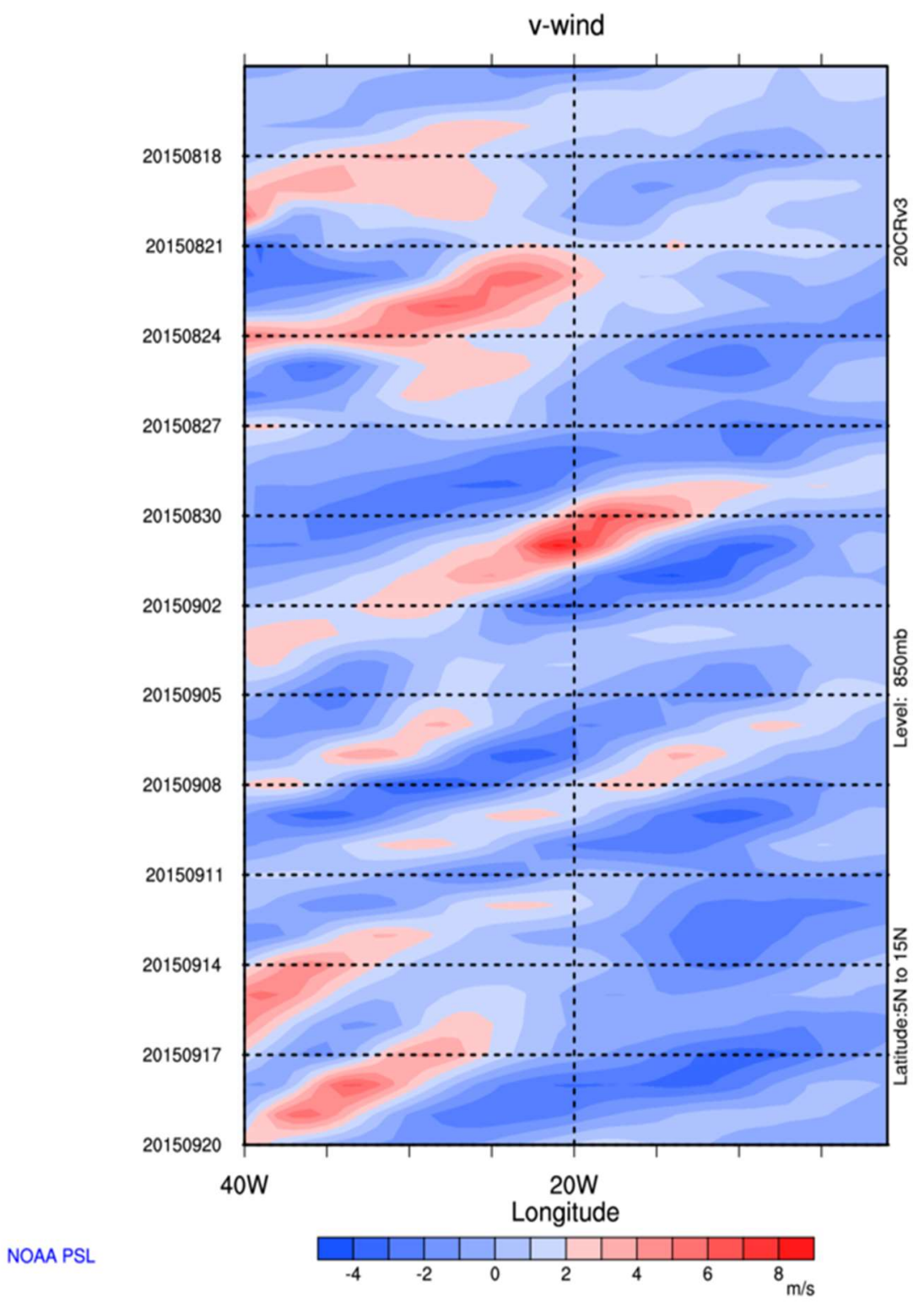

FIG. 4. Meridional Wind at $850 \mathrm{hPa}$ from 20th Century Reanalysis V3. Image provided by the NOAA/ESRL Physical Sciences Laboratory, Boulder Colorado from their Web site at http://psl.noaa.gov/. 


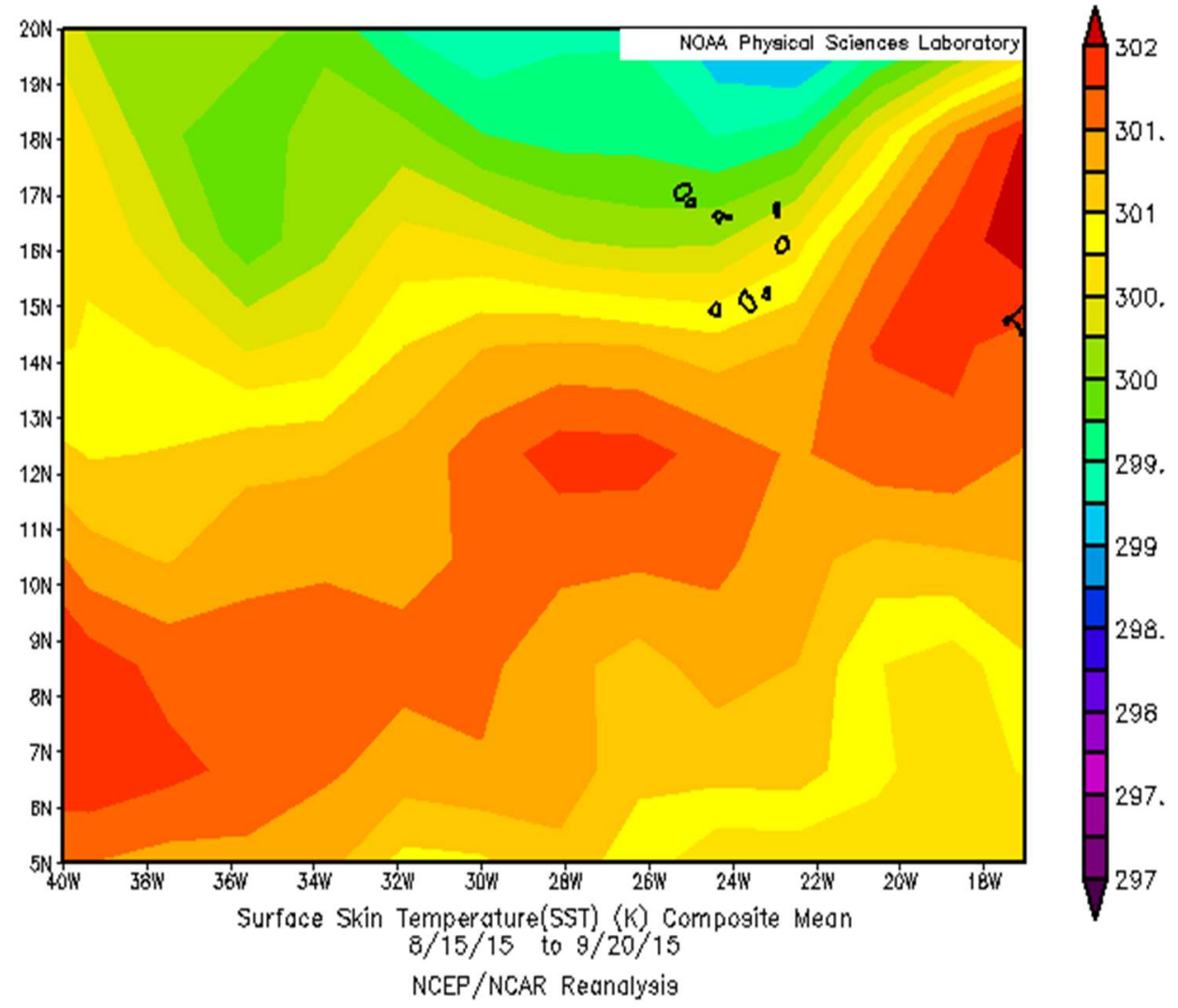

FIG. 5. SST of the central Atlantic Ocean Basin. Image provided by the NOAA/ESRL Physical Sciences Laboratory, Boulder Colorado from their Web site at http://psl.noaa.gov/.

\section{b. Heatmaps}

RH data from NCEP-FNL and MERRA-2 represented in heatmaps offered overviews of air moisture by location and time. Heatmaps showed the RH at every best location of the TC's storm track as time progressed. For example, one could see how far ahead dry air was located in relation to the actual storm and where the dry air was located physically on the storm path at a given time point. As these graphics were intended for a general overview, some RH values may not fall within the 3-day limit designated in the methodology section. In addition, the heatmaps included a glimpse into the moisture amount in the environment after the respective TC had passed by. 


\section{1) Tropical Depression 9}

Like TS Grace (2015), the heatmaps for TD9 displayed two dry air overlaps on the storm path prior to the TC passing through (Fig. 6, Fig. 7). The gap between the two dry air incidences appeared to be larger than for TS Grace, about 2 days. This was visible in both MERRA-2 and NCEP-FNL. Dry air would again follow after the TC had passed through the storm path. This may be evidence of the dry wake after a hurricane passes by (Makarieva et al. 2017).
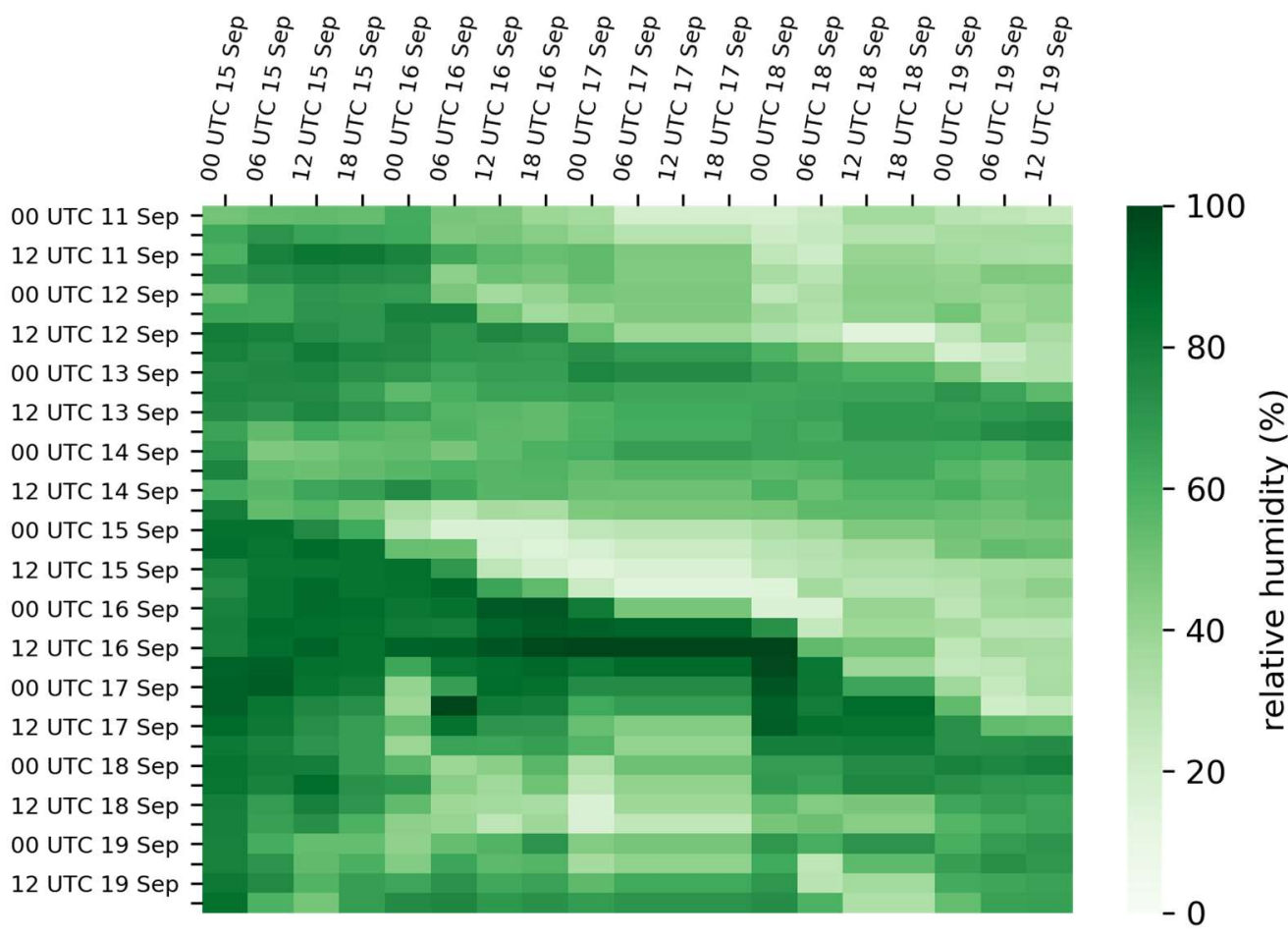

FIG. 6. Heatmap of RH values for TD9 (2015) at $700 \mathrm{hPa}$ from NCEP-FNL; vertical $\mathrm{x}$-axis denotes the time point and the horizontal y-axis shows the time of the NHC best location of the TC. 


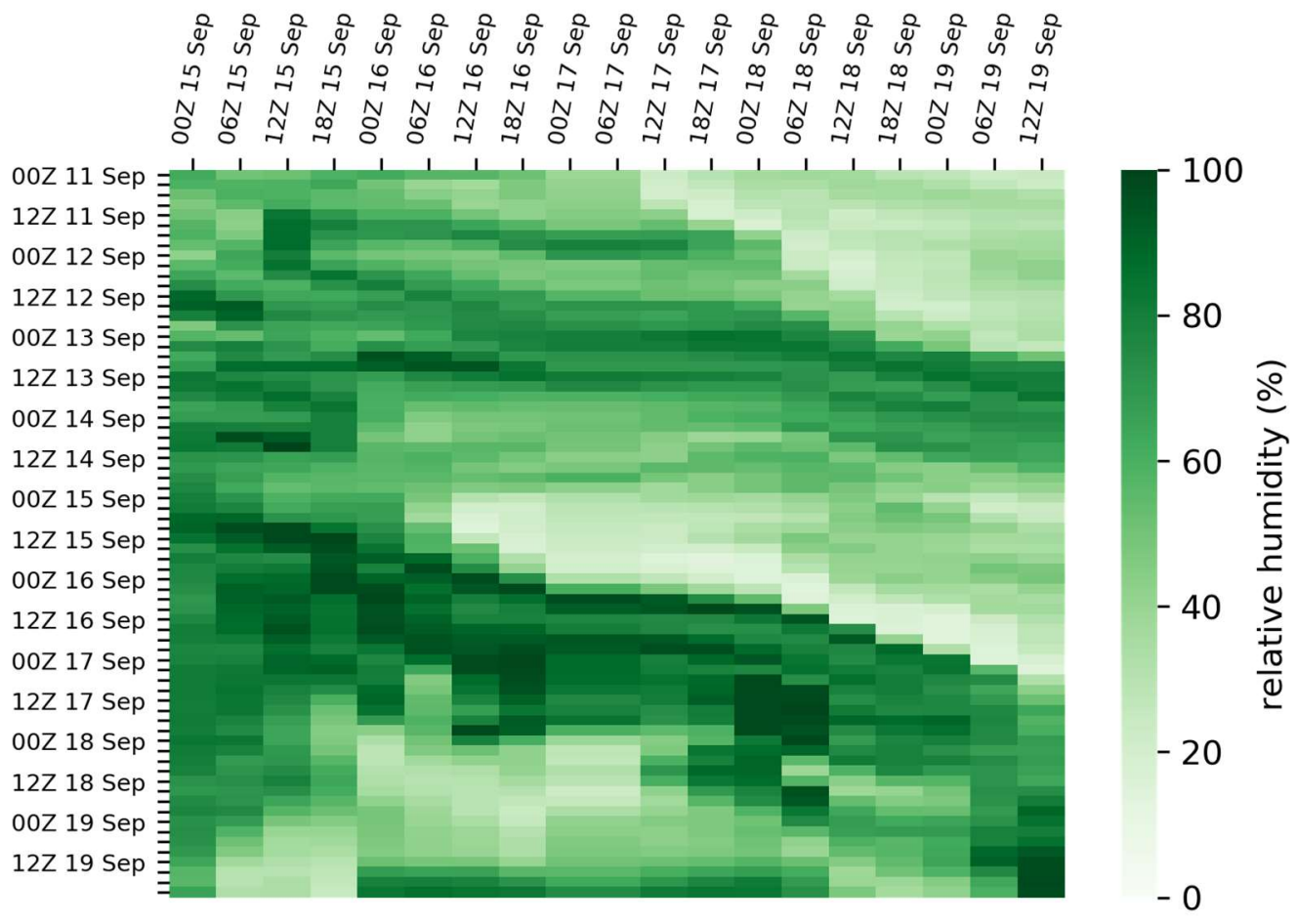

FIG. 7. Heatmap of RH values for TD9 (2015) at $700 \mathrm{hPa}$ from MERRA-2; vertical x-axis denotes the time point and the horizontal y-axis shows the time of the NHC best location of the TC.

At $850 \mathrm{hPa}$, the overall heatmap for MERRA-2 appeared as if more humid values frequent the storm track locations (Fig. 9). Both MERRA-2 and NCEP-FNL did not match well in terms of RH (Fig. 8, Fig. 9). 


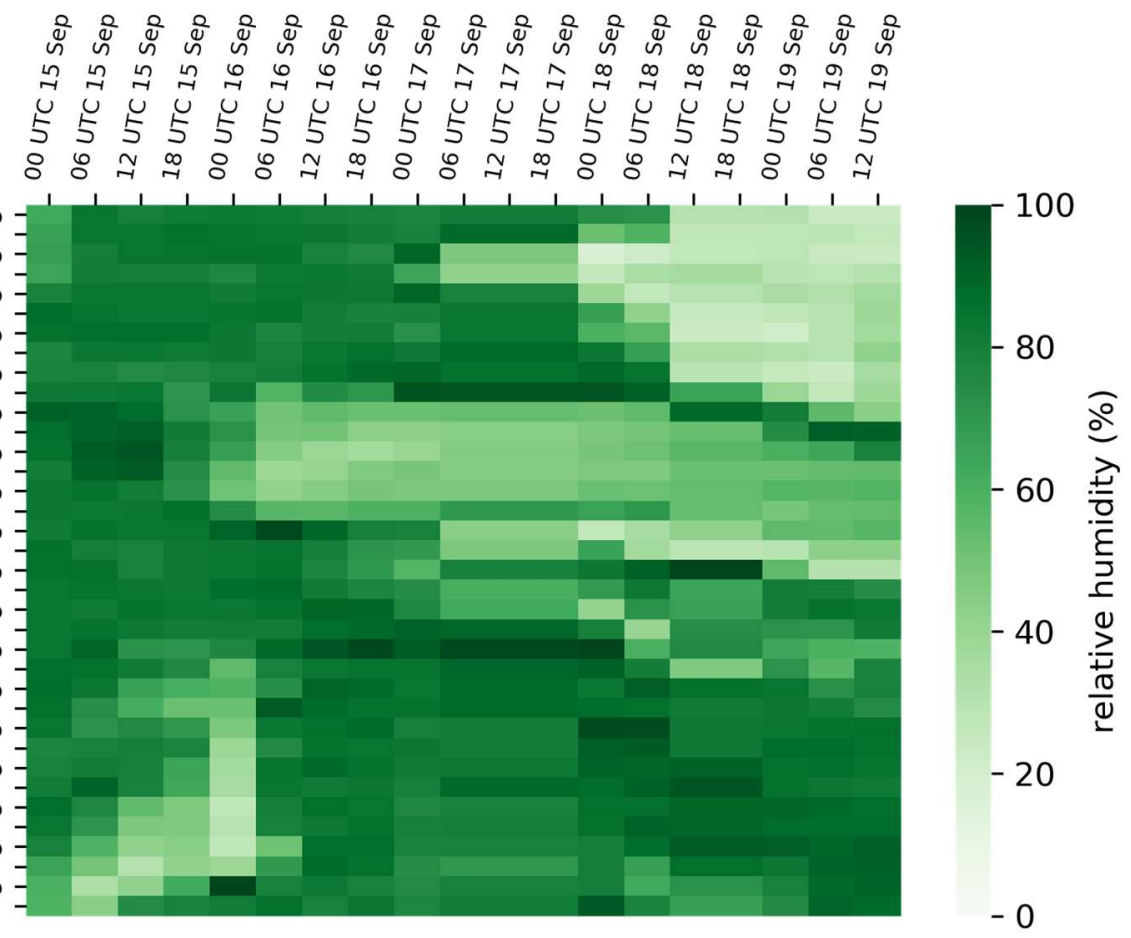

FIG. 8. Heatmap of RH values for TD9 (2015) at $850 \mathrm{hPa}$ from NCEP-FNL; vertical $\mathrm{x}$-axis denotes the time point and the horizontal $\mathrm{y}$-axis shows the time of the NHC best location of the TC.

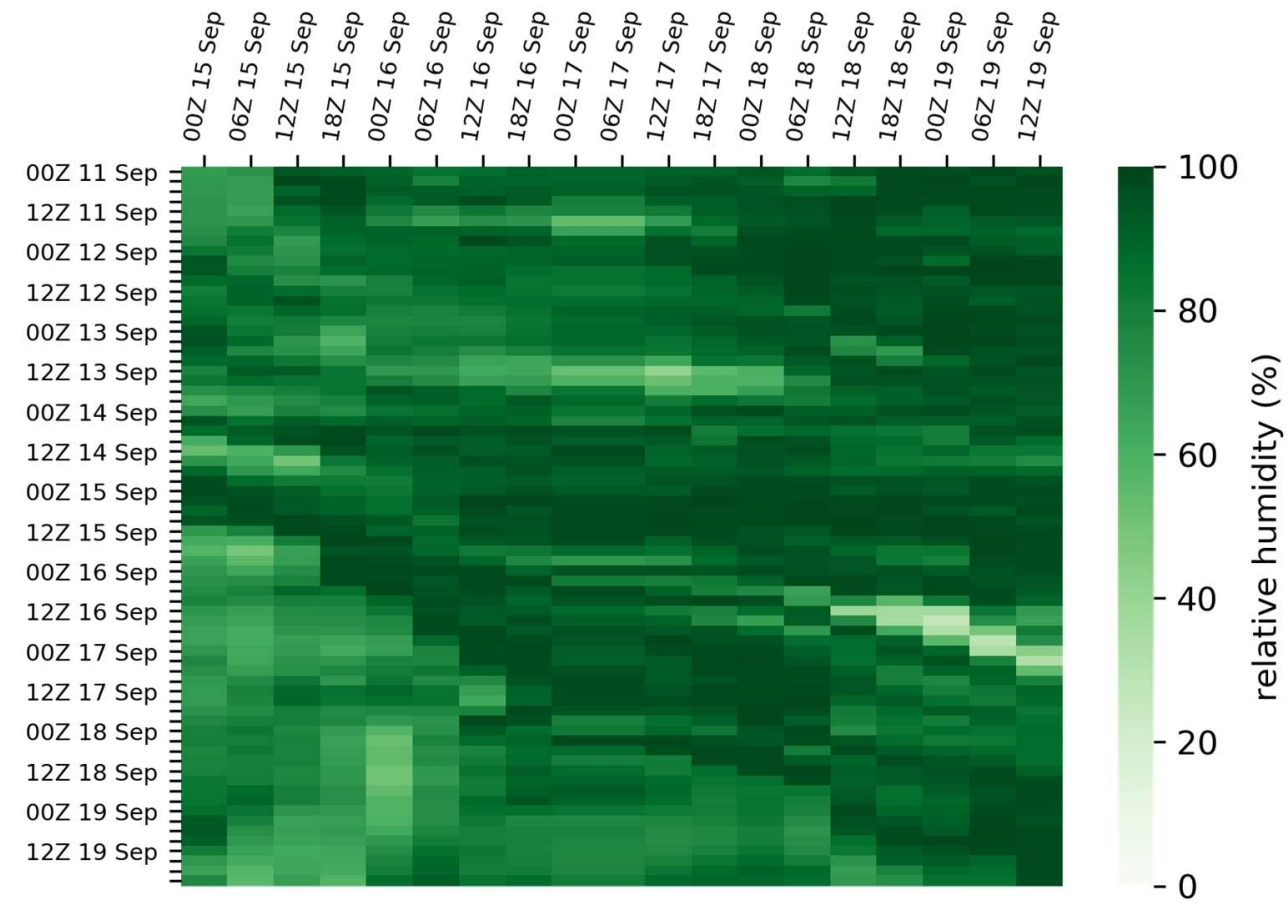

FIG. 9. Heatmap of RH values for TD9 (2015) at $850 \mathrm{hPa}$ from MERRA-2; vertical x-axis denotes the time point and the horizontal y-axis shows the time of the NHC best location of the TC. 


\section{2) Tropical Storm Grace}

At the $700 \mathrm{hPa}$ level, the general features of dry air on the latter half of storm path, days before the TC appeared on the first storm position were observed in heatmaps from both MERRA-2 and NCEP-FNL (Fig. 10, Fig. 11). Two wave-like incidences of dry air appeared to have occurred on the storm locations before the TC would traverse down the path. In both datasets, the incidences appeared to be separated by a more humid air occurrence (Fig. 10, Fig. 11). Similarly, as with Danny and Fred, dry air would also traverse the storm path after the TC passed through.

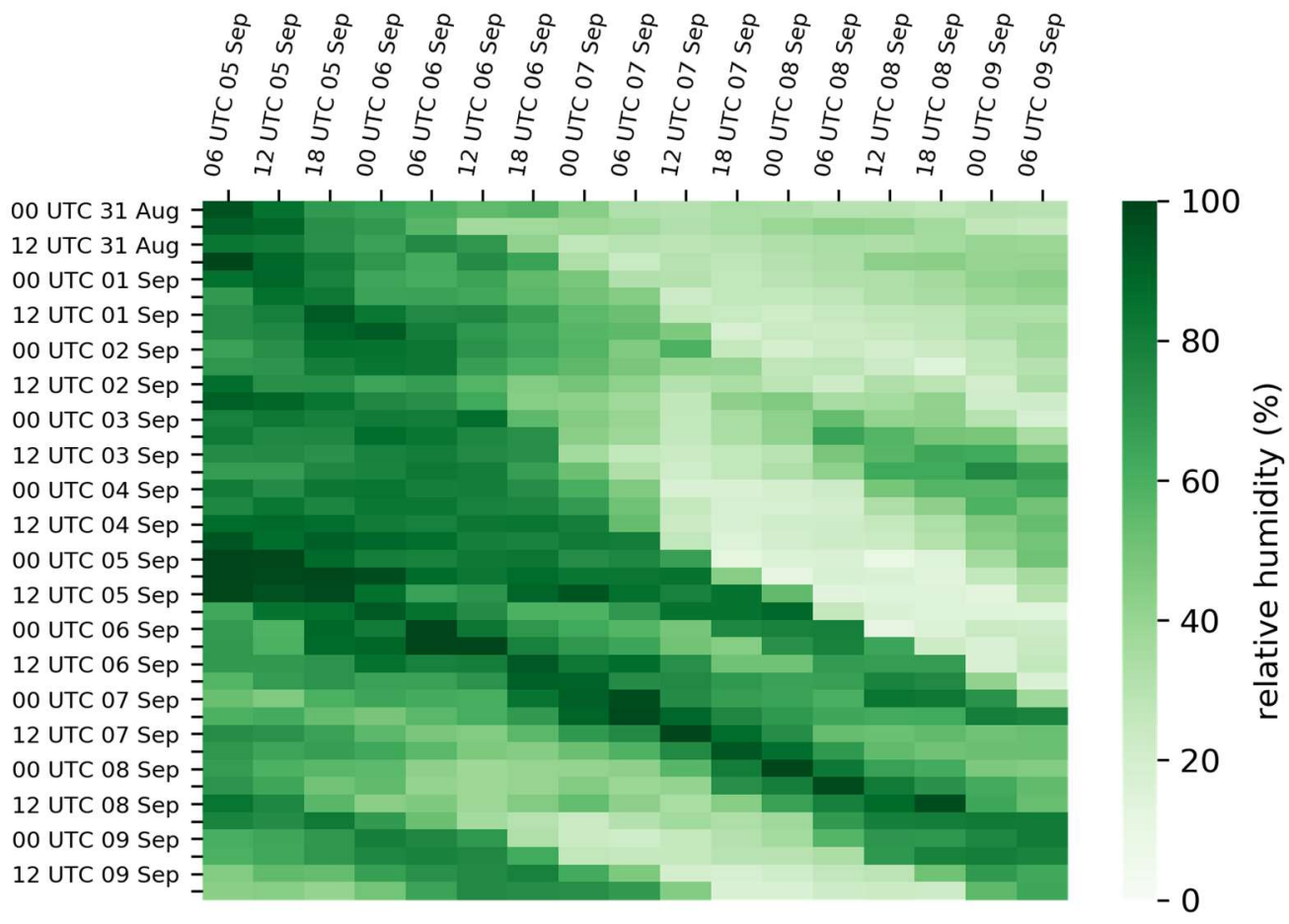

FIG. 10. Heatmap of RH values for TS Grace (2015) at $700 \mathrm{hPa}$ from NCEP-FNL; vertical x-axis denotes the time point and the horizontal y-axis shows the time of the NHC best location of the TC. 


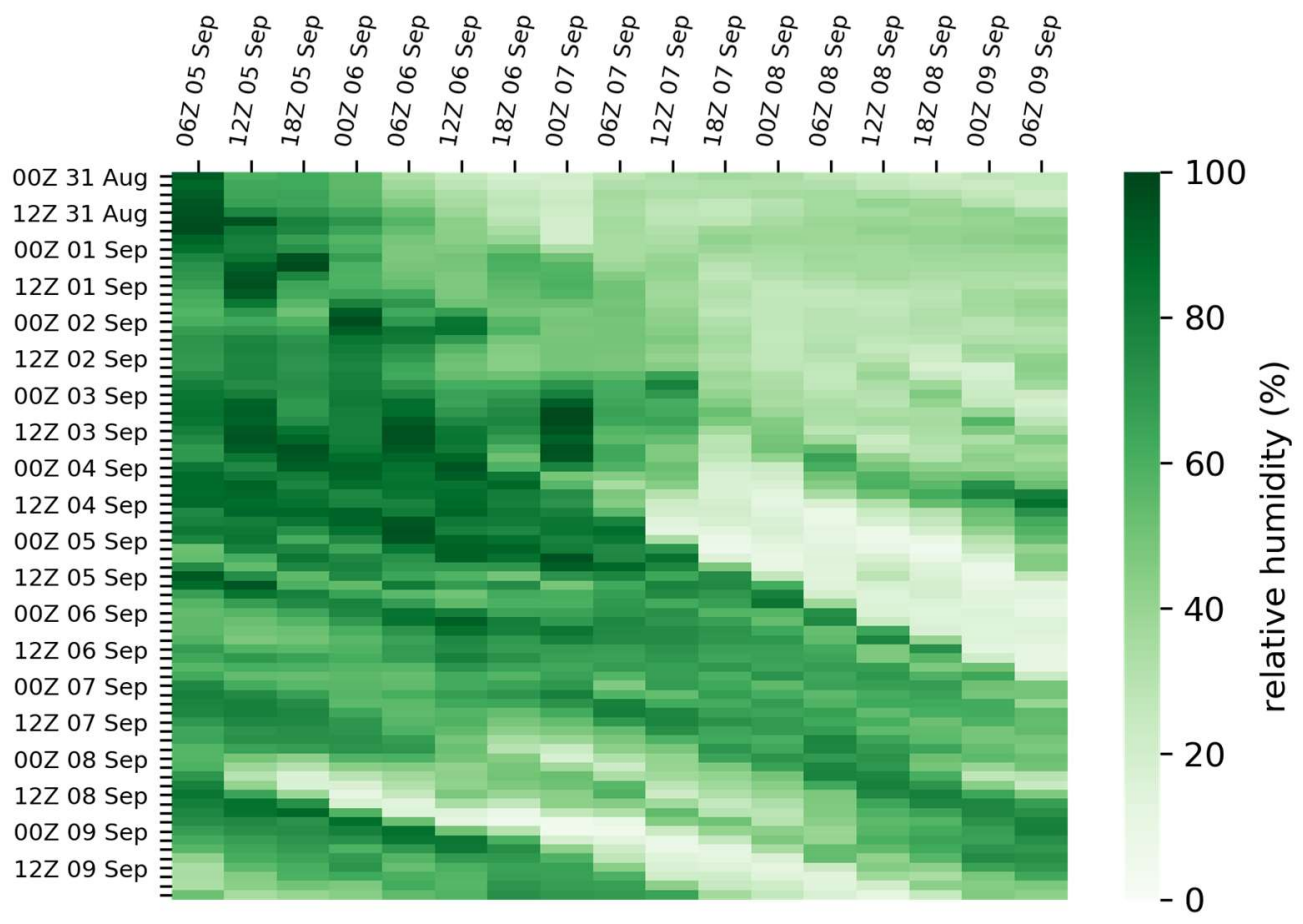

FIG. 11. Heatmap of RH values for TS Grace (2015) at $700 \mathrm{hPa}$ from MERRA-2; vertical x-axis denotes the time point and the horizontal y-axis shows the time of the NHC best location of the TC.

Like TD9, the $850 \mathrm{hPa}$ environment differed between datasets as the patterns did not match well. The heatmap for MERRA-2 appeared generally more humid than that of NCEP-FNL (Fig. 12, Fig. 13). 

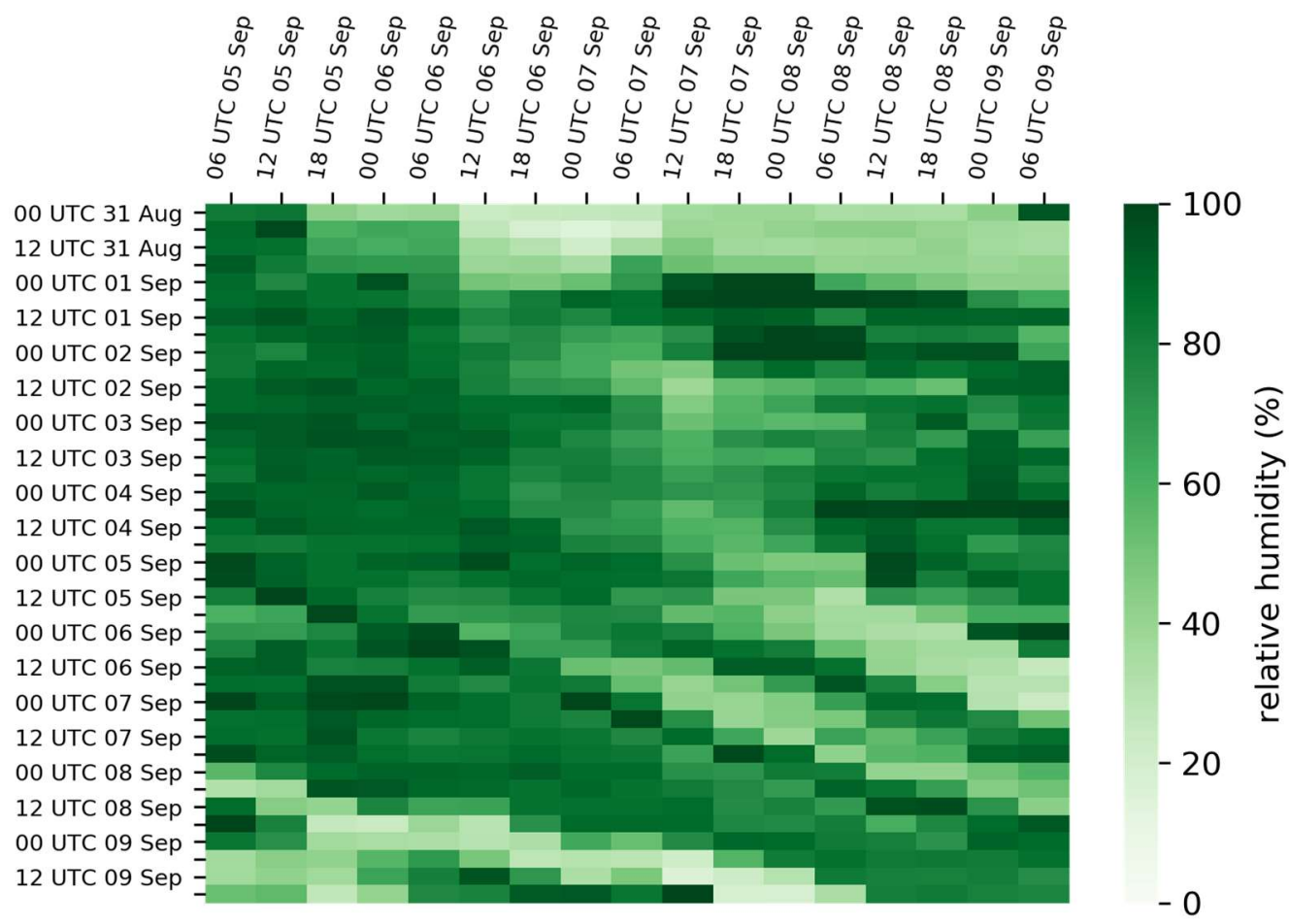

FIG. 12. Heatmap of RH values for TS Grace (2015) at $850 \mathrm{hPa}$ from NCEP-FNL; vertical x-axis denotes the time point and the horizontal y-axis shows the time of the NHC best location of the TC.
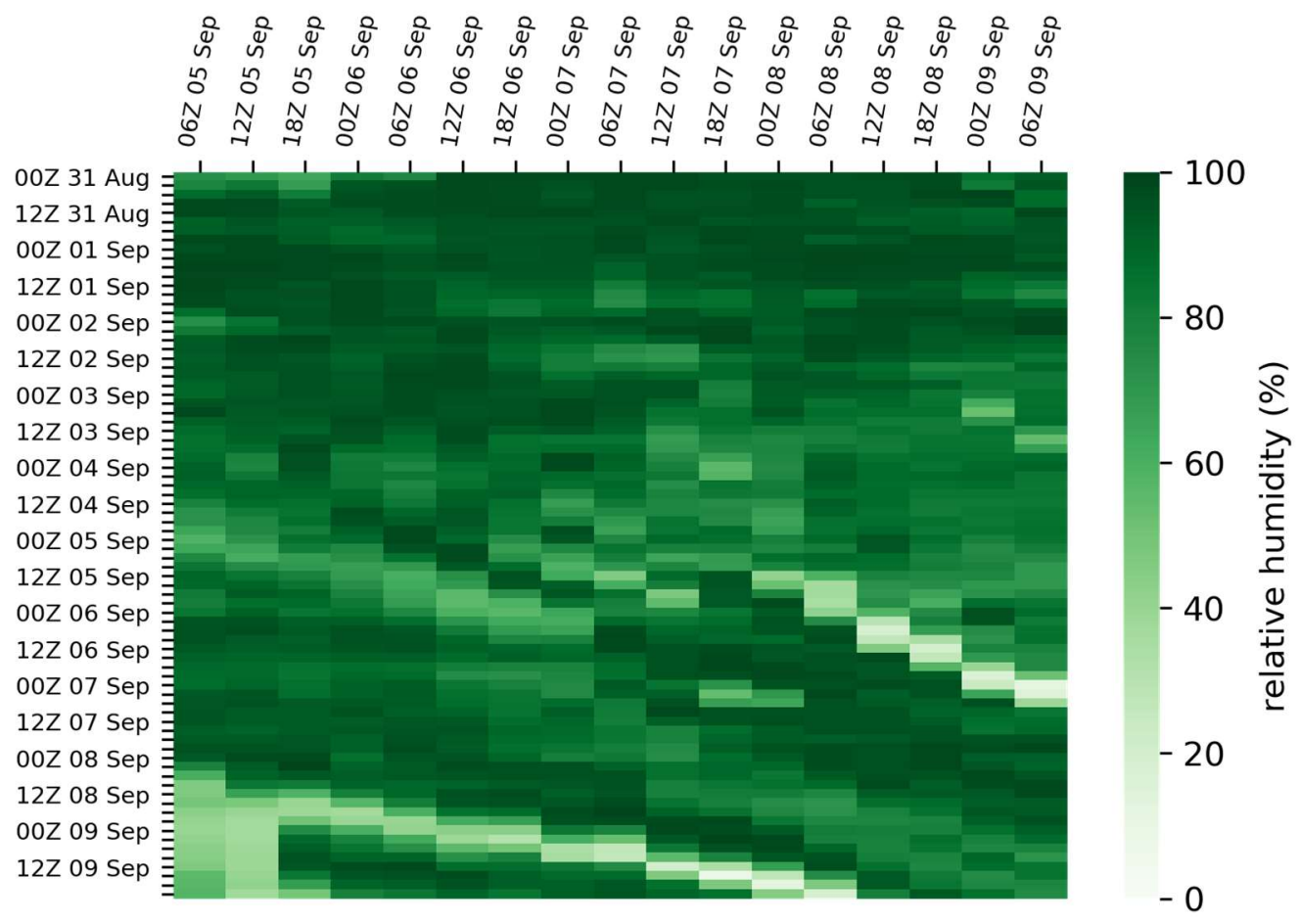

FIG. 13. Heatmap of RH values for TS Grace (2015) at $850 \mathrm{hPa}$ from MERRA-2; vertical x-axis denotes the time point and the horizontal y-axis shows the time of the NHC best location of the TC. 


\section{3) Hurricane Fred}

The dry air at the $700 \mathrm{hPa}$ level appeared more frequently near the actual location of the precursor of Hurricane Fred (2015) (Fig. 14, Fig. 15). Indeed, more RH values appeared to fit the study's parameters compared to Hurricane Danny (Fig. 14, Fig. 15). Like Hurricane Danny, dry air would eventually intersect the storm path after the storm had already passed by. Similarly, the $850 \mathrm{hPa}$ environment of the storm track appeared very dry within days before the storm reached the physical location (Fig. 16, Fig. 17).

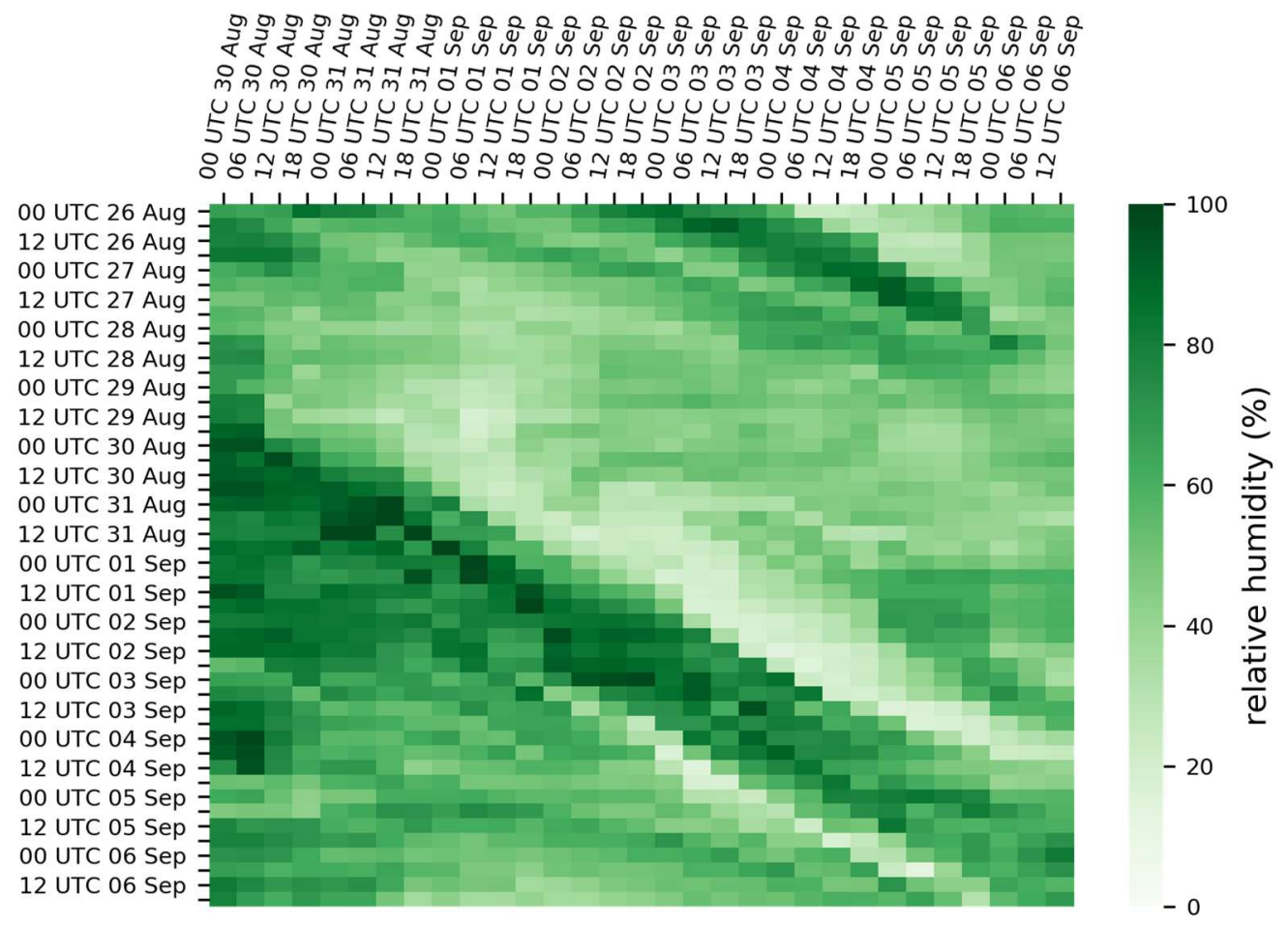

FIG. 14. Heatmap of RH values for Hurricane Fred (2015) at $700 \mathrm{hPa}$ from NCEP-FNL; vertical x-axis denotes the time point and the horizontal y-axis shows the time of the NHC best location of the TC. 


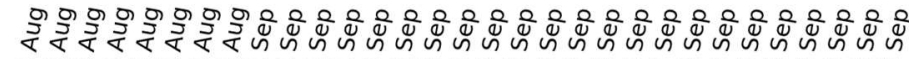

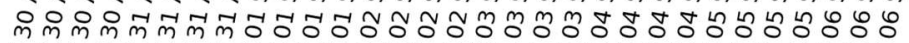

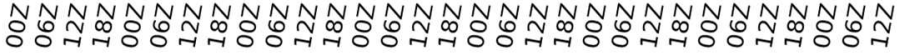

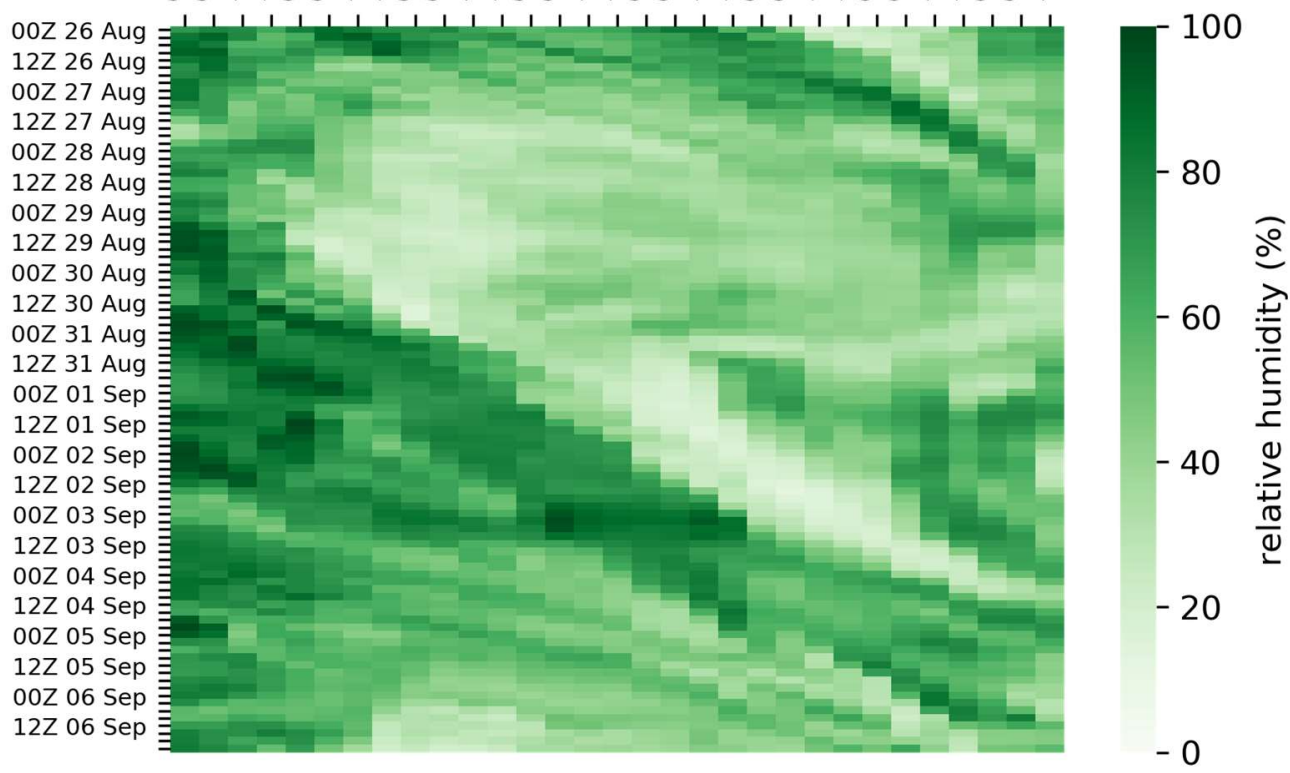

FIG. 15. Heatmap of RH values for Hurricane Fred (2015) at $700 \mathrm{hPa}$ from MERRA-2; vertical x-axis denotes the time point and the horizontal y-axis shows the time of the NHC best location of the TC.

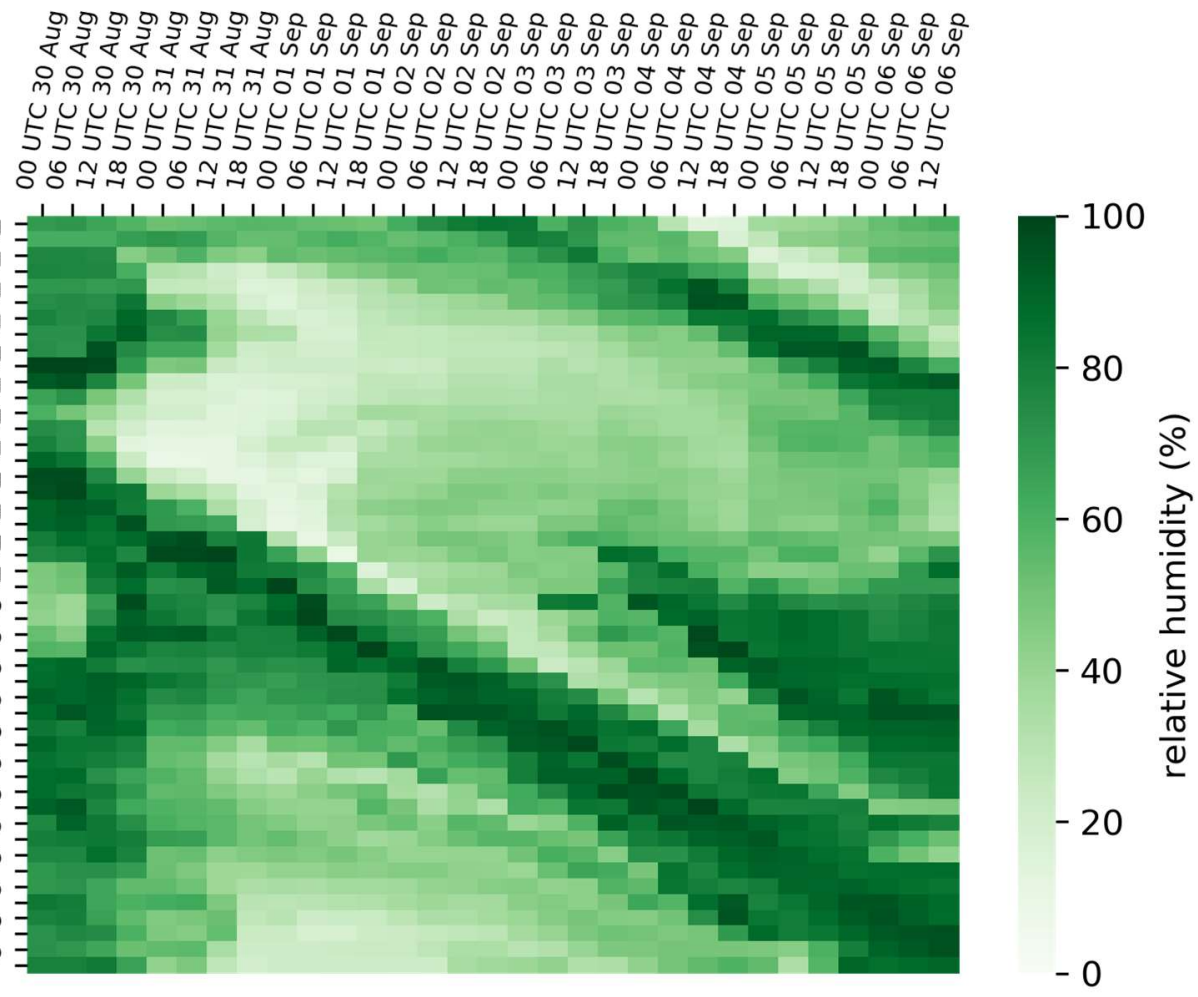

FIG. 16. Heatmap of RH values for Hurricane Fred (2015) at $850 \mathrm{hPa}$ from NCEP-FNL; vertical x-axis denotes the time point and the horizontal y-axis shows the time of the NHC best location of the TC. 


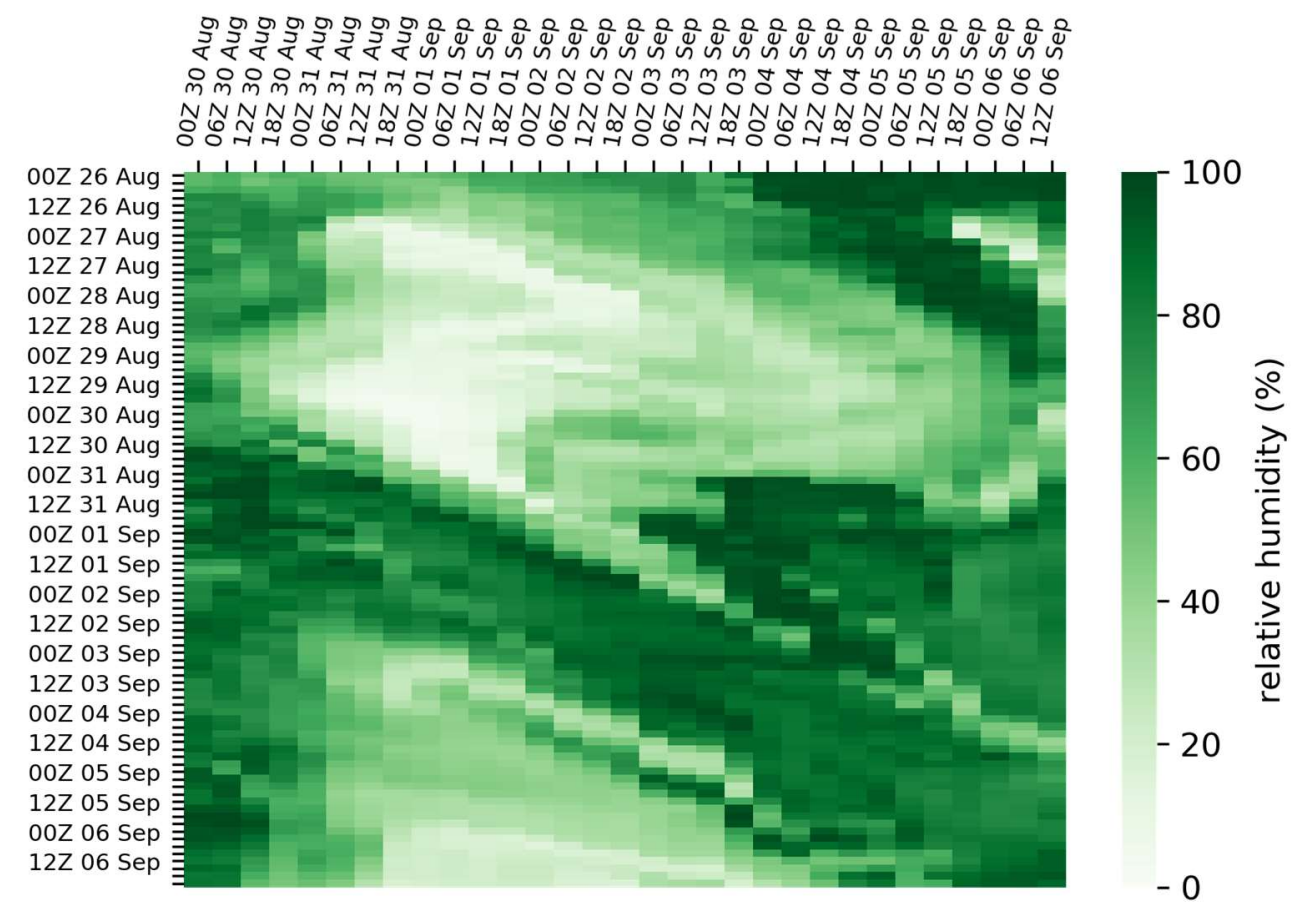

FIG. 17. Heatmap of RH values for Hurricane Fred (2015) at $850 \mathrm{hPa}$ from MERRA-2; vertical x-axis denotes the time point and the horizontal y-axis shows the time of the NHC best location of the TC.

\section{4) Hurricane Danny}

The environment for Hurricane Danny at $700 \mathrm{hPa}$ was generally dry on the storm path for NCEP-FNL before the storm traversed through (Fig. 18). Dry air (10\% RH or less) on the latter half of Hurricane Danny was observed per NCEP-FNL, 4-5 days before the hurricane stage was reached (Fig. 18). The positions in the latter half the storm path recorded more dry RH values compared to positions physically closer to where the TC would be located. 


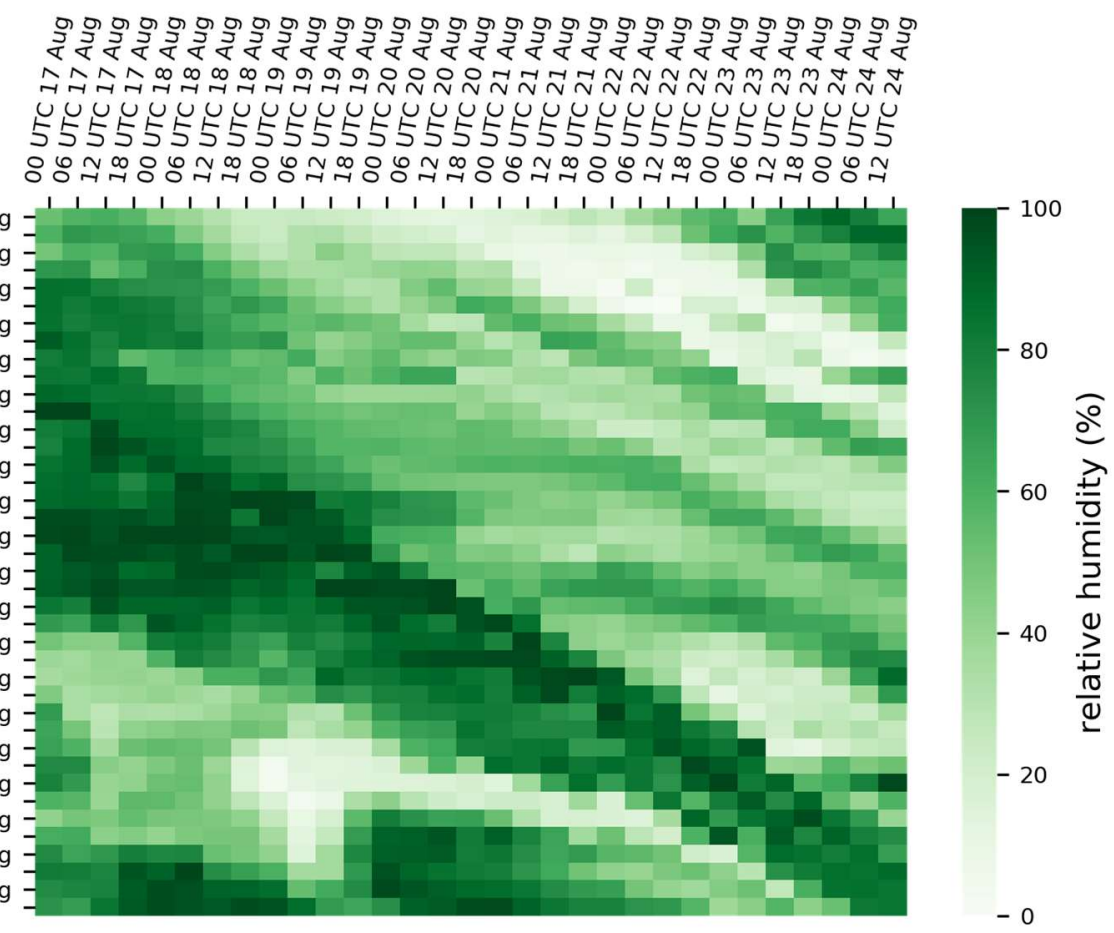

FIG. 18. Heatmap of RH for Hurricane Danny (2015) at $700 \mathrm{hPa}$ from NCEP-FNL; vertical x-axis denotes the time point and the horizontal y-axis shows the time of the NHC best location of the TC.

According the MERRA-2 data, the $700 \mathrm{hPa}$ environment on the storm track for Danny appeared more dry (Fig. 19) preceding the TC compared to NCEP-FNL (Fig. 18); a possible reason would be the increased number of data points as MERRA-2 recorded data documented every 3 hours compared to every 6 hours. Evidence of a possible dry air intrusion after hurricane stage (12 UTC 20 Aug) was observed around a day or more later in both NCEP-FNL and MERRA-2 (Fig. 18, Fig. 19). This coincided with the respective NHC report, stating that Hurricane Danny lost momentum and devolved into a TS by 00 UTC 23 Aug (Stewart 2016). Overall, the two heatmaps appeared very similar in pattern (Fig. 18, Fig. 19). 


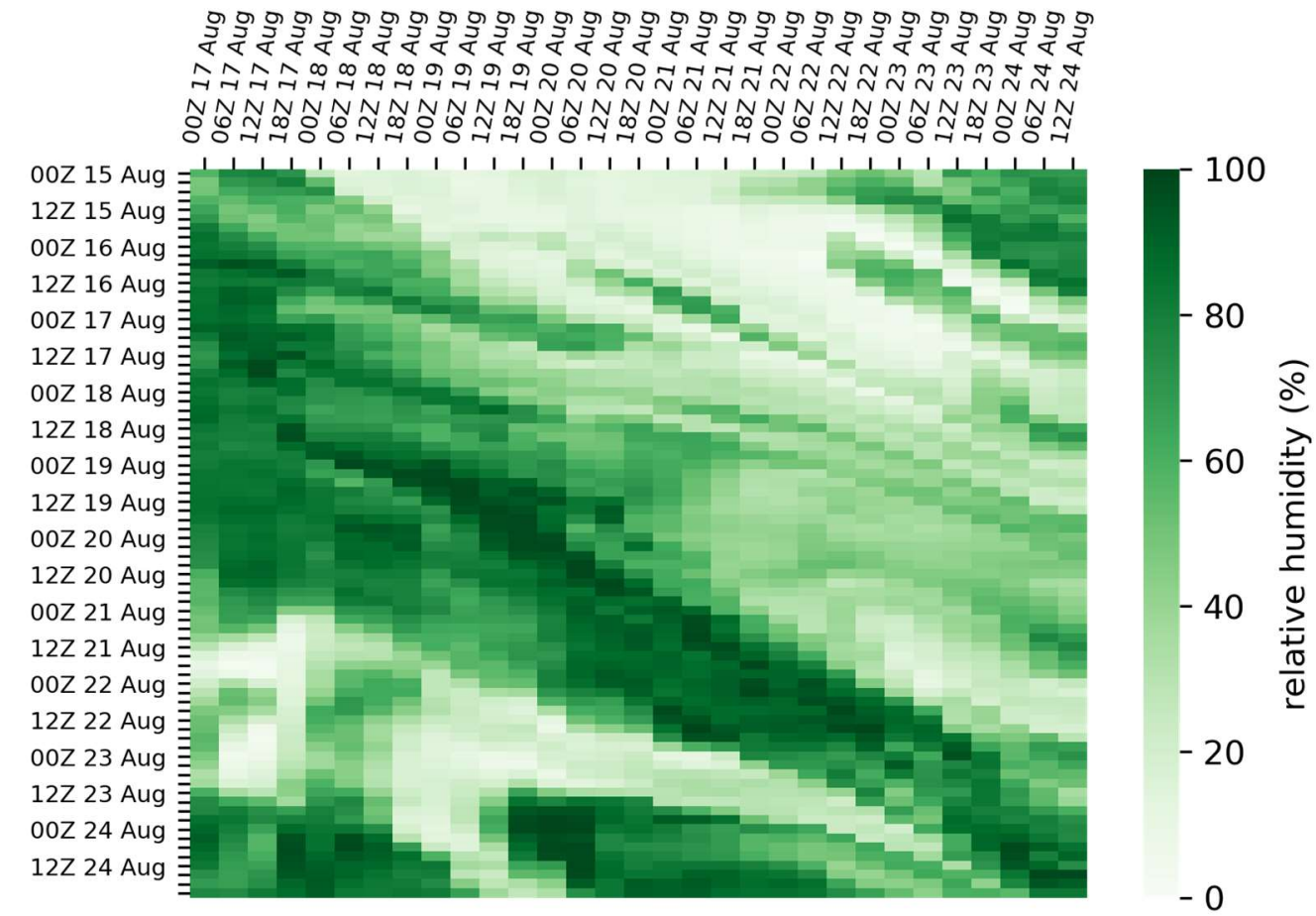

FIG. 19. Heatmap of RH values for Hurricane Danny (2015) at $700 \mathrm{hPa}$ from MERRA-2; vertical xaxis denotes the time point and the horizontal y-axis shows the time of the NHC best location of the TC.

Again, NCEP-FNL showed more lower RH values compared to MERRA-2 at 850

hPa (Fig. 20, Fig. 21). 


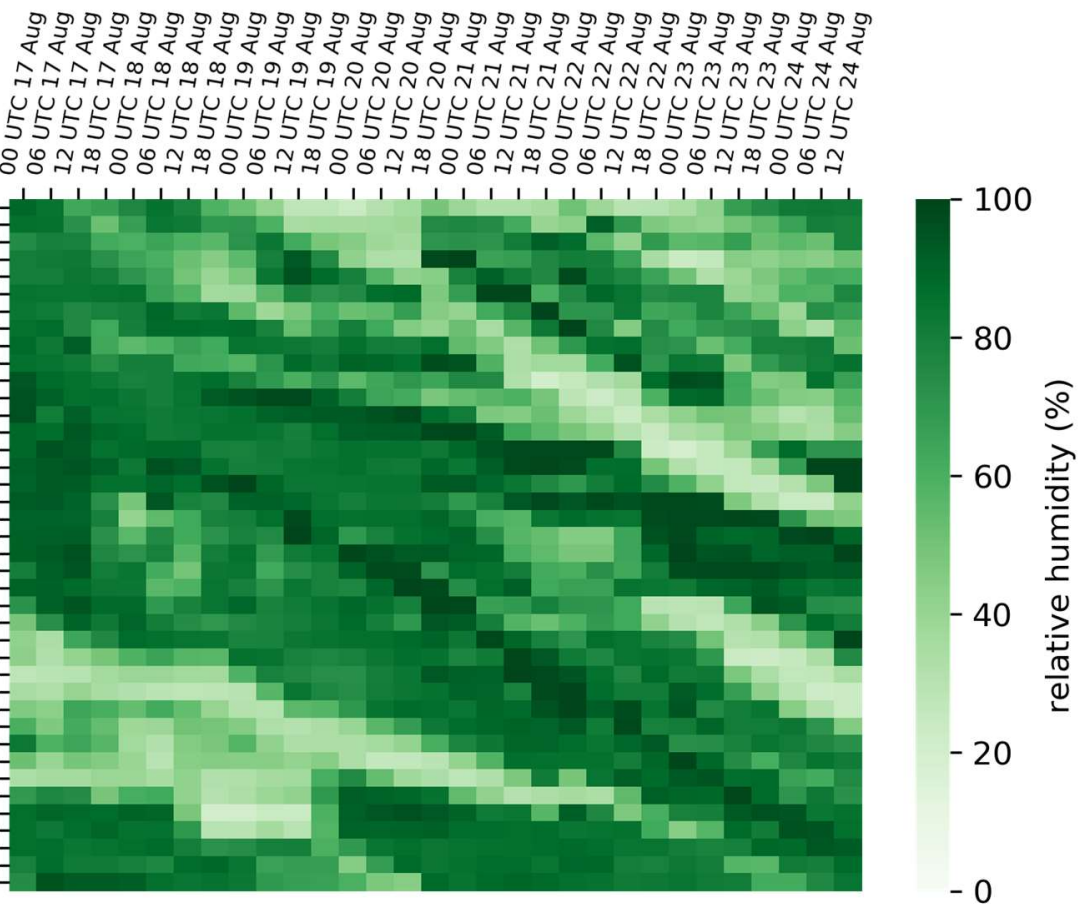

FIG. 20. Heatmap of RH for Hurricane Danny (2015) at $850 \mathrm{hPa}$ from NCEP-FNL; vertical x-axis denotes the time point and the horizontal y-axis shows the time of the NHC best location of the TC.

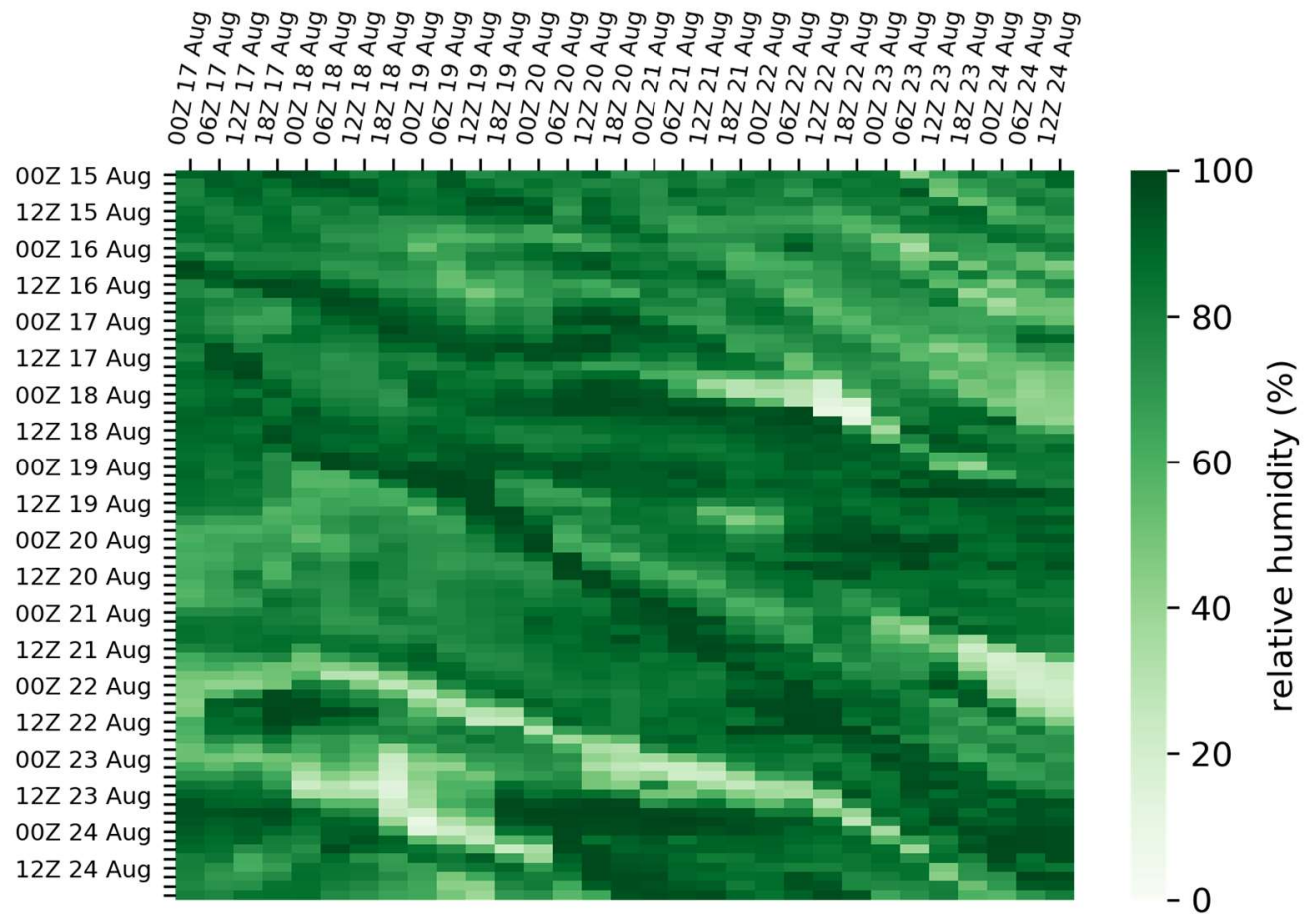

FIG. 21. Heatmap of RH values for Hurricane Danny (2015) at $850 \mathrm{hPa}$ from MERRA-2; vertical xaxis denotes the time point and the horizontal y-axis shows the time of the NHC best location of the TC. 
Analyzing 3 days ahead of the TC by location and time, 69 instances of dry air for Hurricane Fred were found from MERRA-2 and followed by TS Grace (Table 2). With NCEP-FNL, TD9 actually recorded the most number of low RH values $(\mathrm{N}=37)$, followed by Hurricane Fred (N=24). In both NCEP-FNL and MERRA-2, the TC with the lowest frequency was Hurricane Danny (Table 2). The higher dry air frequencies for all cases when comparing MERRA-2 to NCEP-FNL was likely due to the MERRA-2 3-hour data interval; data points were recorded every 6 hours in NCEP-FNL.

TABLE 2. Time and frequency when dry air ( $\mathrm{RH} \leq 30 \%)$ occurred within 3 days of TC approach up to the highest storm stage at $700 \mathrm{hPa}$.

\begin{tabular}{l|c|c|c|c|} 
& \multicolumn{2}{c}{ Average Hours Ahead } & \multicolumn{2}{c}{ Frequency } \\
\cline { 2 - 5 } & NCEP-FNL & MERRA-2 & NCEP-FNL & MERRA-2 \\
\cline { 2 - 5 } TD9 & 48.49 & 45.98 & 37 & 58 \\
TS Grace & 68.50 & 66.91 & 12 & 23 \\
H Fred & 54.50 & 49.96 & 24 & 69 \\
H Danny & 48.00 & 62.67 & 1 & 9 \\
\cline { 2 - 5 } & & &
\end{tabular}

Except for Danny, the average number of hours when dry air was present ahead of the actual time point on the storm track were similar between datasets. This suggested that there was some discrepancy between NCEP-FNL and MERRA-2 with the number of dry air instances. Dry air was more likely to be farther away on TS Grace's storm path and not as frequent as TD9 or Hurricane Fred. TD9 and Fred had similar frequencies and hours ahead and interestingly, the storm paths turned more northward (Fig. 1). Danny had the lowest number of $\mathrm{RH}$ values $\leq 30 \%$ but had a similar average time period of expecting dry air as TD9 and Fred. 
It should be noted that Hurricane Danny only had one NCEP-FNL value recorded at $700 \mathrm{hPa}$ considered dry in this study. Thus, this may explain why the average and minimum value was the highest of the 4 cases (Table 3). There was a wider range of dry air for the non-hurricanes in general. The environments around TD9 and TS Grace may be drier and contained more values lower than the $30 \%$ limit.

TABLE 3. Average, minimum and maximum $\mathrm{RH} \leq 30 \%$ within 3 days of TC approach and highest storm stage.

\begin{tabular}{l|ccc|ccc|}
\multicolumn{3}{c}{} & \multicolumn{3}{c|}{ NCEP-FNL } & \multicolumn{3}{c}{ MERRA-2 } \\
\cline { 2 - 7 } \multicolumn{1}{c|}{ Average } & Minimum & Maximum & Average & Minimum & Maximum \\
\cline { 2 - 7 } TD9 & 22.6 & 13.8 & 30.2 & 0.215 & 0.135 & 0.297 \\
TS Grace & 17.7 & 12.4 & 26.4 & 0.160 & 0.068 & 0.286 \\
H Fred & 26.5 & 22.9 & 30.2 & 0.241 & 0.150 & 0.296 \\
H Danny & 28.0 & 28.0 & 28.0 & 0.267 & 0.198 & 0.300 \\
\cline { 2 - 8 }
\end{tabular}

\section{c. Tropical Depression 9}

\section{1) T= -3 DAYS STARTING AT 12 UTC 13 SEP 2015}

The approximate area where the precursor for TD9 showed mainly clouds speckled with tiny indications of dry air in the SAL-dry air product imagery from CIMSS (2020) (Fig. 22). More expansive areas of dry air were located north, an estimated $5^{\circ} \mathrm{N}$ away from the precursor of TD9 (Fig. 22). The environment near the precursor appeared neither humid nor dry (Fig. 23, Fig. 24). This corresponded with the lack of low RH (30\% or less) on the storm track at $700 \mathrm{hPa}$ from both NCEP-FNL and MERRA-2. 


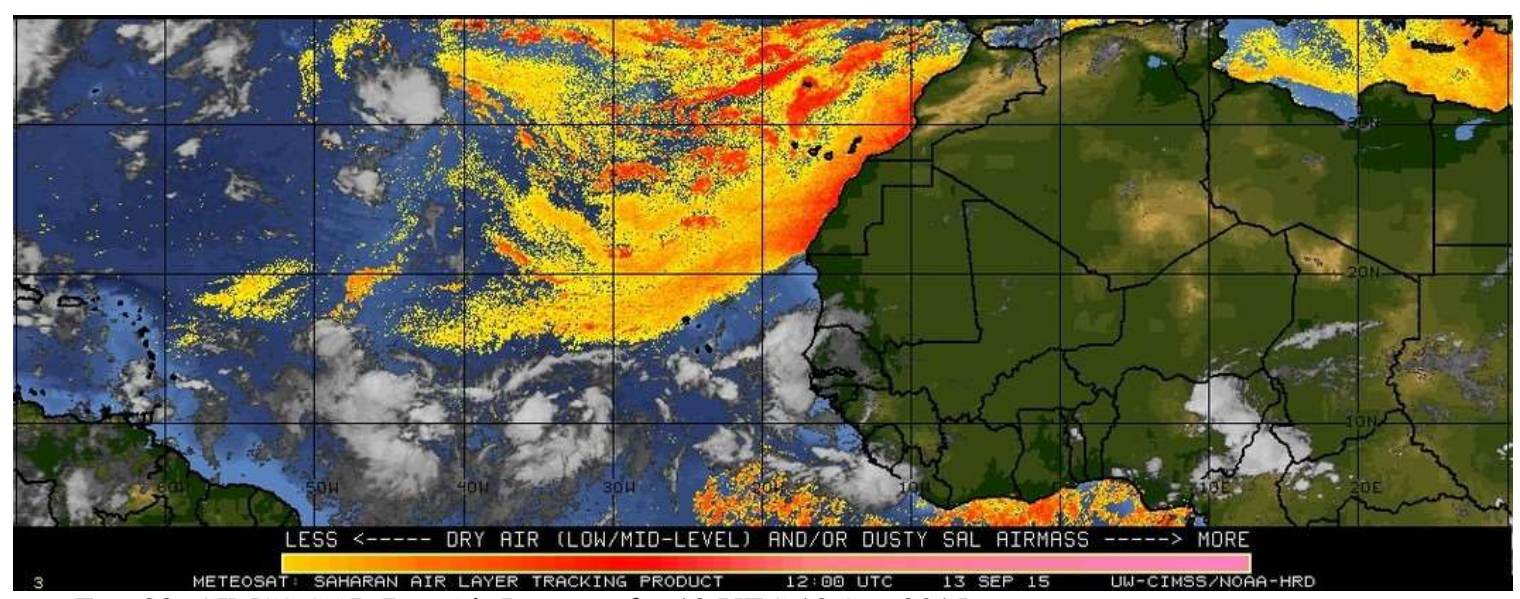

FIG. 22. CIMSS SAL-Dry Air Imagery for 12 UTC 13 Sep 2015.

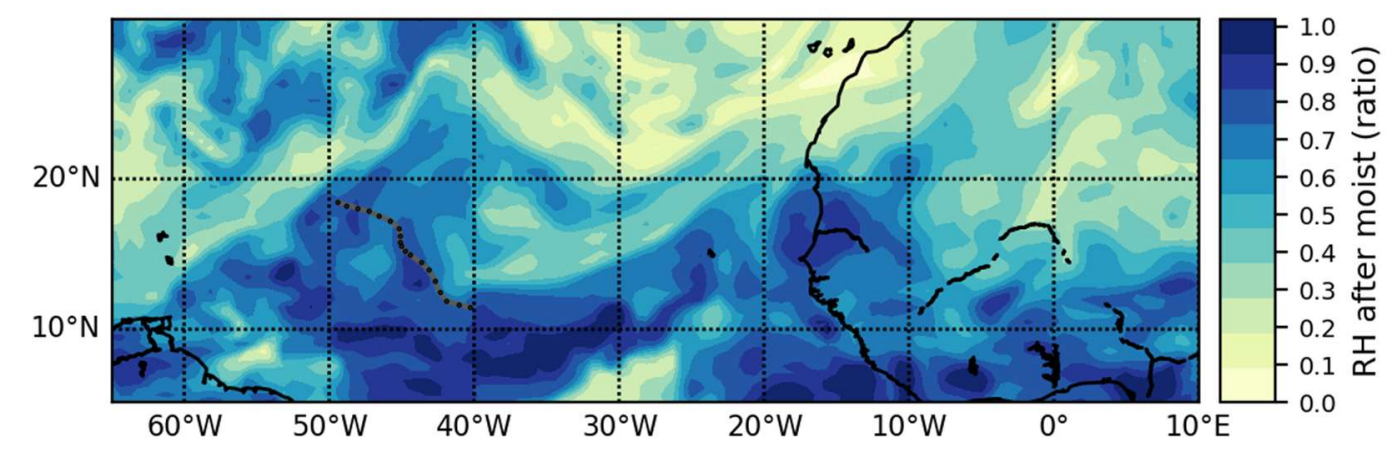

FIG. 23. RH at $700 \mathrm{hPa}$ for TD9 at 12 UTC $13 \mathrm{Sep} 2015$ from MERRA-2; grey line is the storm track with best locations (black dots) from NHC.

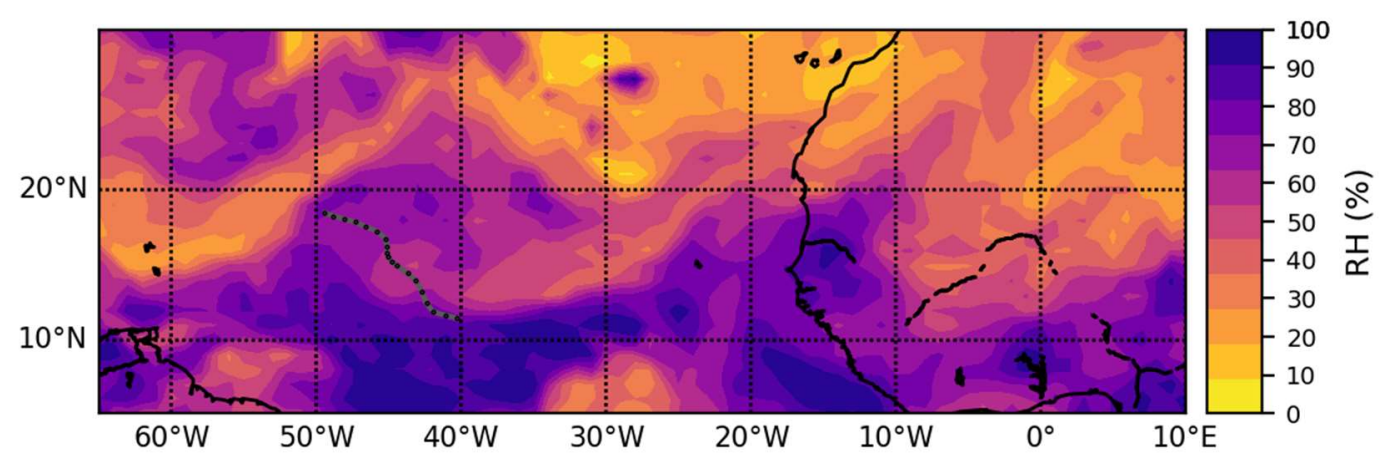

FIG. 24. RH at $700 \mathrm{hPa}$ for TD9 at 12 UTC 13 Sep 2015 from NCEP-FNL; grey line is the storm track with best locations (black dots) from NHC.

However, a cross section from NCEP-FNL showed a sizable dry air presence from $600 \mathrm{hPa}$ to around $250 \mathrm{hPa}$ (Fig. 25). Dry air in the upper levels for MERRA-2 cross sections with the same path did not appear as dry at 12 UTC 13 Sep until 21 UTC 13 Sep 
(Fig. 26, Fig. 27). Though the cross sections following the storm path were not exactly coinciding with the best NHC track, humidity properties in the surrounding environment were detectable (Fig. 28).

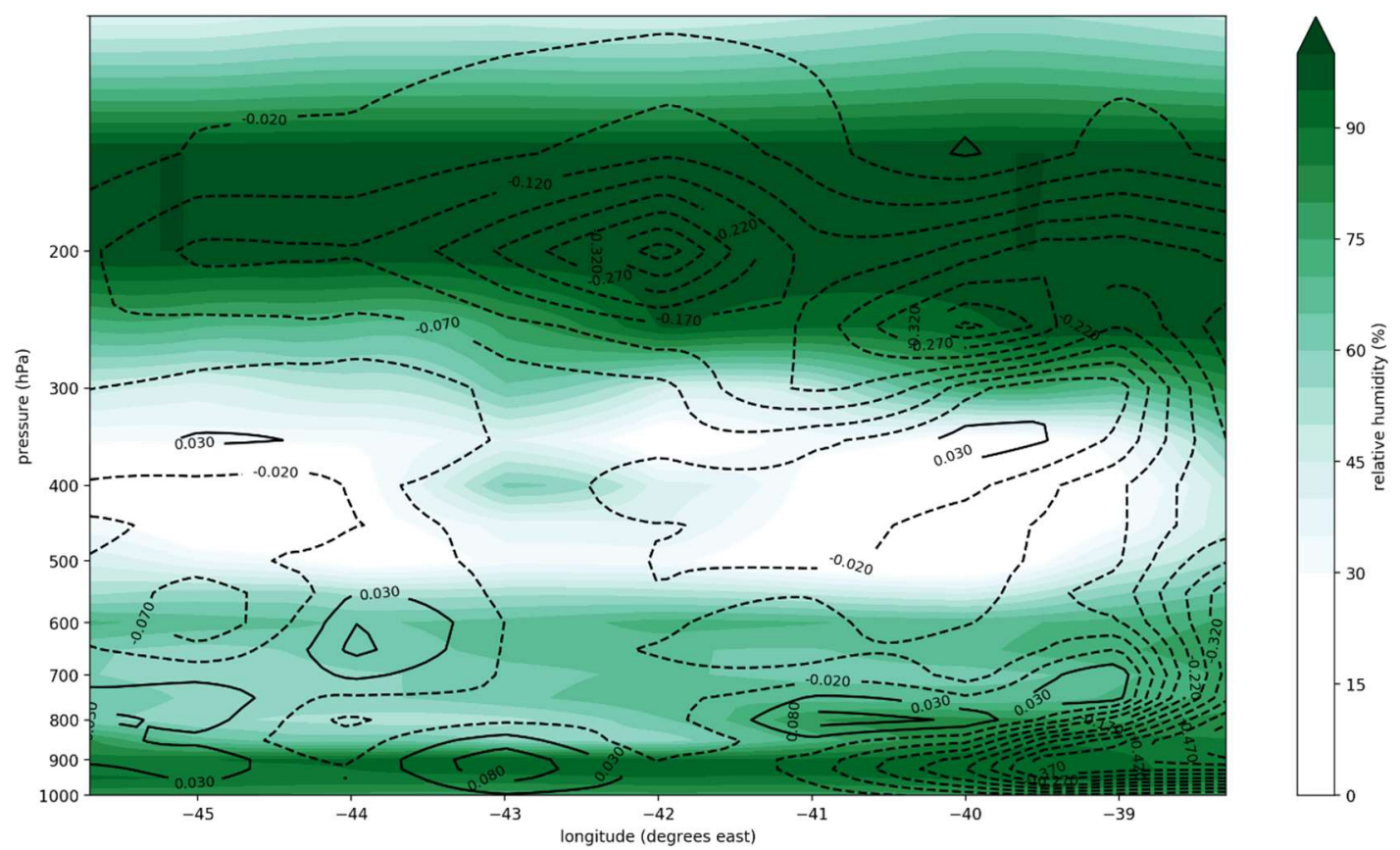

FIG. 25. Cross section of storm path from the first available best location $\left(11.5^{\circ} \mathrm{N},-38.3^{\circ} \mathrm{E}\right)$ to near the location of TD status $\left(14.5^{\circ} \mathrm{N},-45.7^{\circ} \mathrm{E}\right)$ for TD9 at 12 UTC 13 Sep 2015 from NCEP-FNL; green contours indicate RH (\%); black lines indicate positive (solid) and negative (dotted) omega values ( $\mathrm{Pa} / \mathrm{s})$. 


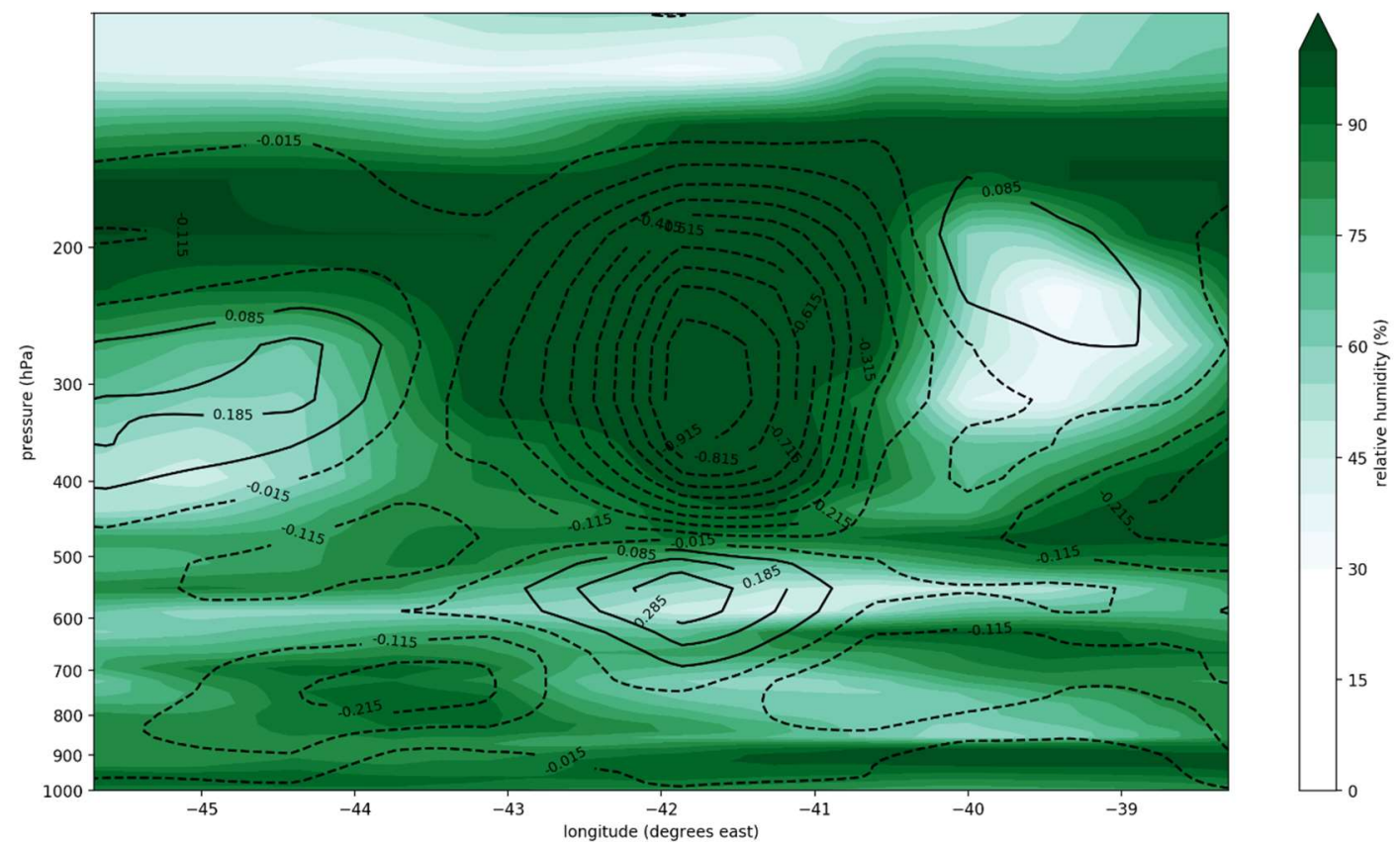

FIG. 26. Cross section of storm path from the first available best location $\left(11.5^{\circ} \mathrm{N},-38.3^{\circ} \mathrm{E}\right)$ to near the location of TD status $\left(14.5^{\circ} \mathrm{N},-45.7^{\circ} \mathrm{E}\right)$ for TD9 at 12 UTC 13 Sep 2015 from MERRA-2; green contours indicate RH (\%); black lines indicate positive (solid) and negative (dotted) omega values ( $\mathrm{Pa} / \mathrm{s})$.

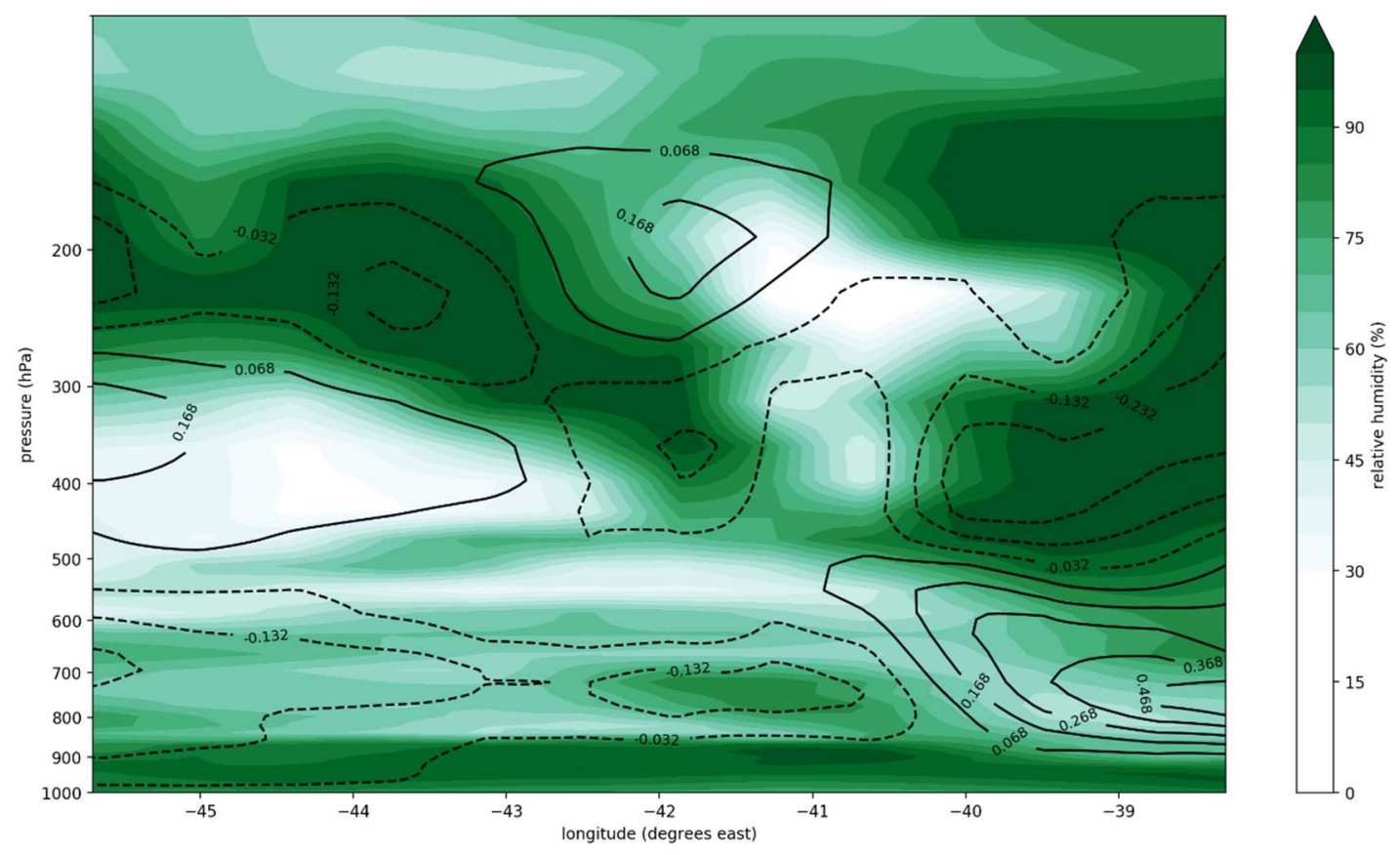

FIG. 27. Cross section of storm path from the first available best location $\left(11.5^{\circ} \mathrm{N},-38.3^{\circ} \mathrm{E}\right)$ to near the location of TD status $\left(14.5^{\circ} \mathrm{N},-45.7^{\circ} \mathrm{E}\right)$ for TD9 at 21 UTC 13 Sep 2015 from MERRA-2; green contours indicate RH (\%); black lines indicate positive (solid) and negative (dotted) omega values ( $\mathrm{Pa} / \mathrm{s})$. 


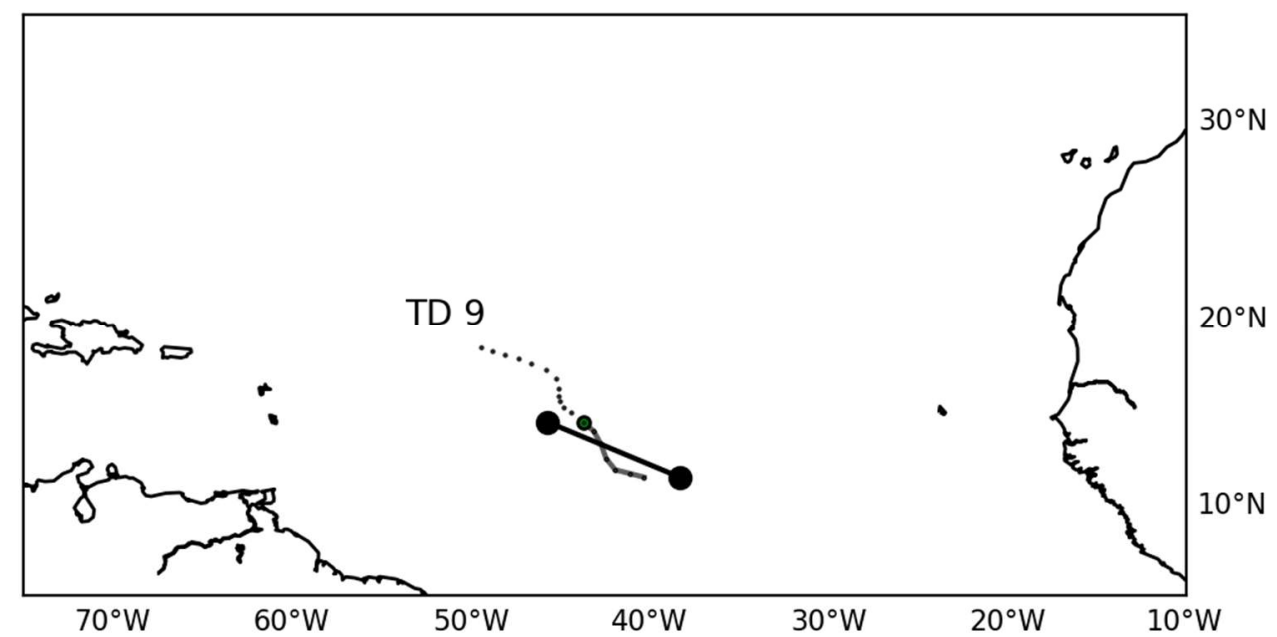

FIG. 28. Cross section path (large black dots, thick black line) for analysis portion of TD9's storm track; similar to FIG. 1.

\section{2) T= -2 DAYS STARTING AT 12 UTC 14 SEP 2015}

The Meteostat imagery showed some dry air closer to the approximate area by the first future storm position $\left(11.5^{\circ} \mathrm{N}, 40.3^{\circ} \mathrm{W}\right)$ at $00 \mathrm{UTC} 15 \mathrm{Sep}$ (Brown 2015, Fig. 29). A similar feature was observed in MERRA-2 and NCEP-FNL at $700 \mathrm{hPa}$ (Fig. 30, Fig. 31); this swath of dry air continued to cross the storm track at later times towards the southwest direction.

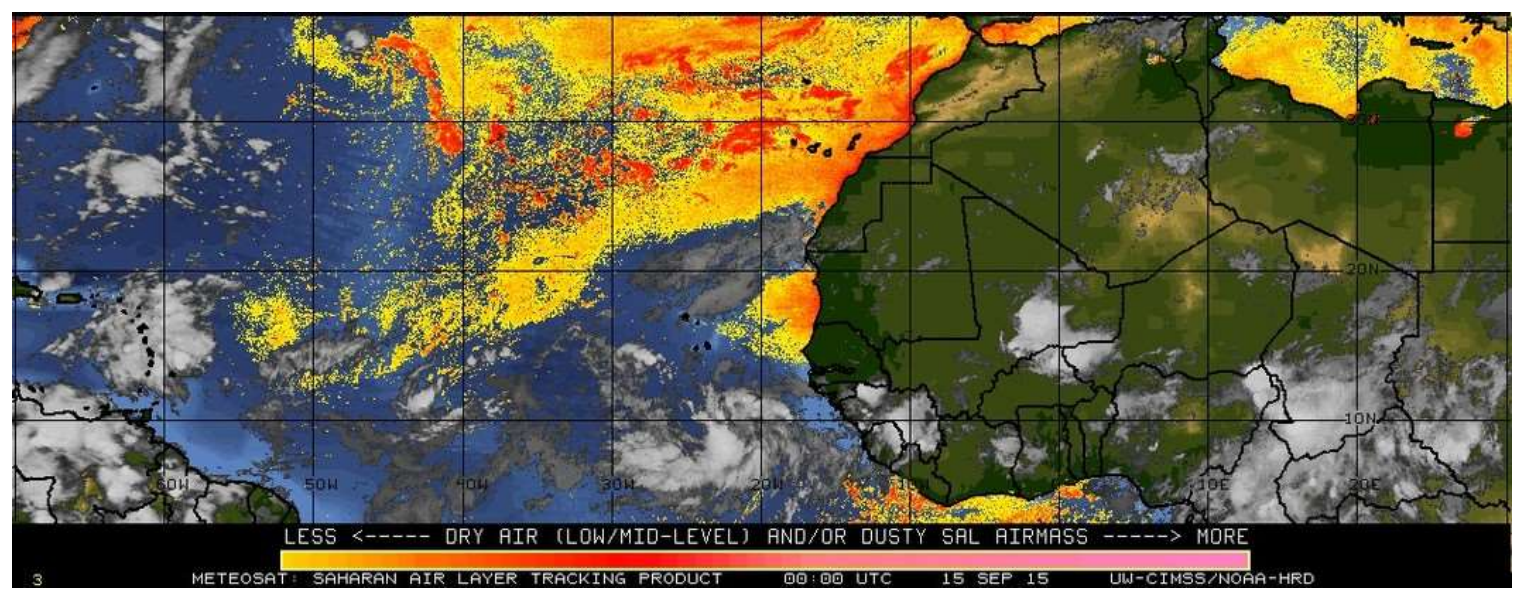

FIG. 29. CIMSS SAL-Dry Air Imagery for 00 UTC 15 Sep 2015. 


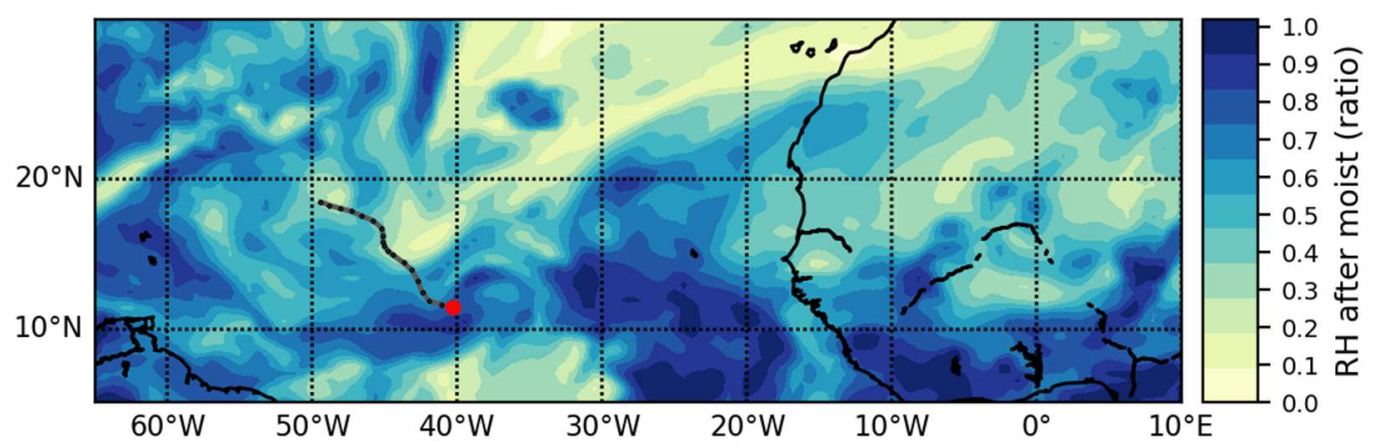

FIG. 30. RH at $700 \mathrm{hPa}$ for TD9 at 00 UTC 15 Sep 2015 from MERRA-2; grey line is the storm track with best locations (black dots) from NHC; red dot indicates TC location at the given time point.

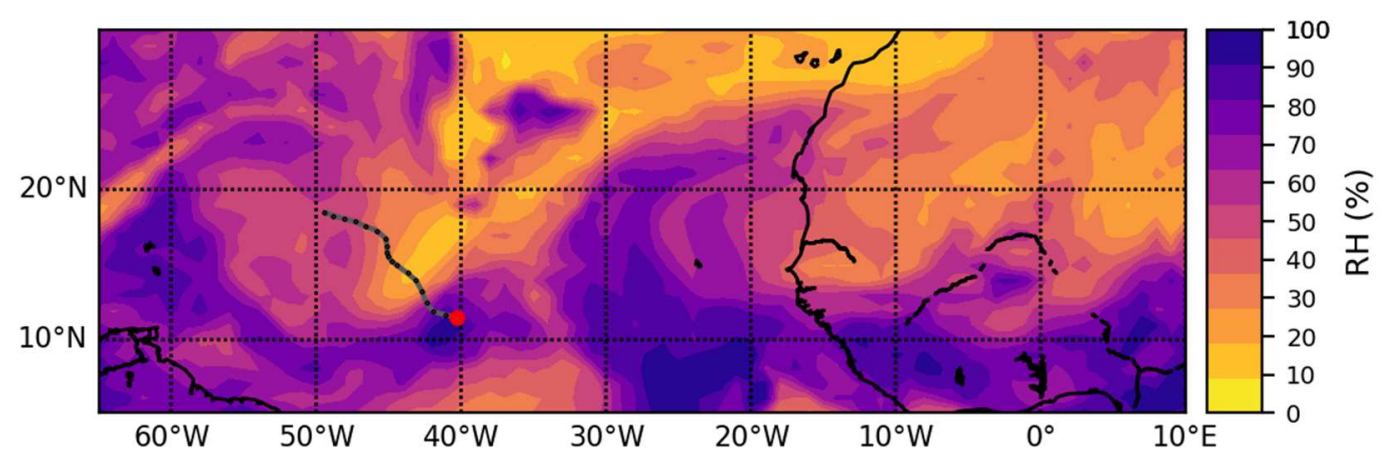

FIG. 31. RH at $700 \mathrm{hPa}$ for TD9 at 00 UTC $15 \mathrm{Sep} 2015$ from NCEP-FNL; grey line is the storm track with best locations (black dots) from NHC; red dot indicates TC location at the given time point.

RH values also reflected the dry air presence at $700 \mathrm{hPa}$. In NCEP-FNL, dry air values occurred within 2 days of reaching TD stage. The first dry air instance of $28.5 \%$ occurred on 18 UTC 14 Sep at the location when the storm would traverse on 06 UTC 16 Sep. In the next time interval at 00 UTC 15 Sep, eight consecutive locations starting at 00 UTC 16 Sep, 1 day ahead, recorded dry air RH values of $29.3 \%, 16.7 \%, 17.5 \%, 18.3 \%$, $27.5 \%$, and $29.8 \%$ for the last 3 spots. The last storm position with the $29.8 \% \mathrm{RH}$ value was 18 UTC 17 Sep, 2 days and 18 hours ahead of the previous time point.

In MERRA-2, dry air was also observed ahead of the first best location position (00 UTC 15 Sep) by 1 day and 18 hours at the location where the storm would be on 18 UTC 16 Sep. At 03 UTC 15 Sep, dry air occurred in front of the TC at the positions 1 day and 
9 hours to 2 days and 15 hours ahead, recording values of $0.21,0.21,0.29,0.29$ and 0.29 . Similarly, at 06 UTC 15 Sep, dry air was present from 1 day and 6 hours to 2 days and 18 hours ahead (storm locations for 12 UTC 16 Sep to 00 UTC 18 Sep), corresponding with values $0.17,0.21,0.28,0.28,0.27,0.27$ and 0.27 . Three hours later at 09 UTC 15 Sep, $\mathrm{RH}$ values of $0.15,0.21,0.25,0.25,0.24$, and 0.28 were seen starting at 1 day and 3 hours ahead (12 UTC 16 Sep) in the path to ending at 2 days and 9 hours (18 UTC 17 Sep).

Upper and mid levels showed a substantial dry air presence in NCEP-FNL and MERRA-2 over the beginning of the storm track (Fig. 32, Fig. 33). There was additional dry air in the 200's hPa levels displayed in MERRA-2 data (Fig. 33).

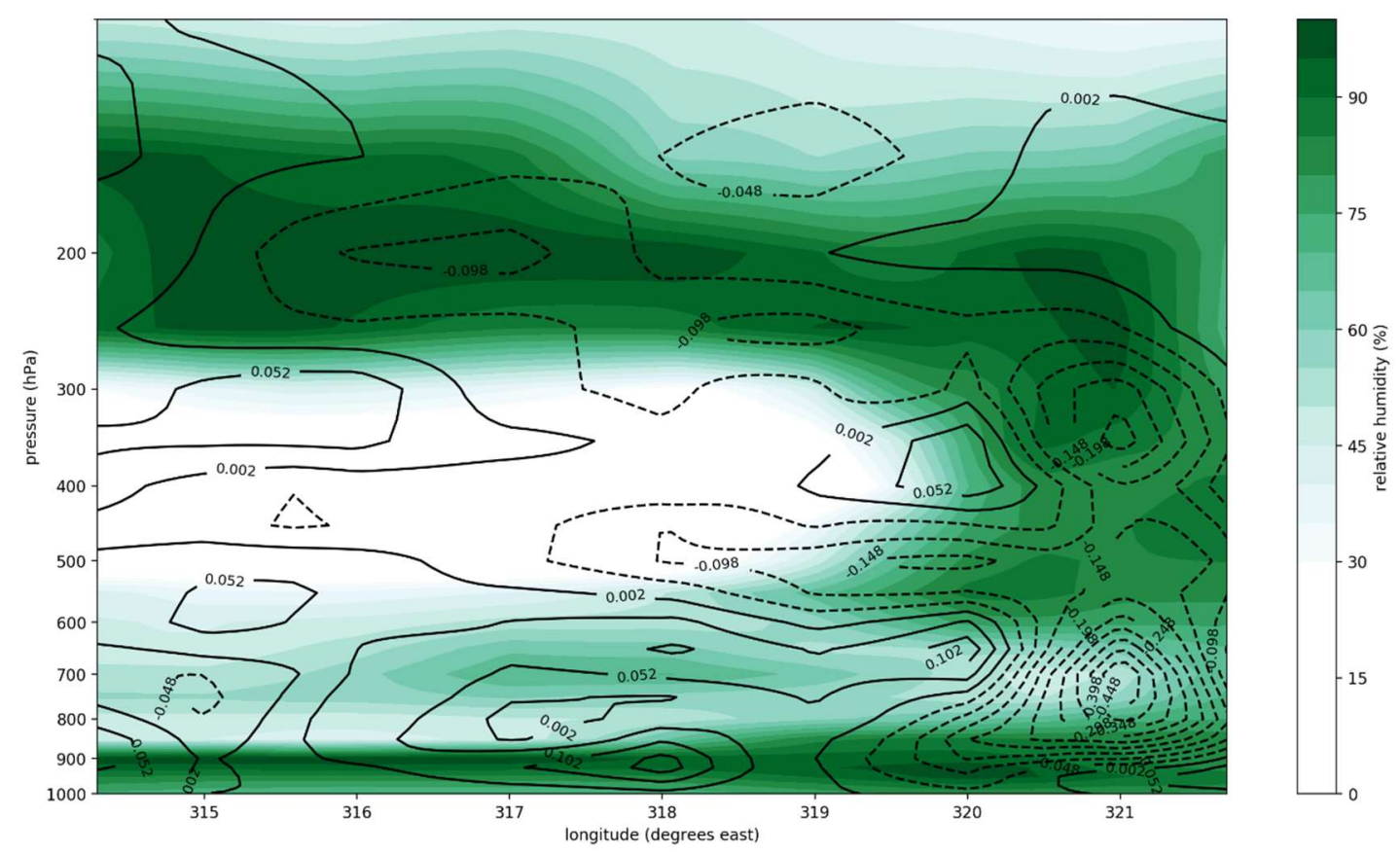

FIG. 32. Cross section of storm path from the first available best location $\left(11.5^{\circ} \mathrm{N},-38.3^{\circ} \mathrm{E}\right)$ to near the location of TD status $\left(14.5^{\circ} \mathrm{N},-45.7^{\circ} \mathrm{E}\right)$ for TD9 at 12 UTC 14 Sep 2015 from NCEP-FNL; green contours indicate RH (\%); black lines indicate positive (solid) and negative (dotted) omega values ( $\mathrm{Pa} / \mathrm{s})$. 


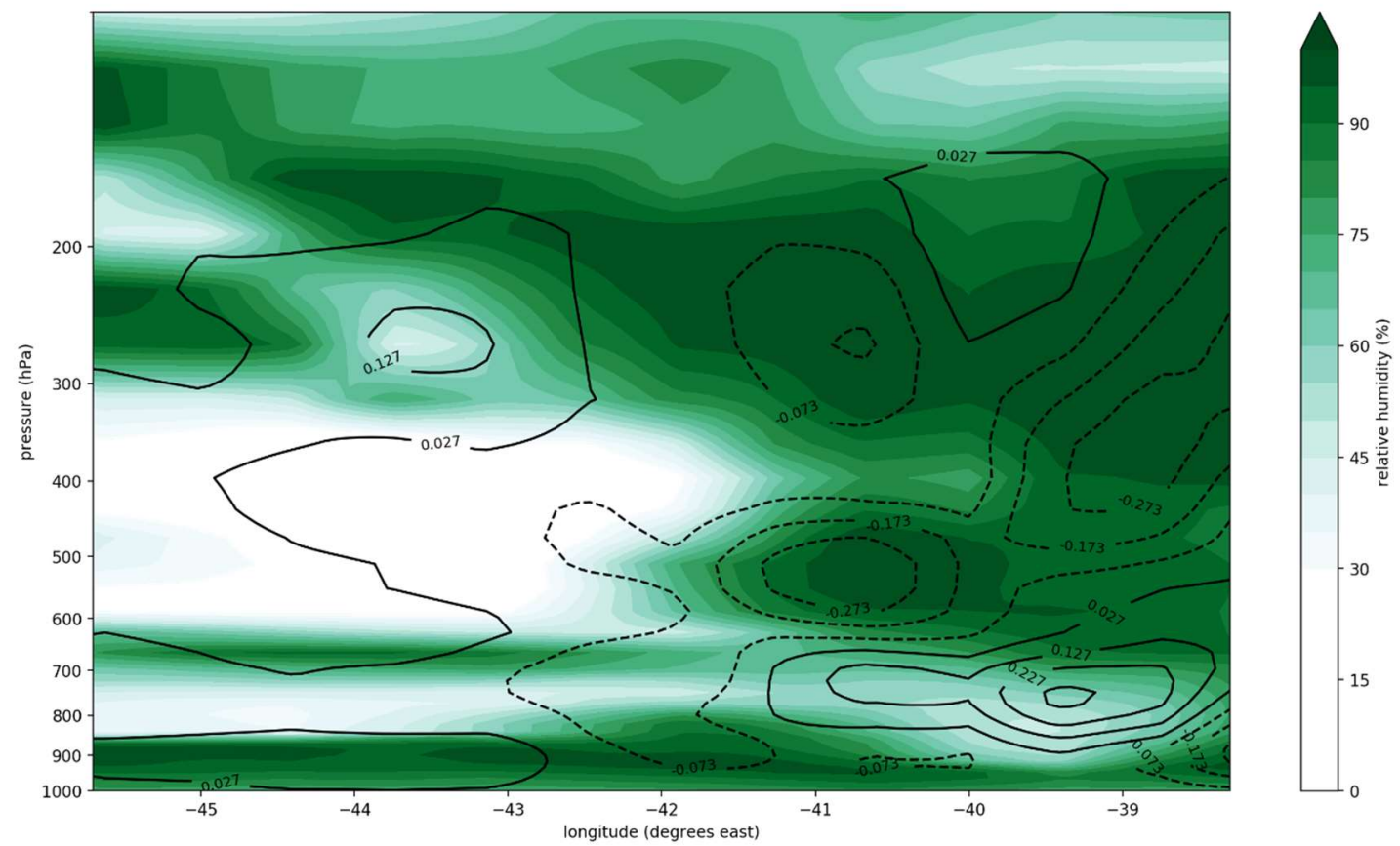

FIG. 33. Cross section of storm path from the first available best location $\left(11.5^{\circ} \mathrm{N},-38.3^{\circ} \mathrm{E}\right)$ to near the location of TD status $\left(14.5^{\circ} \mathrm{N},-45.7^{\circ} \mathrm{E}\right)$ for TD9 at 12 UTC 14 Sep 2015 from MERRA-2; green contours indicate RH (\%); black lines indicate positive (solid) and negative (dotted) omega values ( $\mathrm{Pa} / \mathrm{s})$.

\section{3) T=-1 DAY STARTING AT 12 UTC 15 SEP 2015}

Satellite imagery displayed the progression of convective clouds, forming at 12 UTC 15 Sep to 18 UTC 15 Sep (Fig. 34, Fig. 35, Fig. 36). The area with higher RH appeared to also increase in size with each time point per MERRA-2 at $700 \mathrm{hPa}$ (Fig. 37, Fig. 38). The change was not as distinctive in NCEP-FNL during the same time points (Fig. 39, Fig. 40). Dry air did appear ahead of the TC on the storm track at $700 \mathrm{hPa}$ (Fig. 37, Fig. 38, Fig. 39, Fig. 40). The amount of low RH instances recorded as follows also reflected this characteristic. 


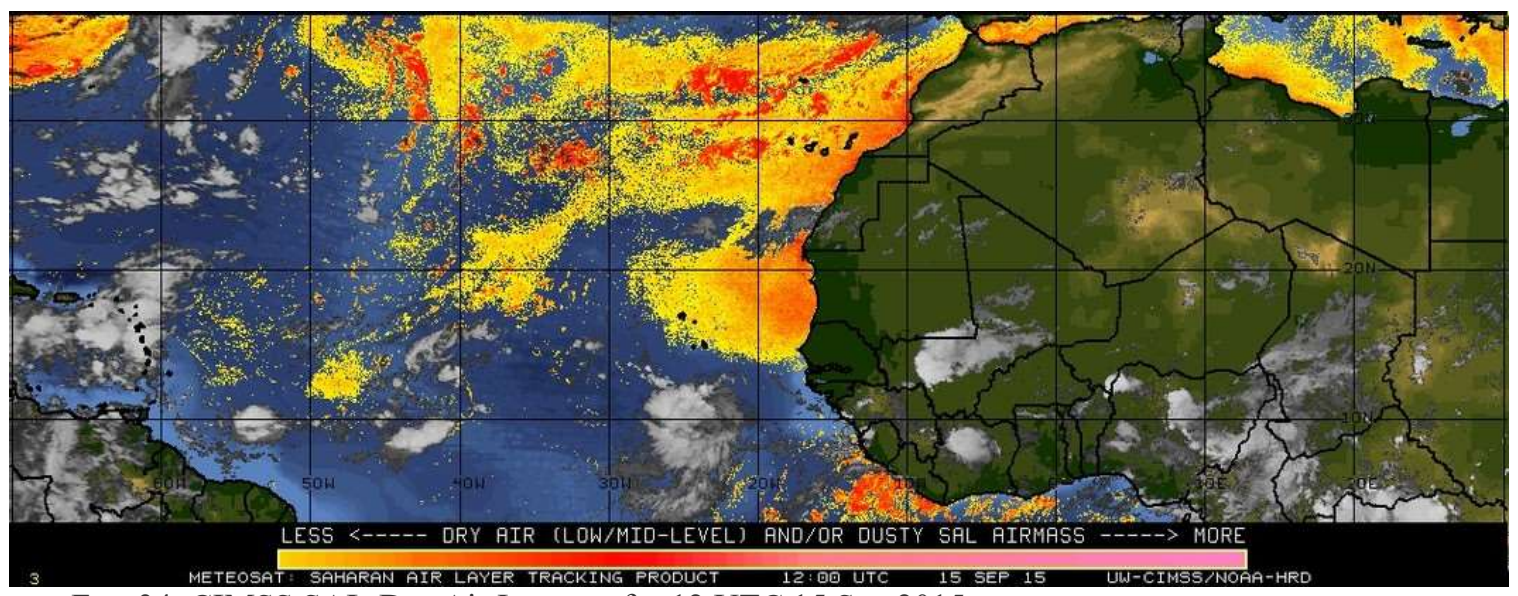

FIG. 34. CIMSS SAL-Dry Air Imagery for 12 UTC 15 Sep 2015.

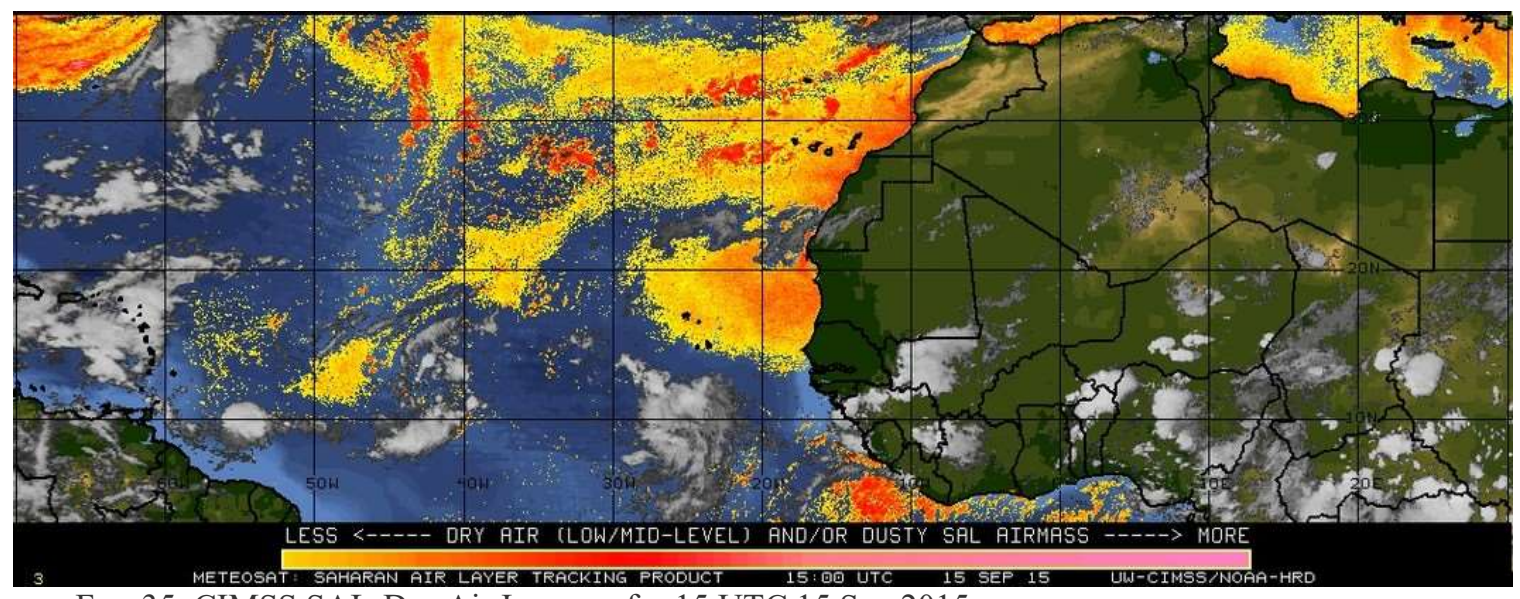

FIG. 35. CIMSS SAL-Dry Air Imagery for 15 UTC 15 Sep 2015.

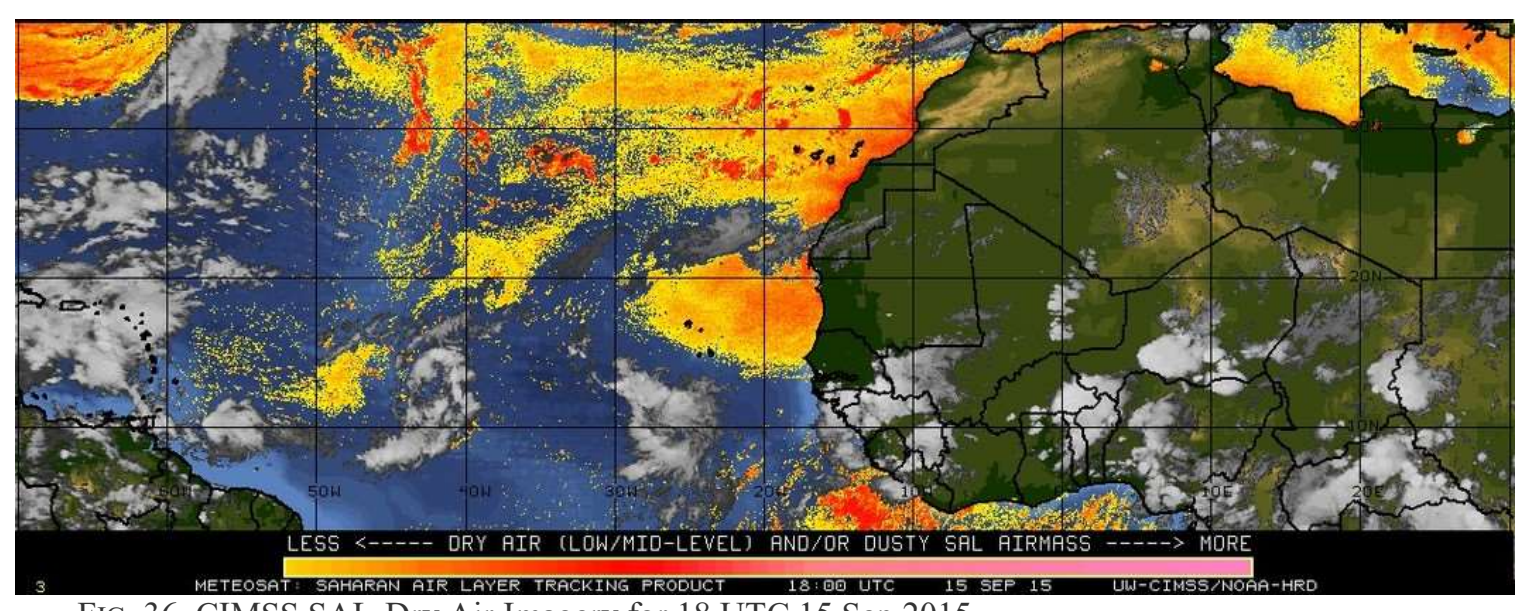

FIG. 36. CIMSS SAL-Dry Air Imagery for 18 UTC 15 Sep 2015. 


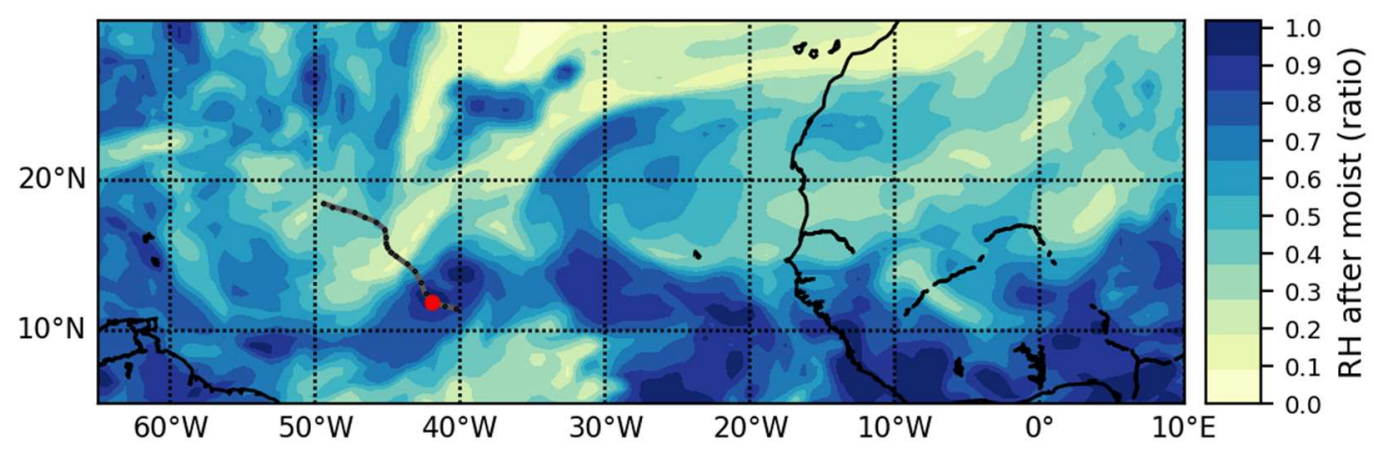

FIG. 37. RH at $700 \mathrm{hPa}$ for TD9 at 12 UTC 15 Sep 2015 from MERRA-2; grey line is the storm track with best locations (black dots) from NHC; red dot indicates TC location at the given time point.

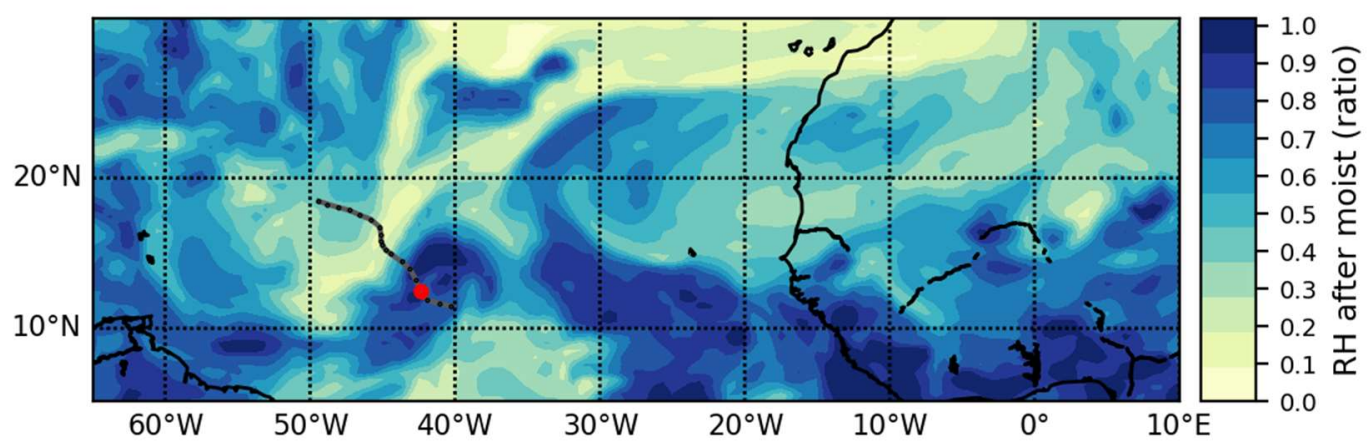

FIG. 38. RH at $700 \mathrm{hPa}$ for TD 9 at 18 UTC 15 Sep 2015 from MERRA-2; grey line is the storm track with best locations (black dots) from NHC; red dot indicates TC location at the given time point.

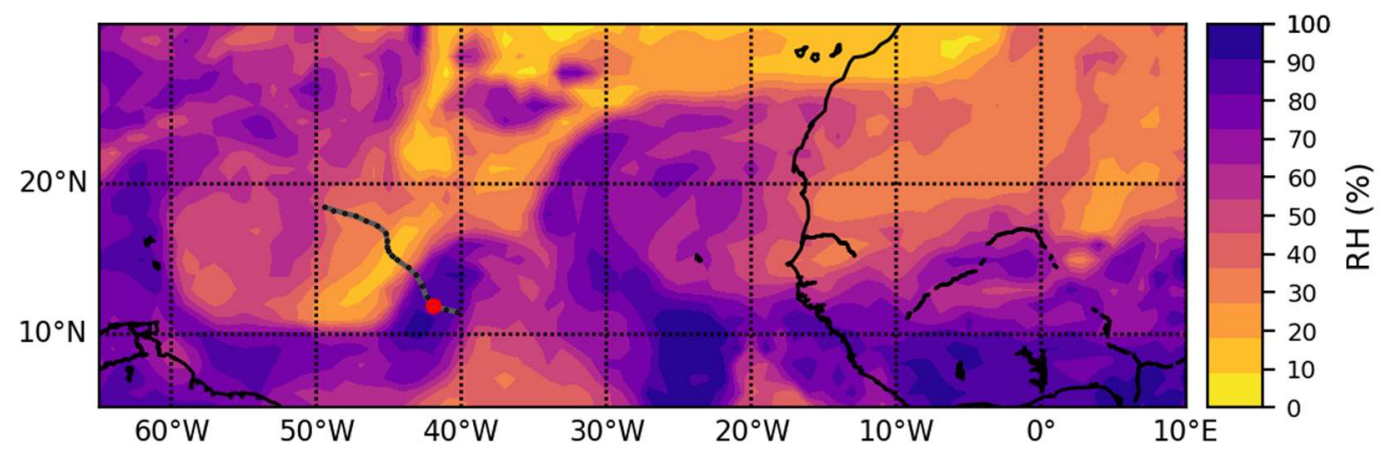

FIG. 39. RH at $700 \mathrm{hPa}$ for TD9 at 12 UTC 15 Sep 2015 from NCEP-FNL; grey line is the storm track with best locations (black dots) from NHC; red dot indicates TC location at the given time point. 


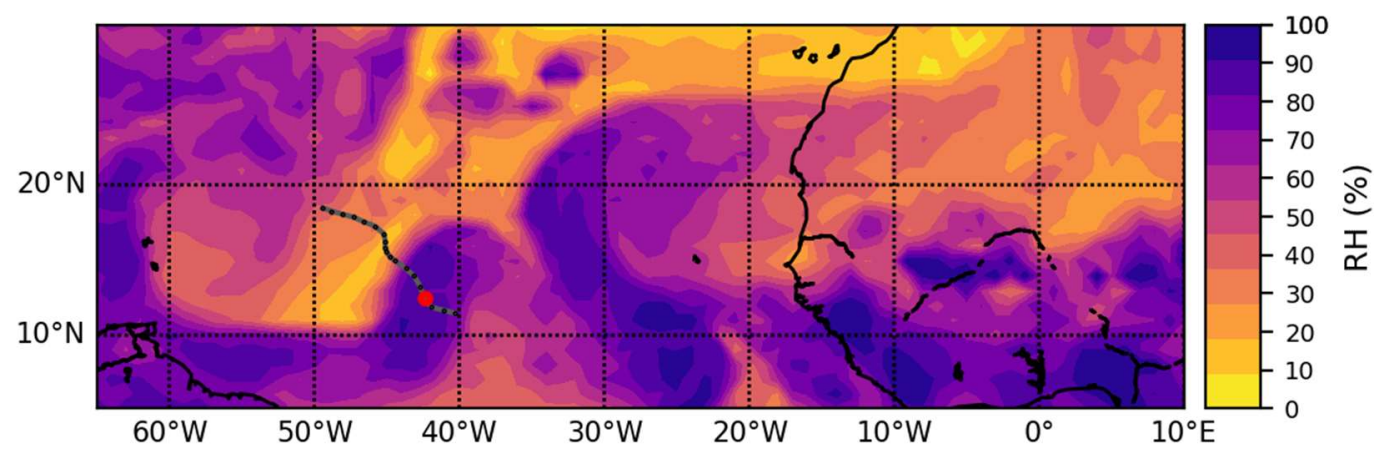

FIG. 40. RH at $700 \mathrm{hPa}$ for TD9 at 18 UTC $15 \mathrm{Sep} 2015$ from NCEP-FNL; grey line is the storm track with best locations (black dots) from NHC; red dot indicates TC location at the given time point.

\section{a) NCEP-FNL at $700 \mathrm{hPa}$}

On 12 UTC 15 Sep, the dry air spanned from the positions where the storm would pass on 12 UTC 16 Sep through 00 UTC 18 Sep with $27.9 \%, 19.6 \% 14.0 \%, 17.0 \%$ (x3), and $27.7 \% \mathrm{RH}$, respectively. At this time point, the dry air was present 1 day to 2 days 12 hours ahead.

At 18 UTC 15 Sep, the low RH values recorded were $24.5 \%, 13.8 \%$ (x3), and $14.9 \%$ at storm position 00 UTC 17 Sep through 00 UTC 18 Sep, 1 day 6 hours to 2 days 6 hours. In addition, another two positions when the storm passed on 12 UTC and 18 UTC $18 \mathrm{Sep}, 2$ days 18 hours to 3 days ahead of the actual time, also showed RH values below $30 \%, 29.4 \%$ for both instances.

During the 12 hours prior to TD status, only a few locations showed dry air occurring. On 00 UTC 16 Sep, three future storm locations recorded $16.6 \%, 17.9 \%$ and $28.8 \% \mathrm{RH}$ values, corresponding to storm passing dates of 00 UTC 18 Sep, 06 UTC 18 Sep and 00 UTC 19 Sep. These locations were 2 days, 2 days 6 hours, and 3 days ahead. Two locations at 06 UTC 18 Sep and 06 UTC 19 Sep, 2 days and 3 days ahead of the time point 06 UTC 16 Sep, recorded RH values of $25.5 \%$ and $29.8 \%$, respectively. 


\section{b) MERRA-2 at $700 \mathrm{hPa}$}

At 12 UTC 15 Sep, dry air was detected 1 day through 2 days ahead with RH values, $0.26,0.18,0.24,0.24$, and 0.24 . In the next 3 hours, four locations on the storm path ahead also showed dry air of $0.18,0.22,0.22,0.21,0.21$ and 0.25 ahead of the storm by 1 day 3 hours through 2 days 9 hours.

Three hours later on 18 UTC 15 Sep and further up the storm path by 1 day and 6 hours, dry air was again observed from the 00 UTC 17 Sep storm position $(\mathrm{RH}=0.20)$ to 00 UTC $18 \operatorname{Sep}(\mathrm{RH}=0.16) ; 0.20,0.16,0.14$, and 0.16 were $\mathrm{RH}$ values documented in between these two positions. In the next 3 hours, similar results were observed as the time point before with an additional lower RH value was observed on the 06 UTC 18 Sep position; RH values corresponded to $0.20,0.20,0.18,0.16,0.14$, and 0.30 .

On 00 UTC 16 Sept, 12 hours before TD status would be declared, dry air would continue to be observed ahead by at least a day. For 00 UTC 16 Sep, the dry started on 12 UTC 17 Sep where the TC would eventually pass, 1 day 12 hours ahead with a value of 0.27 , followed by $0.20,0.15$, and 0.16 . Approaching the final 9 hours before TD status would be declared, only three of the future storm positions registered RH values 0.30 and below. On 03 UTC 16 Sep, the storm position 1 day 21 hours ahead at 00 UTC 18 Sep had a RH value of 0.28 , followed by 0.14 and 0.26 for the next 2 storm positions. On 06 UTC 16 Sep, 0.16 was the RH value for the storm position 2 days ahead at 06 UTC 18 Sep, followed by 0.21 and 0.27 for the next 2 subsequent storm positions of 12 UTC 18 Sep and 18 UTC 18 Sep. On 09 UTC 16 Sep, the RH values registered below 0.20 with 
0.16, 0.17 and 0.19 , starting at the storm position 12 UTC 18 Sep through 00 UTC 19

Sep.

From around 800-300 hPa, dry air remained present on the western end of the storm path (Fig. 41). For MERRA-2, the dry air was also observable from the same levels except the RH appeared more dry (Fig. 42). This may be related to the small yellow indications next to the TC in the SAL dry air satellite imagery (Fig. 35).

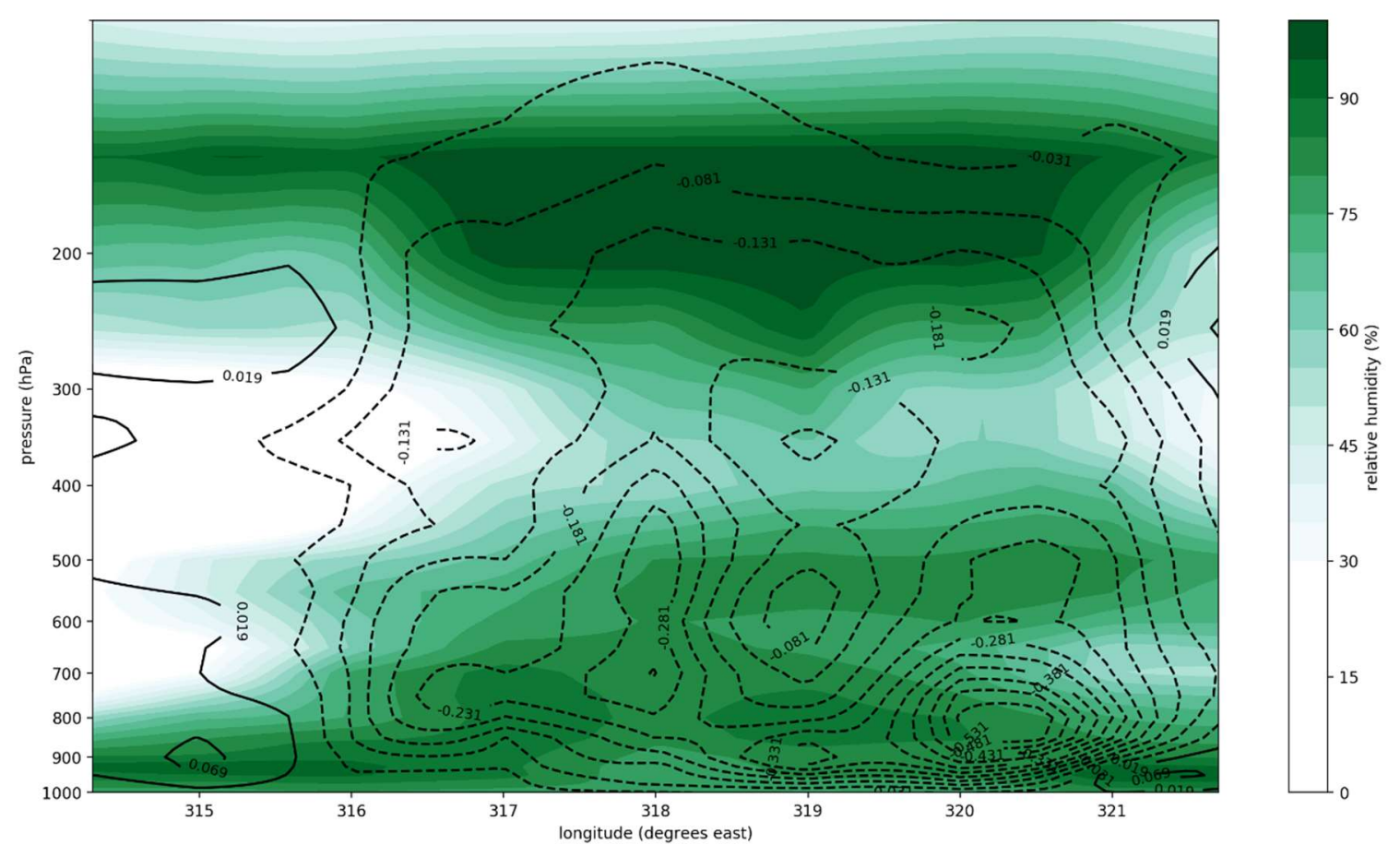

FIG. 41. Cross section of storm path from the first available best location $\left(11.5^{\circ} \mathrm{N},-38.3^{\circ} \mathrm{E}\right)$ to near the location of TD status $\left(14.5^{\circ} \mathrm{N},-45.7^{\circ} \mathrm{E}\right)$ for TD9 at 18 UTC 15 Sep 2015 from NCEP-FNL; green contours indicate RH (\%); black lines indicate positive (solid) and negative (dotted) omega values ( $\mathrm{Pa} / \mathrm{s})$. 


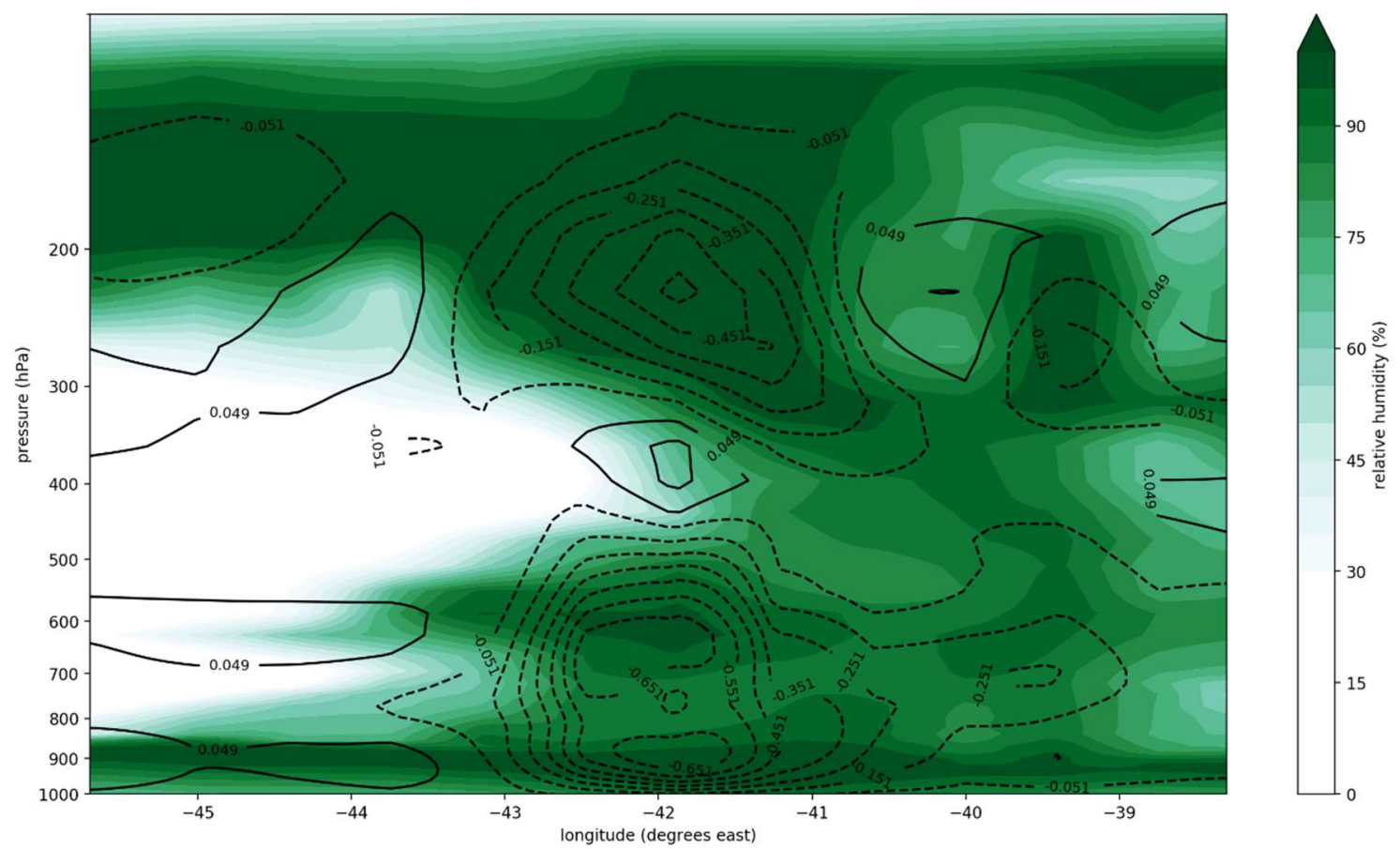

FIG. 42. Cross section of storm path from the first available best location $\left(11.5^{\circ} \mathrm{N},-38.3^{\circ} \mathrm{E}\right)$ to near the location of TD status $\left(14.5^{\circ} \mathrm{N},-45.7^{\circ} \mathrm{E}\right)$ for TD9 at 12 UTC 15 Sep 2015 from MERRA-2; green contours indicate RH (\%); black lines indicate positive (solid) and negative (dotted) omega values ( $\mathrm{Pa} / \mathrm{s})$.

\section{4) $\mathrm{T}=$ 0 AT 12 UTC 16 SEP 2015}

The satellite imagery showed dry air west and north of TD9, corresponding to the RH contour plots from NCEP-FNL and MERRA-2 (Fig. 43, Fig. 44, Fig. 45). At the $700 \mathrm{hPa}$ level, NCEP-FNL indicated only one location 2 days 12 hours ahead (00 UTC 19 Sep) with a dry air RH value of $28.4 \%$. Four storm positions starting 2 days ahead recorded dry RH values at $0.15,0.16,0.14$ and 0.24 in MERRA-2. Mid to upper levels continued to show dry air around the storm track close to the expected position of the TD (Fig. 46, Fig. 47). Dry air presence appeared to be west of the TD for both MERRA-2 and NCEPFNL (Fig. 48, Fig. 49). The SLP from MERRA-2 appeared to correspond more closely to the NHC best location compared with NCEP-FNL (Fig. 48, Fig. 49). 


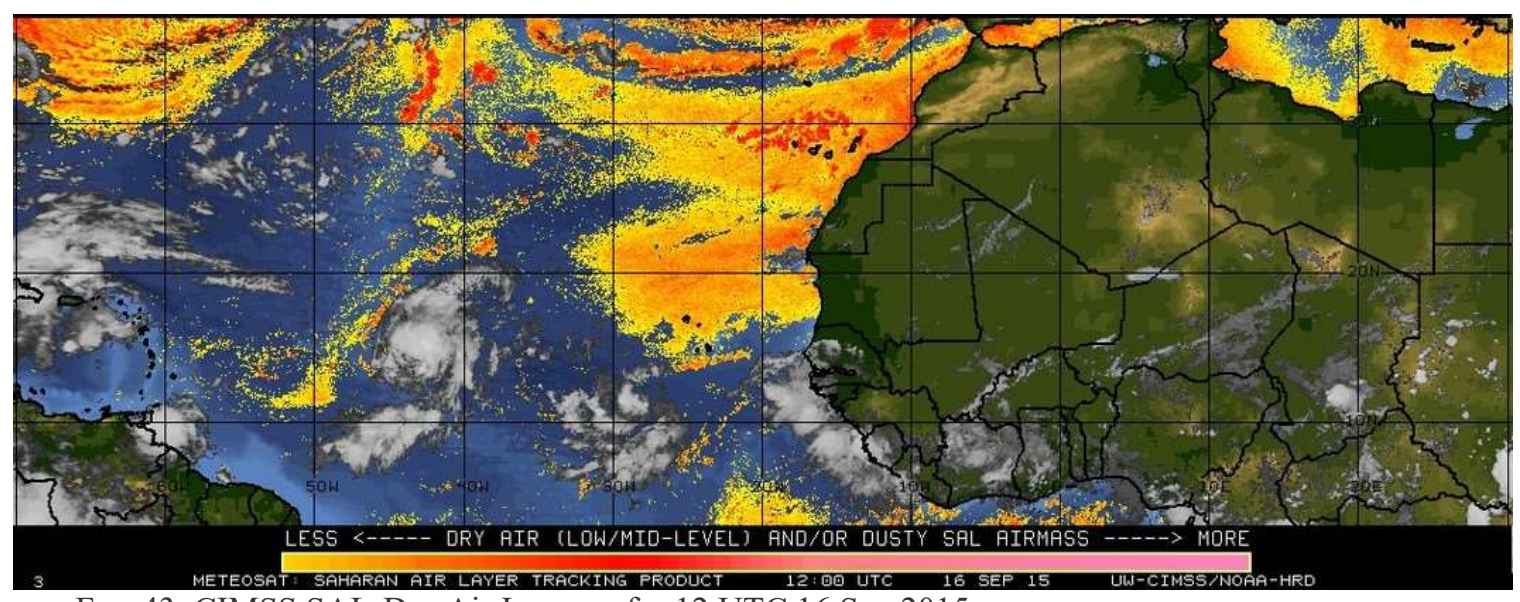

FIG. 43. CIMSS SAL-Dry Air Imagery for 12 UTC 16 Sep 2015.

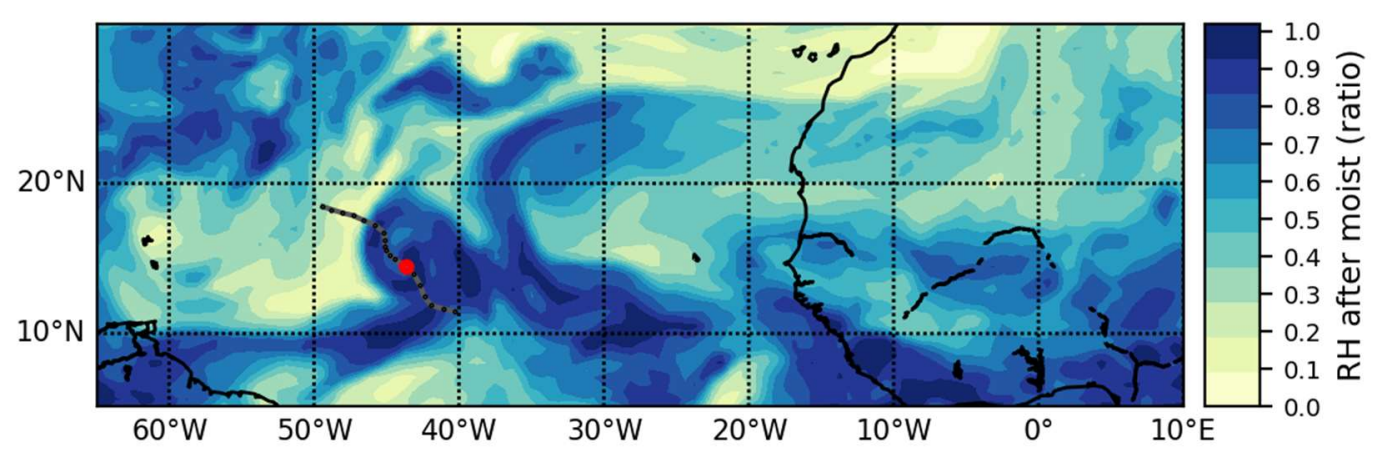

FIG. 44. RH at $700 \mathrm{hPa}$ for TD9 at 12 UTC 16 Sep 2015 from MERRA-2; grey line is the storm track with best locations (black dots) from NHC; red dot indicates TC location when TD stage was declared.

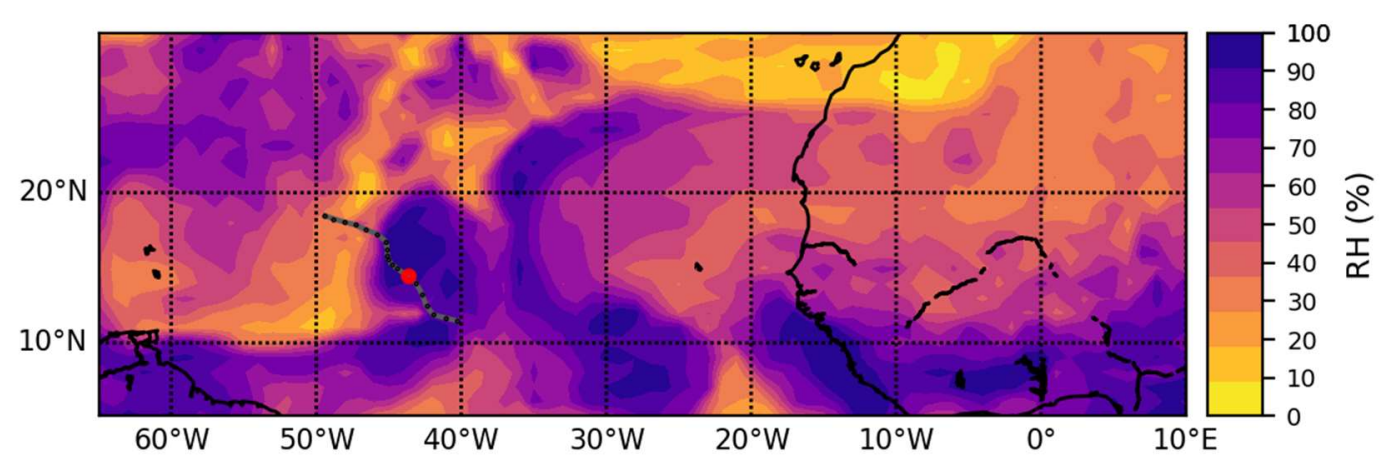

FIG. 45. RH at $700 \mathrm{hPa}$ for TD9 at 12 UTC 16 Sep 2015 from NCEP-FNL; grey line is the storm track with best locations (black dots) from NHC; red dot indicates TC location when TD stage was declared. 


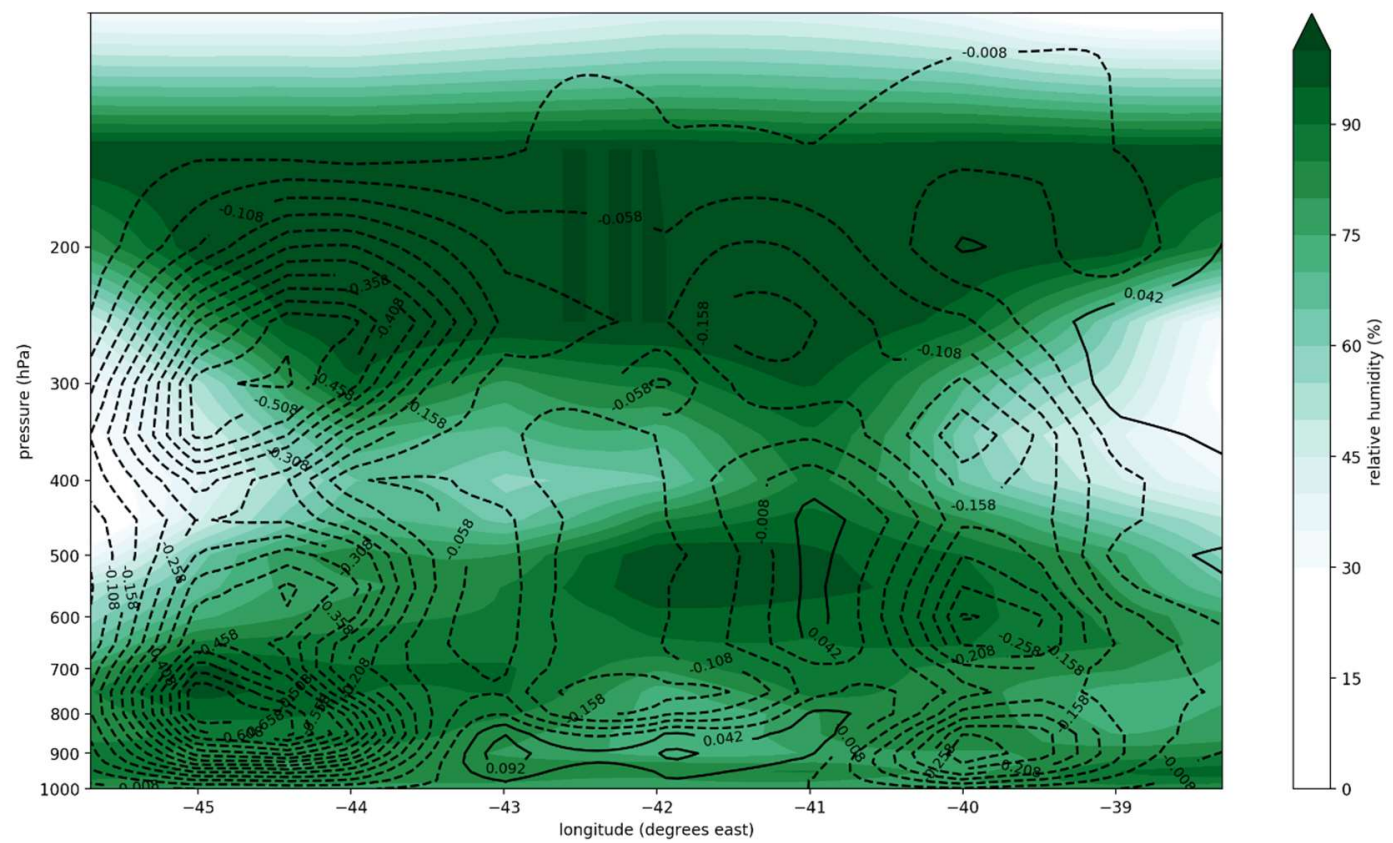

FIG. 46. Cross section of storm path from the first available best location $\left(11.5^{\circ} \mathrm{N},-38.3^{\circ} \mathrm{E}\right)$ to near the location of TD status $\left(14.5^{\circ} \mathrm{N},-45.7^{\circ} \mathrm{E}\right)$ for TD9 at 12 UTC 16 Sep 2015 from NCEP-FNL; green contours indicate RH (\%); black lines indicate positive (solid) and negative (dotted) omega values ( $\mathrm{Pa} / \mathrm{s})$.

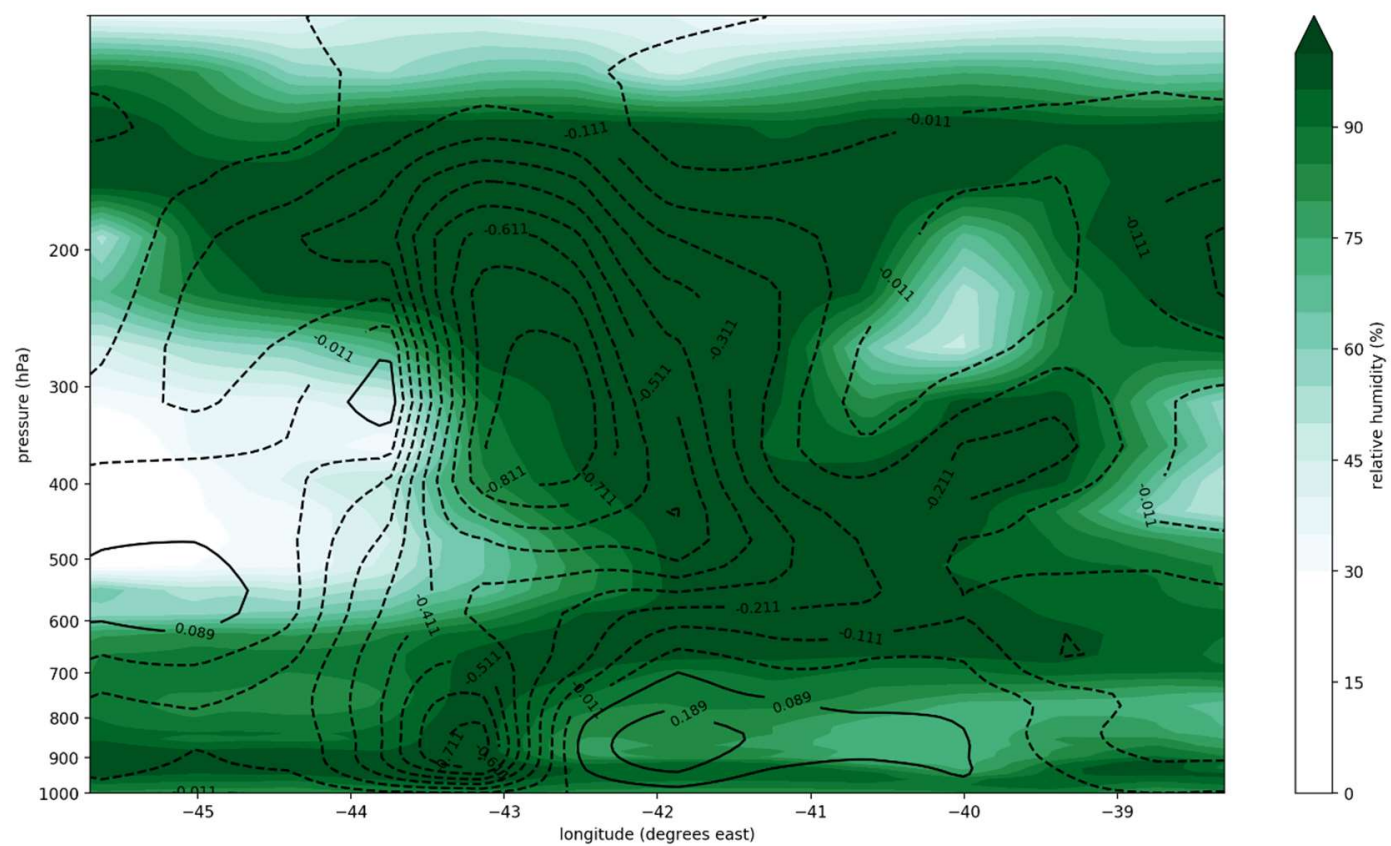

FIG. 47. Cross section of storm path from the first available best location $\left(11.5^{\circ} \mathrm{N},-38.3^{\circ} \mathrm{E}\right)$ to near the location of TD status $\left(14.5^{\circ} \mathrm{N},-45.7^{\circ} \mathrm{E}\right)$ for TD9 at 12 UTC 16 Sep 2015 from MERRA-2; green contours indicate RH (\%); black lines indicate positive (solid) and negative (dotted) omega values ( $\mathrm{Pa} / \mathrm{s})$. 

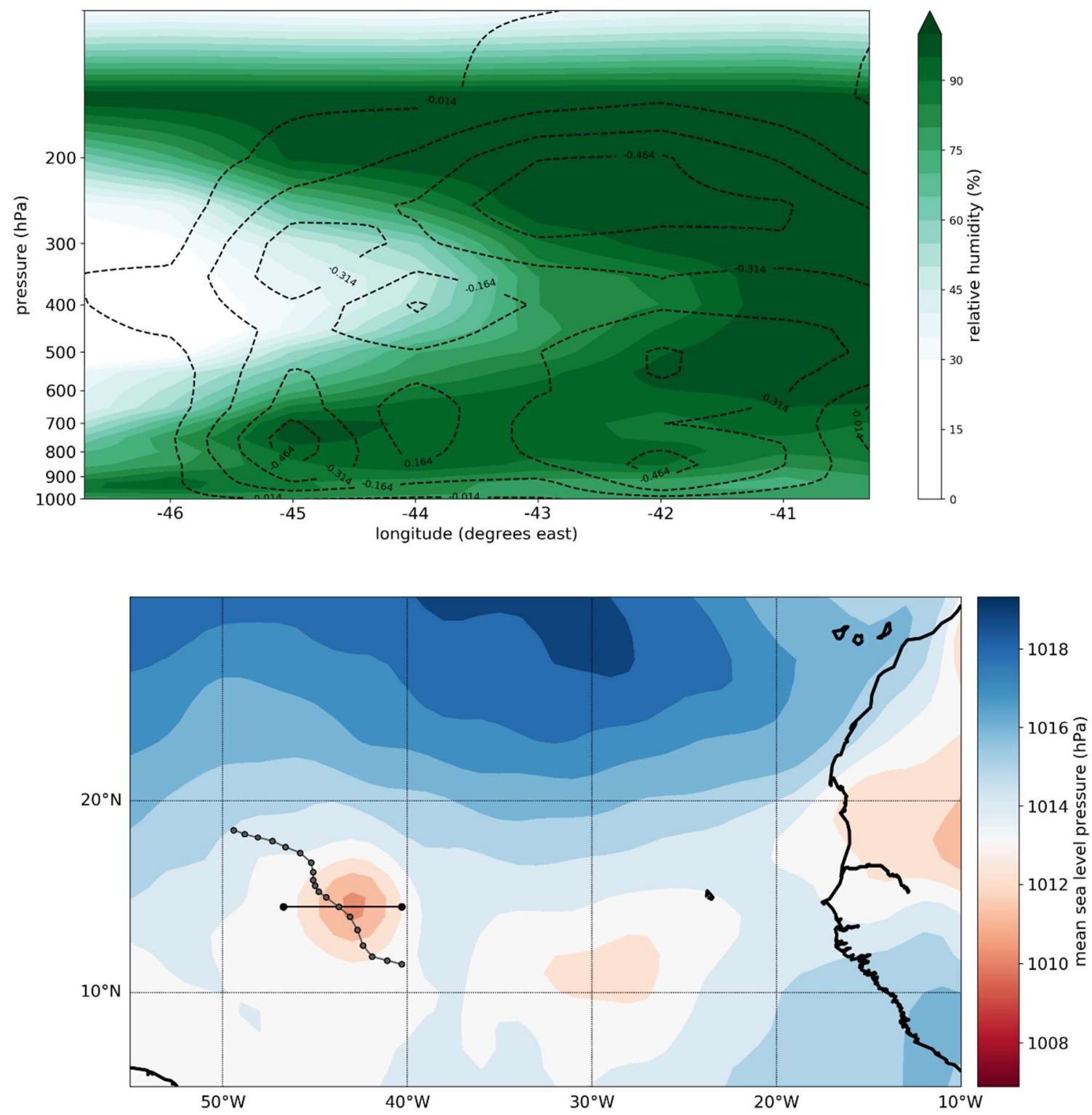

FIG. 48. (above) RH cross section beginning at $14.5^{\circ} \mathrm{N},-40.3^{\circ} \mathrm{E}$ to $14.5^{\circ} \mathrm{N},-46.7^{\circ} \mathrm{E}$ at $12 \mathrm{UTC} 16 \mathrm{Sep}$ 2015 for TD9 at TD stage from NCEP-FNL; green contours indicate RH (\%); black lines indicate positive (solid) and negative (dotted) omega values $(\mathrm{Pa} / \mathrm{s})$; (below) cross section path with SLP; contours indicate the mean SLP (hPa); grey line with small black dots showing the entire storm path based on NHC's best locations; larger solid dots and black line shows the location of the cross section. 

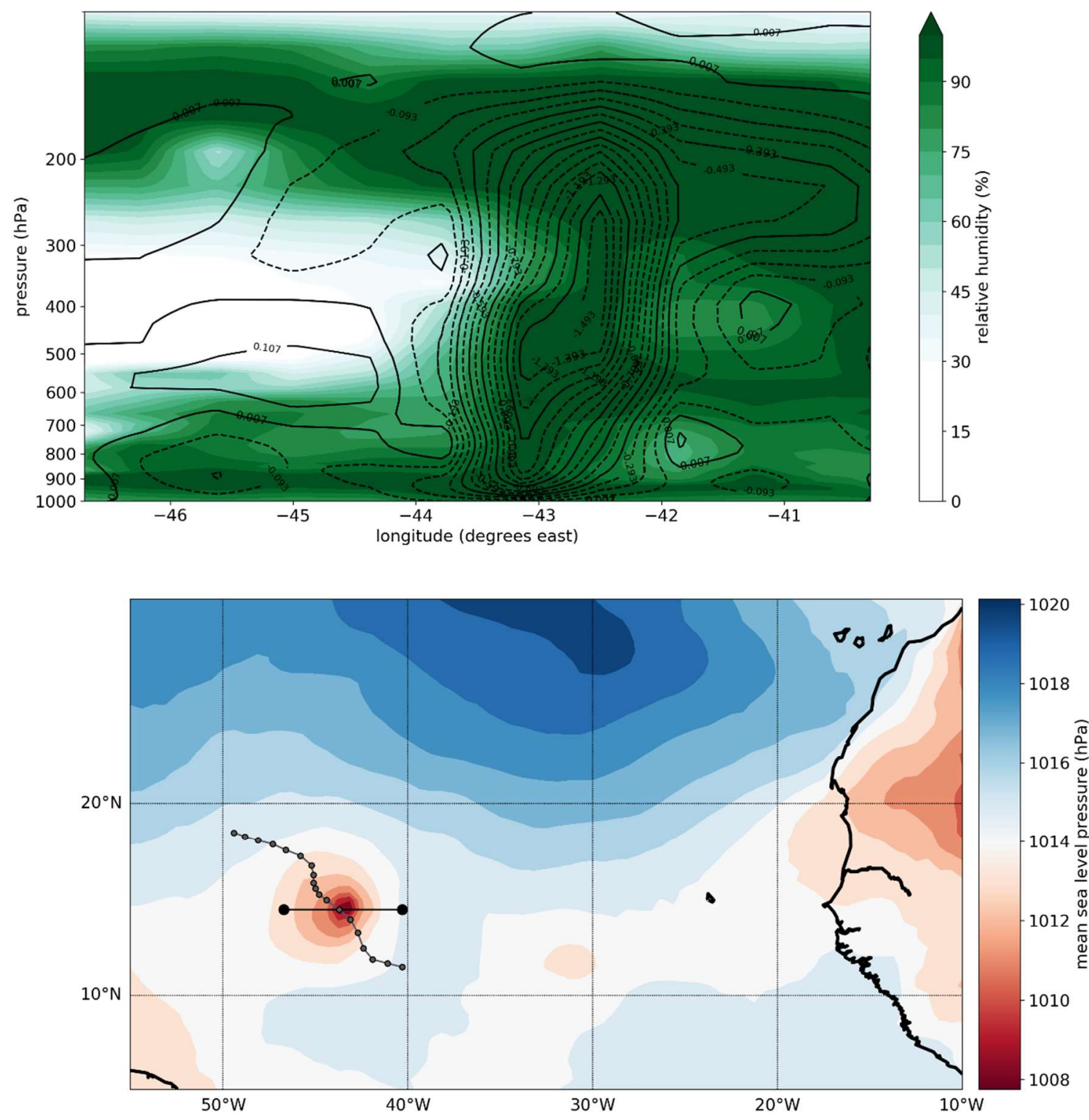

FIG. 49. (above) RH cross section beginning at $14.5^{\circ} \mathrm{N},-40.3^{\circ} \mathrm{E}$ to $14.5^{\circ} \mathrm{N},-46.7^{\circ} \mathrm{E}$ at $12 \mathrm{UTC} 16$ Sep 2015 for TD9 at TD stage from MERRA-2; green contours indicate RH (\%); black lines indicate positive (solid) and negative (dotted) omega values ( $\mathrm{Pa} / \mathrm{s})$; (below) cross section path with SLP; contours indicate the mean SLP; grey line with small black dots showing the entire storm path based on NHC's best locations; larger solid dots and black line shows the location of the cross section. 


\section{d. Tropical Storm Grace}

\section{1) $\mathrm{T}=$-3 STARTING AT 18 UTC 02 SEP 2015}

At $700 \mathrm{hPa}$, no dry air occurrences were present at this time period for both NCEPFNL and MERRA-2. The satellite imagery and example plots from 06 UTC 03 Sep also reflected these findings as the environment appeared quite high in $\mathrm{RH}$ on the storm track (Fig. 50, Fig. 51, Fig. 52). Some dry air instances were observed above and below the estimated location of the beginning of the storm track (Fig. 50). Beyond the 3 day limit, the latter half of the storm path appeared quite dry in both MERRA-2 and NCEP-FNL (Fig. 51, Fig. 52).

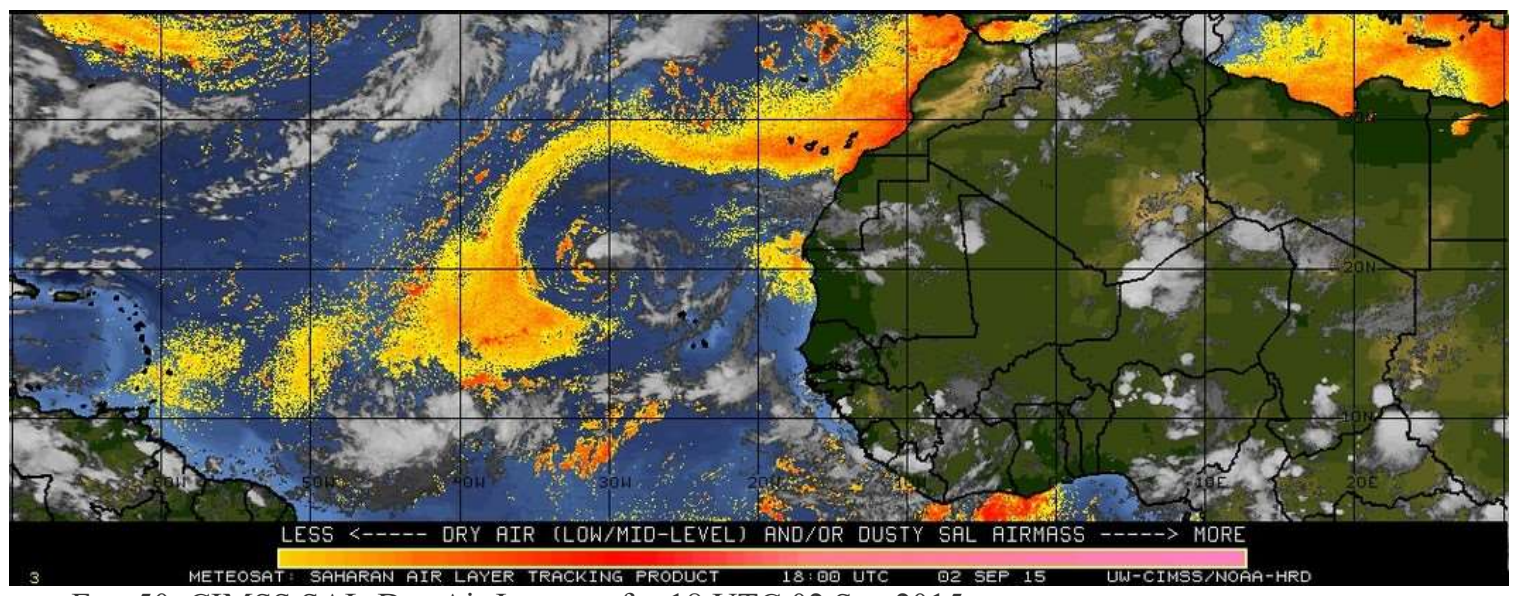

FIG. 50. CIMSS SAL-Dry Air Imagery for 18 UTC 02 Sep 2015.

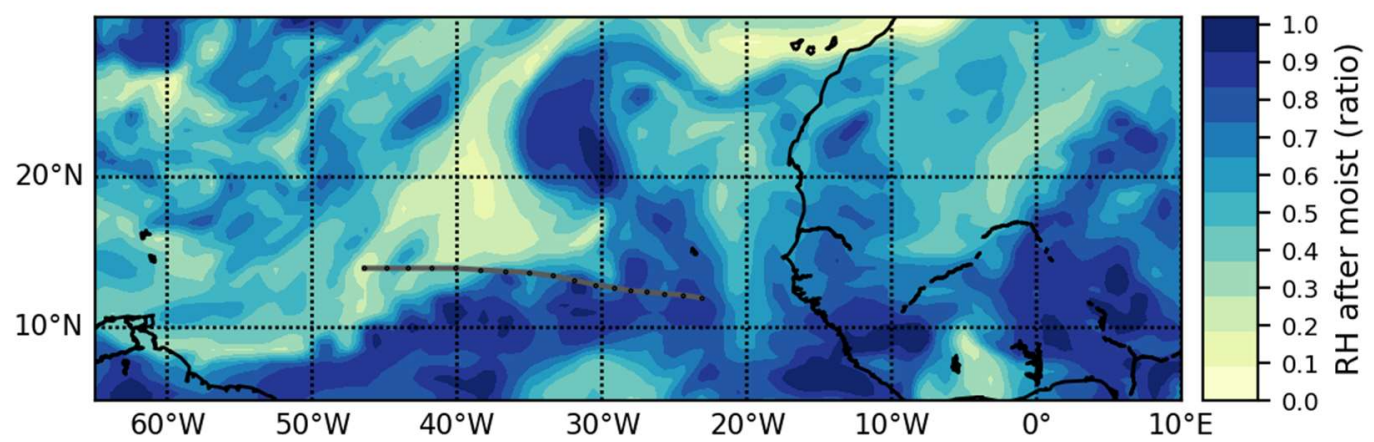

FIG. 51. RH at $700 \mathrm{hPa}$ for TS Grace at 06 UTC 03 Sep 2015 from MERRA-2; grey line is the storm track with best locations (black dots) from NHC. 


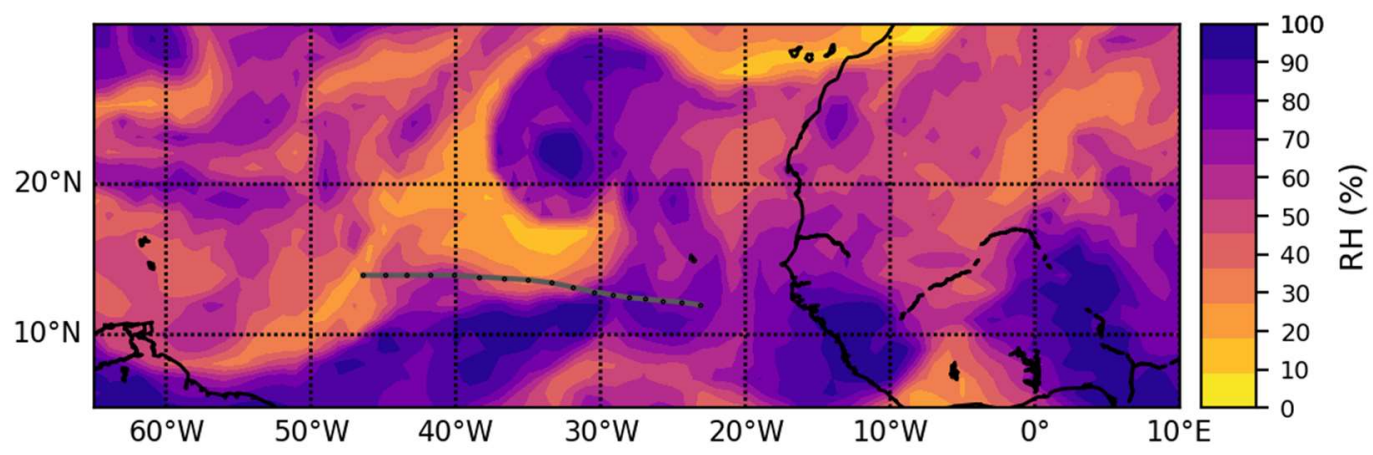

FIG. 52. RH at $700 \mathrm{hPa}$ for TS Grace at 06 UTC 03 Sep 2015 from NCEP-FNL; grey line is the storm track with best locations (black dots) from NHC.

Vertical cross sections of the storm track also confirmed a lack of dry air in the lower levels of the atmosphere; however, dry air can be seen in the upper levels of atmosphere, around 500-250 hPa for NCEP-FNL and near $500 \mathrm{hPa}$ for MERRA-2 (Fig. 53, Fig. 54). As some dry air instances were observed north and south of the beginning of the storm track in the satellite imagery, they may be reflecting the upper level dry air presence. RH in levels below $700 \mathrm{hPa}$ also appeared to be less or equal to 30\% in MERRA-2 (Fig. 54). As Fig. 55 showed, the cross section slicing nearly overlapped the best positions from NHC. 


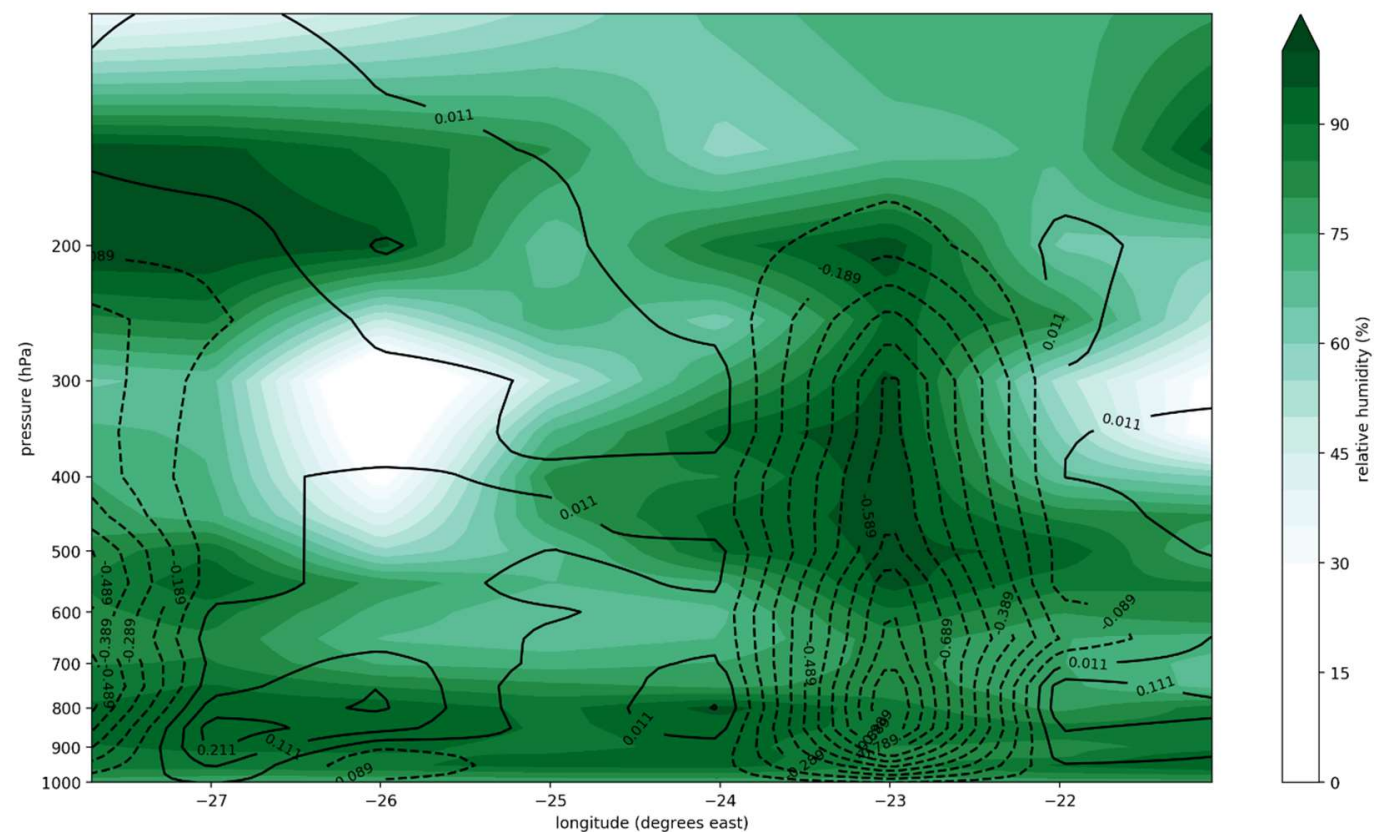

FIG. 53. Cross section of storm path from the first available best location $\left(12.0^{\circ} \mathrm{N},-21.1^{\circ} \mathrm{E}\right)$ to near the location of TS status $\left(12.3^{\circ} \mathrm{N},-27.7^{\circ} \mathrm{E}\right)$ for TS Grace at 06 UTC 03 Sep 2015 from NCEP-FNL; green contours indicate RH (\%); black lines indicate positive (solid) and negative (dotted) omega values $(\mathrm{Pa} / \mathrm{s})$.

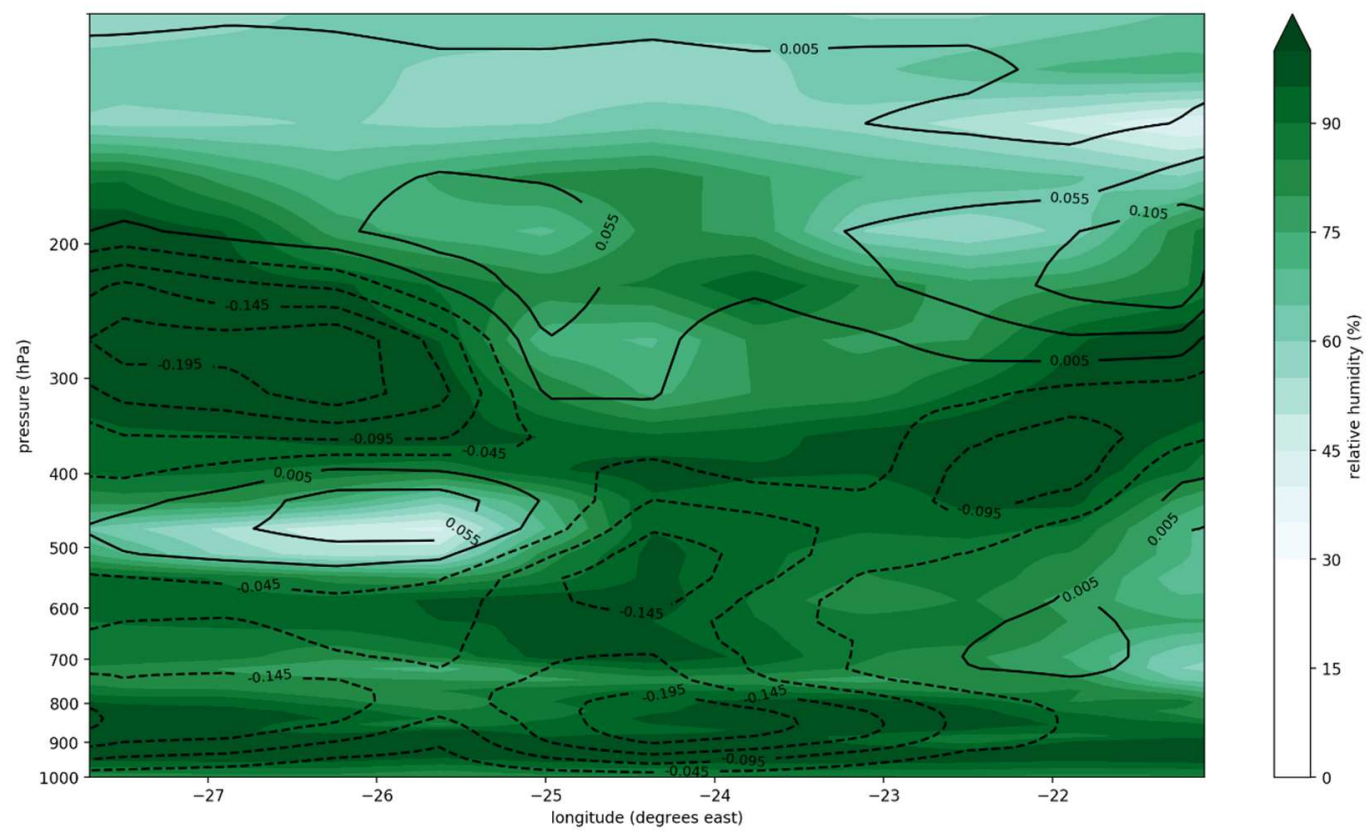

FIG. 54. Cross section of storm path from the first available best location $\left(12.0^{\circ} \mathrm{N},-21.1^{\circ} \mathrm{E}\right)$ to near the location of TS status $\left(12.3^{\circ} \mathrm{N},-27.7^{\circ} \mathrm{E}\right)$ for TS Grace at 06 UTC 03 Sep 2015 from MERRA-2; green contours indicate RH (\%); black lines indicate positive (solid) and negative (dotted) omega values ( $\mathrm{Pa} / \mathrm{s})$. 


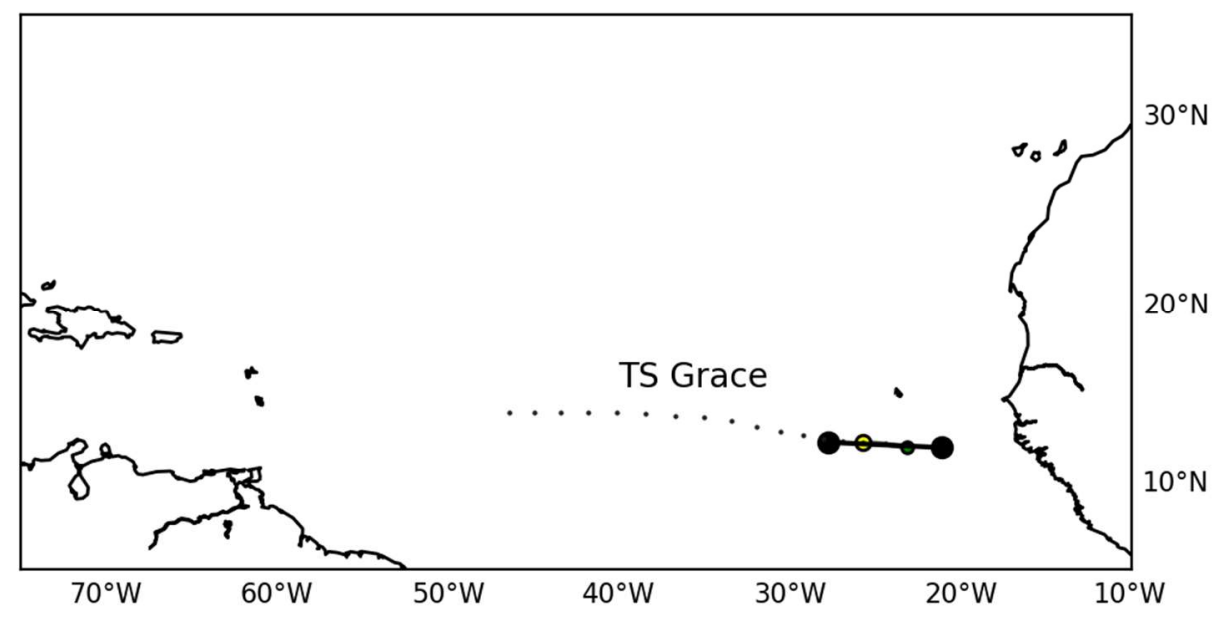

FIG. 55. Cross section path (large black dots, thick black line) for analysis portion of TS Grace's storm track; similar to FIG. 1.

\section{2) T= -2 STARTING AT 18 UTC O3 SEP 2015}

One RH value of $23.6 \%$ was recorded at 12 UTC 04 Sep on storm position 12 UTC 07 Sep for NCEP-FNL at $700 \mathrm{hPa}$. For MERRA-2, two dry air instances were found at 12 UTC $04 \operatorname{Sep}(0.221)$ and 15 UTC $04 \operatorname{Sep}(0.205)$ at the future storm locations of 12 UTC 04 Sep and 15 UTC 04 Sep, respectively. A wider view of RH also corresponded with the lack of dry air values as the environment on the storm path prior to the TS stage was quite humid (Fig. 56, Fig. 57).

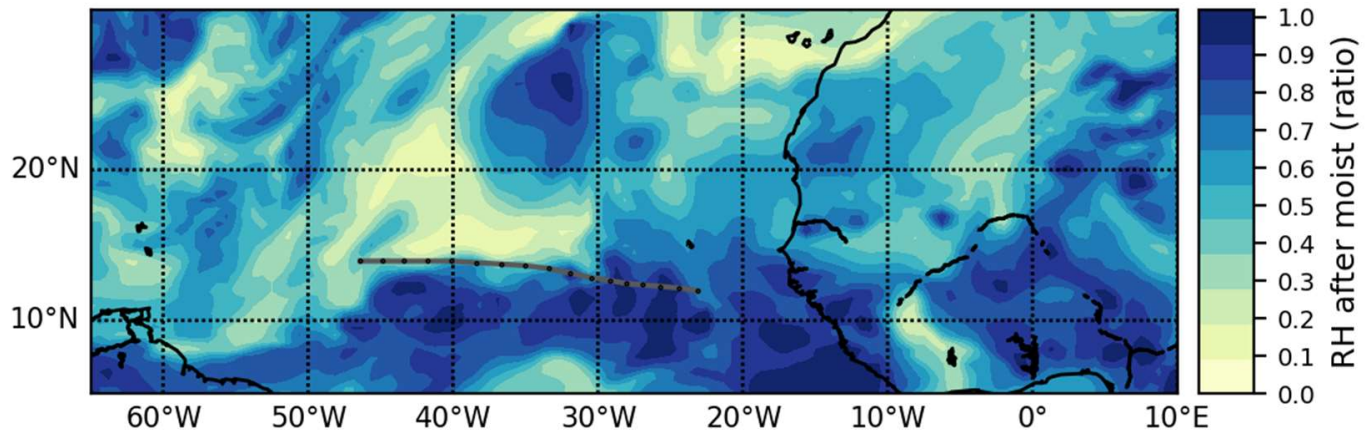

FIG. 56. RH at $700 \mathrm{hPa}$ for TS Grace at 18 UTC 03 Sep 2015 from MERRA-2; grey line is the storm track with best locations (black dots) from NHC. 


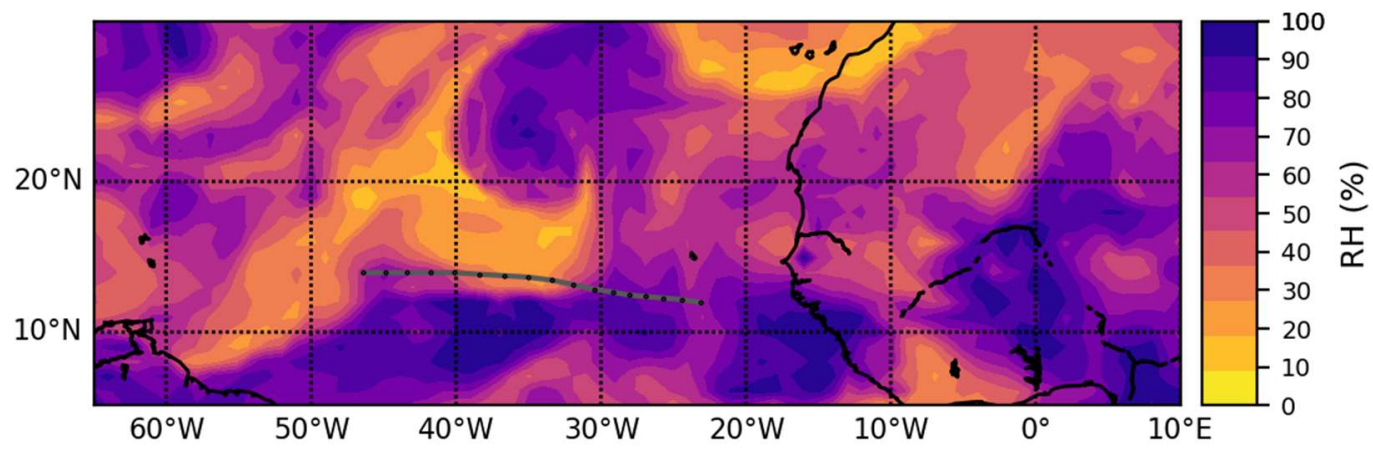

FIG. 57. RH at $700 \mathrm{hPa}$ for TS Grace at 18 UTC 03 Sep 2015 from NCEP-FNL; grey line is the storm track with best locations (black dots) from NHC.

Despite the lack of low RH values at $700 \mathrm{hPa}$, both NCEP-FNL and MERRA-2 showed an expanse of dry air from the lower to upper levels (Fig. 58, Fig. 59). A very dry section was visible from about 500-200 hPa, with additional dry air presence extending to around $900 \mathrm{hPa}$ (Fig. 58). MERRA-2 also showed areas of low moisture air at similar vertical levels, though more humid air was also noted (Fig. 59). Satellite imagery also showed indications of low humidity being near the TC (Fig. 60). 


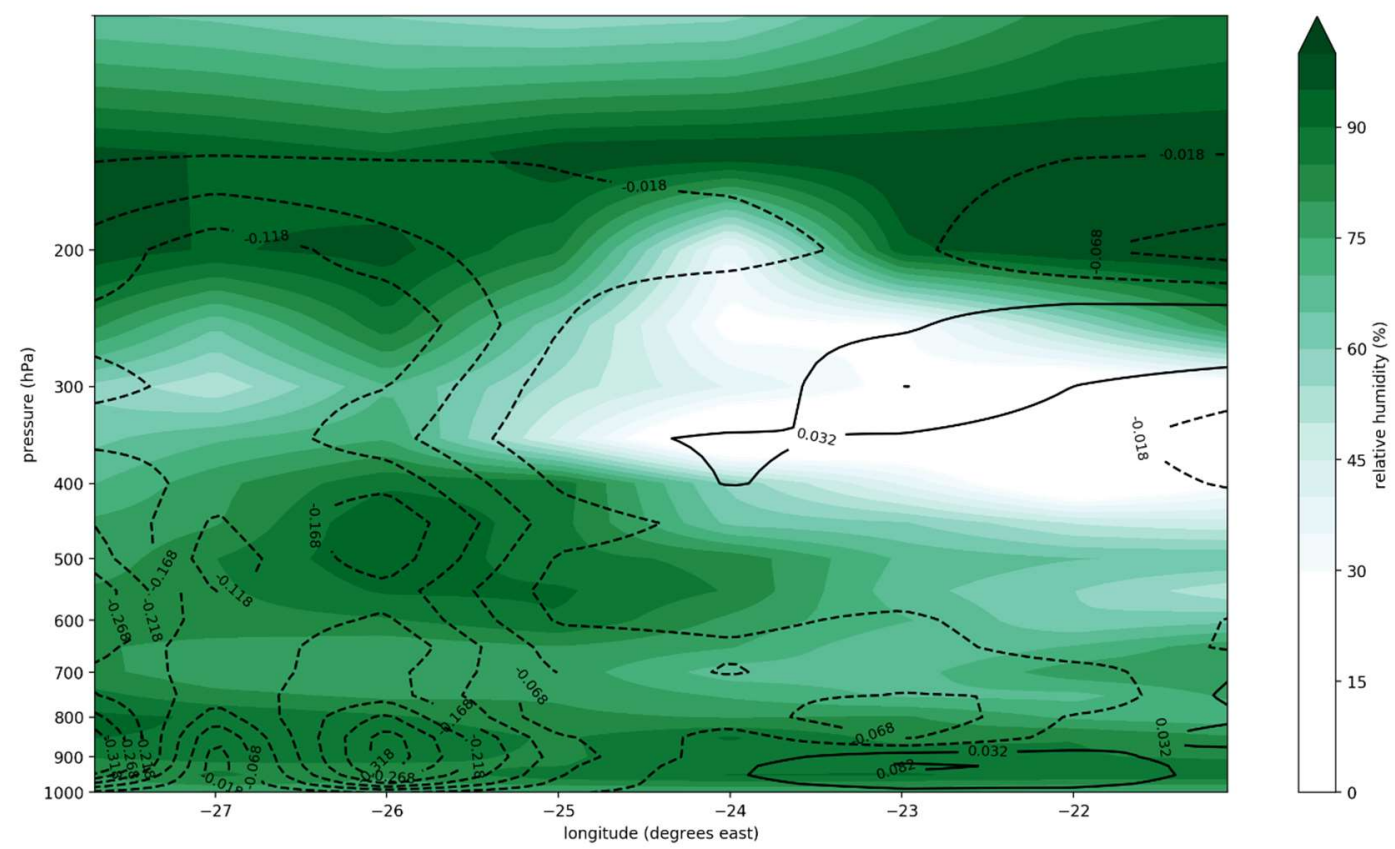

FIG. 58. Cross section of storm path from the first available best location $\left(12.0^{\circ} \mathrm{N},-21.1^{\circ} \mathrm{E}\right)$ to near the location of TS status $\left(12.3^{\circ} \mathrm{N},-27.7^{\circ} \mathrm{E}\right)$ for TS Grace at 18 UTC 03 Sep 2015 from NCEP-FNL; green contours indicate RH (\%); black lines indicate positive (solid) and negative (dotted) omega values ( $\mathrm{Pa} / \mathrm{s}$ ).

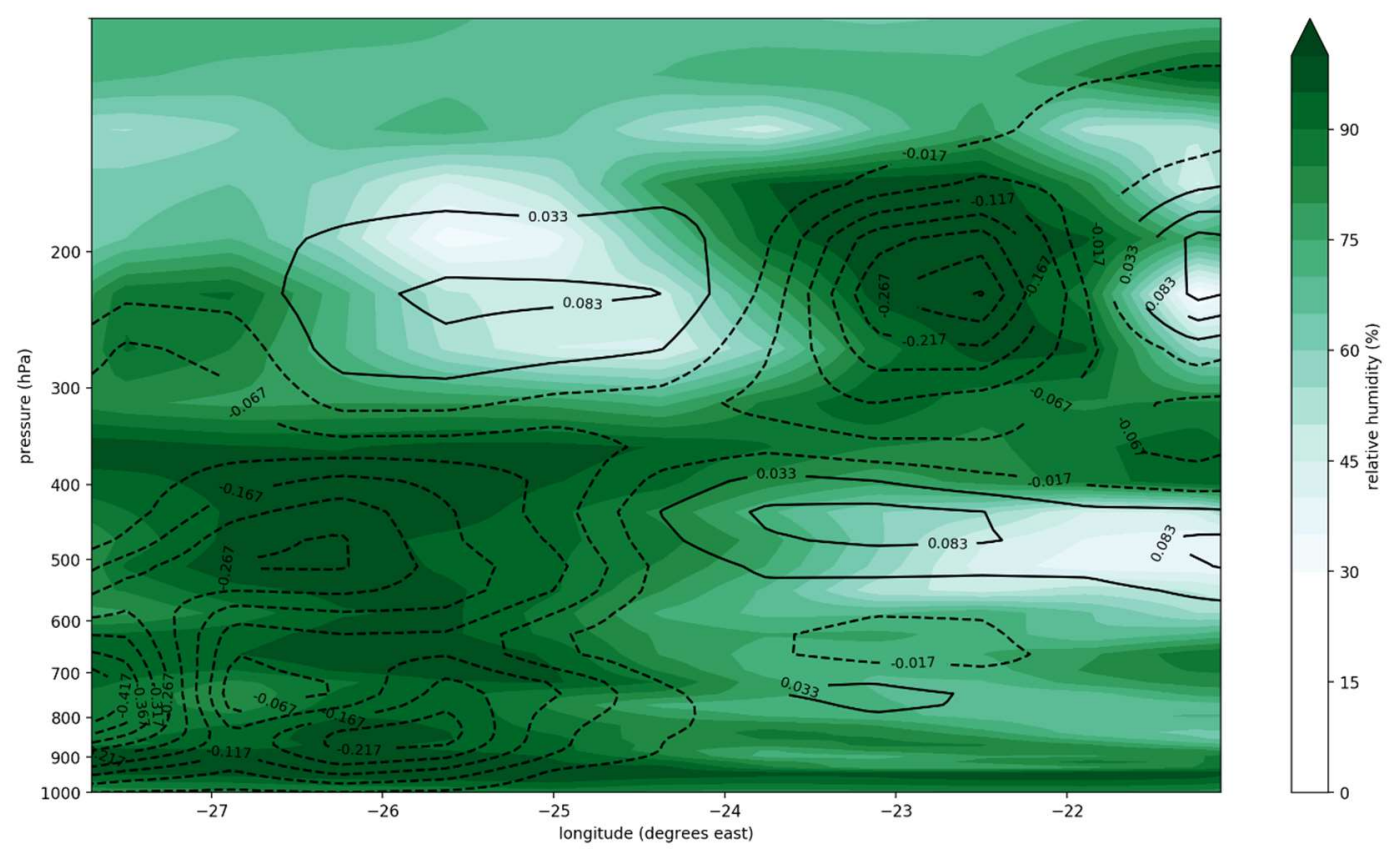

FIG. 59. Cross section of storm path from the first available best location $\left(12.0^{\circ} \mathrm{N},-21.1^{\circ} \mathrm{E}\right)$ to near the location of TS status $\left(12.3^{\circ} \mathrm{N},-27.7^{\circ} \mathrm{E}\right)$ for TS Grace at 18 UTC 03 Sep 2015 from MERRA-2; green contours indicate RH (\%); black lines indicate positive (solid) and negative (dotted) omega values $(\mathrm{Pa} / \mathrm{s})$. 


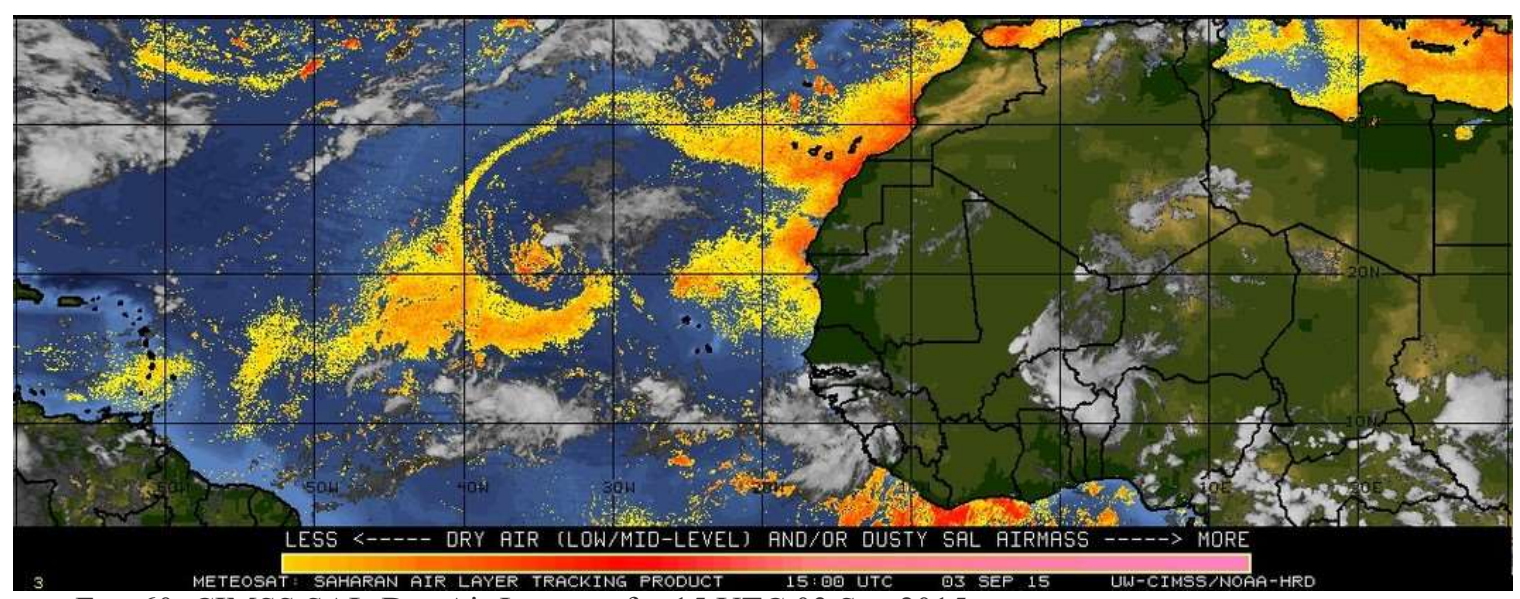

FIG. 60. CIMSS SAL-Dry Air Imagery for 15 UTC 03 Sep 2015.

\section{3) $T=-1$ STARTING AT 18 UTC 04 SEP 2015}

For NCEP-FNL at $700 \mathrm{hPa}$, low RH values $(\mathrm{N}=8)$ were observed at 66 to 72 hours ahead of the storm. RH values ranged from 14.0-26.4\%. MERRA-2 also showed similar results where dry air was present in the last 2-3 storm locations of each 3-hour interval. $\mathrm{RH}$ values $(\mathrm{N}=18)$ ranged from 0.068 to 0.286 . Taking a wider view, it was difficult to detect these low RH points (Fig. 63, Fig. 64). However, satellite imagery showed that some small pockets of dry air next to the TC and some may be covered by the clouds (Fig. 61, Fig. 62). Moreover, dry air did appear in the mid and lower levels for MERRA2 while NCEP-FNL showed more humid air dominated the vertical layers (Fig. 65, Fig. 66). 


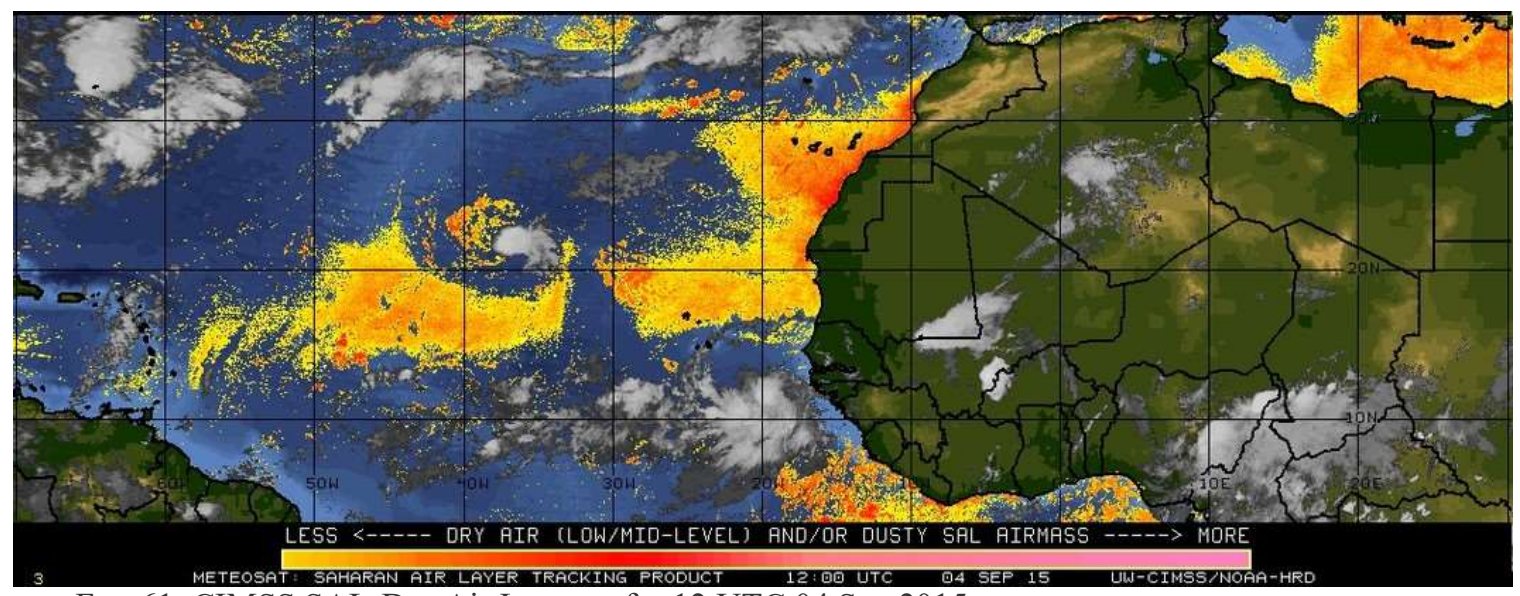

FIG. 61. CIMSS SAL-Dry Air Imagery for 12 UTC 04 Sep 2015.

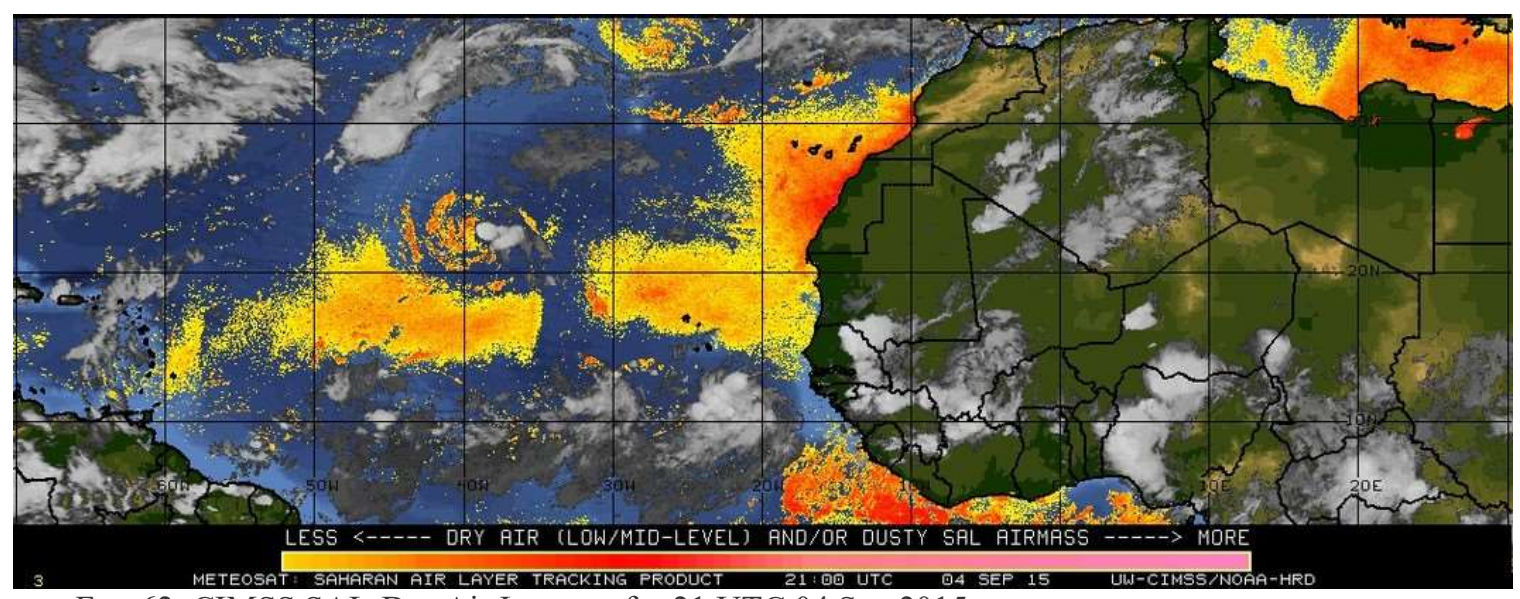

FIG. 62. CIMSS SAL-Dry Air Imagery for 21 UTC 04 Sep 2015.

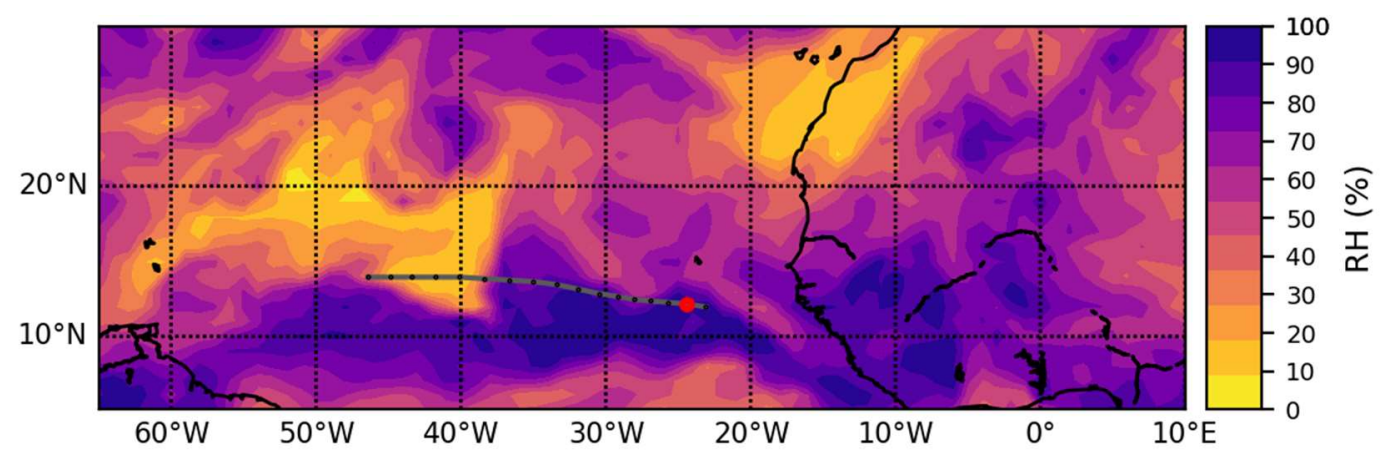

FIG. 63. RH at $700 \mathrm{hPa}$ for TS Grace at 12 UTC 05 Sep 2015 from NCEP-FNL; grey line is the storm track with best locations (black dots) from NHC; red dot indicates the TC location at the given time point 


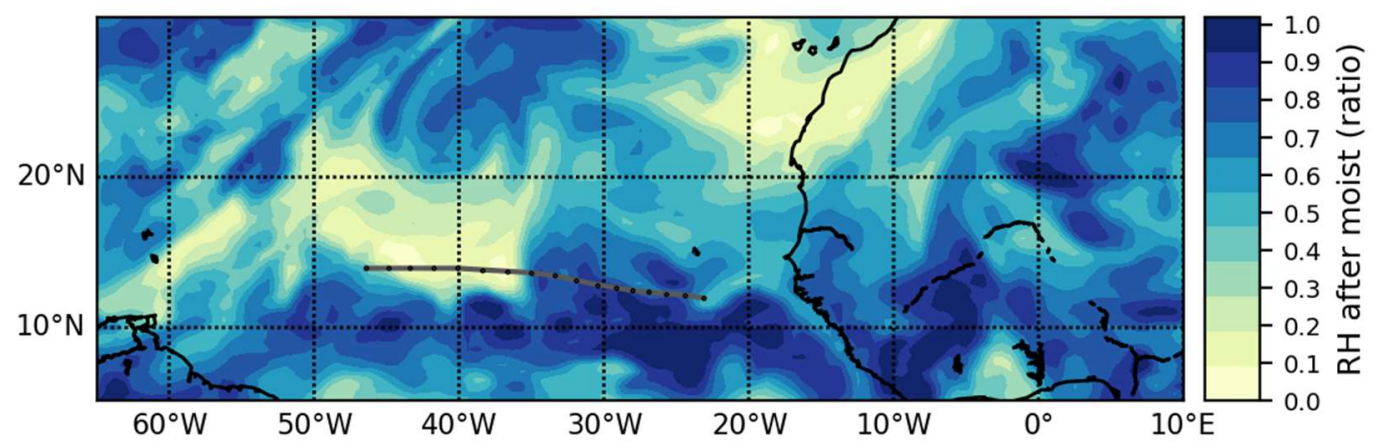

FIG. 64. RH at $700 \mathrm{hPa}$ for TS Grace at 03 UTC 05 Sep 2015 from MERRA-2; grey line is the storm track with best locations (black dots) from NHC.

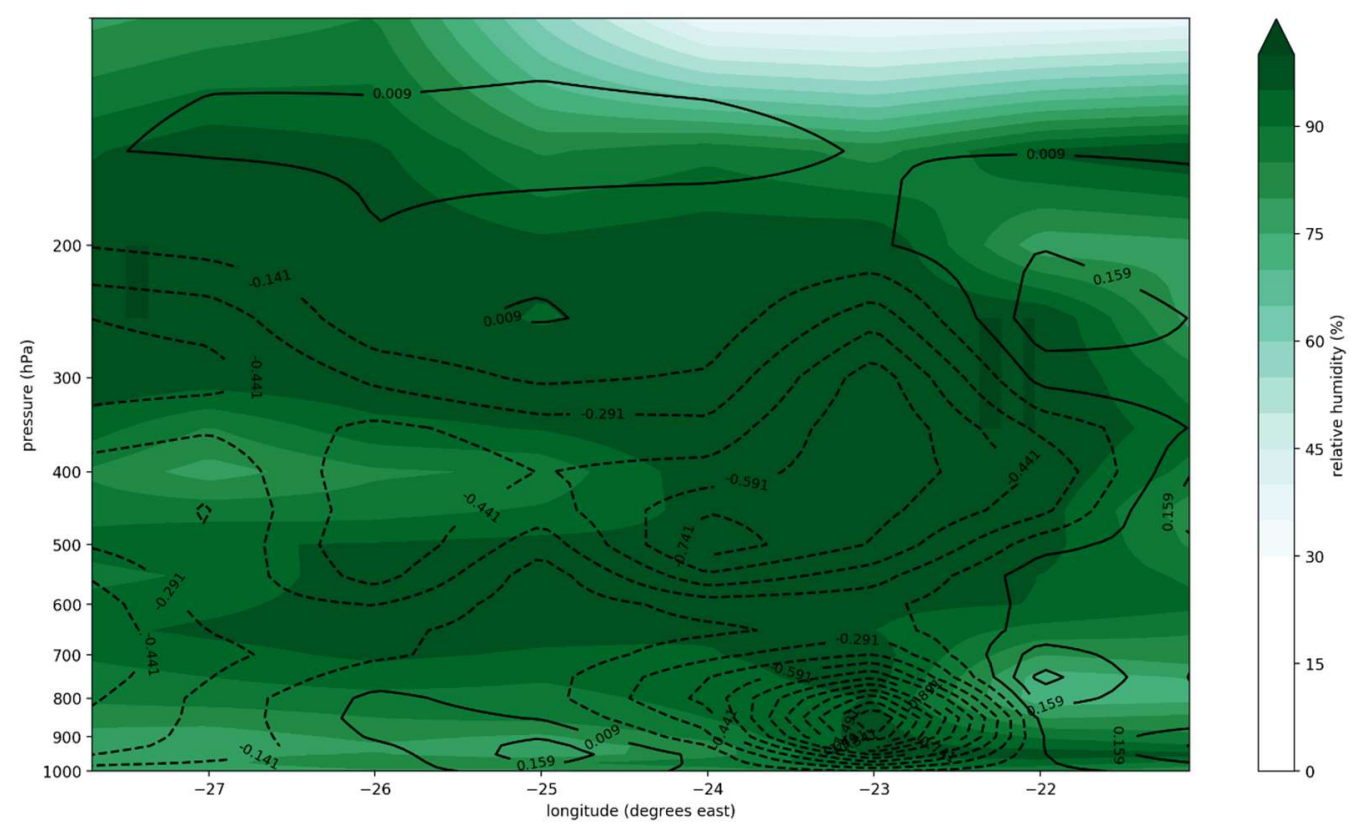

FIG. 65. Cross section of storm path from the first available best location $\left(12.0^{\circ} \mathrm{N},-21.1^{\circ} \mathrm{E}\right)$ to near the location of TS status $\left(12.3^{\circ} \mathrm{N},-27.7^{\circ} \mathrm{E}\right)$ for TS Grace at 06 UTC 05 Sep 2015 from NCEP-FNL; green contours indicate RH (\%); black lines indicate positive (solid) and negative (dotted) omega values ( $\mathrm{Pa} / \mathrm{s})$. 


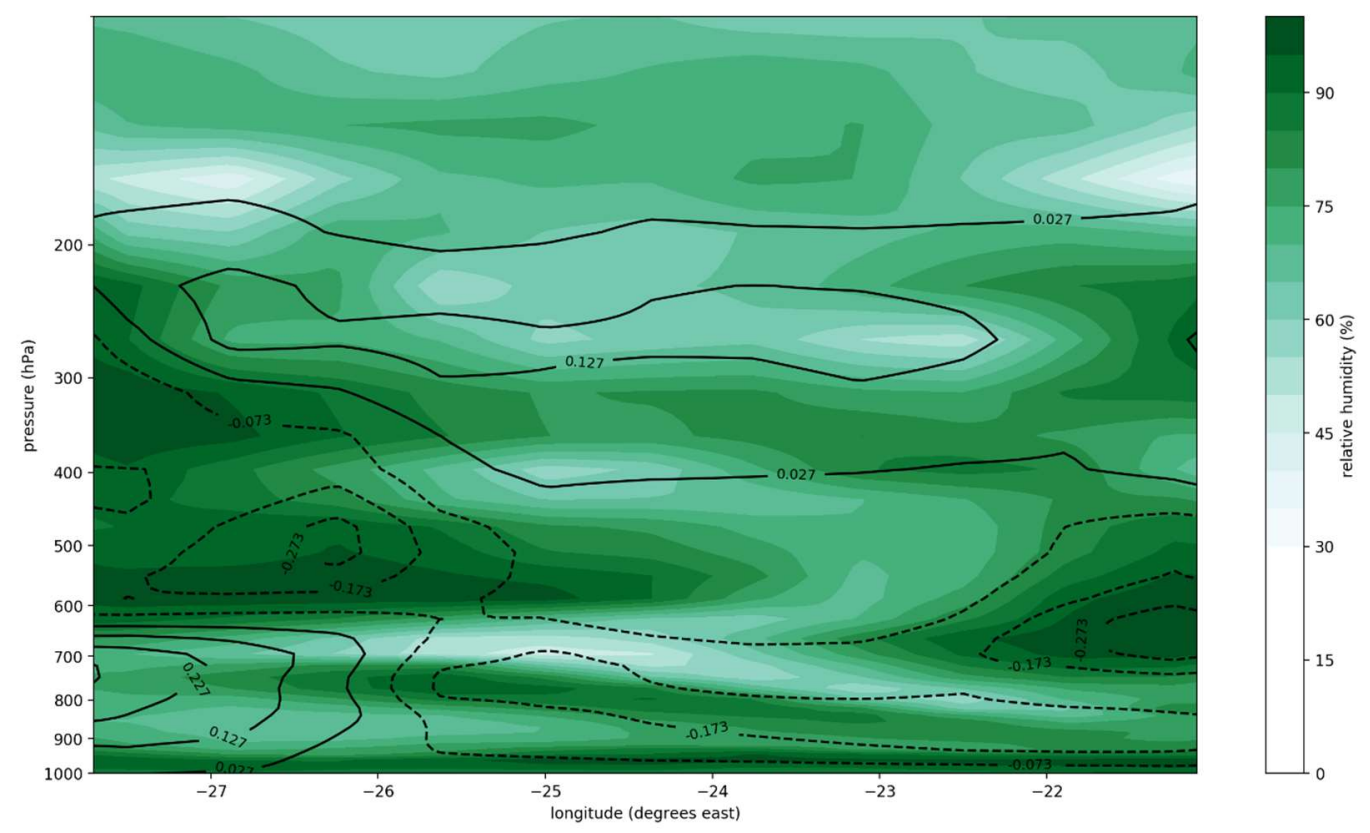

FIG. 66. Cross section of storm path from the first available best location $\left(12.0^{\circ} \mathrm{N},-21.1^{\circ} \mathrm{E}\right)$ to near the location of TS status $\left(12.3^{\circ} \mathrm{N},-27.7^{\circ} \mathrm{E}\right)$ for TS Grace at 09 UTC 05 Sep 2015 from MERRA-2; green contours indicate RH (\%); black lines indicate positive (solid) and negative (dotted) omega values $(\mathrm{Pa} / \mathrm{s})$.

\section{4) T= 0 AT 18 UTC 05 SEP 2015}

Upon reaching TS status, the latter storm positions up to the 3 day limit recorded by NHC, 06 UTC 08 Sep to 18 UTC 08 Sep showed $25.5 \%, 16.8 \%$, and 16.0\%, respectively under NCEP-FNL at $700 \mathrm{hPa}$ (Blake 2015). High moisture appeared concentrated around the storm as compared to previous time points (Fig. 67, Fig. 68). For MERRA-2, the nearest dry air (RH $\sim 19 \%, 15 \%$ and $21 \%)$ at the TS stage occupied the area $63-72$ hours ahead on the storm path when TD Grace was named TS Grace. 


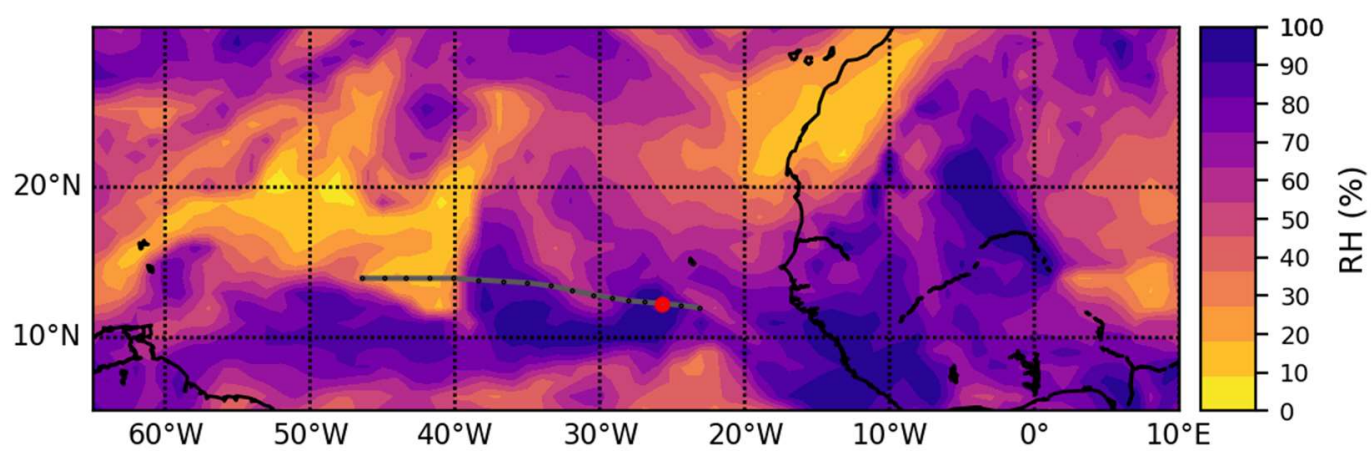

FIG. 67. RH at $700 \mathrm{hPa}$ for TS Grace at 18 UTC 05 Sep 2015 from NCEP-FNL; grey line is the storm track with best locations (black dots) from NHC; red dot indicates the TC location at the given time point.

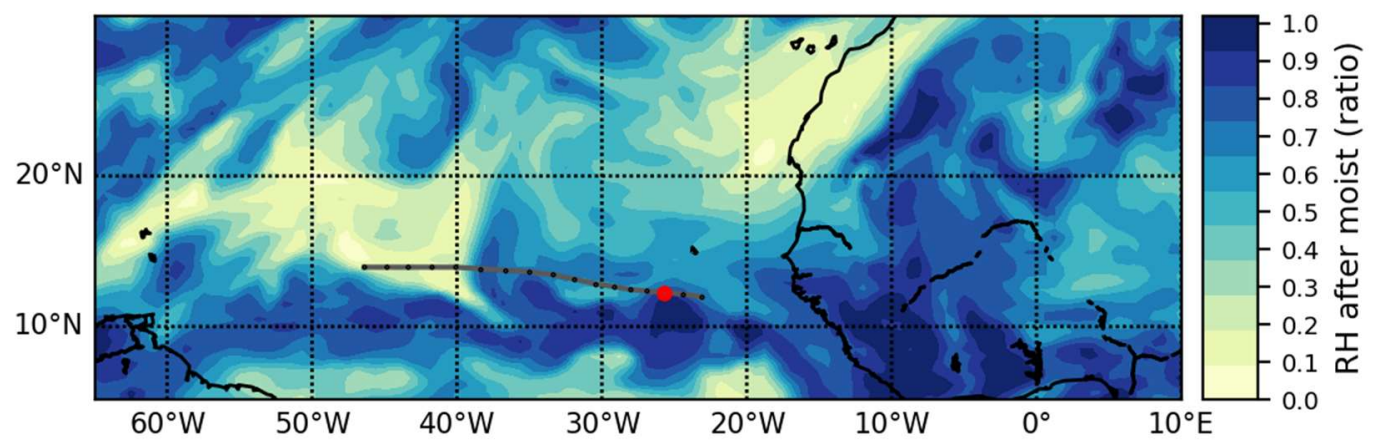

FIG. 68. RH at $700 \mathrm{hPa}$ for TS Grace at 18 UTC 05 Sep 2015 from MERRA-2; grey line is the storm track with best locations (black dots) from NHC; red dot indicates the $\mathrm{TC}$ location at the given time point.

The NCEP-FNL cross section of TS Grace displayed high moisture in the upper levels of the atmosphere from about $350 \mathrm{hPa}$ and beyond $200 \mathrm{hPa}$ (Fig. 69). Dry air was once again observed on the western side around $500 \mathrm{hPa}$ to about $350 \mathrm{hPa}$. Most of the air in the presumably center of the storm was rising and also high in RH. Drier sinking air at the lower tropospheric levels could also be observed to the east and west of the center. 


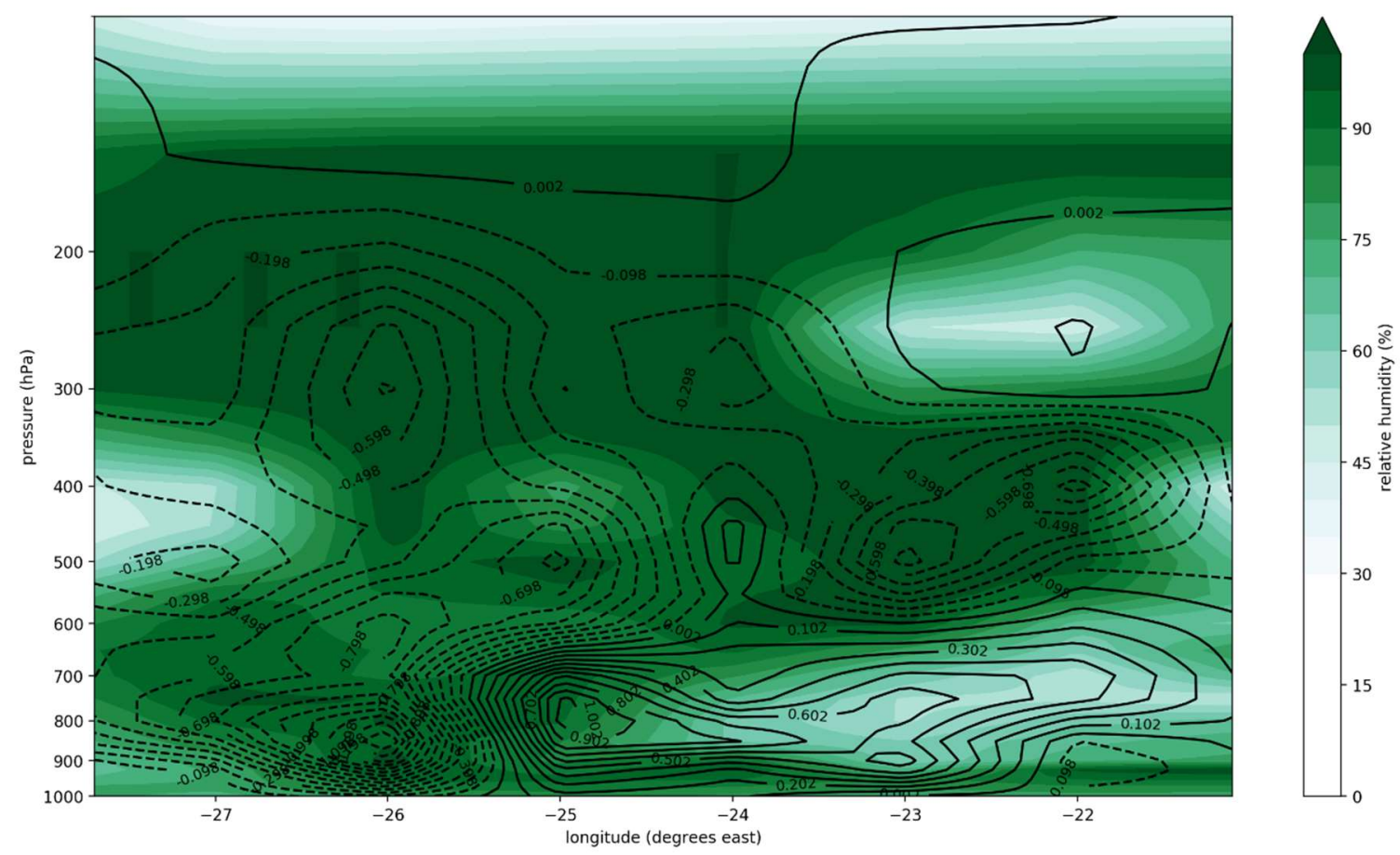

FIG. 69. Cross section of storm path from the first available best location $\left(12.0^{\circ} \mathrm{N},-21.1^{\circ} \mathrm{E}\right)$ to near the location of TS status $\left(12.3^{\circ} \mathrm{N},-27.7^{\circ} \mathrm{E}\right)$ for TS Grace at 18 UTC 05 Sep 2015 from NCEP-FNL; green contours indicate RH (\%); black lines indicate positive (solid) and negative (dotted) omega values (Pa/s).

While the TS was depicted more circular in the MERRA-2 RH data compared to NCEP-FNL, the center of the storm did not appear aligned with the best NHC location (Fig. 70, Fig. 68). The mean sea level pressure showed more evidence that the center of storm did not match up in MERRA-2 while NCEP-FNL corresponded more closely (Fig. 72, Fig. 73). This was a plausible explanation why the two cross sections of the path appeared very different (Fig. 71, Fig. 69). Though the storm track showed a large area of rising moist air spanning the surface to past $200 \mathrm{hPa}$, the cross section for MERRA-2 was likely slicing another feature of the storm and not near the storm's center (Fig. 71). The center of TS Grace determined in NCEP-FNL matched well with the expected NHC location (Fig. 72). Both cuts through the center of the TS also corresponded well from 
NCEP-FNL and MERRA-2, a mostly saturated column of air with some pockets of dry upper level air west and below $700 \mathrm{hPa}$ (Fig. 72, Fig. 73).

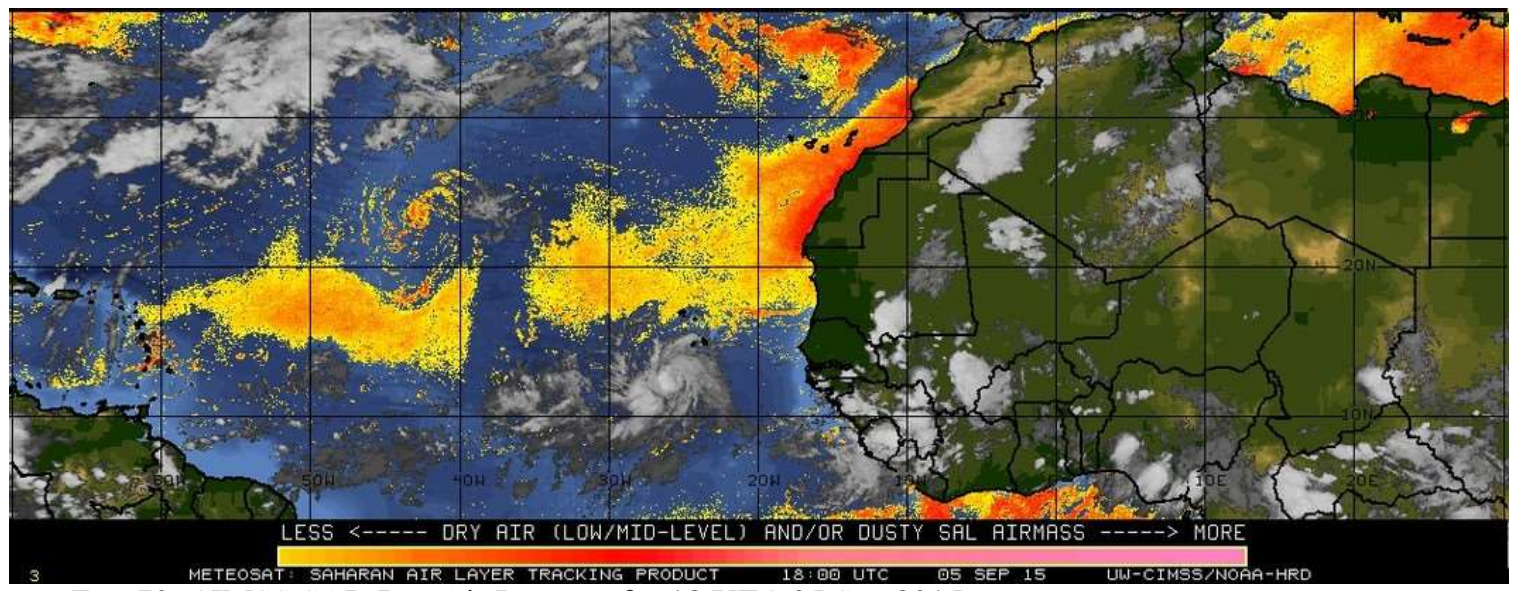

FIG. 70. CIMSS SAL-Dry Air Imagery for 18 UTC 05 Sep 2015.

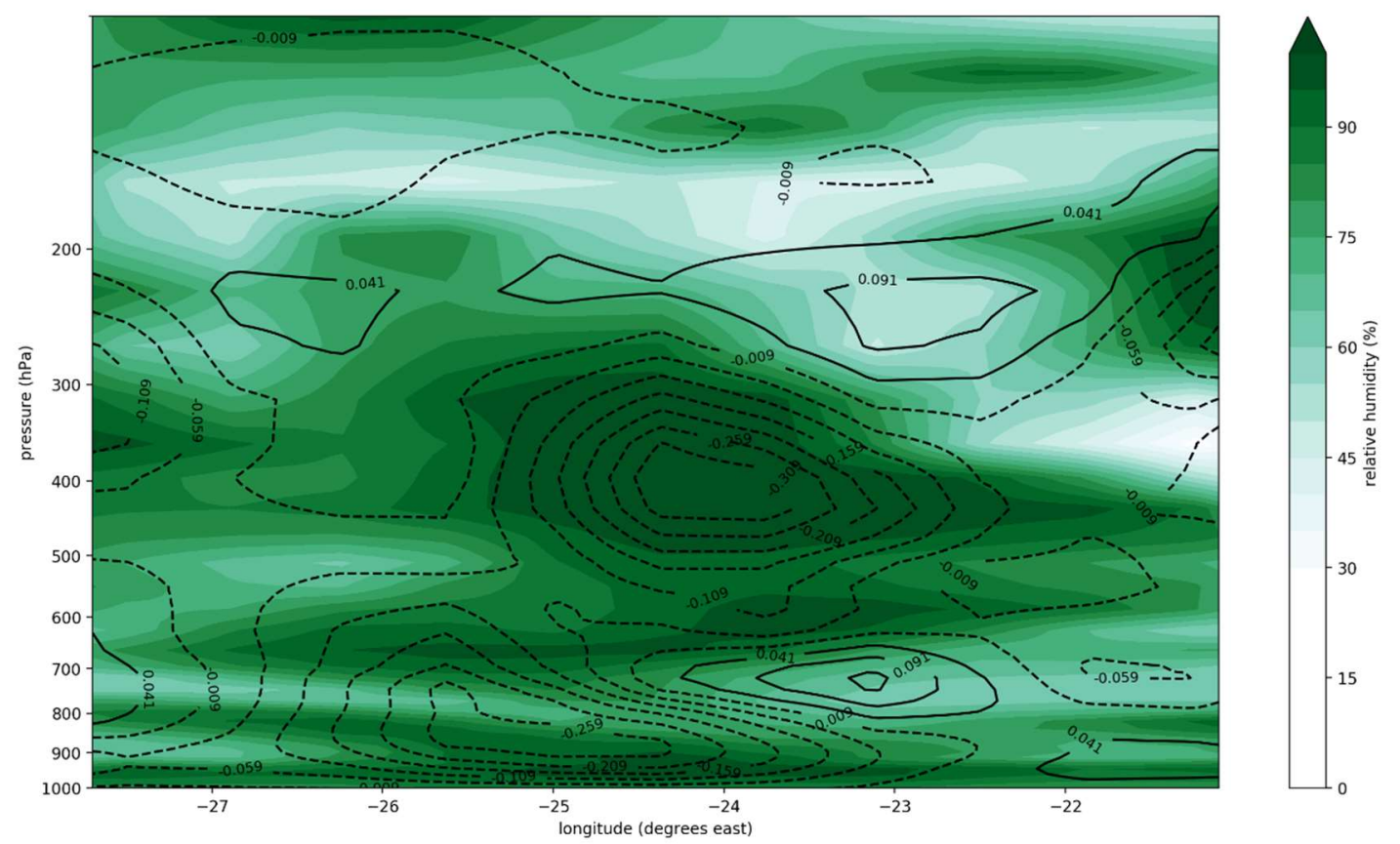

FIG. 71. Cross section of storm path from the first available best location $\left(12.0^{\circ} \mathrm{N},-21.1^{\circ} \mathrm{E}\right)$ to near the location of TS status $\left(12.3^{\circ} \mathrm{N},-27.7^{\circ} \mathrm{E}\right)$ for TS Grace at 18 UTC 05 Sep 2015 from MERRA-2; green contours indicate RH (\%); black lines indicate positive (solid) and negative (dotted) omega values $(\mathrm{Pa} / \mathrm{s})$. 

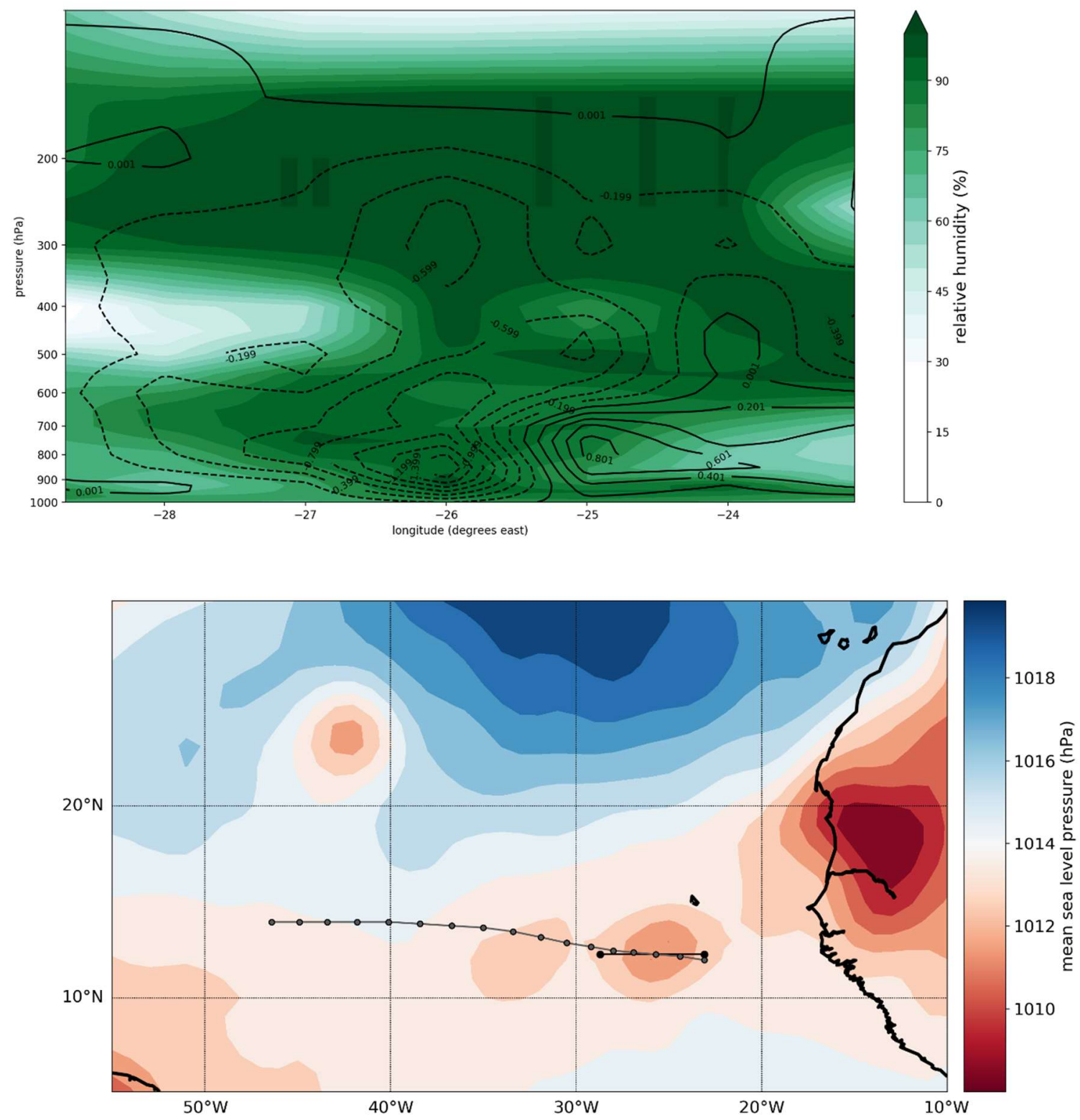

FIG. 72 . (above) RH cross section beginning at $12.3^{\circ} \mathrm{N},-23.1^{\circ} \mathrm{E}$ to $12.3^{\circ} \mathrm{N},-28.7^{\circ} \mathrm{E}$ at 18 UTC 05 Sep 2015 for TS Grace at TS stage from NCEP-FNL; green contours indicate RH (\%); black lines indicate positive (solid) and negative (dotted) omega values ( $\mathrm{Pa} / \mathrm{s})$; (below) cross section path with SLP; contours indicate the mean SLP; grey line with small black dots showing the entire storm path based on NHC's best locations; larger solid dots and black line shows the location of the cross section. 

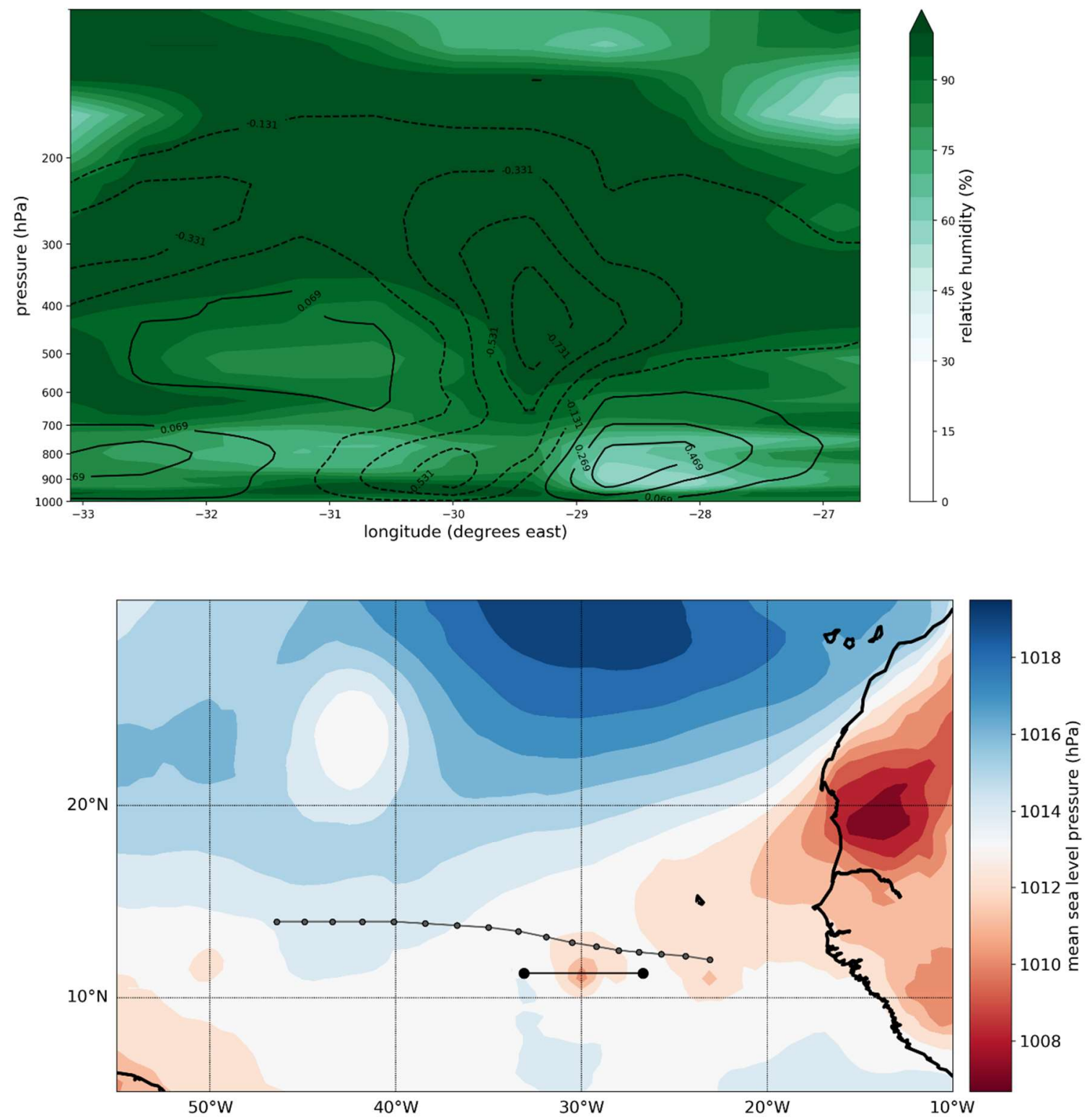

FIG. 73. (above) RH cross section beginning at $11.3^{\circ} \mathrm{N},-33.1^{\circ} \mathrm{E}$ to $11.3^{\circ} \mathrm{N},-26.7^{\circ} \mathrm{E}$ at $18 \mathrm{UTC} 05$ Sep 2015 for TS Grace at TS stage from MERRA-2; green contours indicate RH; black lines indicate positive (solid) and negative (dotted) omega values; (below) cross section path with SLP; contours indicate the mean SLP; grey line with small black dots showing the entire storm path based on NHC's best locations; larger solid dots and black line shows the location of the cross section. 
Near saturated air appeared for the lower and upper levels in MERRA-2; NCEP-FNL showed more wet swaths of air above $500 \mathrm{hPa}$ (Fig. 72, Fig. 73). Both figures indicated dry air presence near the upper levels on the western side and at the near surface levels east of the TC.

\section{e. Hurricane Fred}

1) $T=-3$ STARTING AT 00 UTC 28 AUg 2015

Per NCEP-FNL and MERRA-2, no RH values 30\% or lower were recorded at 700 $\mathrm{hPa}$. The satellite imagery of SAL displayed dry air present in the latter sections of the storm track, suggesting dry air was located in other pressure levels (Fig. 74). In contrast, a view at $700 \mathrm{hPa}$ also indicated a lack of dry air overlapping the storm track (

Fig. 75,Fig. 76). Indeed, cross sections along the storm path corresponded with the SAL imagery and suggested the nearby environment contained multiple layers of dry air (Fig. 77, Fig. 78). Dry air dominated more area of the cross section from NCEP-FNL compared to that of MERRA-2. Similar to the circumstance for TD9, it was noted that cross section path and actual best track did not match well (Fig. 79). However, these and subsequent cross sections of the approximate path displayed the $\mathrm{RH}$ characteristics near the actual storm path. 


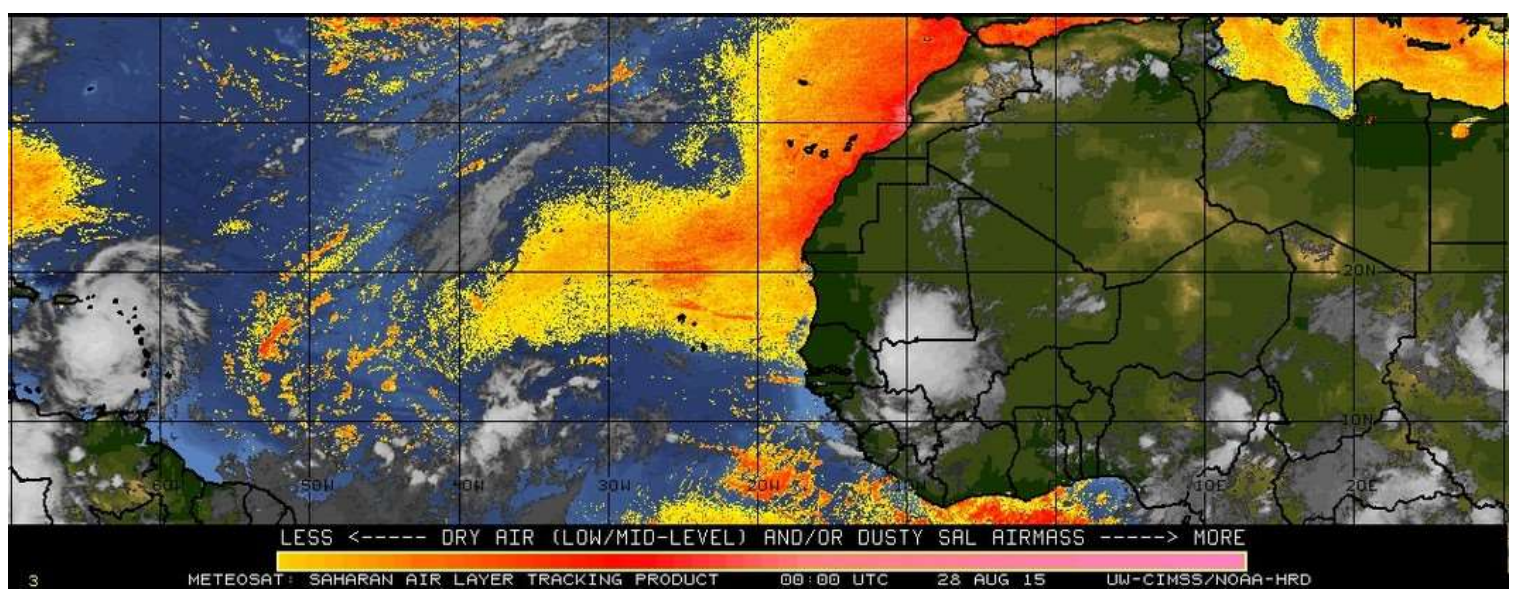

FIG. 74. CIMSS SAL-Dry Air Imagery for 00 UTC 28 Aug 2015.

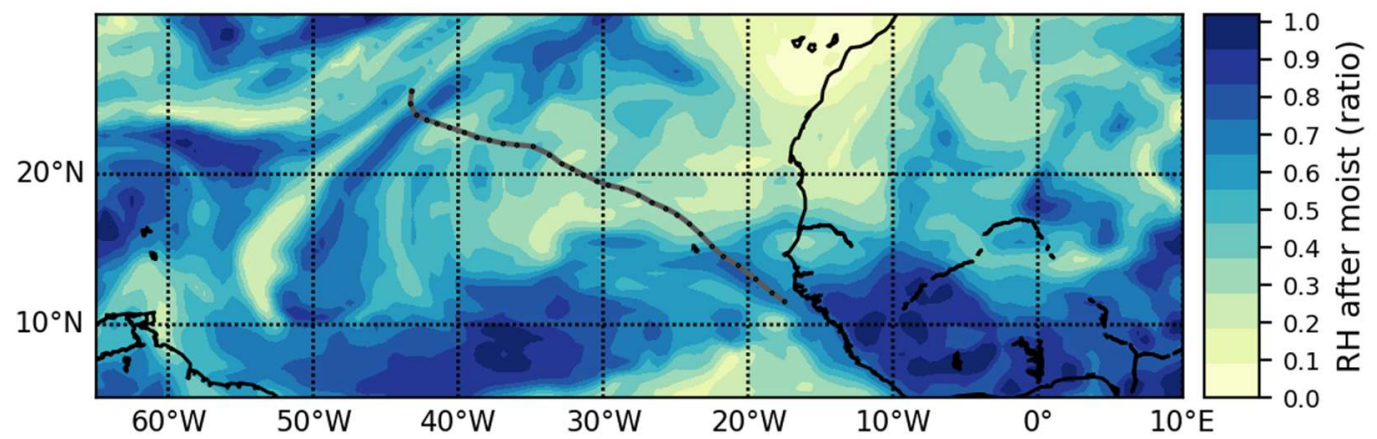

FIG. 75. RH at $700 \mathrm{hPa}$ for Hurricane Fred at 00 UTC 28 Aug 2015 from MERRA-2; grey line is the storm track with best locations (black dots) from NHC.

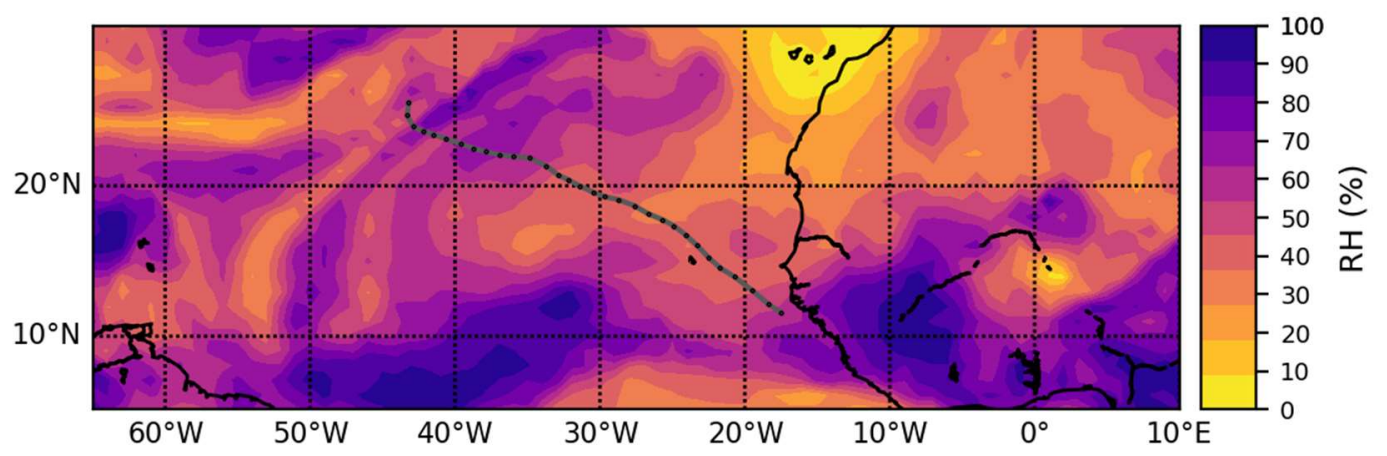

FIG. 76. RH at $700 \mathrm{hPa}$ for Hurricane Fred at 00 UTC 28 Aug 2015 from NCEP-FNL; grey line is the storm track with best locations (black dots) from NHC. 


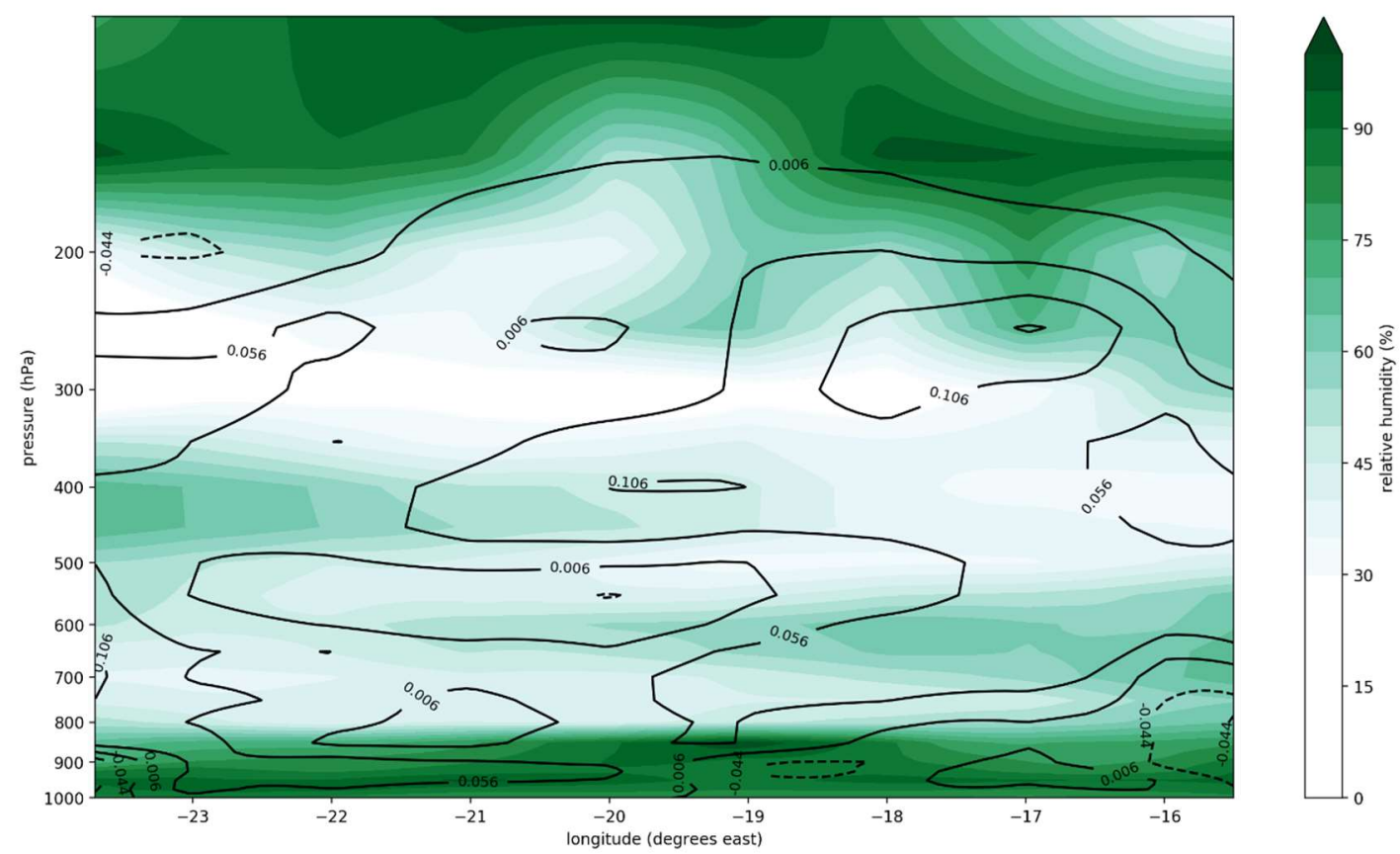

FIG. 77. Cross section of storm path from the first available best location $\left(11.6^{\circ} \mathrm{N},-15.5^{\circ} \mathrm{E}\right)$ to near the location of hurricane status $\left(14.6^{\circ} \mathrm{N},-23.7^{\circ} \mathrm{E}\right)$ for Hurricane Fred at $00 \mathrm{UTC} 28$ Aug 2015 from NCEPFNL; green contours indicate RH (\%); black lines indicate positive (solid) and negative (dotted) omega values $(\mathrm{Pa} / \mathrm{s})$.

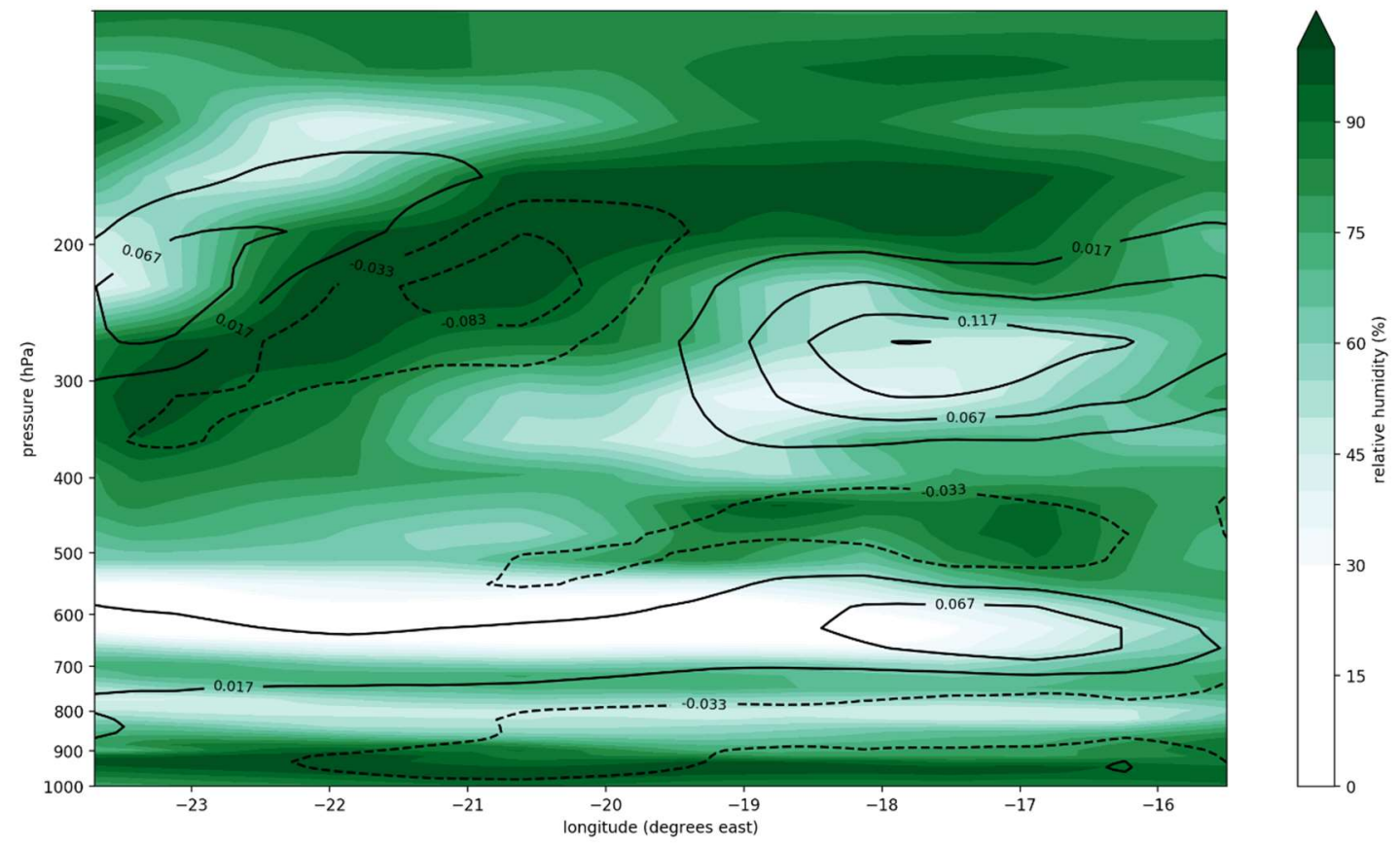

FIG. 78. Cross section of storm path from the first available best location $\left(11.6^{\circ} \mathrm{N},-15.5^{\circ} \mathrm{E}\right)$ to near the location of hurricane status $\left(14.6^{\circ} \mathrm{N},-23.7^{\circ} \mathrm{E}\right)$ for Hurricane Fred at 00 UTC 28 Aug 2015 from MERRA-2; green contours indicate RH (\%); black lines indicate positive (solid) and negative (dotted) omega values $(\mathrm{Pa} / \mathrm{s})$. 


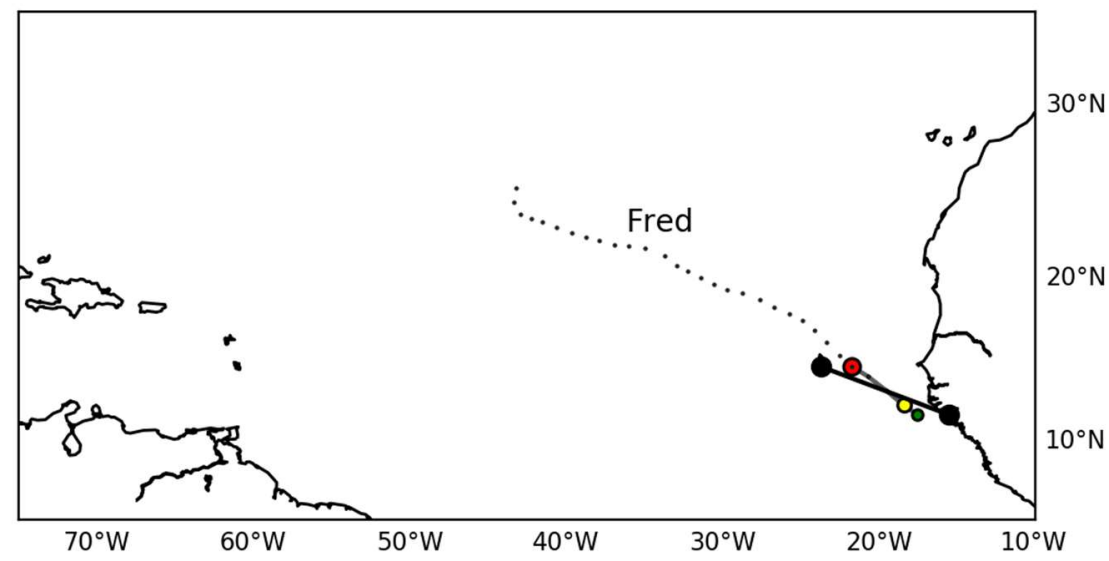

FIG. 79. Cross section path (large black dots, thick black line) for analysis portion of Hurricane Fred's storm track; similar to FIG. 1.

\section{2) T= -2 STARTING AT 00 UTC 29 AUg 2015}

At $700 \mathrm{hPa}$ in the NCEP-FNL data, dry air values began to appear 2 days before hurricane status was declared. At 06 UTC 29 Aug, 25.4\% RH was recorded, occurring 3 days ahead. On 12 UTC 29 Aug, three storm positions showed low RH values of $26.0 \%$, $18.6 \%$ and $22.5 \%$ at future storm locations of 12 UTC Aug 31, 06 UTC 01 Sep and 12 UTC 01 Sep; these locations were 2-3 days ahead of the TC. At 18 UTC 29 Aug, 3 RH values, $30.2 \%, 19.9 \%$ and $25.7 \% \mathrm{RH}$ were observed at storm locations 2 to 2 days +18 hours ahead of the actual storm location. Likewise, RH contours indicated dry air traversing over the storm track (Fig. 80).

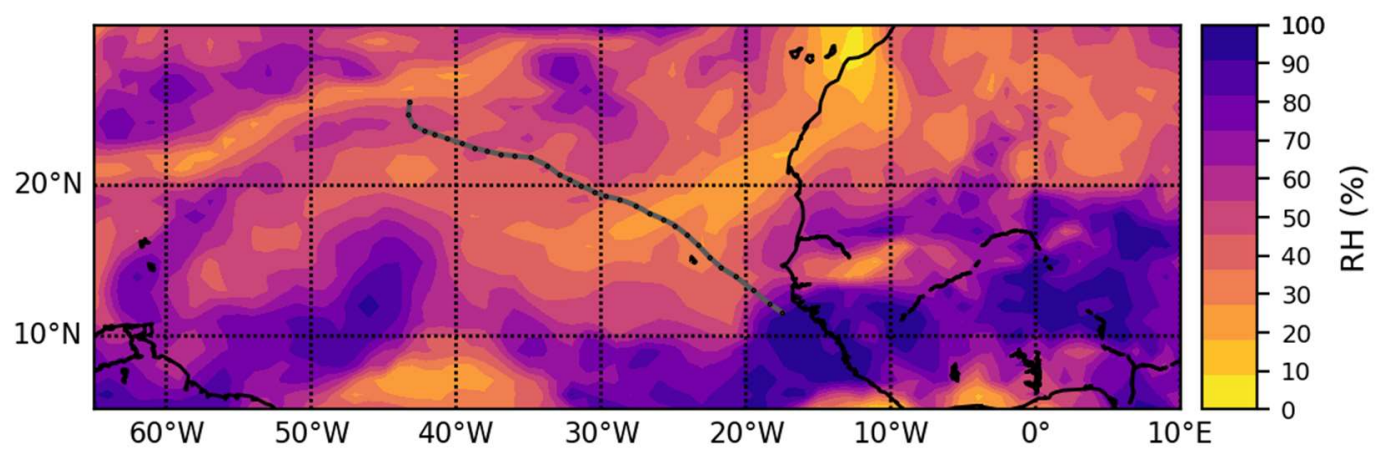

FIG. 80. RH at $700 \mathrm{hPa}$ for Hurricane Fred at 12 UTC 29 Aug 2015 from NCEP-FNL; grey line is the storm track with best locations (black dots) from NHC. 
Numerous instances of dry air were also found in MERRA-2. Starting on 00 UTC 29 Aug, three storm locations starting 2 days and 6 hours ahead (06 UTC 31 Aug) recorded dry air values of $0.292,0.277$, and 0.265 ; the location where the storm would pass on 18 UTC 31 Aug was the exception in the sequential locations. However, in the next time points, 09 and 12 UTC 29 Aug, dry air began at the location when the storm would pass on 00 UTC 31 Aug, which is about 1 day 15 hours and 1 day 12 hours ahead. The next subsequent storm locations until the 3 day parameter also indicated dry air presence. For 15 and 18 UTC 29 Aug, storm positions starting at the future location of 06 UTC 31 Aug recorded dry air less than 0.30 . The value sets $(0.186,0.213,0.296,0.264,0.231,0.203)$ and $(0.242,0.213,0.284,0.246,0.227,0.213,0.252)$ corresponded with the previous time points. On 21 UTC Aug, $0.221,0.267,0.231,0.244,0.233$, and 0.285 were noted, starting at the storm location of 12 UTC 31 Aug, which is 1 day 15 hours ahead. FIG. 81 visualized an example of the dry air traversing parts of the storm path at $700 \mathrm{hPa}$.

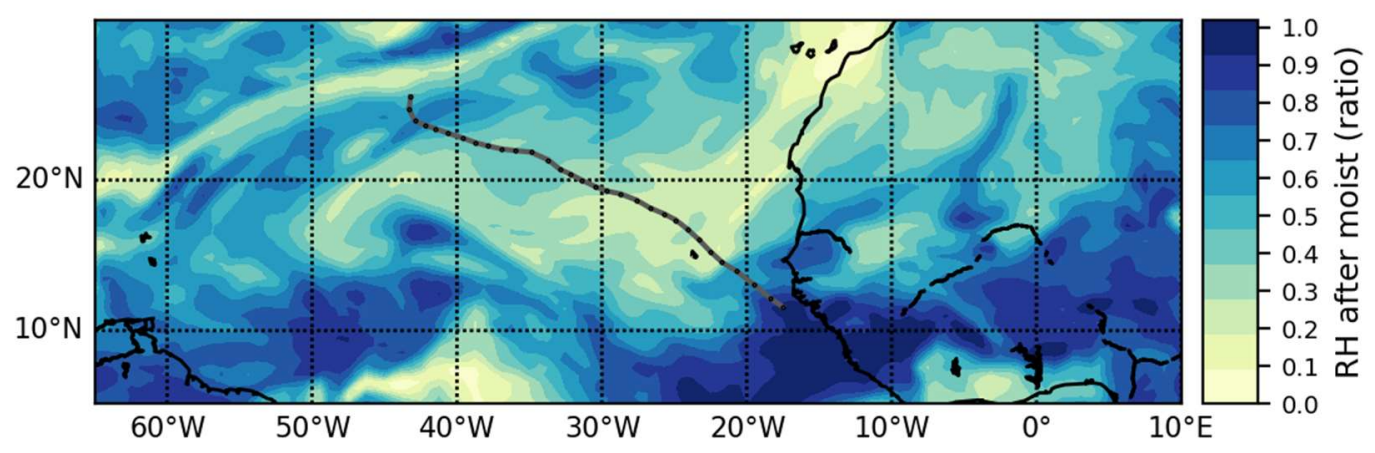

FIG. 81. RH at $700 \mathrm{hPa}$ for Hurricane Fred at 12 UTC 29 Aug 2015 from MERRA-2; grey line is the storm track with best locations (black dots) from NHC.

Further evidence of dry air in other pressure levels was also observed. A strong continuous dry air mass was evident in the SAL dry air imagery product (Fig. 82, Fig. 
83). The cross sections of the storm path also corresponded to the satellite images (Fig. 84, Fig. 85). Large areas of rising motion were also seen in both cross sections (Fig. 84, Fig. 85). Some type of circulation or winds appeared to have been captured as these features were present in front of Fred's precursor. In regards to the dry air presence in the surrounding environment, cloud density appeared to increase between 00 UTC 29 Aug and 18 UTC 29 Aug 2015, possibly due to the precursor moving from land to the Atlantic Ocean (Fig. 82, Fig. 83).

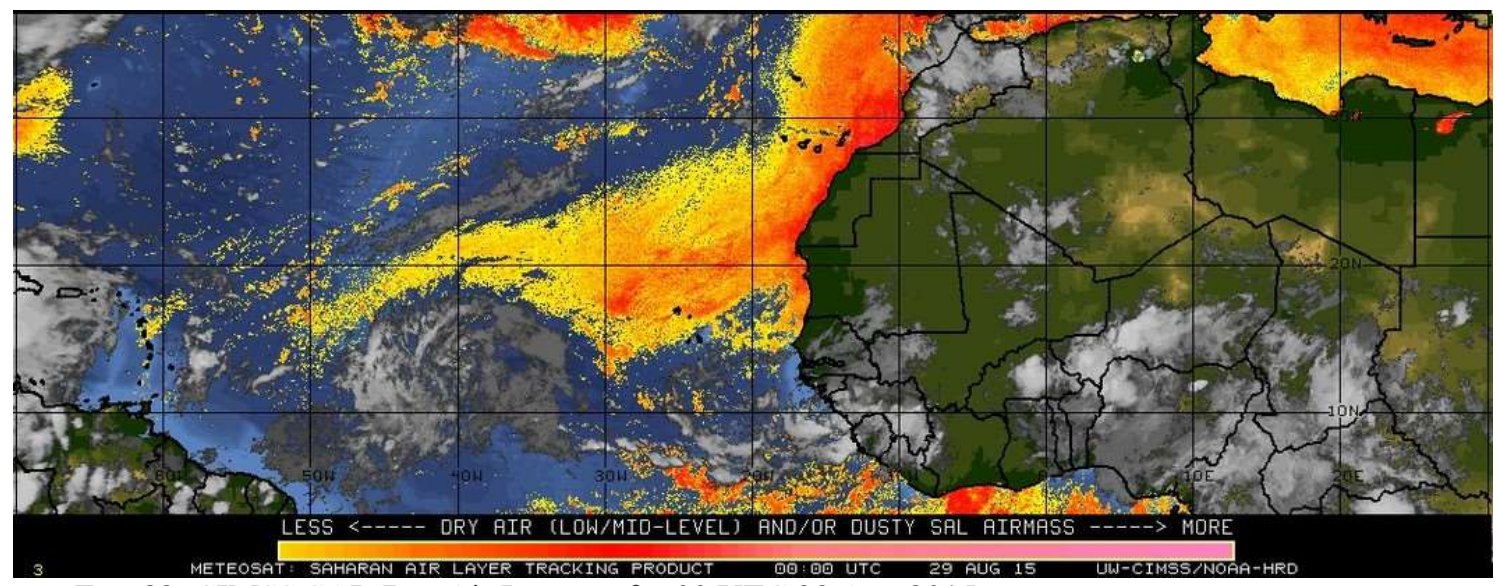

FIG. 82. CIMSS SAL-Dry Air Imagery for 00 UTC 29 Aug 2015.

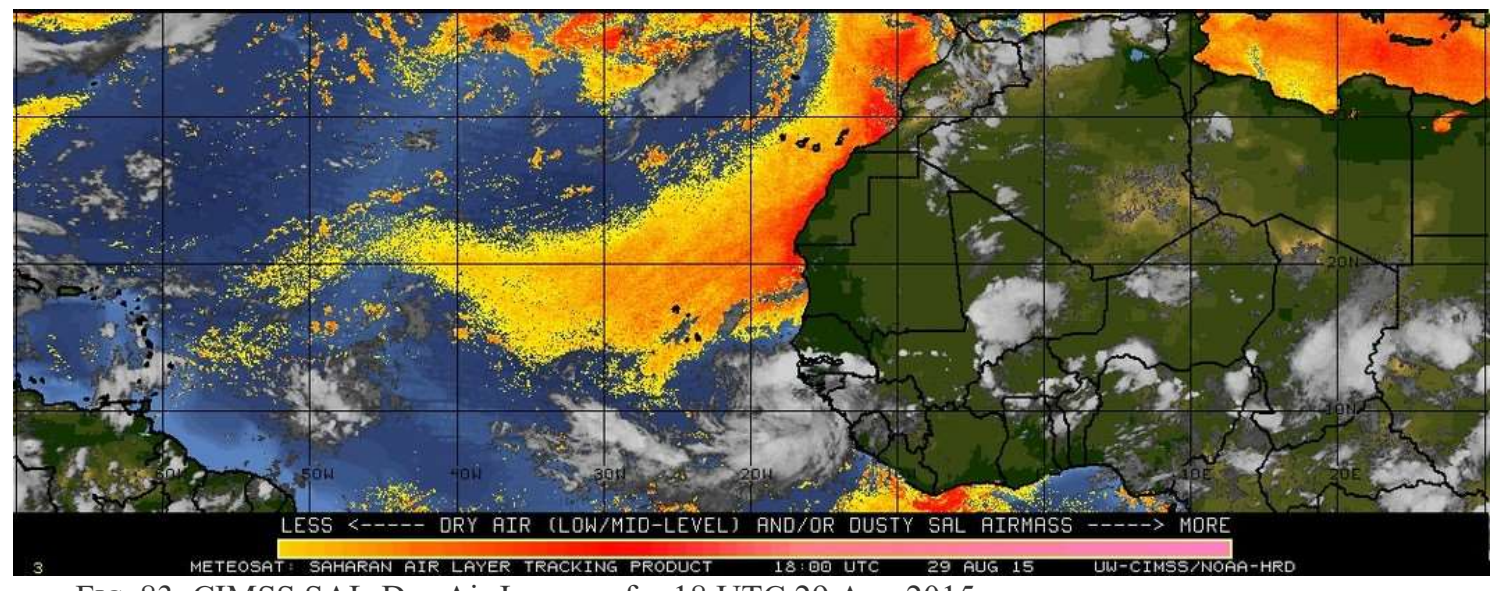

FIG. 83. CIMSS SAL-Dry Air Imagery for 18 UTC 29 Aug 2015. 


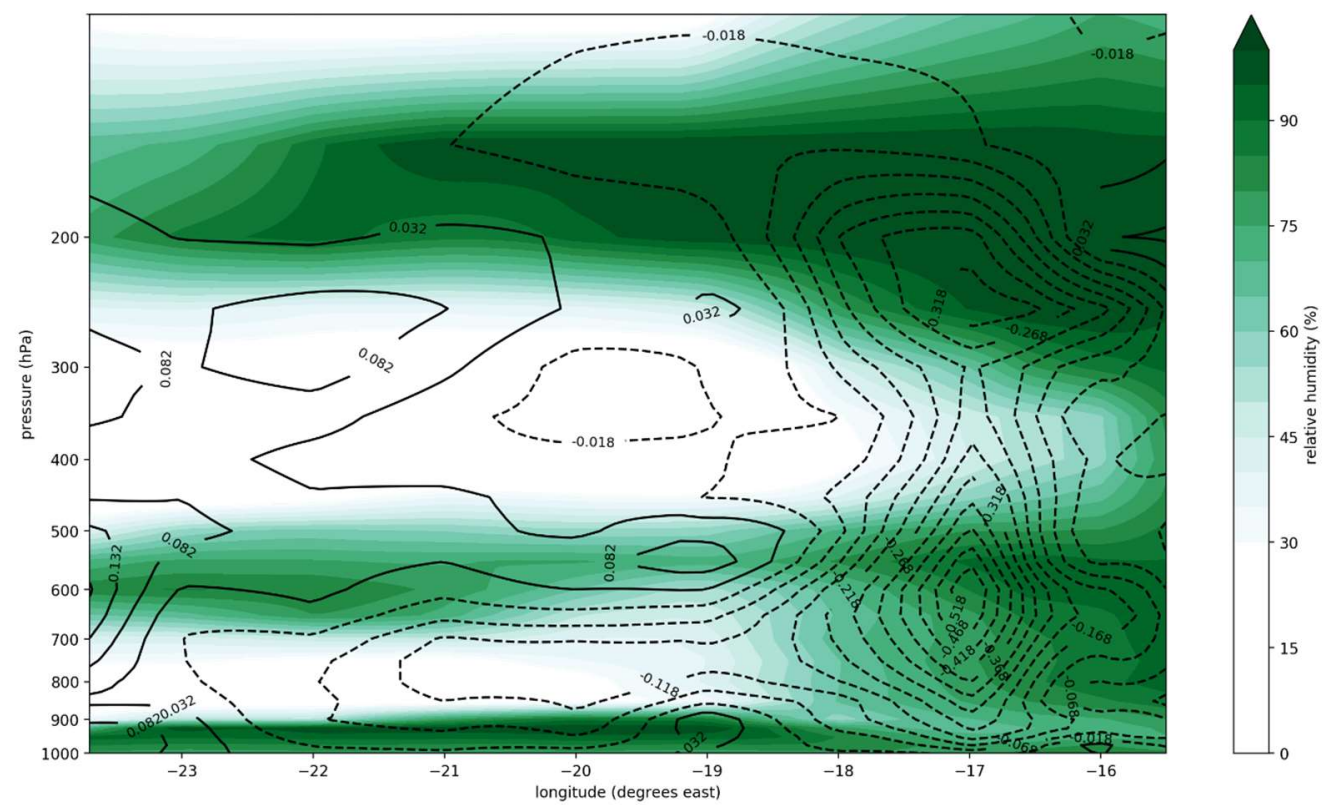

FIG. 84. Cross section of storm path from the first available best location $\left(11.6^{\circ} \mathrm{N},-15.5^{\circ} \mathrm{E}\right)$ to near the location of hurricane status $\left(14.6^{\circ} \mathrm{N},-23.7^{\circ} \mathrm{E}\right)$ for Hurricane Fred at 06 UTC 29 Aug 2015 from NCEPFNL; green contours indicate RH (\%); black lines indicate positive (solid) and negative (dotted) omega values $(\mathrm{Pa} / \mathrm{s})$.

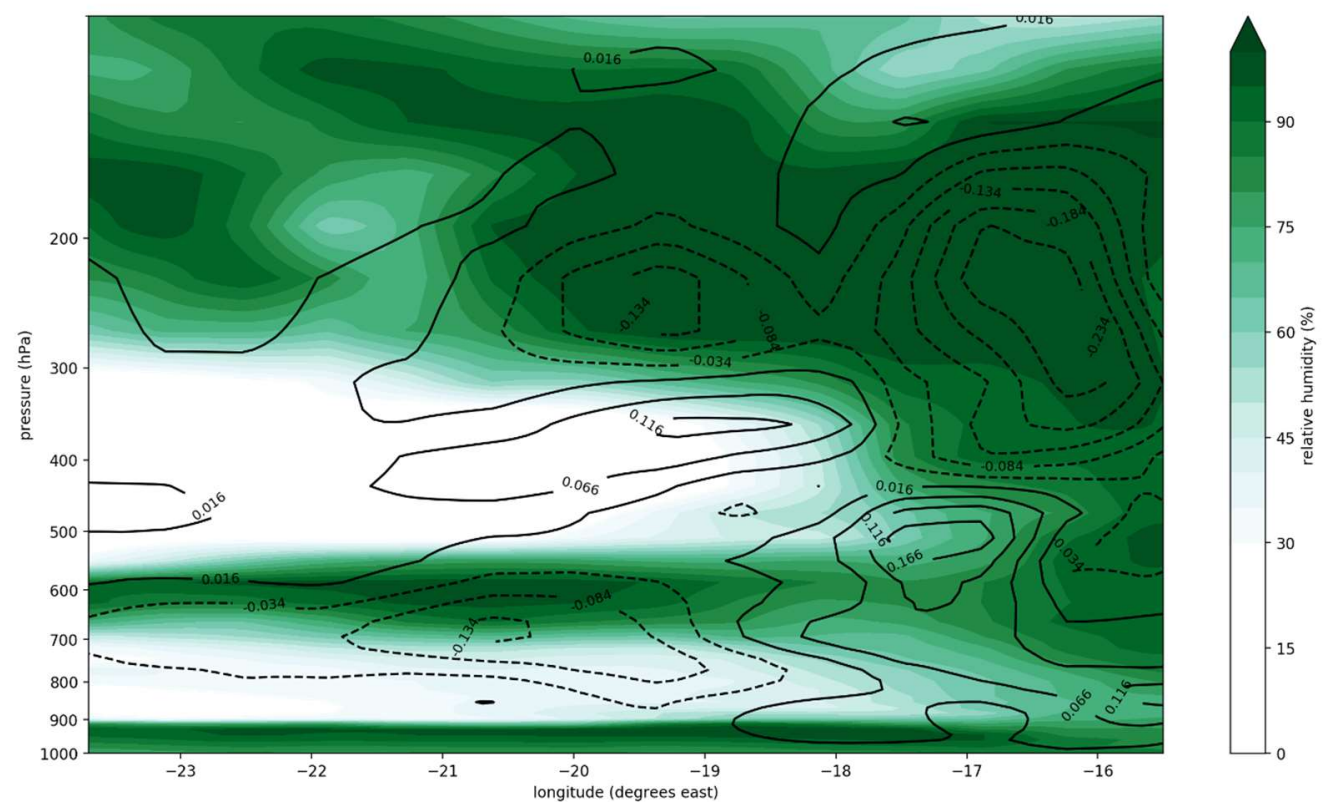

FIG. 85. Cross section of storm path from the first available best location $\left(11.6^{\circ} \mathrm{N},-15.5^{\circ} \mathrm{E}\right)$ to near the location of hurricane status $\left(14.6^{\circ} \mathrm{N},-23.7^{\circ} \mathrm{E}\right)$ for Hurricane Fred at 00 UTC 29 Aug 2015 from MERRA-2; green contours indicate RH (\%); black lines indicate positive (solid) and negative (dotted) omega values $(\mathrm{Pa} / \mathrm{s})$. 


\section{3) T= -1 STARTING AT 00 UTC 30 AUg 2015}

Dry air remained present north of the storm, cutting across Cape Verde and overlapping the majority of the storm track (Fig. 86, Fig. 87, Fig. 88, Fig. 89, Fig. 90,

Fig. 91). Possible plumes of convective activity could be evident from the visible satellite imagery (Fig. 86, Fig. 87). Cross sections displayed dry air in the upper and lower atmospheric levels, though moist air overtook the vertical layers as Fred traverse through (Fig. 92, Fig. 93). In addition, dry air was also present ahead of the TC in the upper levels around $400 \mathrm{hPa}$ to above $200 \mathrm{hPa}$ and in the lower troposphere around 850 900 hPa (Fig. 92, Fig. 93).

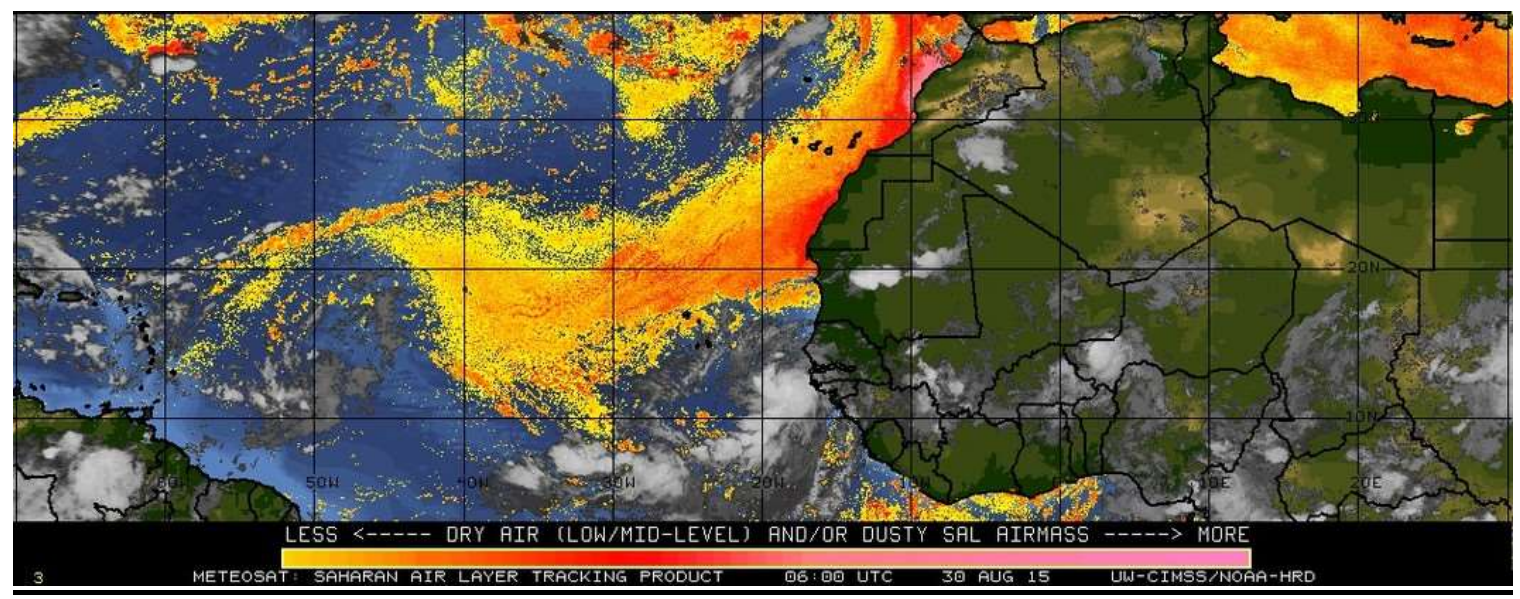

FIG. 86. CIMSS SAL-Dry Air Imagery for 06 UTC 30 Aug 2015. 


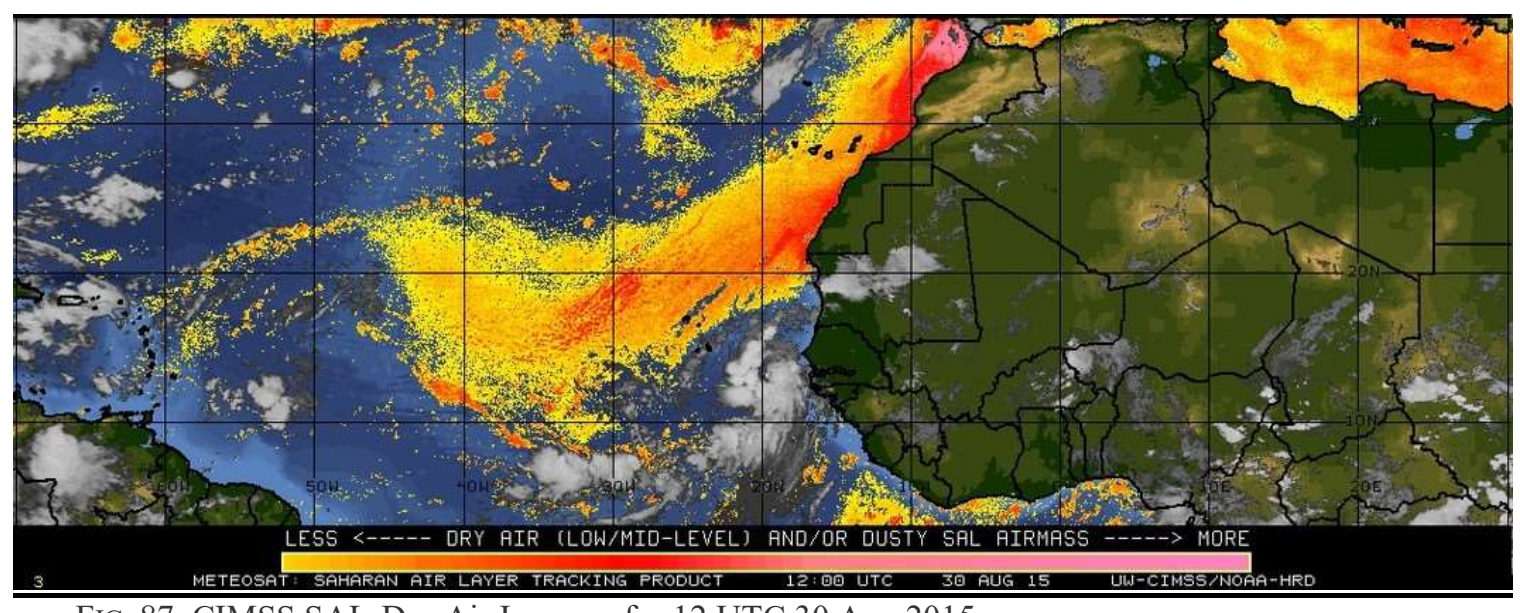

FIG. 87. CIMSS SAL-Dry Air Imagery for 12 UTC 30 Aug 2015.

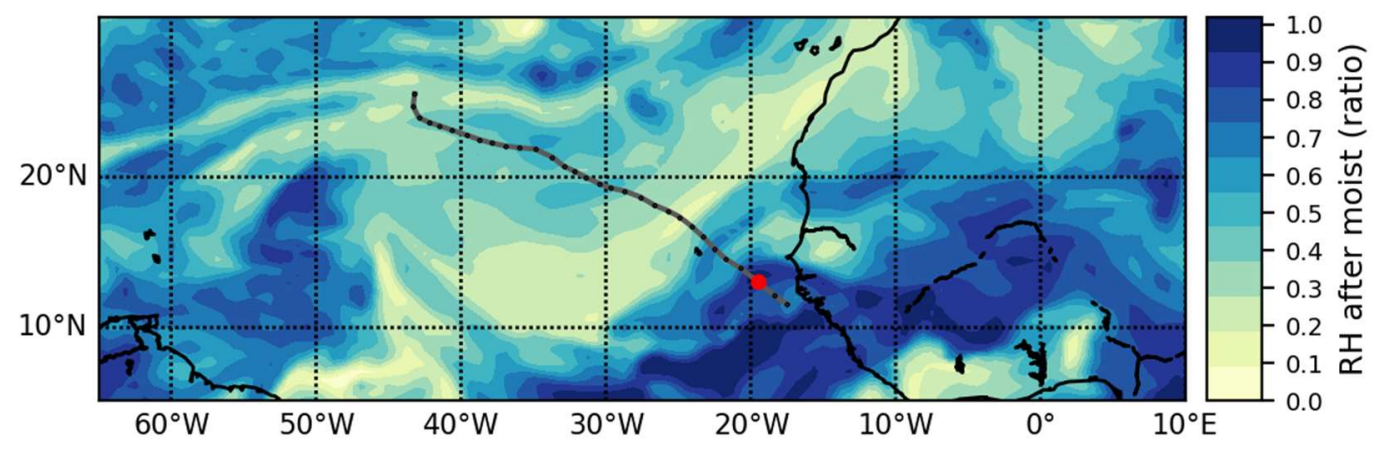

FIG. 88. RH at $700 \mathrm{hPa}$ for Hurricane Fred at 12 UTC 30 Aug 2015 from MERRA-2; grey line is the storm track with best locations (black dots) from NHC. red dot indicates the TC location at the given time point.

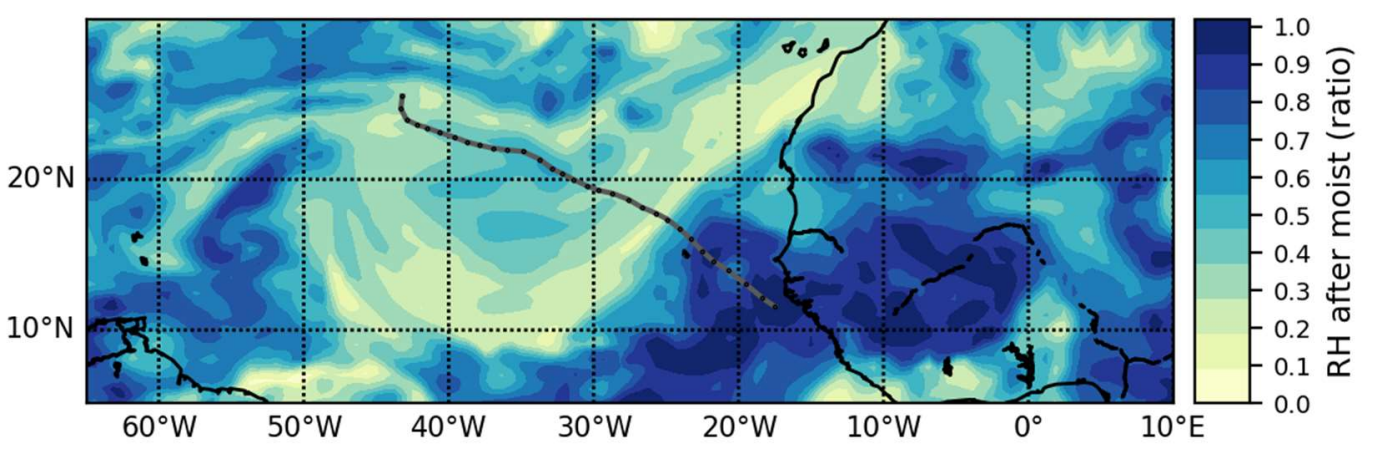

FIG. 89. RH at $700 \mathrm{hPa}$ for Hurricane Fred at 21 UTC 30 Aug 2015 from MERRA-2; grey line is the storm track with best locations (black dots) from NHC. 


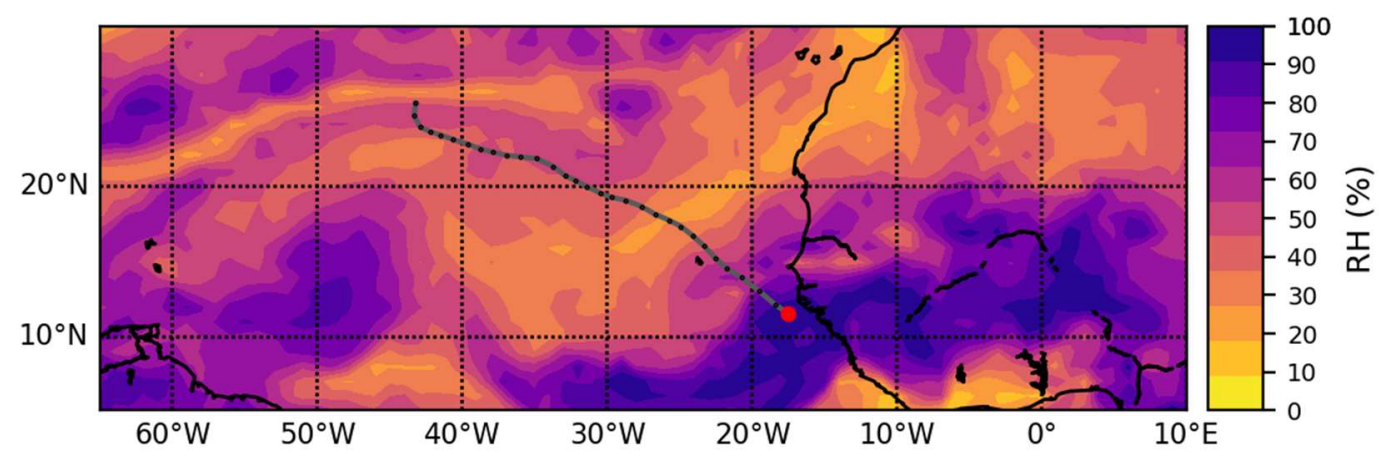

FIG. 90. RH at $700 \mathrm{hPa}$ for Hurricane Fred at 00 UTC 30 Aug 2015 from NCEP-FNL; grey line is the storm track with best locations (black dots) from NHC; red dot indicates the TC location at the given time point.

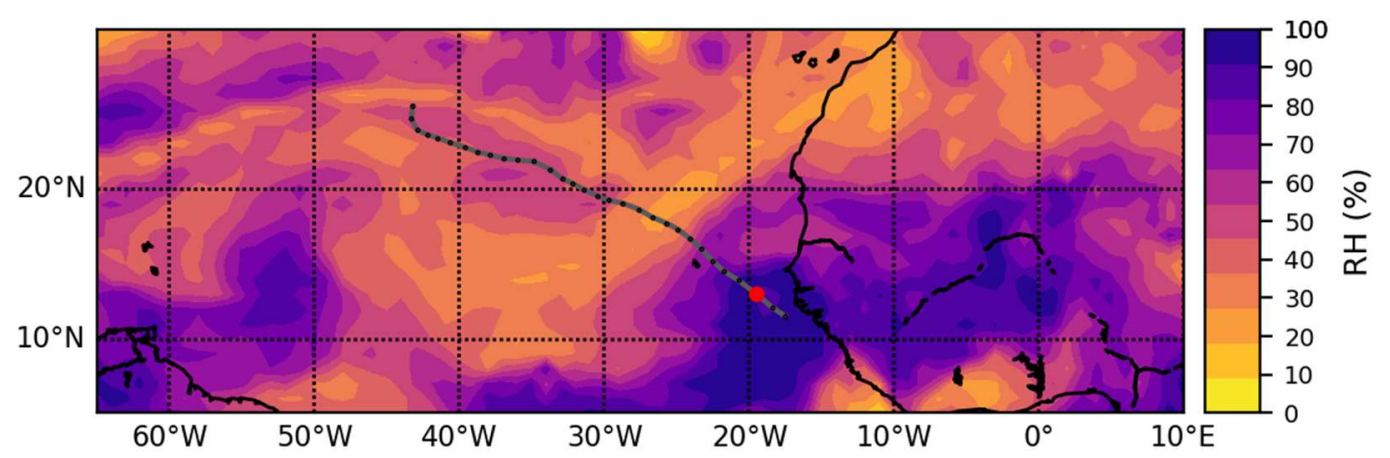

FIG. 91. RH at $700 \mathrm{hPa}$ for Hurricane Fred at 12 UTC 30 Aug 2015 from NCEP-FNL; grey line is the storm track with best locations (black dots) from $\mathrm{NHC}$; red dot indicates the TC location at the given time point. 


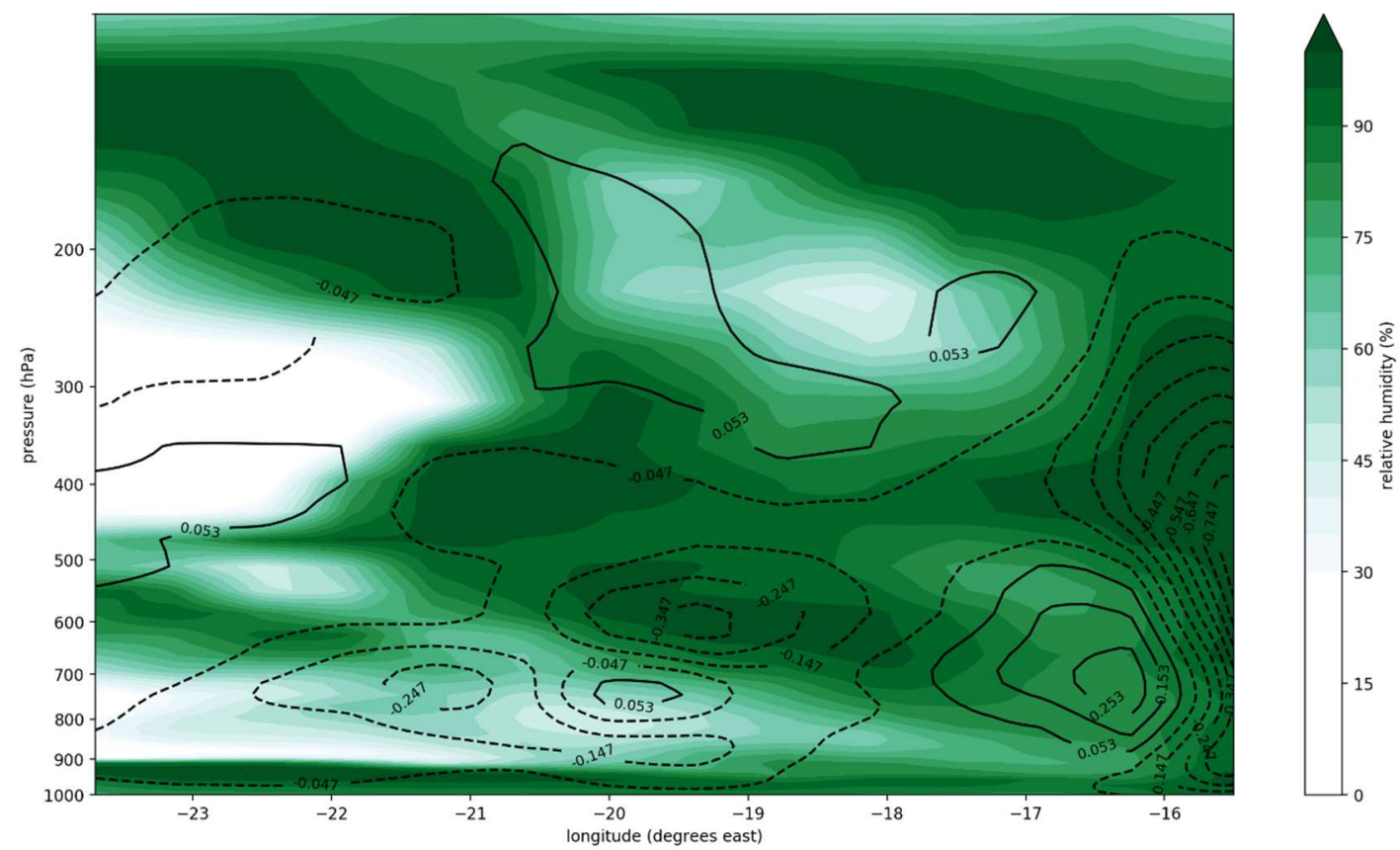

FIG. 92. Cross section of storm path from the first available best location $\left(11.6^{\circ} \mathrm{N},-15.5^{\circ} \mathrm{E}\right)$ to near the location of hurricane status $\left(14.6^{\circ} \mathrm{N},-23.7^{\circ} \mathrm{E}\right)$ for Hurricane Fred at 03 UTC 30 Aug 2015 from MERRA-2; green contours indicate RH (\%); black lines indicate positive (solid) and negative (dotted) omega values $(\mathrm{Pa} / \mathrm{s})$.

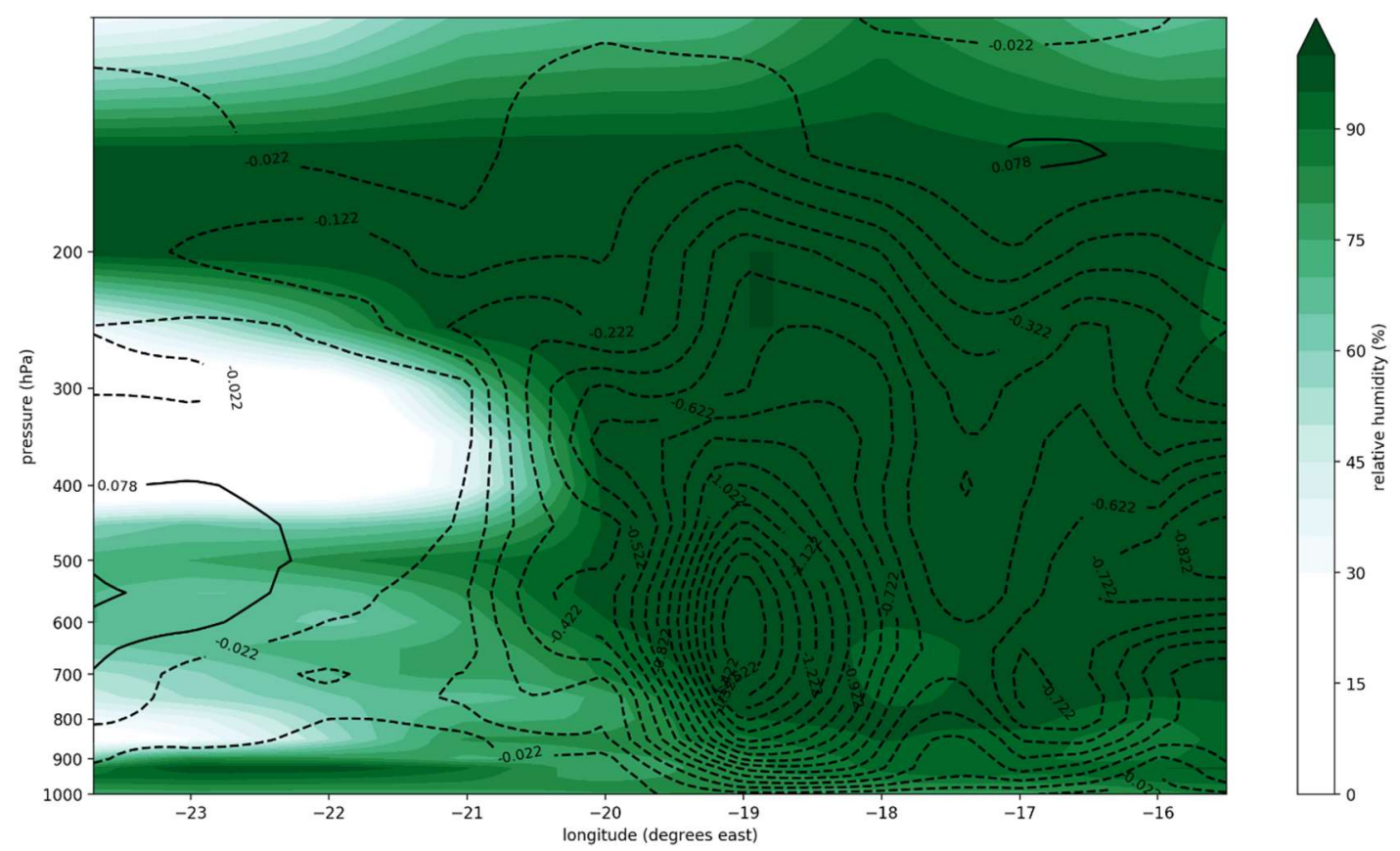

FIG. 93. Cross section of storm path from the first available best location $\left(11.6^{\circ} \mathrm{N},-15.5^{\circ} \mathrm{E}\right)$ to near the location of hurricane status $\left(14.6^{\circ} \mathrm{N},-23.7^{\circ} \mathrm{E}\right)$ for Hurricane Fred at 06 UTC 30 Aug 2015 from NCEPFNL; green contours indicate RH (\%); black lines indicate positive (solid) and negative (dotted) omega values $(\mathrm{Pa} / \mathrm{s})$. 
The frequency of RH values within 3 days of the time and location also reflected a strong presence of dry air in both datasets. More details about the RH values found at 700 $\mathrm{hPa}$ are as follows:

\section{a) NCEP-FNL at $700 \mathrm{hPa}$}

On 00 UTC 30 Aug 1 day before hurricane stage and reaching TD intensity, the future location on 18 UTC 31 Aug to 06 UTC 01 Sep showed 29.7\%, 28.5\% and 24.4\% RH values, 1 day 18 hours to 2 days 6 hours ahead. Upon reaching TS status on 06 UTC 30 Aug, only two spots recorded lower than $30 \% \mathrm{RH}$ values, $29.0 \%$ and $27.7 \% \mathrm{RH}$ at the storm positions for $06 \mathrm{UTC}$ and 12 UTC 01 Sep. At the next time point of 12 UTC 30 Aug, $26.6 \%$ and $25.1 \%$ RH were recorded at the same storm positions as before, only 1 day 12 hours and 1 day 18 hours ahead. Likewise, the same storm positions were also shared with the next time point of 18 UTC 30 Aug in addition to the storm position for 18 UTC 01 Sep; the corresponding RH values were $27.3 \%, 22.6 \%$ and $28.5 \% \mathrm{RH}$, occurring 2 days and earlier. In addition, two more positions located where the TC would pass on 12 UTC and 18 UTC 02 Sep registered 29.8\% and 27.4\% RH at 18 UTC 30 Aug.

\section{b) MERRA-2 at $700 \mathrm{hPa}$}

Compared to the previous day with MERRA-2, less dry occurrences frequented the storm track. On 00 UTC 30 Aug, $0.251,0.252,0.241,0.257$, and 0.271 were the RH values that started at the storm position of 12 UTC 31 Aug, 1 day 12 hours ahead. Three hours ahead in time, $0.239,0.227,0.255$, and 0.282 were the $\mathrm{RH}$ values recorded starting at future storm location of 12 UTC 31 Aug, 1 day 15 hours ahead of the time point. On 06 UTC 30 Aug, three locations starting with storm positions for 18 UTC 31 Aug showed 
dry air values, $0.211,0.229$ and 0.295 . In the next 3 hours, only 2 storm positions starting at 1 day 9 hours ahead showed low RH values of 0.19 and 0.22 . On 12 UTC and 15 UTC 30 Aug, the RH values of $0.197,0.1884$ and 0.266 and $0.285,0.150$, and 0.249 were recorded for the same storm positions less than 2 days away. On 18 UTC and 21 UTC 30 Aug, the same two storm positions, 00 UTC and 06 UTC 01 Sep, recorded values 0.154 and 0.260 , and 0.258 and 0.244 , respectively. On the day TS Fred became a hurricane, one $\mathrm{RH}$ value, 0.259 was recorded 1 day 6 hours ahead.

A period of six hours made a large difference in the appearance of the storm, similar to Hurricane Danny's development (next section). At 06 UTC 30 Aug, the clouds appeared more wispy compared to signs of high convective activity at 12 UTC 30 Aug (Fig. 86, Fig. 87). RH contours with MERRA-2 did not appear to significantly different at these time points; however, an observable increase in humid area around the storm center continued from 12 UTC 30 Aug to 21 UTC 30 Aug (Fig. 88, Fig. 89). The change was more noticeable starting at 00 UTC 30 Aug in NCEP-FNL (Fig. 90,

Fig. 91).

\section{4) T= 0 STARTING AT 00 UTC 31 AUg 2015}

When Fred was upgraded to a hurricane, six future storm locations were observed with $30 \%$ and lower RH values at the associated future storm locations in NCEP-FNL: 26.3\% (12 UTC $01 \mathrm{Sep}$ ), 27.8\% (18 UTC $01 \mathrm{Sep}$ ), 28.8\% (12 UTC $02 \mathrm{Sep}$ ), 29.4\% (18 UTC $02 \mathrm{Sep}$ ), and 29.2\% (00 UTC $03 \mathrm{Sep}$ ). In contrast, one RH value, 0.259 was recorded 1 day 6 hours ahead in MERRA-2. 
CIMSS's imagery showed dry air surrounding west and north areas of the Hurricane Fred (2015) (Fig. 94). RH data from NCEP-FNL and MERRA-2 at $700 \mathrm{hPa}$ also reflected similar regions with dry air (Fig. 95, Fig. 96). In contrast, the cross sections of the approximate storm path displayed dry air in opposite physical locations. An area of low RH was observed behind the hurricane in NCEP-FNL while dry air spanned the upper levels from MERRA-2 (Fig. 97, Fig. 98). These differences may reflect a discrepancy of the storm center between the two datasets.

Like for Hurricane Danny (refer to next section), the cross section of the TC also showed dry air on the western side, though the dry air did not span as large vertically as it did with Danny in the NCEP-FNL data (Fig. 99, Fig. 100). Dry air 30\% and less was observed from approximately $400 \mathrm{hPa}$ to $250 \mathrm{hPa}$. Below $400 \mathrm{hPa}$, the air was also on the drier side until around $900 \mathrm{hPa}$ (Fig. 99, Fig. 100). The NCEP-FNL cross section may be cutting into the eye of the hurricane as sinking air is noted in the center flanked by two rising motions (Fig. 99). The rising air on the western side appeared to contain more moisture compared to that on the eastern direction. If the cross section was cutting through the center of the storm $\left(15.1^{\circ} \mathrm{N},-22.0^{\circ} \mathrm{E}\right)$, the hurricane depicted in NCEP-FNL was off the mark of the NHC best location $\left(14.6^{\circ} \mathrm{N},-21.7^{\circ} \mathrm{E}\right)$ by about $0.58^{\circ}$ or almost 65 $\mathrm{km}$. For MERRA-2, the cross sections did not appear to be cutting through the hurricane's center directly, despite the multiple attempts, as the RH and omega did not clearly show where the eye, eyewalls or rainbands may be located (Fig. 100, Fig. 101). Rising moist and sinking dry air can be observed in the cross section of the storm track (Fig. 98) so it was unusual to not find the same vigorous activity in other cross sections. 


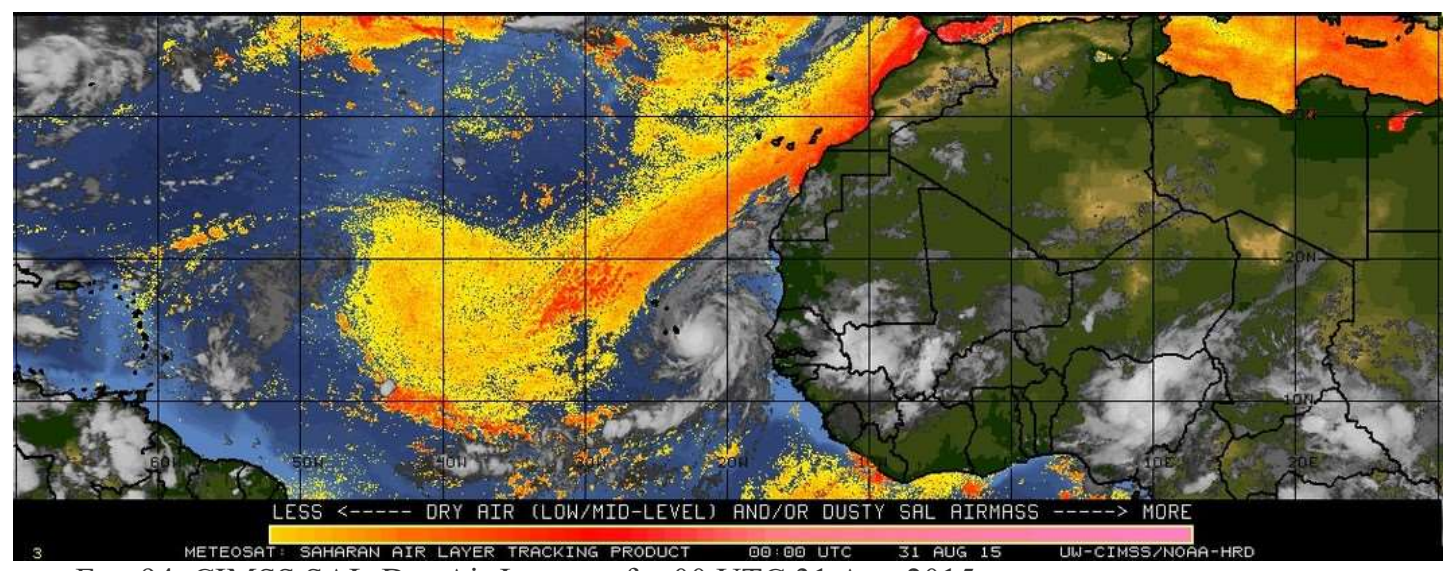

FIG. 94. CIMSS SAL-Dry Air Imagery for 00 UTC 31 Aug 2015.

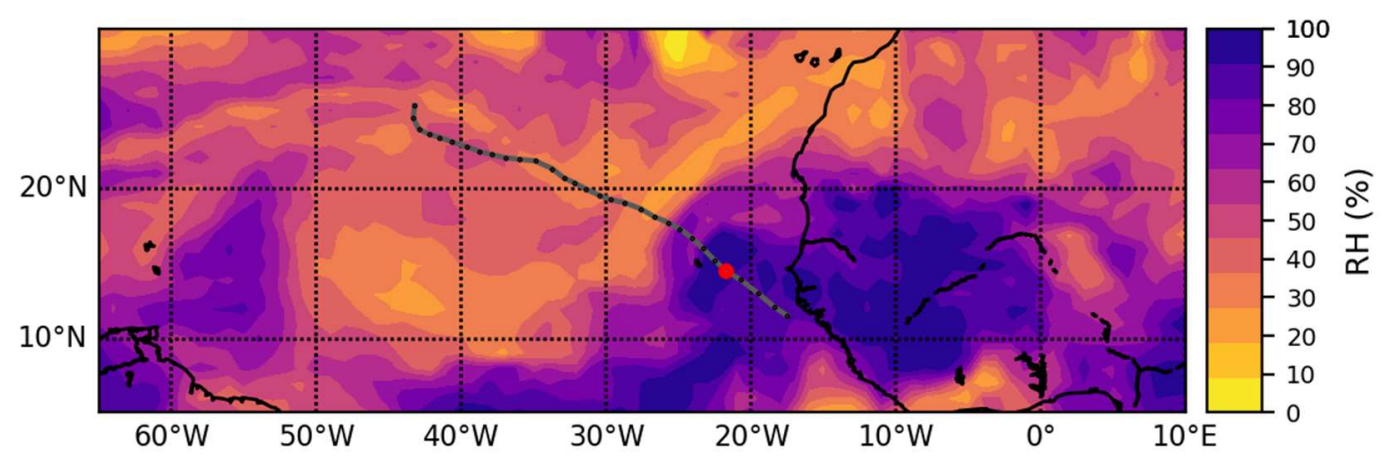

FIG. 95. RH at $700 \mathrm{hPa}$ for Hurricane Fred at 00 UTC 31 Aug 2015 from NCEP-FNL; grey line is the storm track with best locations (black dots) from NHC; red dot indicates the TC location when hurricane stage was declared.

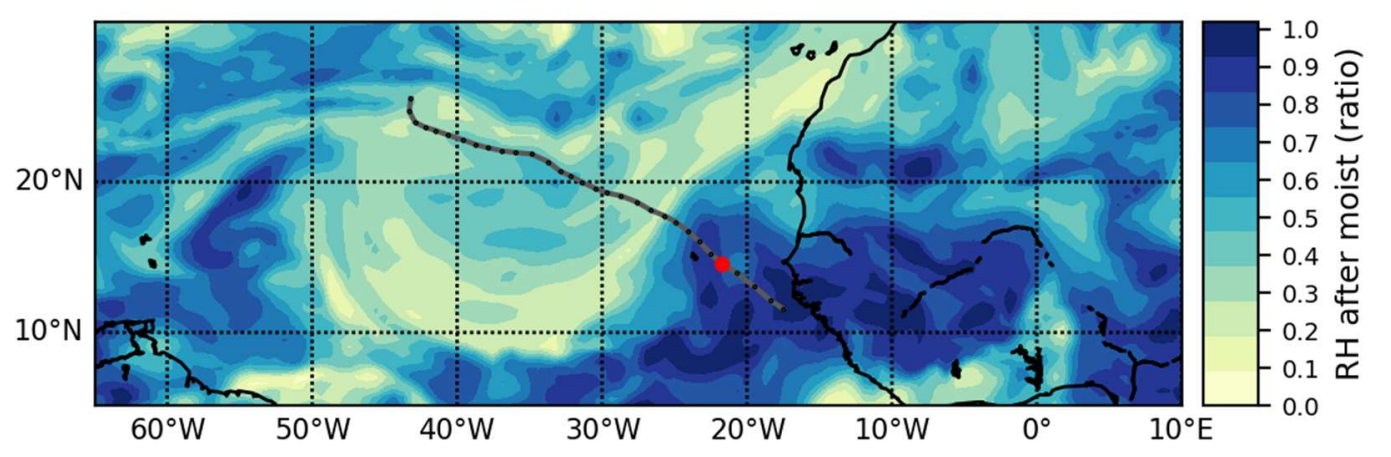

FIG. 96. RH at $700 \mathrm{hPa}$ for Hurricane Fred at 00 UTC 31 Aug 2015 from MERRA-2; grey line is the storm track with best locations (black dots) from NHC; red dot indicates the TC location when hurricane stage was declared. 


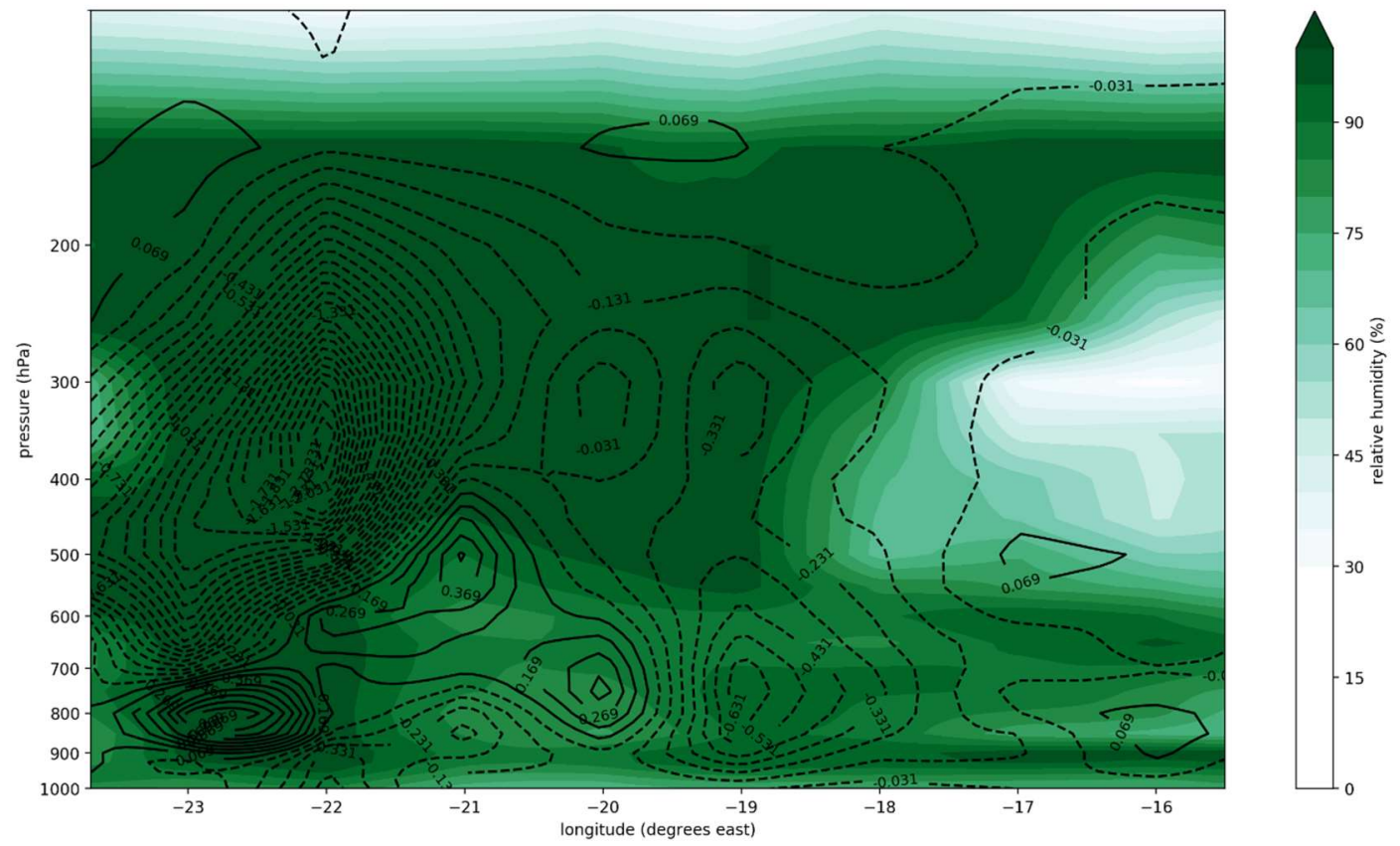

FIG. 97. Cross section of storm path from the first available best location $\left(11.6^{\circ} \mathrm{N},-15.5^{\circ} \mathrm{E}\right)$ to near the location of hurricane status $\left(14.6^{\circ} \mathrm{N},-23.7^{\circ} \mathrm{E}\right)$ for Hurricane Fred at 00 UTC 31 Aug 2015 from NCEPFNL; green contours indicate RH (\%); black lines indicate positive (solid) and negative (dotted) omega values $(\mathrm{Pa} / \mathrm{s})$.

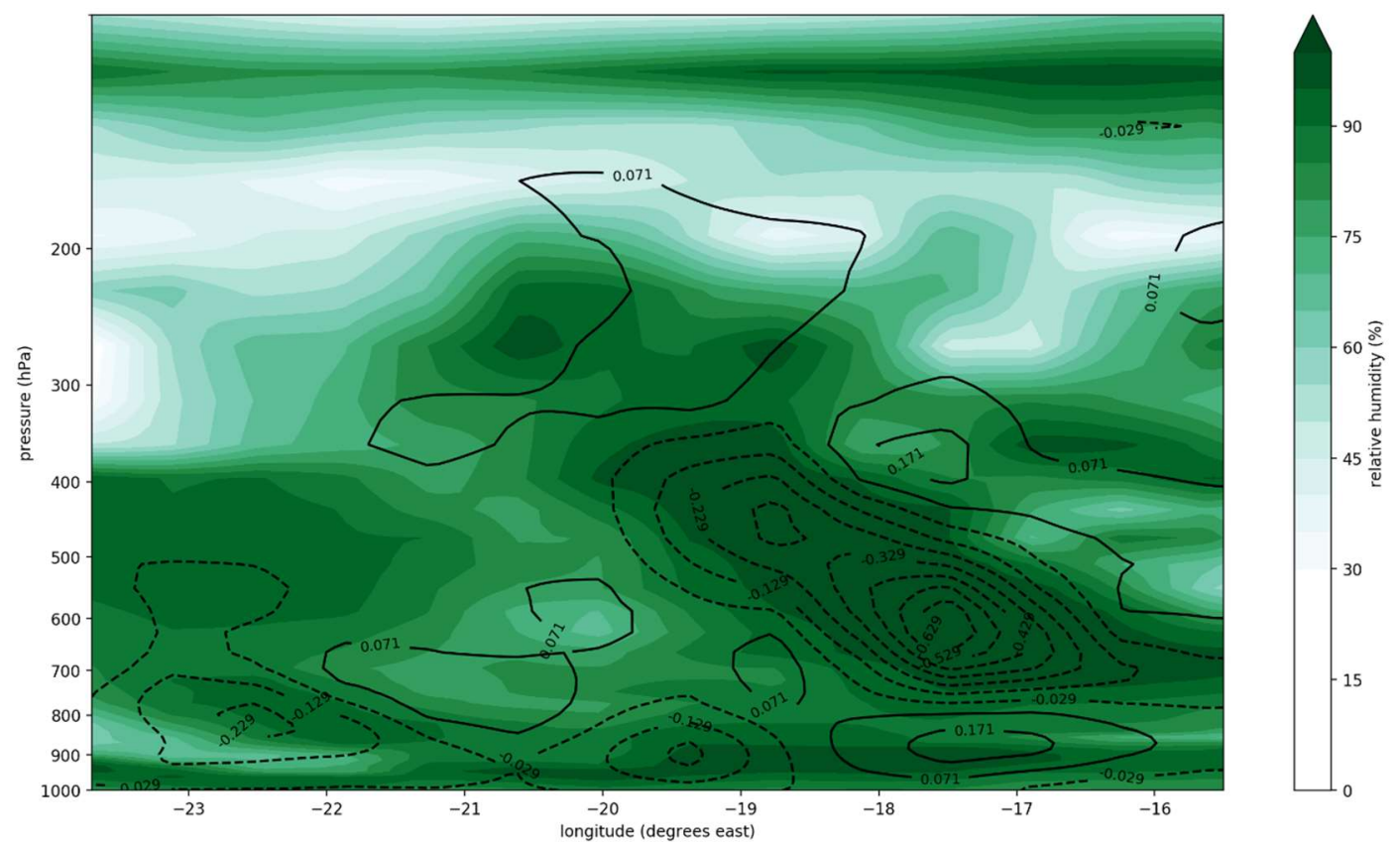

FIG. 98. Cross section of storm path from the first available best location $\left(11.6^{\circ} \mathrm{N},-15.5^{\circ} \mathrm{E}\right)$ to near the location of hurricane status $\left(14.6^{\circ} \mathrm{N},-23.7^{\circ} \mathrm{E}\right)$ for Hurricane Fred at 00 UTC 31 Aug 2015 from MERRA-2; green contours indicate RH (\%); black lines indicate positive (solid) and negative (dotted) omega values $(\mathrm{Pa} / \mathrm{s})$. 

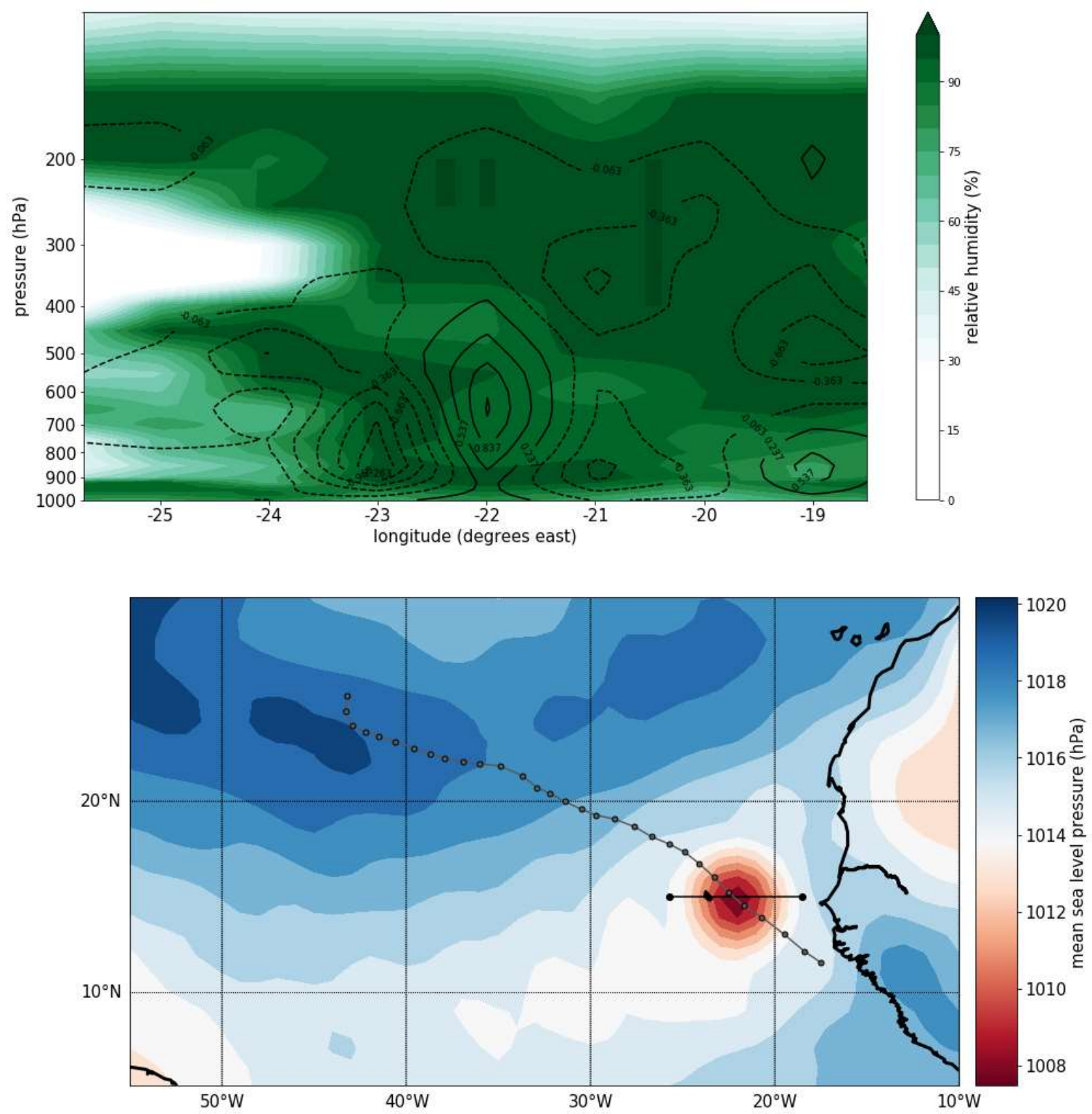

FIG. 99. (above) RH cross section beginning at $15.1^{\circ} \mathrm{N},-18.5^{\circ} \mathrm{E}$ to $15.1^{\circ} \mathrm{N},-25.7^{\circ} \mathrm{E}$ at $00 \mathrm{UTC} 31 \mathrm{Aug}$ 2015 for Hurricane Fred at hurricane stage from NCEP-FNL; green contours indicate RH; black lines indicate positive (solid) and negative (dotted) omega values; (below) cross section path with SLP; contours indicate the mean SLP; grey line with small black dots showing the entire storm path based on NHC's best locations; larger solid dots and black line shows the location of the cross section. 

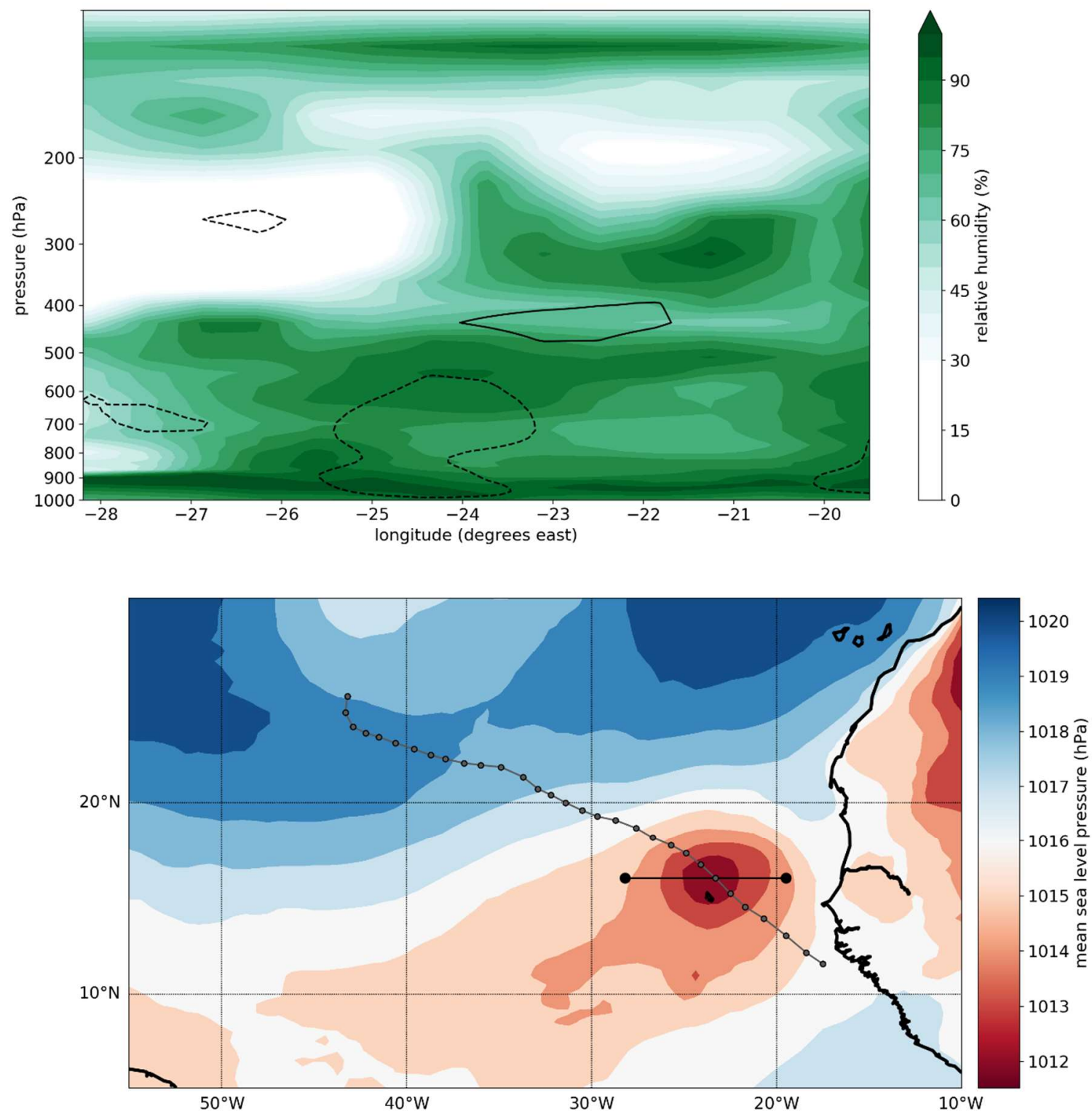

FIG. 100. (above) RH cross section beginning at $16.1^{\circ} \mathrm{N},-19.5^{\circ} \mathrm{E}$ to $16.1^{\circ} \mathrm{N},-28.2^{\circ} \mathrm{E}$ at $12 \mathrm{UTC} 31 \mathrm{Aug}$ 2015 for Hurricane Fred at hurricane stage from MERRA-2; green contours indicate RH (\%); black lines indicate positive (solid) and negative (dotted) omega values ( $\mathrm{Pa} / \mathrm{s}$ ); (below) cross section path with SLP; contours indicate the mean SLP; grey line with small black dots showing the entire storm path based on NHC's best locations; larger solid dots and black line shows the location of the cross section. 

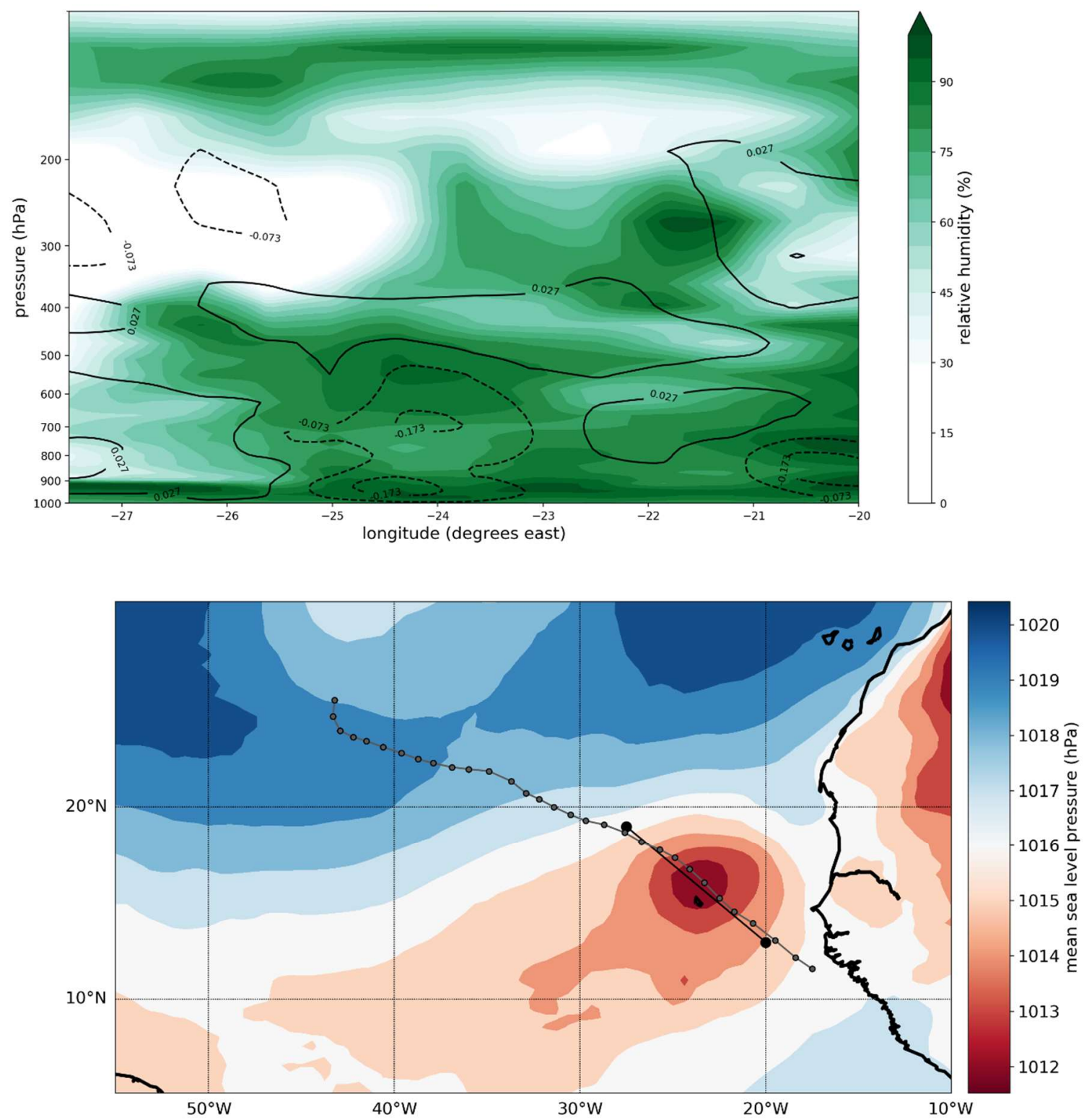

FIG. 101. (above) $\mathrm{RH}$ cross section beginning at $13.0^{\circ} \mathrm{N},-20.0^{\circ} \mathrm{E}$ to $19.0^{\circ} \mathrm{N},-27.5^{\circ} \mathrm{E}$ at $12 \mathrm{UTC} 31 \mathrm{Aug}$ 2015 for Hurricane Fred at hurricane stage from MERRA-2; green contours indicate RH (\%); black lines indicate positive (solid) and negative (dotted) omega values $(\mathrm{Pa} / \mathrm{s})$; (below) cross section path with SLP; contours indicate the mean SLP; grey line with small black dots showing the entire storm path based on NHC's best locations; larger solid dots and black line shows the location of the cross section. 


\section{f. Hurricane Danny}

1) $T=-3$ STARTING AT 12 UTC 17 AUg 2015

At $700 \mathrm{hPa}$, no dry air was observed on the storm path for Hurricane Danny at this time period in NCEP-FNL. In contrast, nearly all the dry air RH values from MERRA-2 were recorded during this time period, ranging from $0.198-0.300$. These were located 2 to almost 3 days ahead in time. Three of these values, 0.300, 0.299 and 0.274 , happened when TC Danny became a TD. Likewise, the contour plots indicated a highly moist environment around the same region and drier air north of the storm track (Fig. 102, Fig. 103). As the satellite imagery accounted for more pressure levels, the dry air appeared quite strong, suggesting that vertical levels above or below $700 \mathrm{hPa}$ was likely contributing to the overall lack of moisture. Since the cross section path generally matched the NHC storm track (Fig. 104), dry air stretching from the surface to the upper levels was evident ahead on the storm path (Fig. 105, Fig. 106). Although the dry air was located possibly beyond the 3 day limit as few RH values were recorded at the $700 \mathrm{hPa}$, the satellite imagery also showed a strong presence of dry air (Fig. 107).

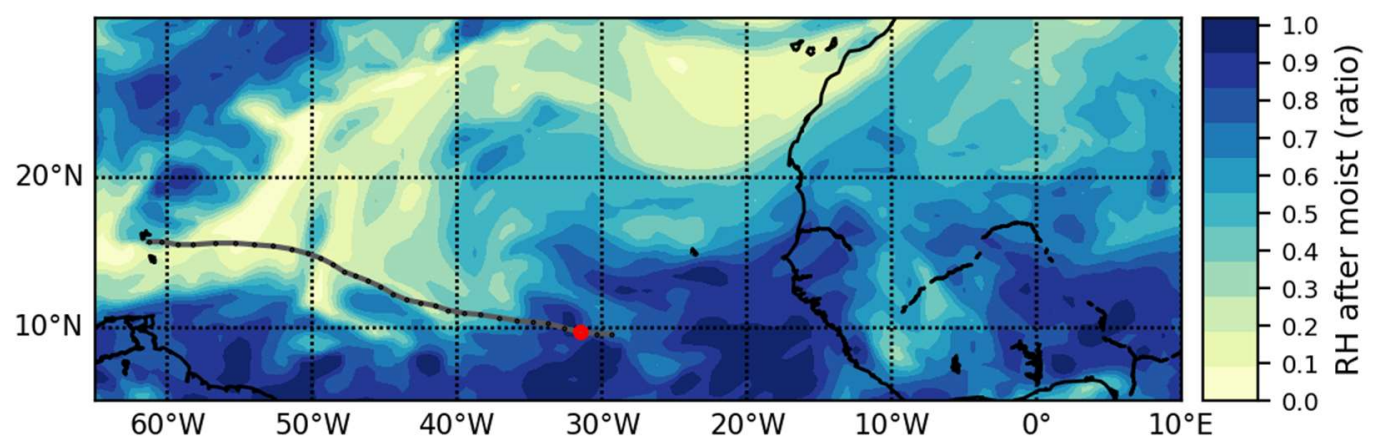

FIG. 102. RH at $700 \mathrm{hPa}$ for Hurricane Danny at 12 UTC 17 Aug 2015 from MERRA-2; grey line is the storm track with best locations (black dots) from NHC; red dot indicates the TC location at the given time point. 


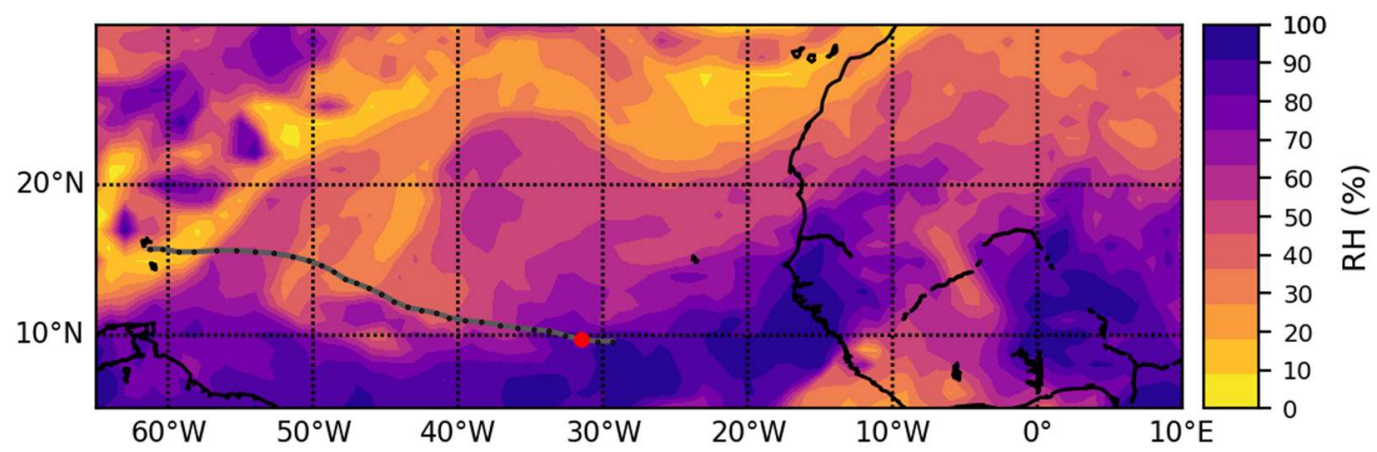

FIG. 103. RH at $700 \mathrm{hPa}$ for Hurricane Danny at 12 UTC 17 Aug 2015 from NCEP-FNL; grey line is the storm track with best locations (black dots) from NHC; red dot indicates the TC location at the given time point.

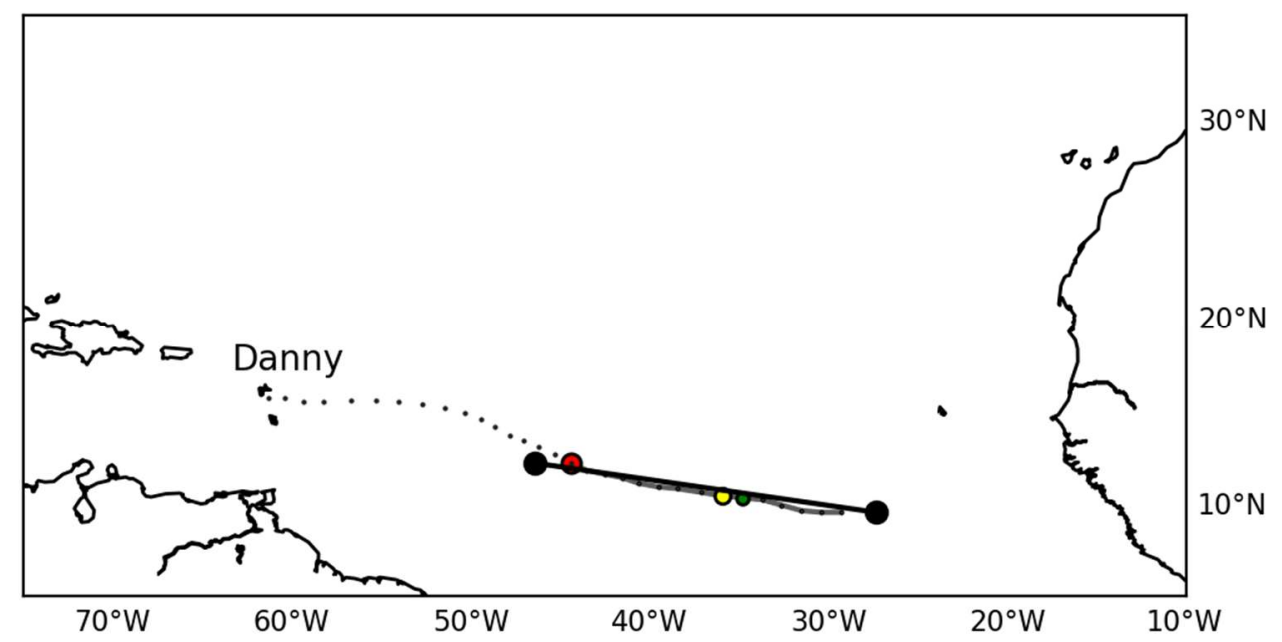

FIG. 104. Cross section path (large black dots, thick black line) for analysis portion of Hurricane Danny's storm track; similar to FIG. 1. 


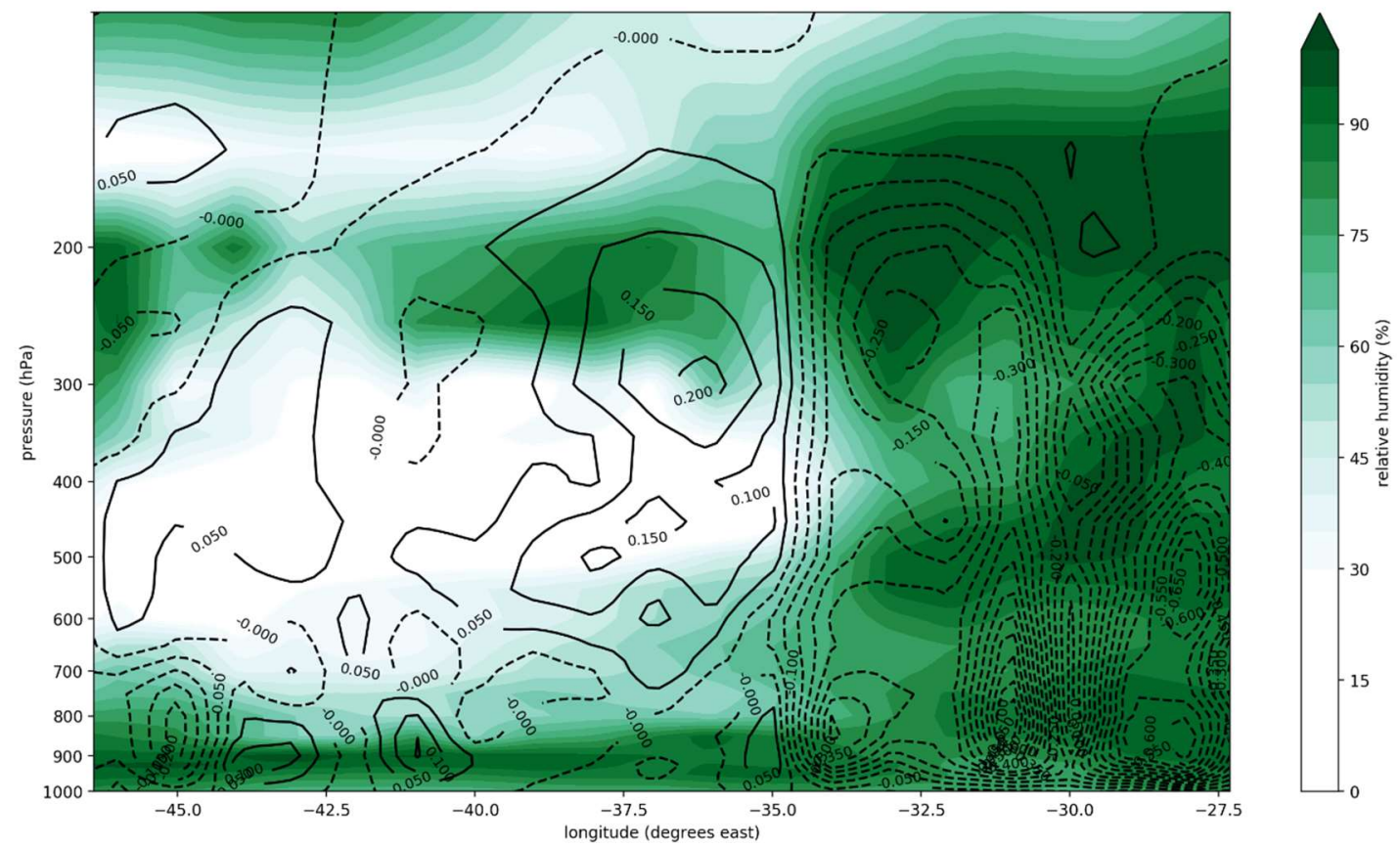

FIG. 105. Cross section of storm path from the first available best location $\left(9.6^{\circ} \mathrm{N},-27.3^{\circ} \mathrm{E}\right)$ to near the location of hurricane status $\left(12.3^{\circ} \mathrm{N},-46.4^{\circ} \mathrm{E}\right)$ for Hurricane Danny at 12 UTC 17 Aug 2015 from NCEPFNL; green contours indicate RH (\%); black lines indicate positive (solid) and negative (dotted) omega values $(\mathrm{Pa} / \mathrm{s})$.

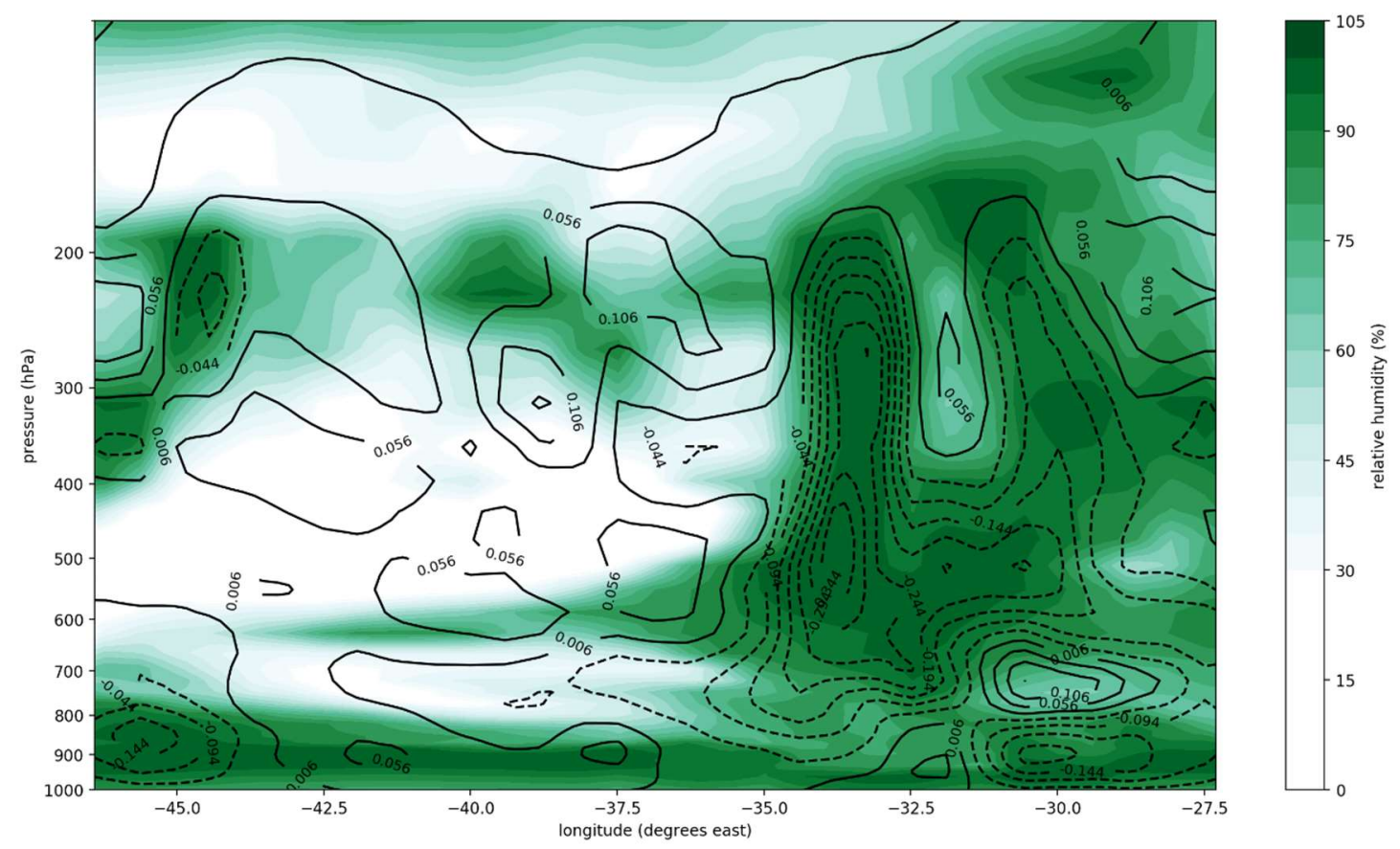

FIG. 106. Cross section of storm path from the first available best location $\left(9.6^{\circ} \mathrm{N},-27.3^{\circ} \mathrm{E}\right)$ to near the location of hurricane status $\left(12.3^{\circ} \mathrm{N},-46.4^{\circ} \mathrm{E}\right)$ for Hurricane Danny at 12 UTC 17 Aug 2015 from MERRA2 ; green contours indicate RH (\%); black lines indicate positive (solid) and negative (dotted) omega values $(\mathrm{Pa} / \mathrm{s})$. 


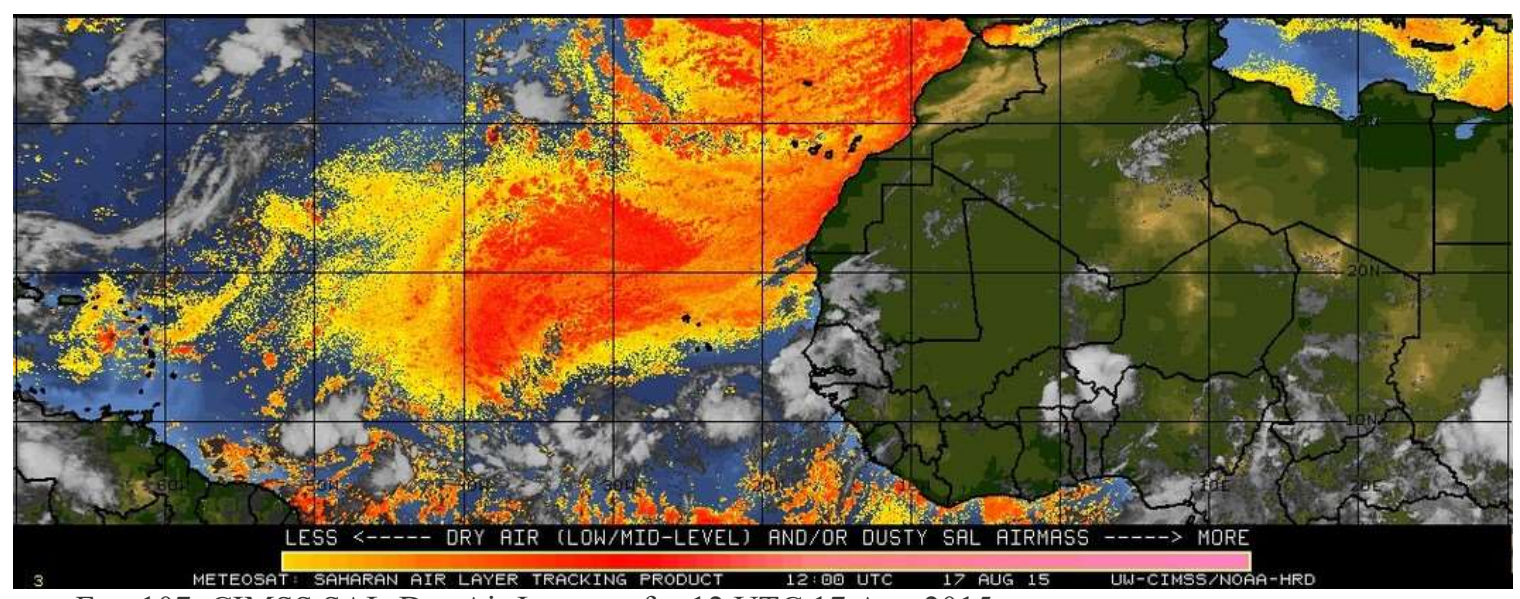

FIG. 107. CIMSS SAL-Dry Air Imagery for 12 UTC 17 Aug 2015.

\section{2) T= -2 STARTING AT 12 UTC 18 AUg 2015}

While no dry air value was recorded on the storm path for Hurricane Danny at this time period for NCEP-FNL, a RH value of 0.285 was seen 3 days ahead in MERRA-2; this time point $(\mathrm{t}=-2)$ was also when the storm was categorized as a TS. However, CIMSS imagery continued to show a strong dry air presence north and west of the storm track as well as at the $700 \mathrm{hPa}$ level (Fig. 108, Fig. 109, Fig. 110). Cross sections also indicated substantial dry air presence west of the TC in the upper levels (Fig. 111, Fig. 112). The beginning structure of a hurricane consisting of a central column of rising moist air flanked by sinking drier air was also visible, especially in MERRA-2 (Fig. 111, Fig. 112). 


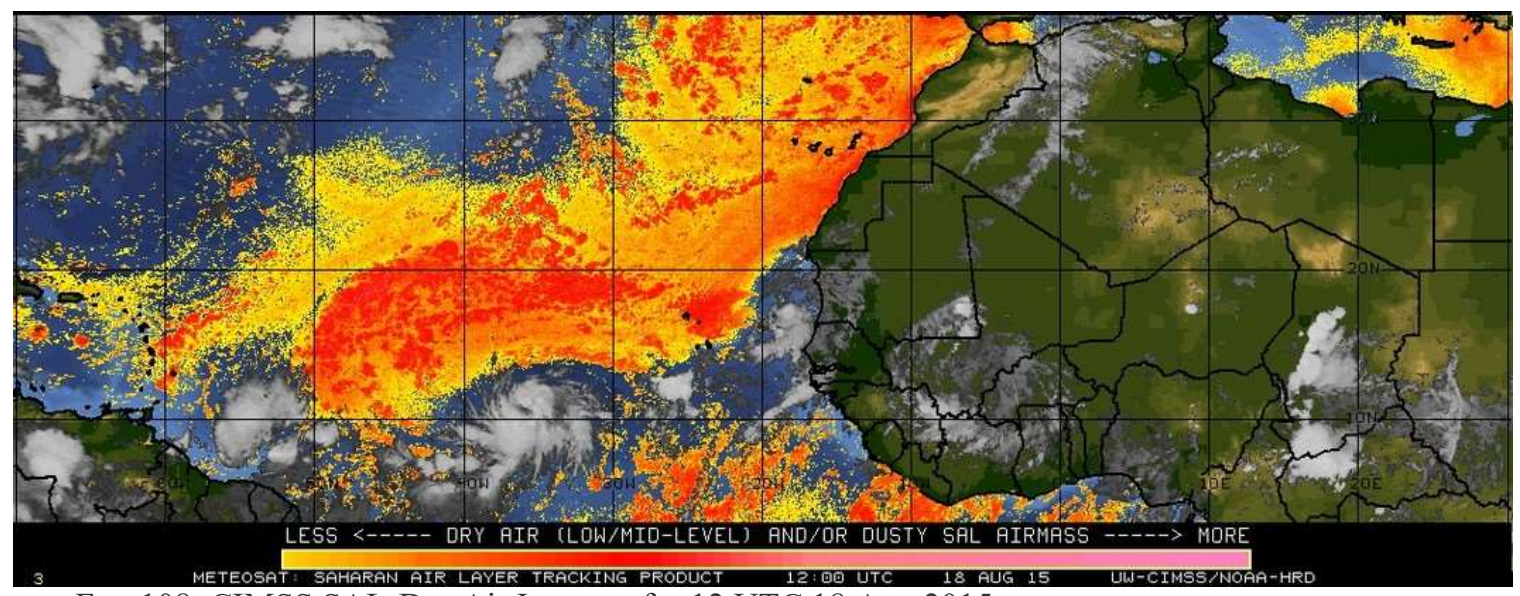

FIG. 108. CIMSS SAL-Dry Air Imagery for 12 UTC 18 Aug 2015.

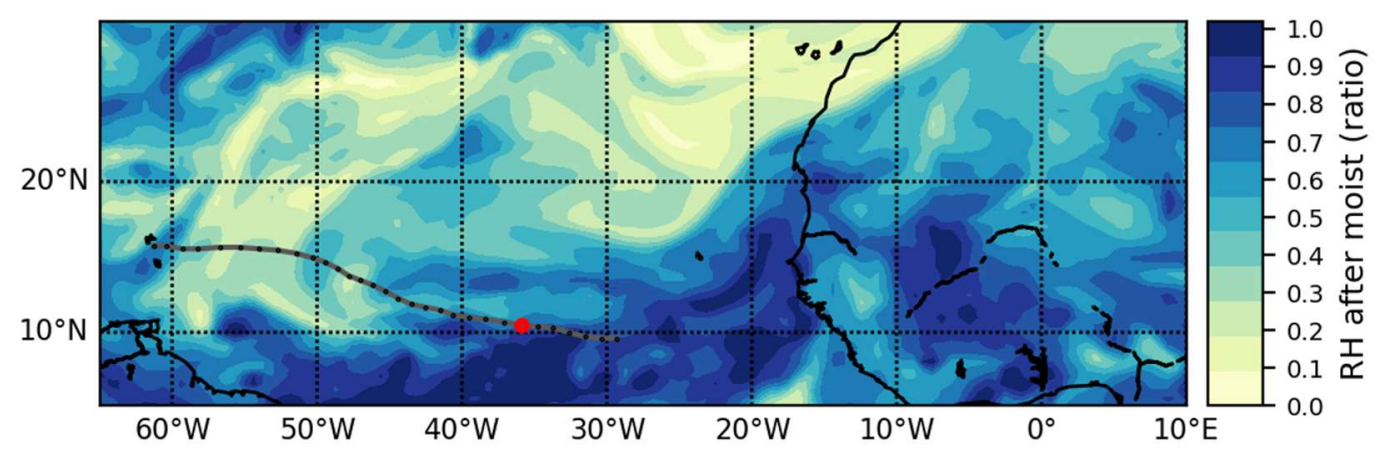

FIG. 109. RH at $700 \mathrm{hPa}$ for Hurricane Danny at 12 UTC 18 Aug 2015 from MERRA-2; grey line is the storm track with best locations (black dots) from NHC; red dot indicates the TC location at the given time point.

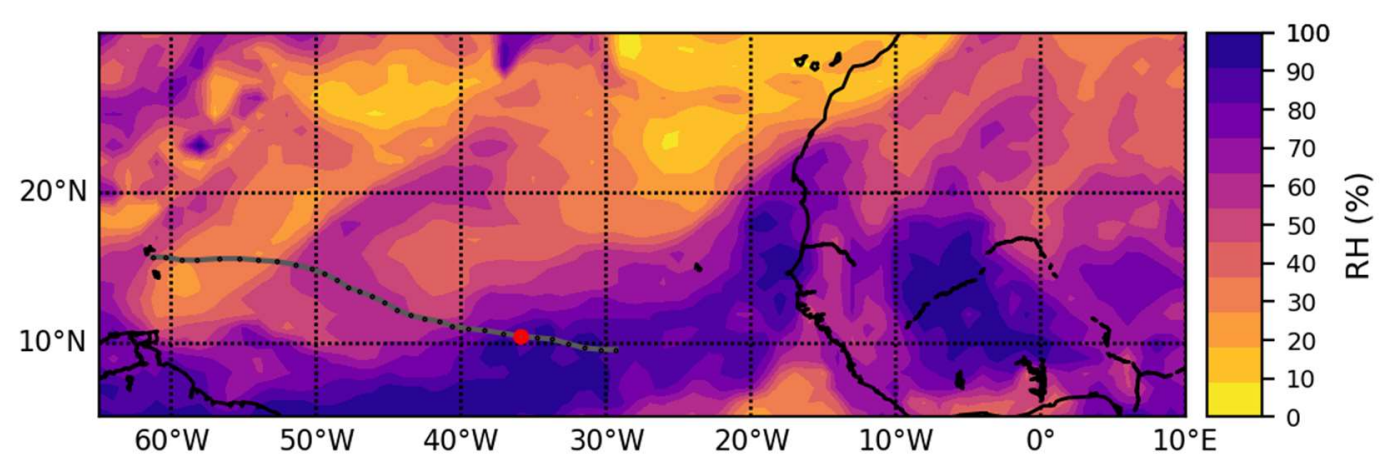

FIG. 110. RH at $700 \mathrm{hPa}$ for Hurricane Danny at 12 UTC 18 Aug 2015 from NCEP-FNL; grey line is the storm track with best locations (black dots) from NHC; red dot indicates the TC location at the given time point. 


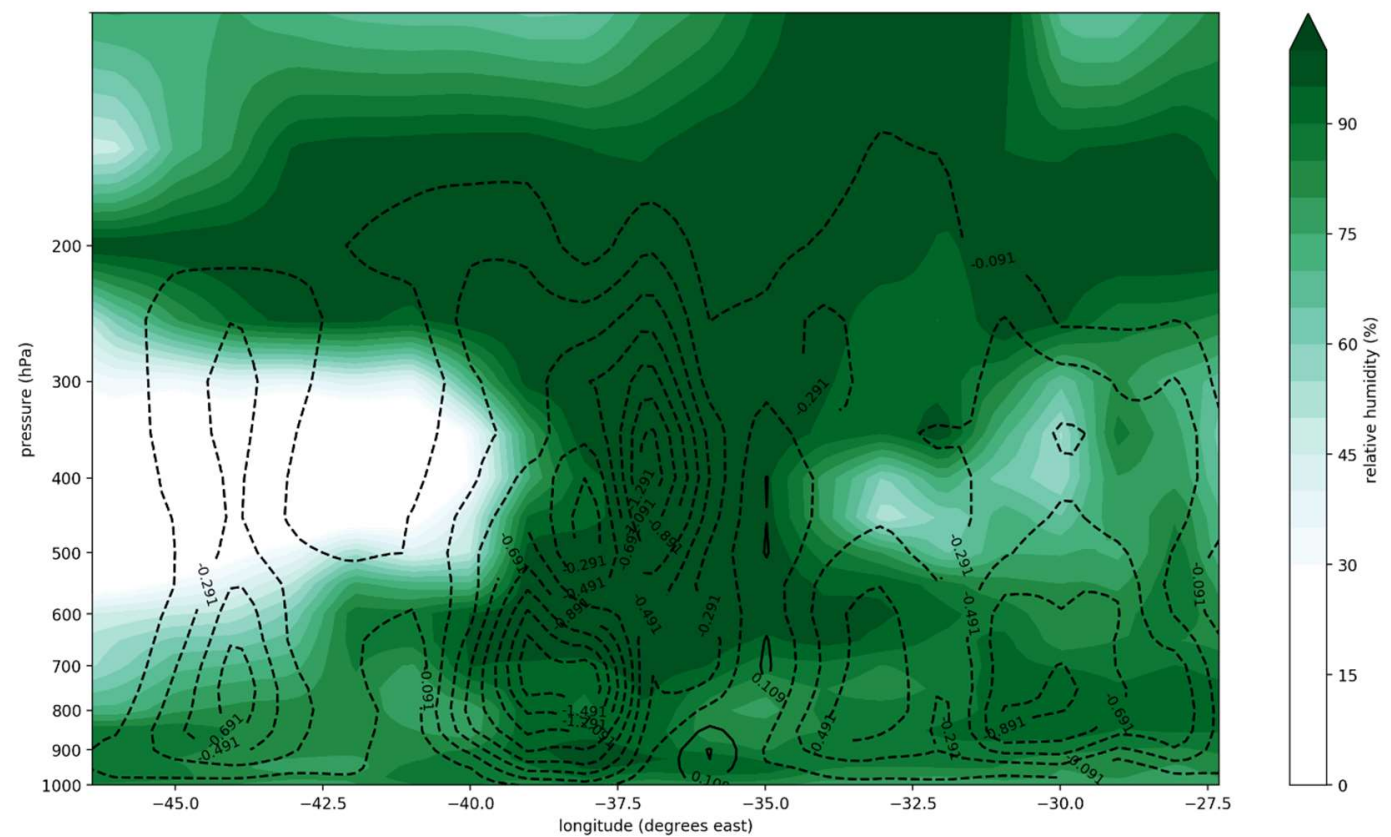

FIG. 111. Cross section of storm path from the first available best location $\left(9.6^{\circ} \mathrm{N},-27.3^{\circ} \mathrm{E}\right)$ to near the location of hurricane status $\left(12.3^{\circ} \mathrm{N},-46.4^{\circ} \mathrm{E}\right)$ for Hurricane Danny at 00 UTC 19 Aug 2015 from NCEPFNL; green contours indicate RH (\%); black lines indicate positive (solid) and negative (dotted) omega values $(\mathrm{Pa} / \mathrm{s})$.

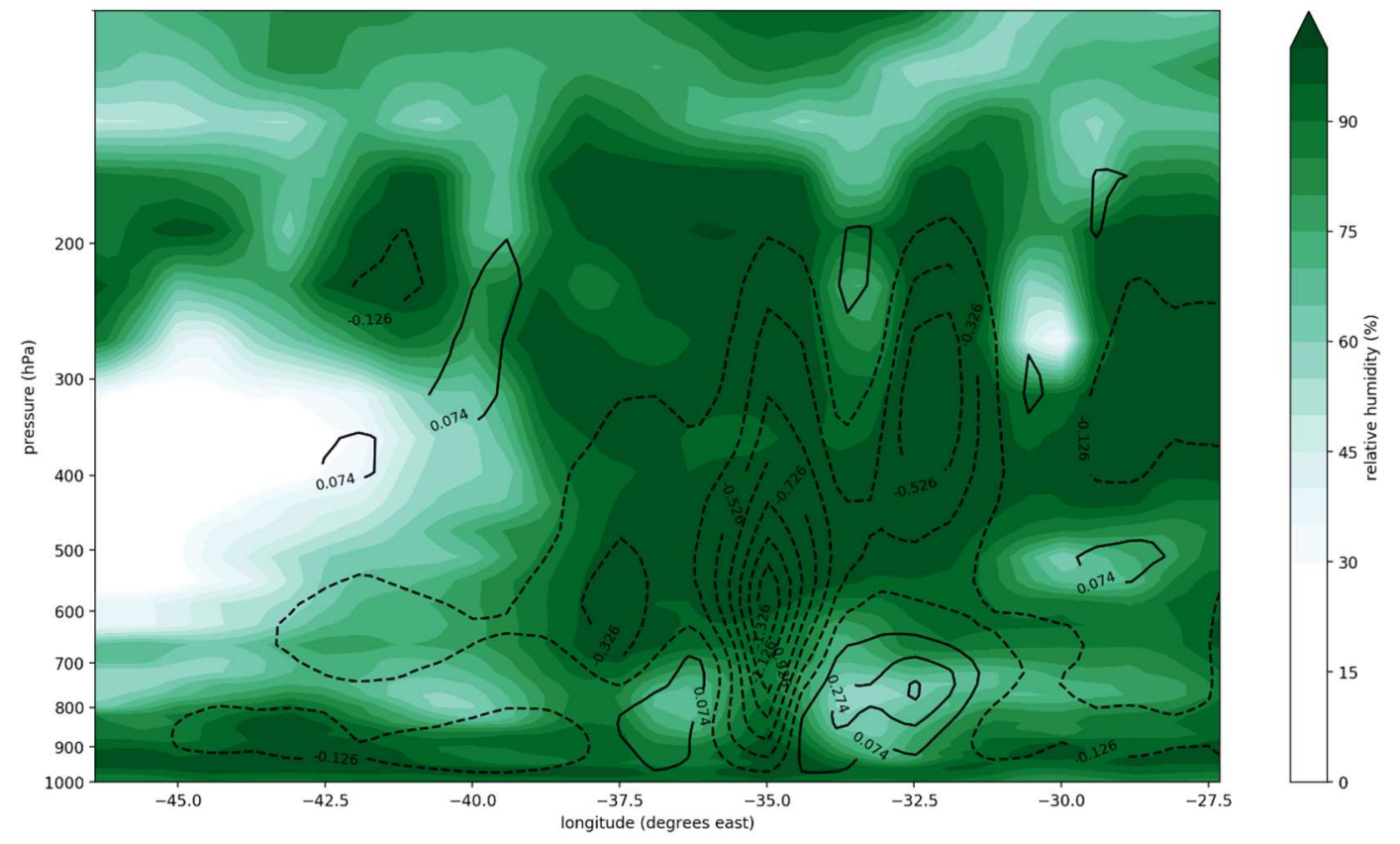

FIG. 112. Cross section of storm path from the first available best location $\left(9.6^{\circ} \mathrm{N},-27.3^{\circ} \mathrm{E}\right)$ to near the location of hurricane status $\left(12.3^{\circ} \mathrm{N},-46.4^{\circ} \mathrm{E}\right)$ for Hurricane Danny at $00 \mathrm{UTC} 19$ Aug 2015 from MERRA2; green contours indicate RH (\%); black lines indicate positive (solid) and negative (dotted) omega values $(\mathrm{Pa} / \mathrm{s})$. 


\section{3) T= -1 STARTING AT 12 UTC 19 AUg 2015}

In NCEP-FNL, the first and only RH value less than 0.30 occurred at 18 UTC 19 Aug over the area where the storm would pass on 18 UTC 21 Aug, 2 days ahead (Table 2).

Fig. 113 also supported the lack of visible dry air. No RH values less than 0.30 were observed on the storm path within 3 days during this time period in MERRA-2, indicating $700 \mathrm{hPa}$ layer was not inundated with dry air (Fig. 114). The Meteostat image continued to show dry air north of the storm track and system but appeared more concentrated and less widespread overall compared to previous days (Fig. 115).

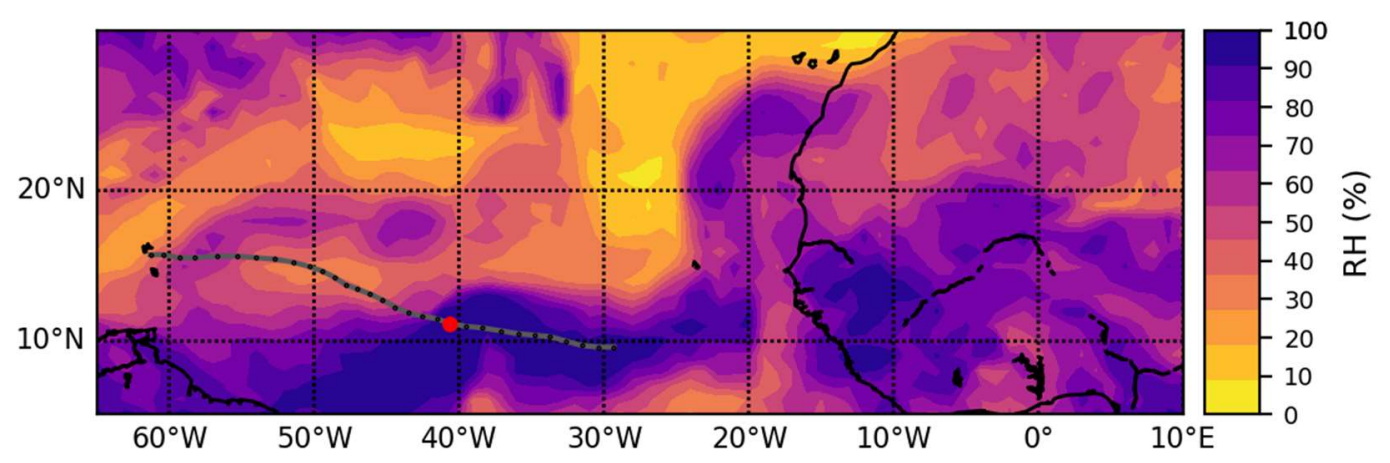

FIG. 113. RH at $700 \mathrm{hPa}$ for Hurricane Danny at 12 UTC 19 Aug 2015 from NCEP-FNL; grey line is the storm track with best locations (black dots) from NHC; red dot indicates the TC location at the given time point.

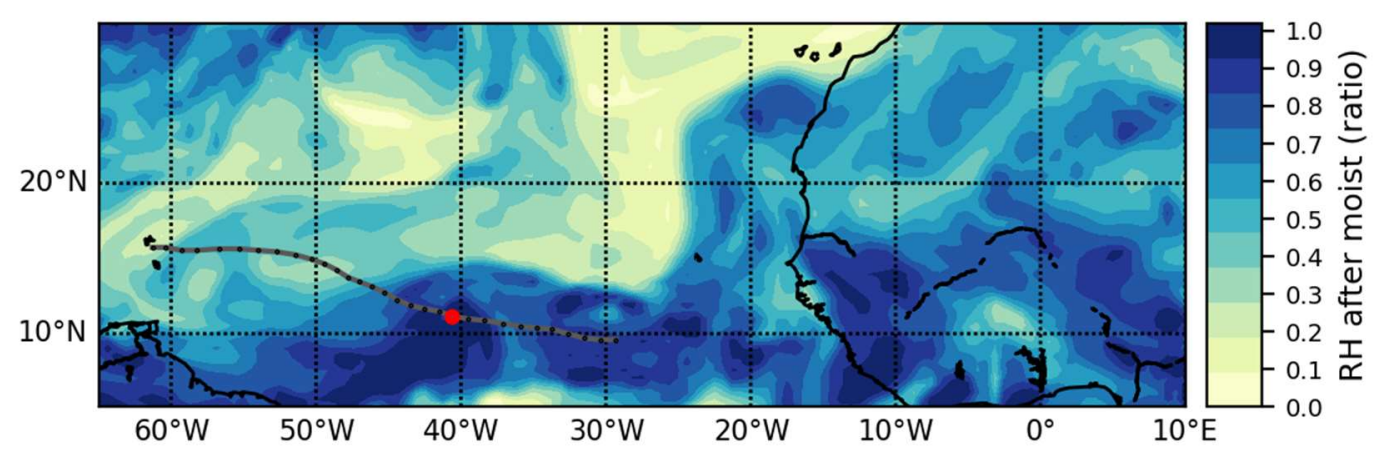

FIG. 114. RH at $700 \mathrm{hPa}$ for Hurricane Danny at 12 UTC 19 Aug 2015 from MERRA-2; grey line is the storm track with best locations (black dots) from NHC; red dot indicates the TC location at the given time point. 


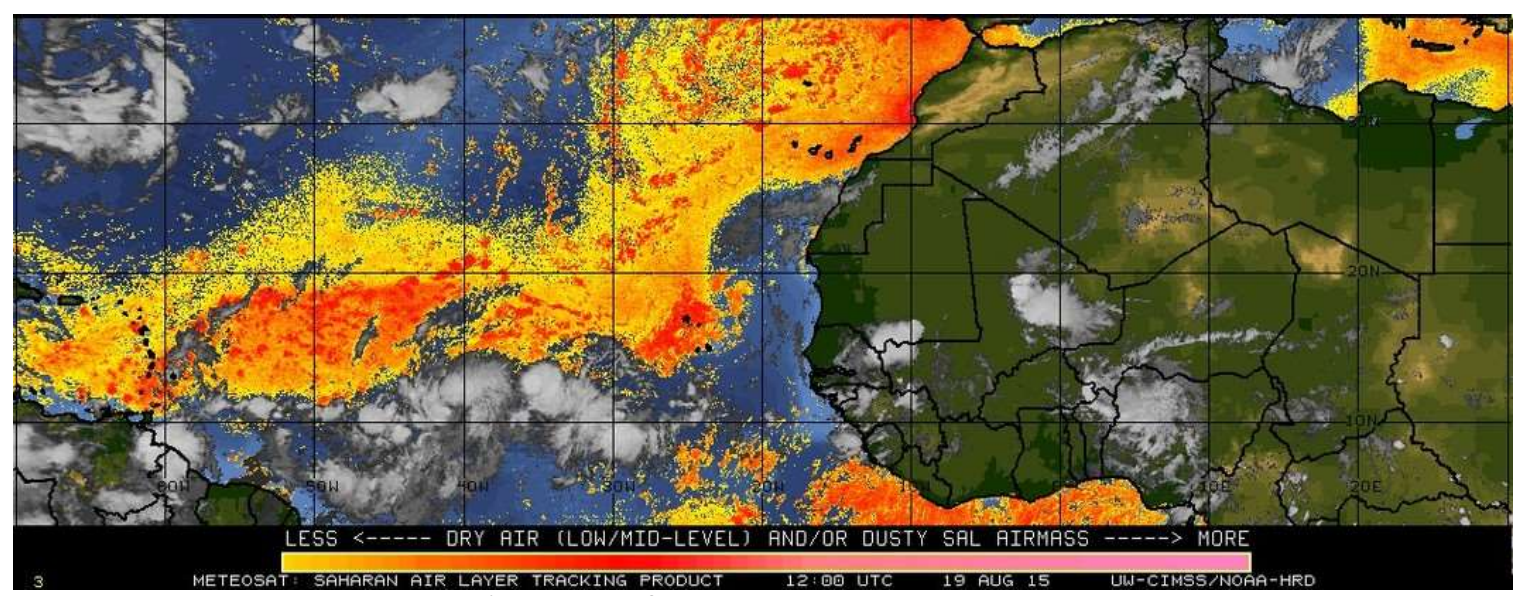

FIG. 115. CIMSS SAL-Dry Air Imagery for 12 UTC 19 Aug 2015.

Between 21 UTC 19 Aug and 00 UTC 20 Aug appeared to be a turning point for

Hurricane Danny. The clouds appeared visibly denser on 00 UTC 20 Aug compared to 3 hours before (Fig. 116, Fig. 117). Cross sections from NCEP-FNL showed intense rising motion, likely a view of the hurricane's vortex (Fig. 118, Fig. 119). Fig. 119 depicted distinctive rainband-like structures. Within this time period, the NHC reported that the TS Danny had intensified while surrounded by the SAL (Steward 2016). Other than dry air, the possibility of another force or factor such as SST or vorticity advection aiding Danny's jump to hurricane status should not be discounted.

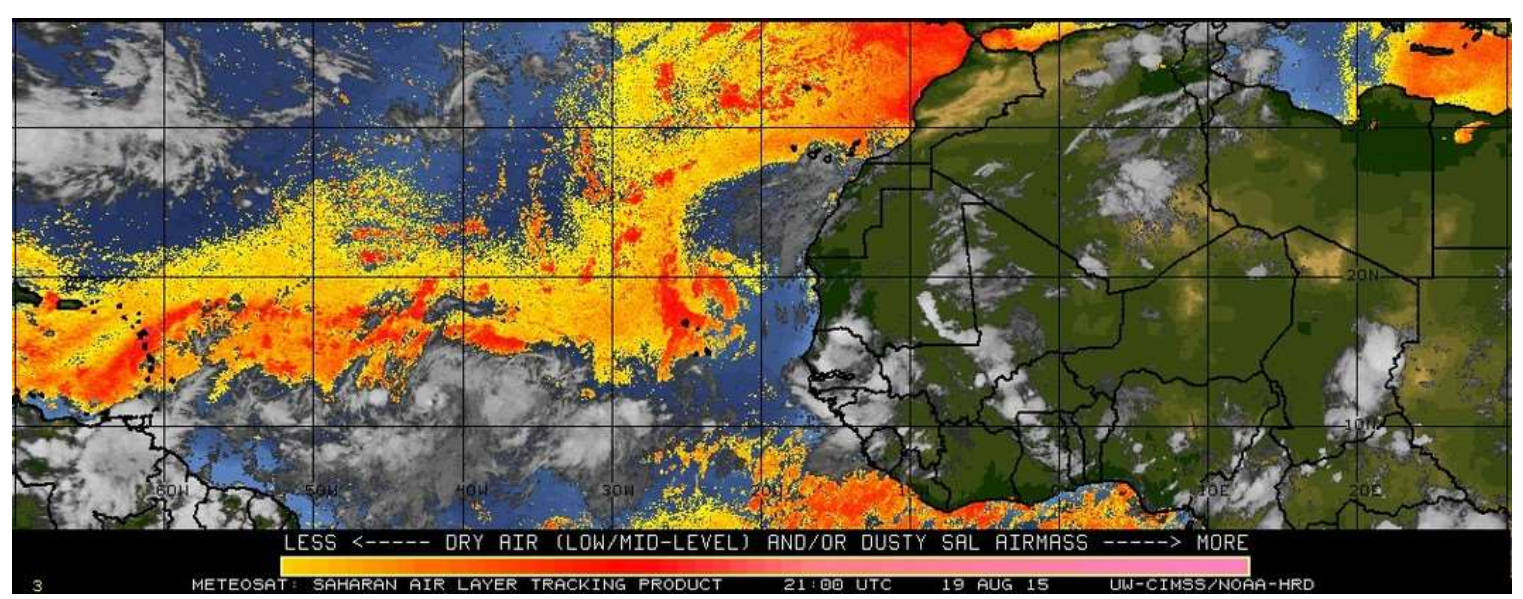

FIG. 116. CIMSS SAL-Dry Air Imagery for 21 UTC 19 Aug 2015. 


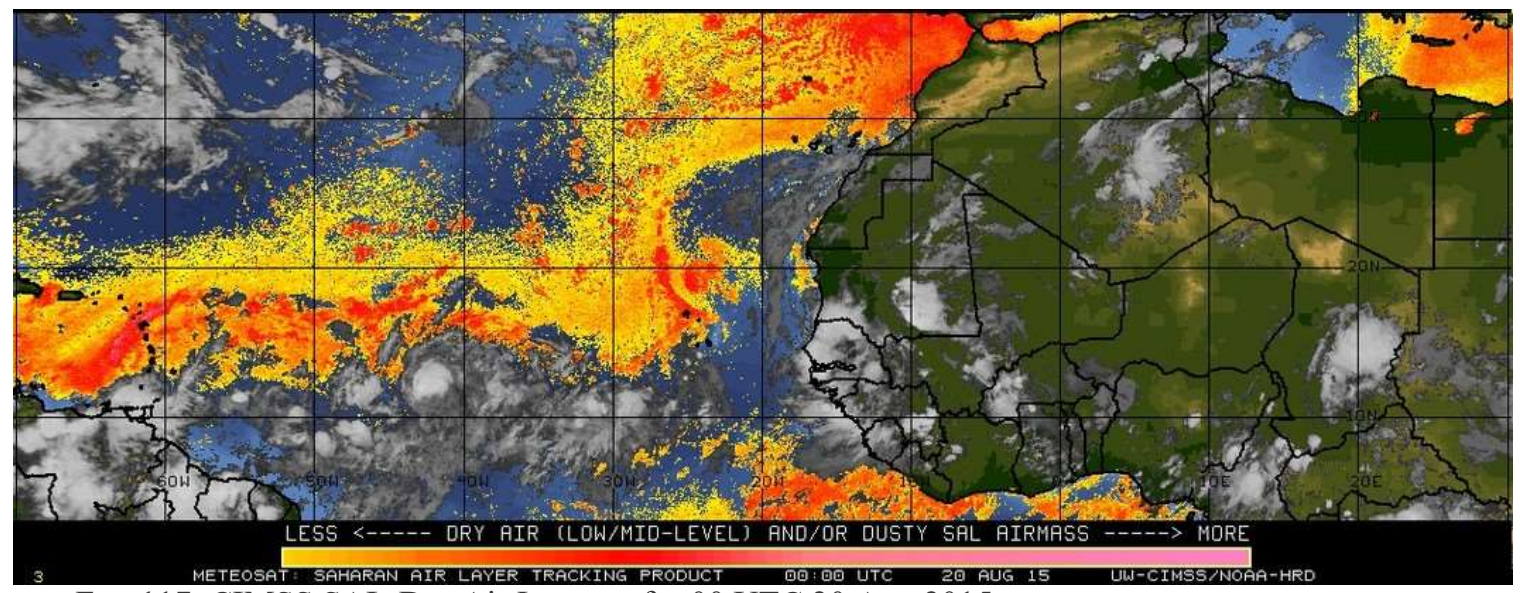

FIG. 117. CIMSS SAL-Dry Air Imagery for 00 UTC 20 Aug 2015.

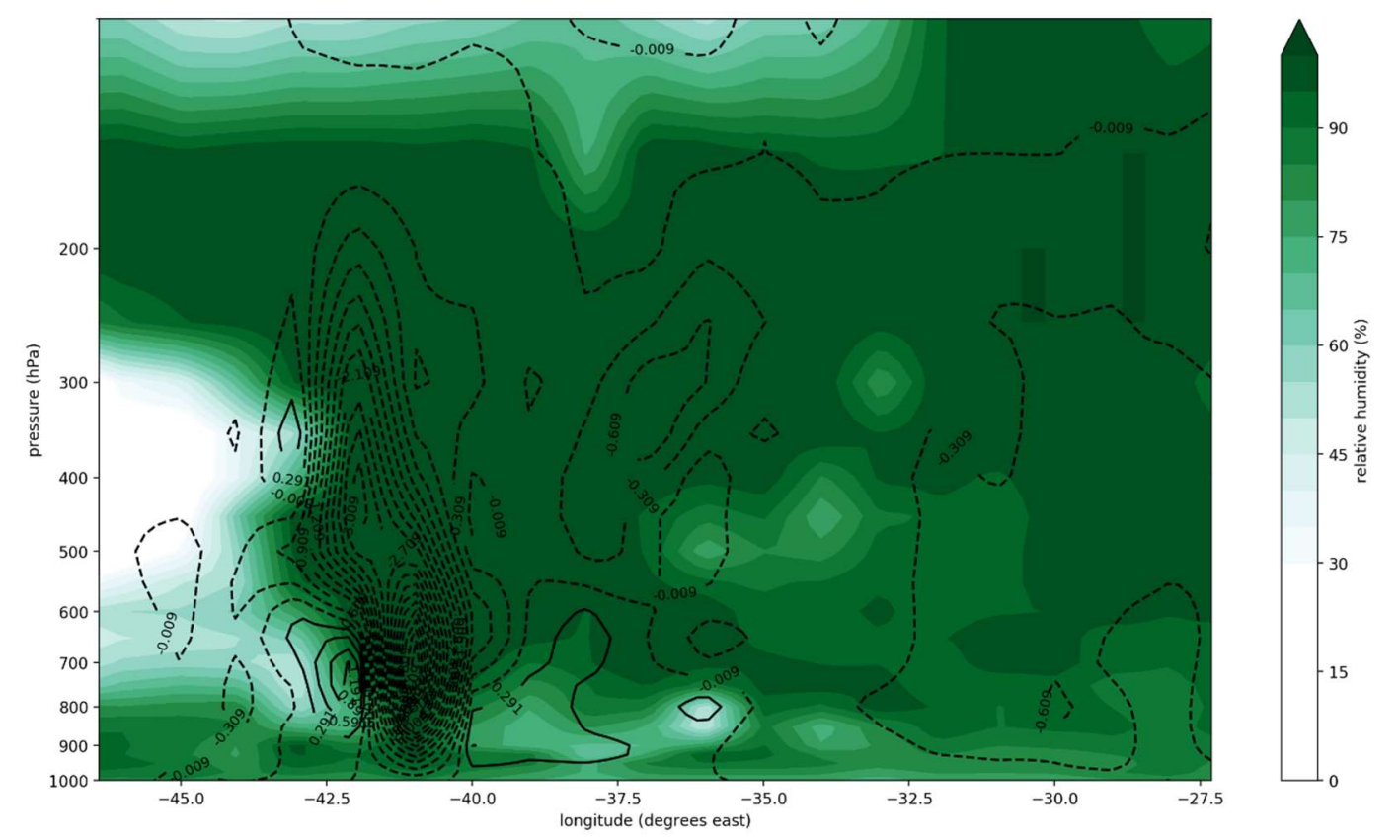

FIG. 118. Cross section of storm path from the first available best location $\left(9.6^{\circ} \mathrm{N},-27.3^{\circ} \mathrm{E}\right)$ to near the location of hurricane status $\left(12.3^{\circ} \mathrm{N},-46.4^{\circ} \mathrm{E}\right)$ for Hurricane Danny at 18 UTC 19 Aug 2015 from NCEPFNL; green contours indicate RH (\%); black lines indicate positive (solid) and negative (dotted) omega values $(\mathrm{Pa} / \mathrm{s})$. 


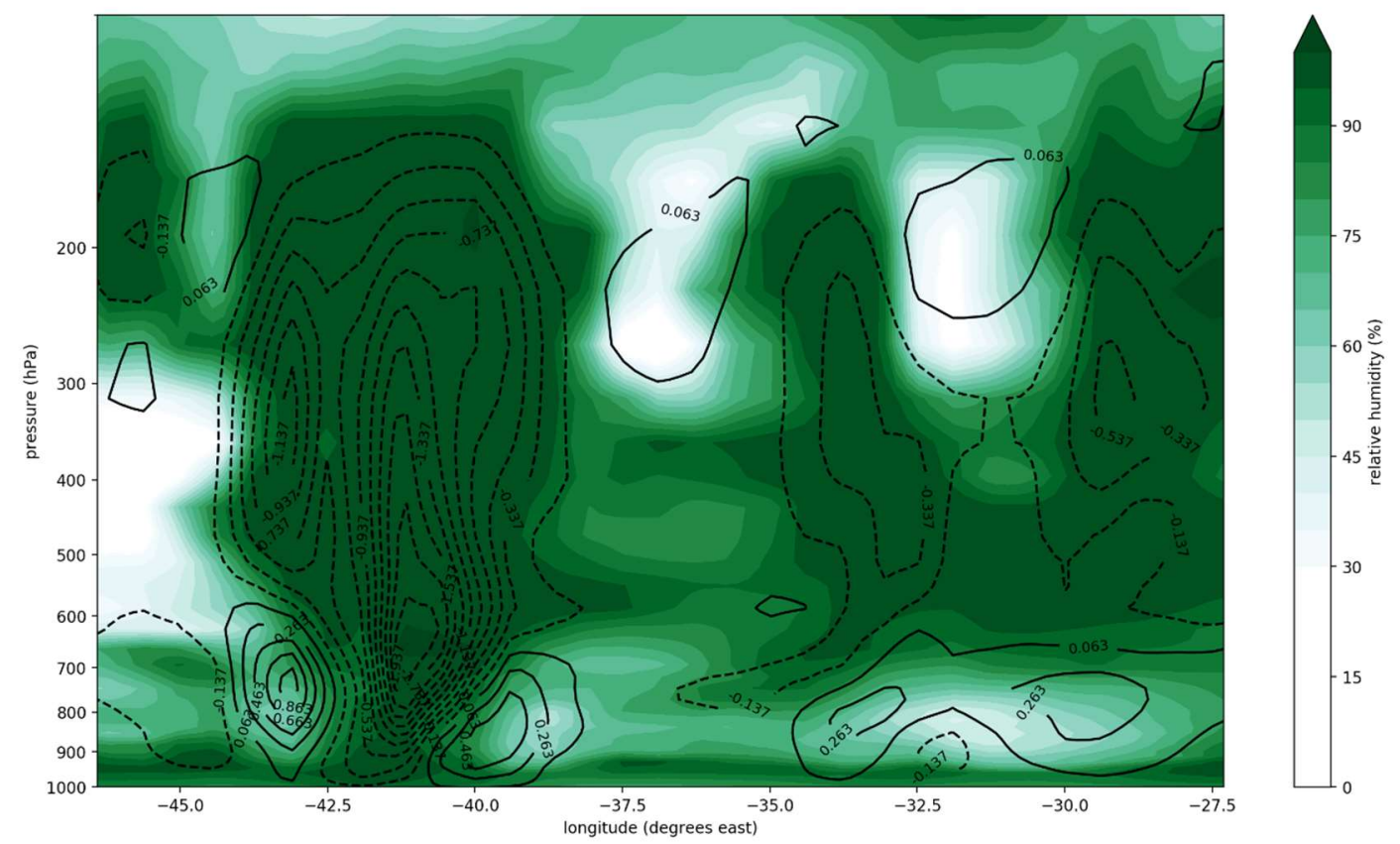

FIG. 119. Cross section of storm path from the first available best location $\left(9.6^{\circ} \mathrm{N},-27.3^{\circ} \mathrm{E}\right)$ to near the location of hurricane status $\left(12.3^{\circ} \mathrm{N},-46.4^{\circ} \mathrm{E}\right)$ for Hurricane Danny at 18 UTC 19 Aug 2015 from MERRA2; green contours indicate RH (\%); black lines indicate positive (solid) and negative (dotted) omega values $(\mathrm{Pa} / \mathrm{s})$.

\section{4) T= 0 STARTING AT 12 UTC 20 AUg 2015}

At $700 \mathrm{hPa}$, no dry air value was found on the storm path for Hurricane Danny at this time period for NCEP-FNL or MERRA-2. Though the TC appeared small and compact, dry air was not visibly close to the system (Fig. 120). MERRA-2 and NCEP-FNL appeared to correspond well with the satellite imagery (Fig. 121, Fig. 122). The cross sections of the TC show drier air to the west of the hurricane (Fig. 123, Fig. 124). MERRA-2 showed more humid air and rising motion in the storm's center compared to NCEP-FNL where rising and sinking motions were also present. A noticeable size difference in low pressure center can be also seen at the SLP between NCEP-FNL and MERRA-2, perhaps suggesting a tighter, smaller vortex was depicted in MERRA-2 than in NCEP-FNL (Fig. 125, Fig. 126). Hurricane structure was not replicated as clearly in 
the horizontal cross sections (Fig. 125, Fig. 126) as compared to Fig. 119. It was possible that the west to east slice did not go through the eye of the storm, though the eye was not clearly observed in the SAL-dry satellite imagery. Though beyond the scope of this study, upper levels above $300 \mathrm{hPa}$ had a substantial dry air presence over the locations the TC had already passed (Fig. 123, Fig. 124).

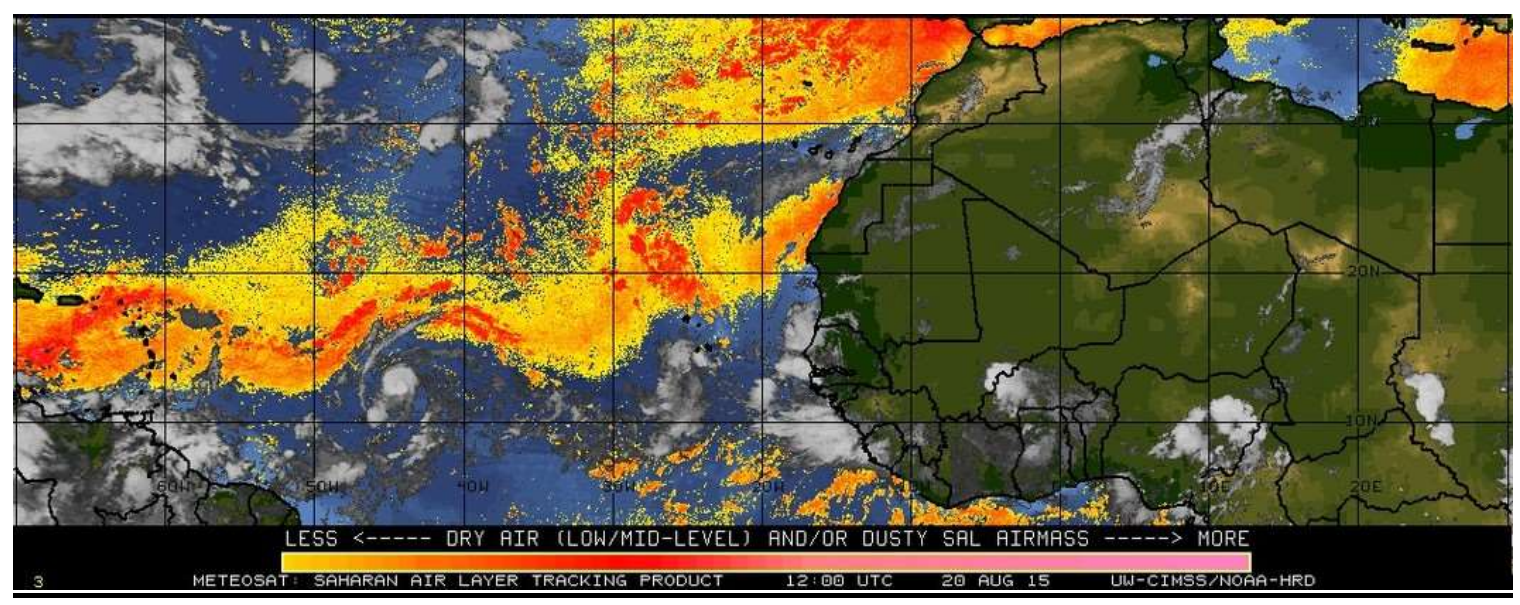

FIG. 120. CIMSS SAL-Dry Air Imagery for 12 UTC 20 Aug 2015.

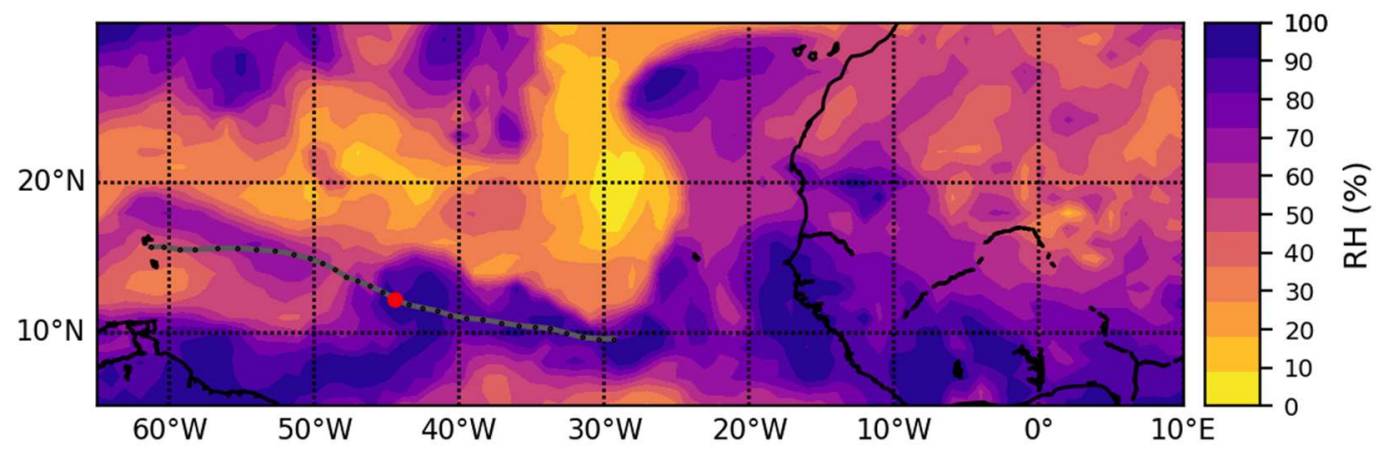

FIG. 121. RH at $700 \mathrm{hPa}$ for Hurricane Danny at 12 UTC 20 Aug 2015 from NCEP-FNL; grey line is the storm track with best locations (black dots) from NHC; red dot indicates the TC location at the given time point. 


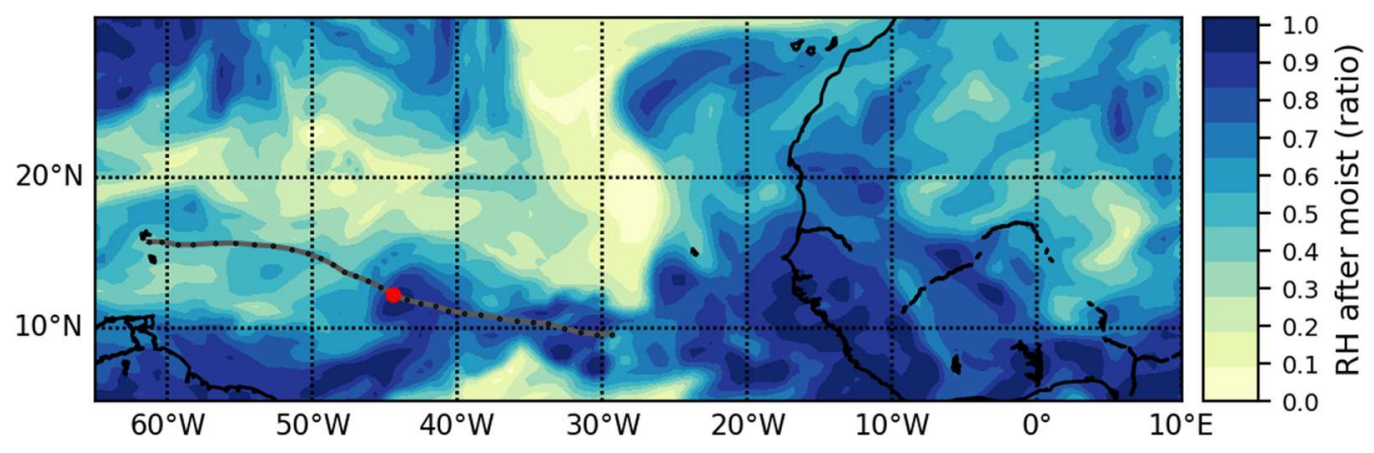

FIG. 122. RH at $700 \mathrm{hPa}$ for Hurricane Danny at 12 UTC 20 Aug 2015 from MERRA-2; grey line is the storm track with best locations (black dots) from NHC; red dot indicates the TC location at the given time point.

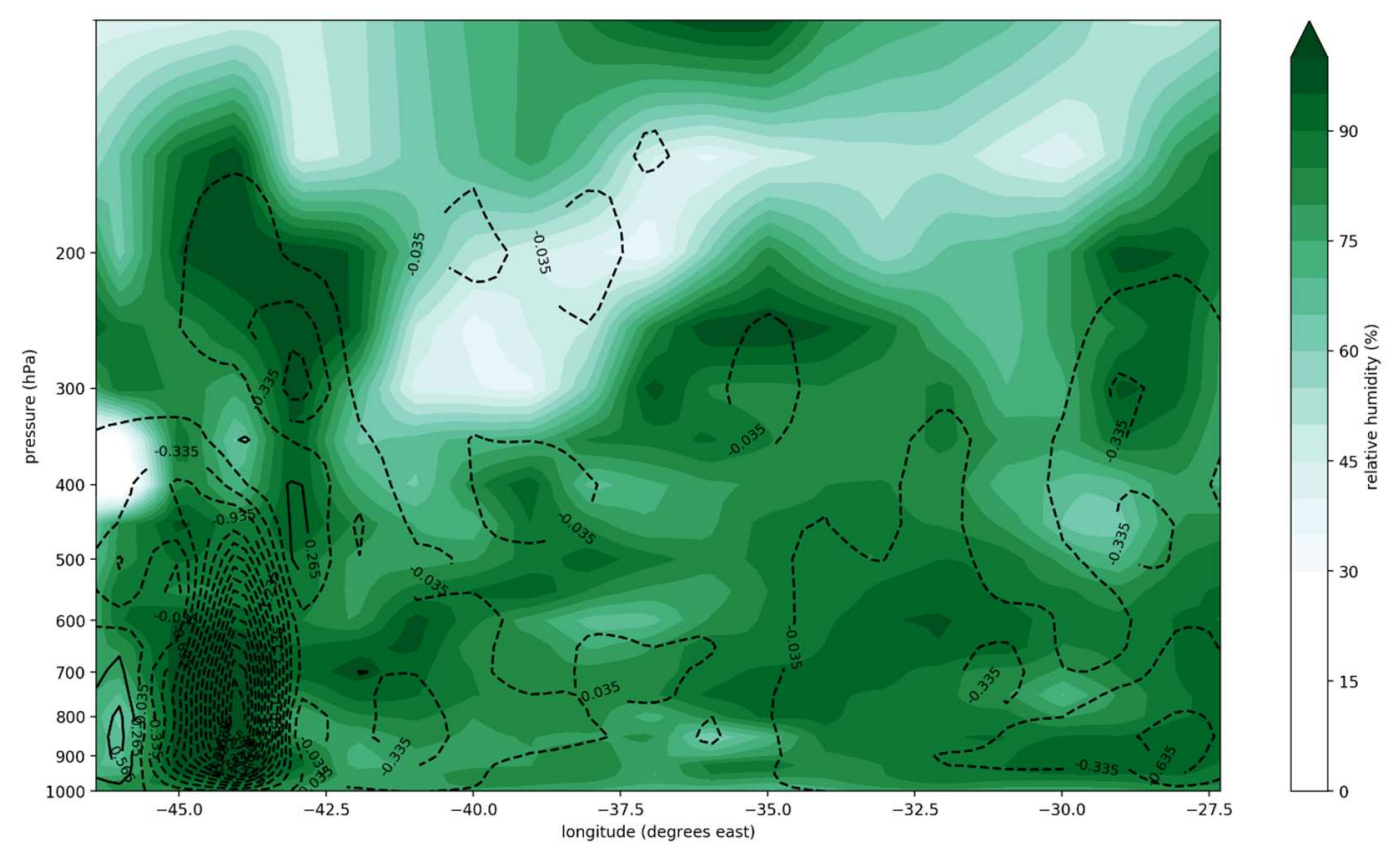

FIG. 123. Cross section of storm path from the first available best location $\left(9.6^{\circ} \mathrm{N},-27.3^{\circ} \mathrm{E}\right)$ to near the location of hurricane status $\left(12.3^{\circ} \mathrm{N},-46.4^{\circ} \mathrm{E}\right)$ for Hurricane Danny at 12 UTC 20 Aug 2015 from NCEPFNL; green contours indicate RH (\%); black lines indicate positive (solid) and negative (dotted) omega values $(\mathrm{Pa} / \mathrm{s})$. 


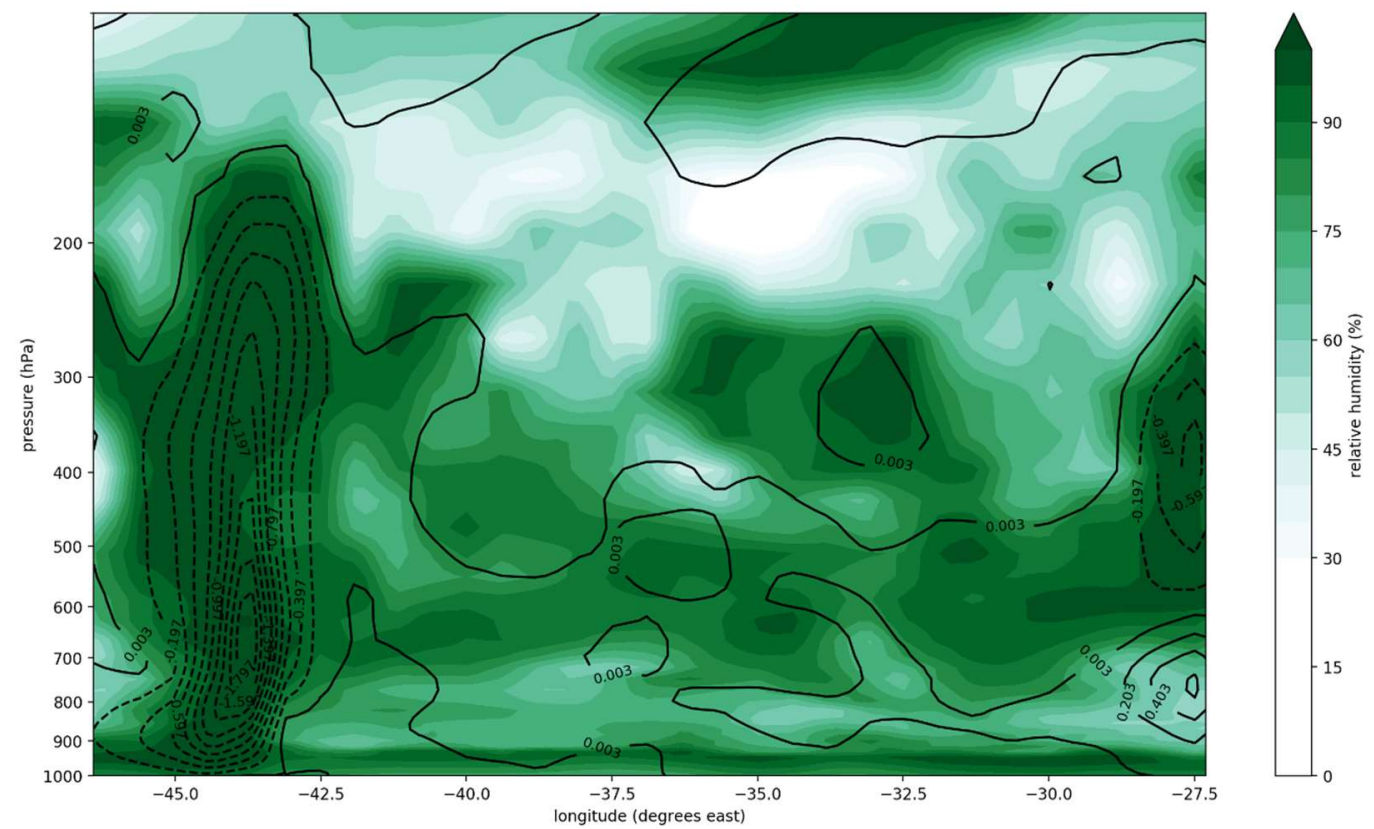

FIG. 124. Cross section of storm path from the first available best location $\left(9.6^{\circ} \mathrm{N},-27.3^{\circ} \mathrm{E}\right)$ to near the location of hurricane status $\left(12.3^{\circ} \mathrm{N},-46.4^{\circ} \mathrm{E}\right)$ for Hurricane Danny at 12 UTC 20 Aug 2015 for MERRA-2; green contours indicate RH (\%); black lines indicate positive (solid) and negative (dotted) omega values $(\mathrm{Pa} / \mathrm{s})$. 

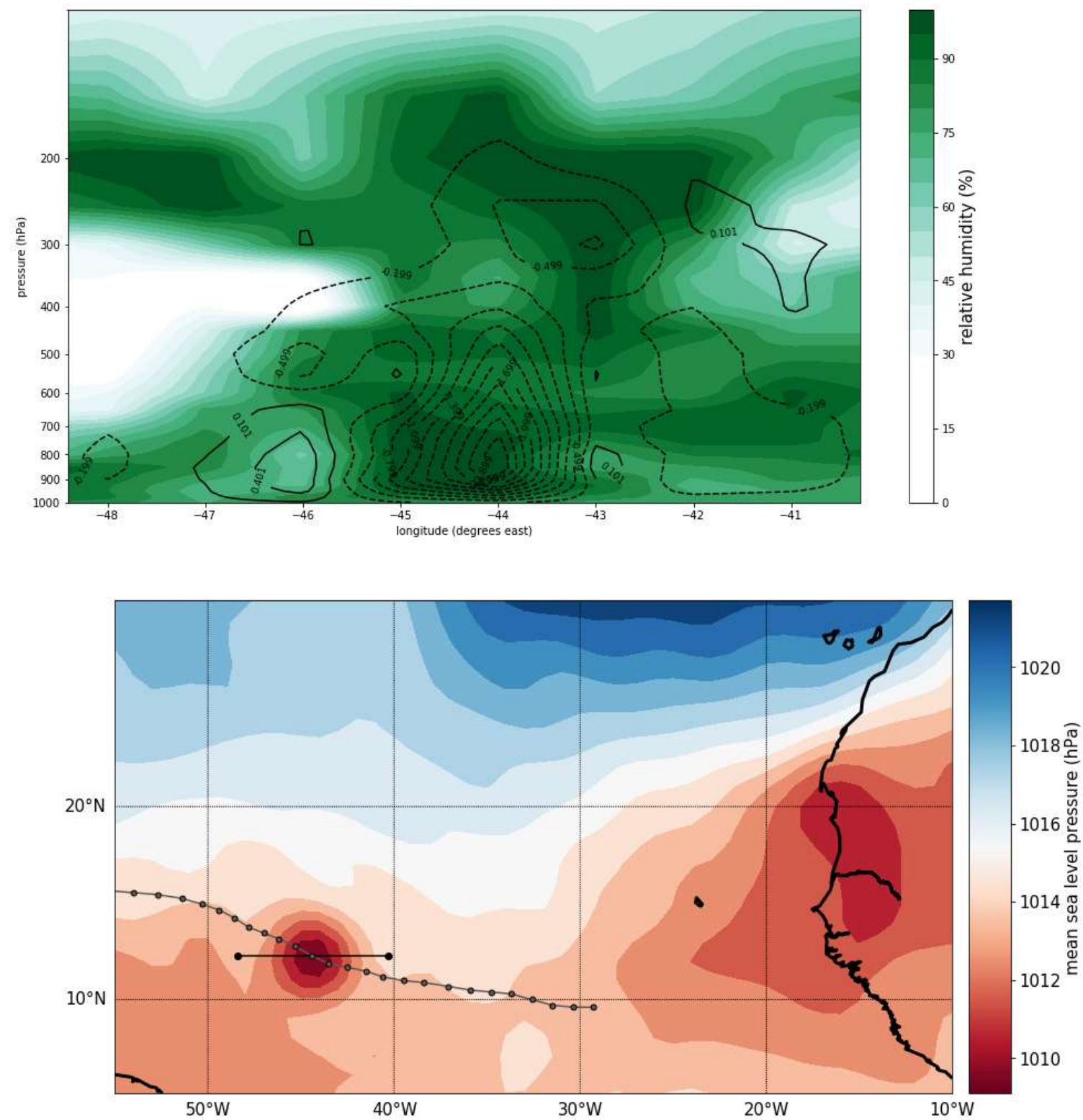

FIG. 125. (above) RH cross section beginning at $12.3^{\circ} \mathrm{N},-40.3^{\circ} \mathrm{E}$ to $12.3^{\circ} \mathrm{N},-48.4^{\circ} \mathrm{E}$ at $12 \mathrm{UTC} 20$ Aug 2015 for Hurricane Danny at hurricane stage from NCEP-FNL; green contours indicate RH (\%); black lines indicate positive (solid) and negative (dotted) omega values ( $\mathrm{Pa} / \mathrm{s}$ ); (below) cross section path with SLP; contours indicate the mean SLP; grey line with small black dots showing the entire storm path based on NHC's best locations; larger solid dots and black line shows the location of the cross section. 

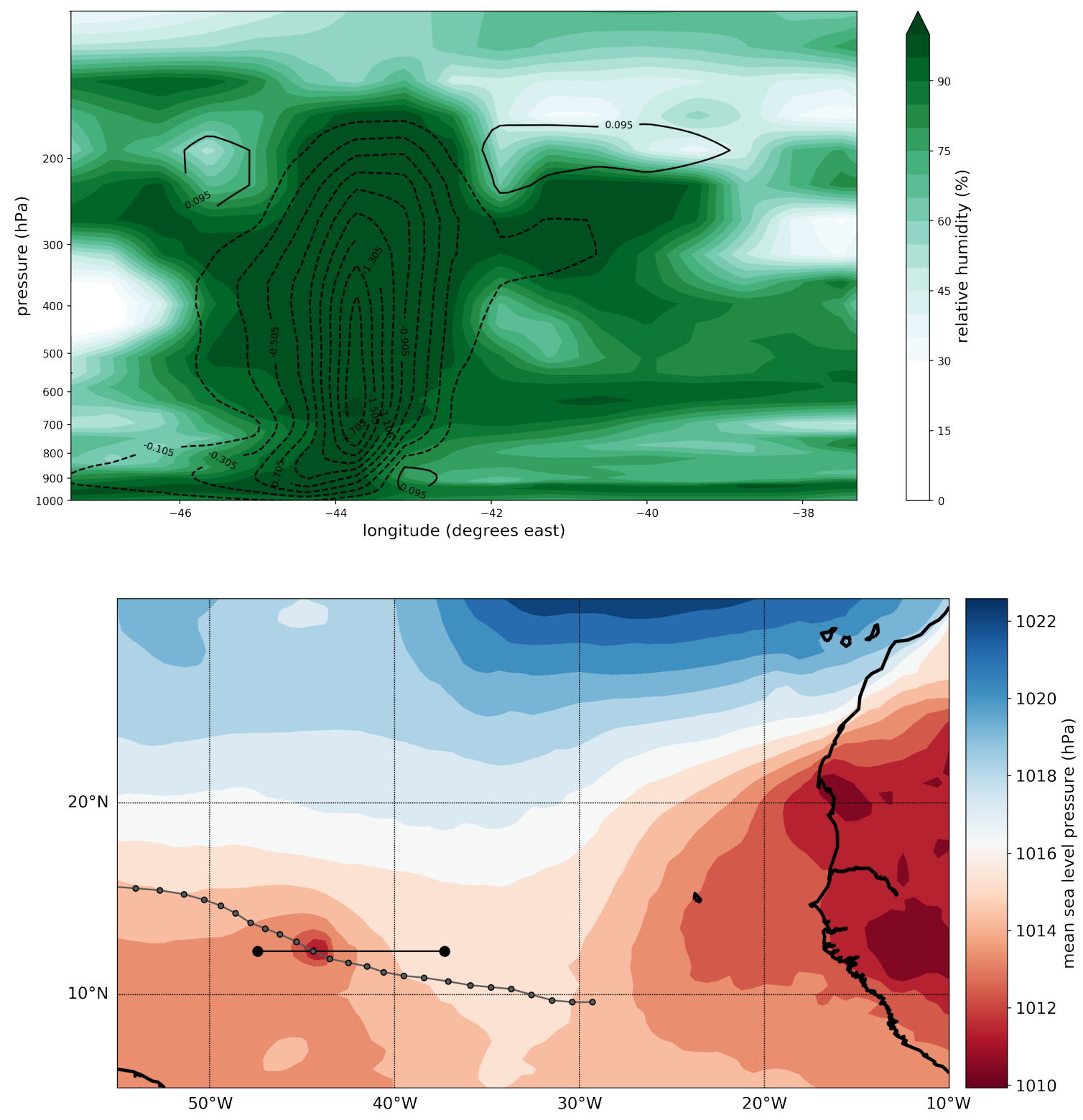

FIG. 126. (above) RH cross section beginning at $12.3^{\circ} \mathrm{N},-37.3^{\circ} \mathrm{E}$ to $12.3^{\circ} \mathrm{N},-47.4^{\circ} \mathrm{E}$ at $12 \mathrm{UTC} 20 \mathrm{Aug}$ 2015 for Hurricane Danny at hurricane stage from MERRA-2; green contours indicate RH (\%); black lines indicate positive (solid) and negative (dotted) omega values (Pa/s).; (below) cross section path with SLP; contours indicate the mean SLP; grey line with small black dots showing the entire storm path based on NHC's best locations; larger solid dots and black line shows the location of the cross section. 


\section{Summary \& Conclusions}

Satellite imagery provided by CIMSS and RH from NCEP-FNL and MERRA-2 datasets were compared within 3 days of reaching the highest TC stage and 3 days ahead on the corresponding storm track. With a focus on $700 \mathrm{hPa}$, a proxy for SAL, RH reanalysis data and the satellite imagery corresponded fairly well at most time points. While air with $30 \%$ or lower RH was observed overlapping storm tracks at $700 \mathrm{hPa}$, the limits of a single pressure level were occasionally evident as RH did not exactly match the SAL-dry air image product. In the case of TS Grace 1 day before TS status was declared, drier air was observed sporadically throughout different vertical levels in MERRA-2 along the storm track, some of which may account for the dry air spots seen in the CIMSS imagery. The heatmaps presented how varied moisture content can be at different pressure levels. Other levels (e.g., 850 or $600 \mathrm{hPa}$ ) may be needed to better illuminate the whole picture of dry locations vertically and horizontally. Still, RH at 700 $\mathrm{hPa}$ adequately depicts the presence of dry air and the possibility of the SAL.

At 3 days before the peak TC status was declared, dry air $(\leq 30 \% \mathrm{RH})$ at $700 \mathrm{hPa}$ was not observed on the storm track for every case, except for Hurricane Danny depicted with MERRA-2. As time approached closer to the date of the status change, more dry air values showed up at this level for TD9, TS Grace and Hurricane Fred but not for Hurricane Danny. For these 3 cases, this implies that dry air at $700 \mathrm{hPa}$ did not deter the propagation of the TC. Along storm paths, Hurricane Danny's contained higher moisture compared to the other 3 cases, suggesting a possible factor for its longer life cycle and continued development into a major hurricane. 
Just as dry air did not drive TCs away, dry air also did not appear to impede TC development for these specific cases. Low humidity $(\leq 30 \%)$ was present ahead of TD9, TS Grace, Hurricane Fred and Hurricane Danny. Evidence of convection changes was noted for TD9 and Hurricane Fred one day before TD and hurricane statuses were reached, respectively. Future research could analyze each stage change (i.e., TD becoming a TS) for each TC and yield different results. Additional investigation on strengthening factors of TCs, such as SSTs and low vertical wind shear, coupled with dry air may also be relevant.

Vertically, dry air at various pressure levels was observed ahead of all four storm paths, though the pattern would differ when comparing NCEP-FNL and MERRA-2 datasets. Moreover, the cross section slices for TD9 and Hurricane Fred were approximations of the actual storm path portion used for analysis (Fig. 28, Fig. 79). Nevertheless, all four TCs showed the presence of dry air in the upper levels at the time of highest TC development stage for this study. The colder temperatures in the upper levels could explain the frequency of low humidity observed. More (less) water vapor is needed to reach saturation when temperatures are higher (lower). If moisture was flowing towards the TC from the surrounding air, this could also account for drier air in its immediate proximity.

Both NCEP-FNL and MERRA-2 were able to capture rainbands and the structural features of the TCs rather distinctly, especially Hurricane Danny. MERRA-2 generally expressed more vertical stratification of dry air while NCEP-FNL appeared to generalize 
areas of low humidity more frequently. The higher grid resolution and 72 hybrid pressure levels could explain the additional moisture diversity observed in MERRA-2.

Based on these 4 cases, NCEP-FNL matched more closely to the best locations from NHC when compared to MERRA-2 at the peak stage. While detecting the storm center may vary by the individual case and the chosen dataset, the minimum SLP from MERRA-2 for TS Grace was strikingly off set from the best position (Fig. 73). For TD9, the storm's position was off slightly to the east using NCEP-FNL. Likewise, the center of Hurricane Fred found with MERRA-2's SLP could not be confirmed by cross sections through the TC. Only Hurricane Danny had a satisfactory overlap with the low pressure point and physical position for both datasets. In addition to SLP, using relative vorticity to determine a storm's center would likely provide a more comprehensive and accurate depiction of the TC. For instance, Hodges et al. (2017) vertically averaged 3 pressure levels to aid in detecting TCs and account for vorticity movement when comparing reanalysis datasets.

For these four specific cases, the TCs travelled toward rather than away from dry air. As evident with Hurricane Fred and TD9, the TCs traversed to dry air regions. Since these 4 cases showed stronger dry air presence north or in close proximity to the storm tracks, this raises another important question: Would TC cases where the surrounding environment was not abundant with dry air yield similar storm motion tendencies? Recent research had suggested that a TC moves in an opposing direction from where moisture uptake occurs (Makarieva et al. 2017). Influences on the storm track could also be investigated along with dry air near the system, such as vorticity advection. Analyzing 
other pressure levels may also be warranted to generate a more complete moisture profile and to help further understanding of factors impacting storm track direction. Overall, dry air did not discourage TC intensification nor deter a TC from heading towards dry air in these 4 cases from 2015. 


\section{REFERENCES}

Acker, J. G., and G. Leptoukh, 2007: Online Analysis Enhances Use of NASA Earth Science Data. Eos, Trans. AGU, 88, 2, 14-17, https://doi.org/10.1029/2007EO020003.

Beven II, J. L., 2016: National Hurricane Center tropical cyclone report, Hurricane Fred. Accessed 27 Sep 2020, https://www.nhc.noaa.gov/data/tcr/AL062015_Fred.pdf.

Blake, E. S., 2015: National Hurricane Center tropical cyclone report, Tropical Storm Grace. Accessed 27 Sep 2020, https://www.nhc.noaa.gov/data/tcr/AL072015_Grace.pdf.

Bosilovich and Coauthors, 2015: MERRA-2: Initial Evaluation of the Climate. Technical Report Series on Global Modeling and Data Assimilation TM-2015-104606, 145 pp, https://gmao.gsfc.nasa.gov/pubs/docs/Bosilovich803.pdf.

Bosilovich, M. G., R. Lucchesi, and M. Suarez, 2016: MERRA-2: File Specification. GMAO Office Note No. 9 (Version 1.1), 73 pp, http://gmao.gsfc.nasa.gov/pubs/office_notes.

Braun, S. A., 2010: Reevaluating the role of the Saharan air layer in Atlantic tropical cyclogenesis and evolution. Mon. Wea. Rev., 138, 2007-2037.

Braun, S. A., J. A. Sippel, C.-L. Shie, and R. A. Boller, 2013: The evolution and role of the Saharan air layer during Hurricane Helene (2006). Mon. Wea. Rev., 141, 42694295, https://doi.org/10.1175/MWR-D-13-00045.1.

Brown, D. P., 2015: National Hurricane Center Tropical Cyclone Report, Tropical Depression Nine. Accessed 27 Sep 2020, https://www.nhc.noaa.gov/data/tcr/AL092015_Nine.pdf.

Carr, L. E., III, and R. L. Elsberry, 1995: Monsoonal interactions leading to sudden tropical cyclone track changes. Mon. Wea. Rev., 123, 265-290, https://doi.org/10.1175/1520-0493(1995)123<0265:MILTST>2.0.CO;2.

Chih, C.-H., and C.-C. Wu, 2020: Exploratory analysis of upper-ocean heat content and sea surface temperature underlying tropical cyclone rapid intensification in the western north Pacific. J. Climate, 33, 1031-1050, https://doi.org/10.1175/JCLI-D19-0305.1.

Cooperative Institute for Meteorological Satellite Studies (CIMSS) / University of Wisconsin-Madison (UW-Madison), 2020: TC Webpage Product Archive. Accessed 17 Oct 2020, http://tropic.ssec.wisc.edu/archive/. 
Dunion, J. P., 2010: Rewriting the climatology of the tropical north Atlantic and Caribbean Sea atmosphere. J. Climate, 24, 893-908, https://doi.org/10.1175/2010JCLI3496.1.

Dunion, J. P., and C. S. Velden, 2004: The impact of the Saharan air layer on Atlantic tropical cyclone activity. Bull. Amer. Meteor. Soc., 85, 353-365, doi:10.1175/BAMS-85-3-353.

Fink, A. H., and D. G. Vincent, 2003: Tropical cyclone environments over the northeastern Pacific, including mid-level dry intrusion cases. Meteorology and Atmospheric Physics, 84, 293-315, https://doi.org/10.1007/s00703-002-0603-5.

Fovell, R. G., K. L. Corbosiero, A. Seifert, and K.-N. Liou, 2010: Impact of cloudradiative processes on hurricane track. Geophysical Research Letters, 37, https://doi.org/10.1029/2010GL042691.

Gelaro, R., and Coauthors, 2017: The Modern-Era Retrospective Analysis for Research and Applications, Version 2 (MERRA-2). J. Climate, 30, 5419-5454, https://doi.org/10.1175/JCLI-D-16-0758.1.

George, J. E., and W. M. Gray, 1976: Tropical Cyclone Motion and Surrounding Parameter Relationships. J. Appl. Meteor., 15, 1252-1264, https://doi.org/10.1175/1520-0450(1976)015<1252:TCMASP >2.0.CO;2.

Gray, W. M., 1977: Tropical Cyclone Genesis in the Western North Pacific. Journal of the Meteor. Society of Japan. Ser. II, 55, 465-482, https://doi.org/10.2151/jmsj1965.55.5_465.

Global Modeling and Assimilation Office (GMAO) (2015), inst3_3d_asm_Nv: MERRA2 3D Incremental Analysis Update (IAU) State, Meteorology Instantaneous 3-hourly (p-coord, 0.625x0.5L42), version 5.12.4, Greenbelt, MD, USA: Goddard Space Flight Center Distributed Active Archive Center (GSFC DAAC), Accessed 2020 Jul 31 at doi: 10.5067/WWQSXQ8IVFW8.

Hankes, I., Z. Wang, G. Zhang, and C. Fritz, 2015: Merger of African easterly waves and formation of Cape Verde storms. Quarterly Journal of the Royal Meteorological Society, 141, 1306-1319, https://doi.org/10.1002/qj.2439.

Hodges, K., A. Cobb, and P. L. Vidale, 2017: How well are tropical cyclones represented in reanalysis datasets? J. Climate, 30, 5243-5264, https://doi.org/10.1175/JCLI-D16-0557.1. 
Holm, E. V., 2003: Revision of the ECMWF humidity analysis: Construction of a Gaussian control variable. Proc. ECMWF/GEWEX Workshop on Humidity Analysis, Reading, United Kingdom, ECMWF/GEWEX, 6 pp., http://www.ecmwf.int/sites/default/files/elibrary/2003/9998-revision-ecmwfhumidity-analysis-construction-gaussian-controlvariable.pdf.

Jenkins, G. S., and Coauthors, 2017: Hurricane Fred (2015): Cape Verde's first hurricane in modern times: Observations, impacts, and lessons learned. Bull. Amer. Meteor. Soc., 98, 2603-2618, https://doi.org/10.1175/BAMS-D-16-0222.1.

Kaplan, J., and M. DeMaria, 2003: Large-scale characteristics of rapidly intensifying tropical cyclones in the North Atlantic basin. Wea. Forecasting, 18, 1093-1108, https://doi.org/10.1175/1520-0434(2003)018,1093:LCORIT.2.0.CO;2.

Karyampudi, V. M., and Coauthors, 1999: Validation of the Saharan dust plume conceptual model using Lidar, Meteosat, and ECMWF data. Bull. Amer. Meteor. Soc., 80, 1045-1076, https://doi.org/10.1175/15200477(1999)080<1045:VOTSDP $>2.0 . \mathrm{CO} ; 2$.

Li, J., and H. Liu, 2009: Improved hurricane track and intensity forecast using single field-of-view advanced IR sounding measurements. Geophysical Research Letters, 36, https://doi.org/10.1029/2009GL038285.

Makarieva, A. M., V. G. Gorshkov, A. V. Nefiodov, A. V. Chikunov, D. Sheil, A. D. Nobre, and B.-L. Li, 2017: Fuel for cyclones: The water vapor budget of a hurricane as dependent on its movement. Atmospheric Research, 193, 216-230, https://doi.org/10.1016/j.atmosres.2017.04.006.

NASA, 2017: README Document for MERRA2 Data Products. Accessed 27 Sep 2020, https://goldsmr5.gesdisc.eosdis.nasa.gov/data/MERRA2/M2I3NVASM.5.12.4/doc/ MERRA2.README.pdf.

National Centers for Environmental Prediction/National Weather Service/NOAA/U.S. Department of Commerce, 2000: NCEP FNL Operational Model Global Tropospheric Analyses, continuing from July 1999. Research Data Archive at the National Center for Atmospheric Research, Computational and Information Systems Laboratory, Boulder, CO, accessed 22 Jul 2019 and 27 Sep 2020, https://doi.org/10.5065/D6M043C6.

NHC and Central Pacific Hurricane Center, NOAA, 2020: Glossary of NHC Terms. Accessed 09 Oct 2020, https://www.nhc.noaa.gov/aboutgloss.shtml\#t.

NOAA PSL, 2020: Daily mean composites. Accessed 08 Nov 2020, https://psl.noaa.gov/data/composites/day/. 
NOAA PSL, 2020: WRIT - Time section plots using gridded daily data. Accessed 08 Nov 2020, https://psl.noaa.gov/map/time_plot/.

Park, M.-S., H.-S. Kim, C.-H. Ho, R. L. Elsberry, and M.-I. Lee, 2015: Tropical cyclone Mekkhala's (2008) formation over the South China Sea: Mesoscale, synoptic-scale, and large-scale contributions. Mon. Wea. Rev., 143, 88-110, https://doi.org/10.1175/MWR-D-14-00119.1.

Plotkin, D. A., R. J. Webber, M. E. O’Neill, J. Weare, and D. S. Abbot, 2019: Maximizing simulated tropical cyclone intensity with action minimization. Journal of Advances in Modeling Earth Systems, 11, 863-891, https://doi.org/10.1029/2018MS001419.

Prospero, J. M., and T. N. Carlson, 1980: Saharan air outbreaks over the tropical north Atlantic. PAGEOPH, 119, 677-691, https://doi.org/10.1007/BF00878167.

Randles, C. A., and Coauthors, 2017: The MERRA-2 aerosol reanalysis, 1980 onward. Part I: system description and data assimilation evaluation. J. Climate, 30, 68236850, https://doi.org/10.1175/JCLI-D-16-0609.1.

Sun, D., W. K. M. Lau, M. Kafatos, Z. Boybeyi, G. Leptoukh, C. Yang, and R. Yang, 2009: Numerical simulations of the impacts of the Saharan air layer on Atlantic tropical cyclone development. J. Climate, 22, 6230-6250, https://doi.org/10.1175/2009JCLI2738.1.

Stewart, S. R., 2016: National Hurricane Center tropical cyclone report, Hurricane Danny. Accessed 27 Sep 2020, https://www.nhc.noaa.gov/data/tcr/AL042015_Danny.pdf.

Thorncroft, C., and K. Hodges, 2001: African easterly wave variability and its relationship to Atlantic tropical cyclone activity. J. Climate, 14, 1166-1179, https://doi.org/10.1175/1520-0442(2001)014<1166:AEWVAI>2.0.CO;2.

Torn, R. D., and C. A. Davis, 2012: The influence of shallow convection on tropical cyclone track forecasts. Mon. Wea. Rev., 140, 2188-2197, https://doi.org/10.1175/MWR-D-11-00246.1.

Ventrice, M. J., C. D. Thorncroft, and M. A. Janiga, 2012: Atlantic tropical cyclogenesis: a three-way interaction between an African easterly wave, diurnally varying convection, and a convectively coupled atmospheric Kelvin wave. Mon. Wea. Rev., 140, 1108-1124, https://doi.org/10.1175.

Wang, B., R. Elsberry, Y. Wang, and L. Wu, 1998: Dynamics in the tropical cyclone motion: a review. Chinese Journal of Atmospheric Sciences, 22, 535-547. 
Wang, Y., Y. Huang, and X. Cui, 2018: Impact of Mid- and Upper-Level Dry Air on Tropical Cyclone Genesis and Intensification: A Modeling Study of Durian (2001). Advances in Atmospheric Sciences, 35, 1505-1521, https://doi.org/10.1007/s00376018-8039-0.

Wu, L., and B. Wang, 2004: Assessing impacts of global warming on tropical cyclone tracks. J. Climate, 17, 1686-1698, https://doi.org/10.1175/15200442(2004)017<1686:AIOGWO>2.0.CO;2.

Zipser, E. J., and Coauthors, 2009: The Saharan air layer and the fate of African easterly waves: NASA's AMMA field study of tropical cyclogenesis. Bull. Amer. Meteor. Soc., 90, 1137-1156. 